\title{
Conversion of a Diesel Engine to a Spark Ignition Natural Gas Engine
}

Thermo Power Corporation, Tecogen Division

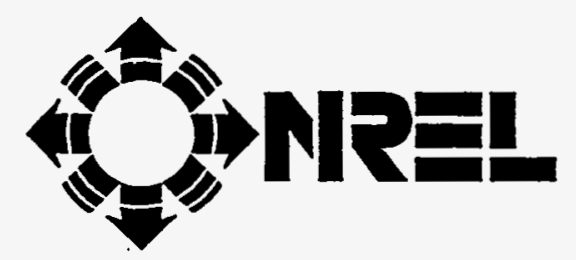

National Renewable Energy Laboratory 1617 Cole Boulevard Golden, Colorado 80401-3393

A national laboratory of the U.S. Department of Energy Managed by Midwest Research Institute for the U.S. Department of Energy under Contract No. DE-AC36-83CH10093 


\section{Conversion of a Diesel Engine to a
Spark Ignition Natural Gas Engin \\ Conversion of a Diesel Engine to a
Spark Ignition Natural Gas Engine}


This publication was reproduced from the best available camera-ready copy submilted by the subcontractor and received no editorial review at NREL.

\section{NOTICE}

This report was prepared as an account of work sponsored by an agency of the United States government. Neither the United States government nor any agency thereof, nor any of their employees, makes any warranty, express or implied, or assumes any legal liability or responsibility for the accuracy, completeness, or usefulness of any information, apparatus, product, or process disclosed, or represents that its use would not infringe privately owned rights. Reference herein to any specific commercial product, process, or service by trade name, trademark, manufacturer, or otherwise does not necessarily constifute or imply its endorsement, recommendation, or favoring by the United States govemment or any agency thereof. The views and opinions of authors expressed herein do not necessarily state or reflect those of the United States government or any agency thereof.

Available to DOE and DOE contractors from:

Office of Scientific and Technical Information (OSTI)

P.O. Box 62

Oak Ridge, TN 37831

Prices available by calling (423) 576-8401

Available to the public from:

National Technical Information Service (NTIS)

U.S. Department of Commerce

5285 Port Royal Road

Springfield, VA 22161

(703) $487-4650$ 
DISCLAIMER

Portions of this document may be illegible in electronic image products. Images are produced from the best available original document. 
CONVERSION OF A DIESEL ENGINE TO A

SPARK IGNITION NATURAL GAS ENGINE

FINAL REPORT

Prepared By:

Thermo Power Corporation, Tecogen Division

45 First Avenue

P.O. Box 8995

Waltham, MA 02254-8995

Prepared For:

Southern California Gas Company

555 West Fifth Street

Los Angeles, CA 90013

Gas Research Institute

8600 West Bryn Mawr Avenue

Chicago, IL 60631

National Renewable Energy Laboratory

U.S. Department of Energy

1617 Cole Boulevard

Golden, CO 80401 


\section{TABI_E OF CONTENTS}

EXECUTIVE SUMMARY $\ldots \ldots \ldots \ldots \ldots \ldots \ldots \ldots \ldots \ldots \ldots \ldots \ldots \ldots \ldots \ldots$ viii

1. INTRODUCTION $\ldots \ldots \ldots \ldots \ldots \ldots \ldots \ldots \ldots \ldots \ldots \ldots \ldots \ldots \ldots \ldots \ldots \ldots$

2. PROGRAM OBJECTIVES $\ldots \ldots \ldots \ldots \ldots \ldots \ldots \ldots \ldots \ldots \ldots \ldots \ldots \ldots \ldots \ldots \ldots$

3. DESCRIPTION OF THE CONVERSION TECHINIQUE $\ldots \ldots \ldots \ldots \ldots \ldots \ldots \ldots \ldots$

4. PROOF-OF-CONCEPT ENGINE DEMONSTRATION $\ldots \ldots \ldots \ldots \ldots \ldots \ldots \ldots \ldots$

4.1 PROOOF OF CONVERSION METHOD $\ldots \ldots \ldots \ldots \ldots \ldots \ldots \ldots \ldots \ldots \ldots \ldots$

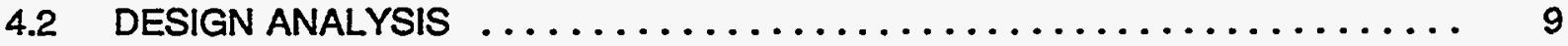

4.3 DESIGN PROOF-OF-CONCEPT ENGINE $\ldots \ldots \ldots \ldots \ldots \ldots \ldots \ldots \ldots \ldots$

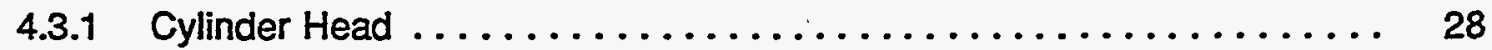

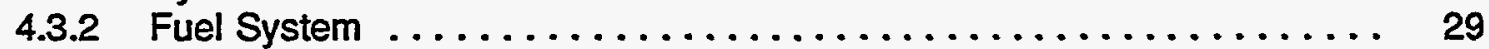

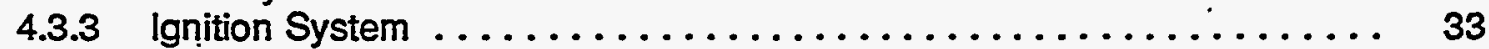

4.3 .4 Camshaft Design . . . . . . . . . . . . . . . . . . . . 33

4.3 .5 Turbocharger and Aftercooler ..................... 35

4.4 PROOF-OF-CONCEPT ENGINE TEST $\ldots \ldots \ldots \ldots \ldots \ldots \ldots \ldots \ldots \ldots \ldots$

4.4.1 Preliminary Engine Calibration Test ...................... 36

4.4.2 Selection of Turbocharger with TE-160 Cam ............... 36

4.4 .3 Performance of Engine with TE-160 Cam ................. 40

4.4.4 Performance Testing of Engine with TE-180 Cam ........... 43

4.4 .5 Combustion Characteristics ..................... 51

4.4 .6 Spark Plug Durability ......................... 51

4.4.7 Engine Test with Prechamber .................... 54

4.5 CONCLUSIONS FROM PROOF-OF-CONCEPT ENGINE DEMONSTRATION ... 65

5. DEVELOPMENT OF PROTOTYPE SYSTEM FOR NAVISTAR DTA-466 ENGINE . . . . 66

5.1 PROTOTYPE CONVERSION SYSTEM $\ldots \ldots \ldots \ldots \ldots \ldots \ldots \ldots \ldots \ldots$

5.1 .1 Electronic Control System Selection .................. 66

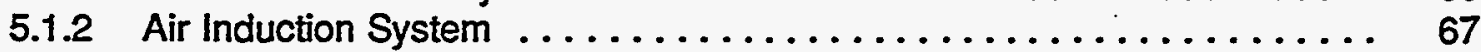

5.1 .3 Ignition System . . . . . . . . . . . . . . . . . . . 67

5.1 .4 Fuel System ............................. 69

5.1.5 Turbocharger With Integral Wastegate and Water-Cooled Center Section .. 74

5.1 .6 Speed Governing System $\ldots \ldots \ldots \ldots \ldots \ldots \ldots \ldots \ldots \ldots \ldots \ldots \ldots \ldots$

5.1 .7 Detonation Control System ...................... 83

5.1 .8 Emissions Control System ..................... 87

5.2 PROTOTYPE ENGINE TEST $\ldots \ldots \ldots \ldots \ldots \ldots \ldots \ldots \ldots \ldots \ldots \ldots \ldots \ldots$

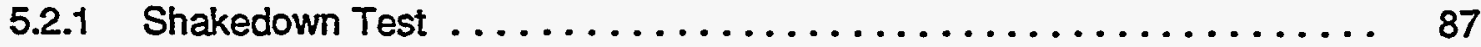

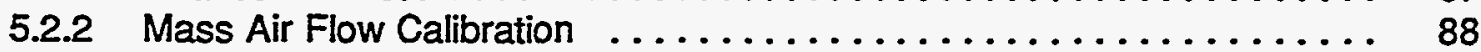

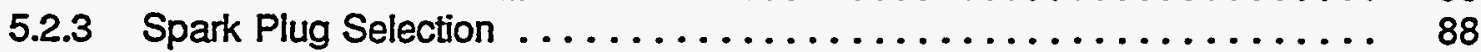

5.2 .4 Low Load and Idle Operation ...................... 101

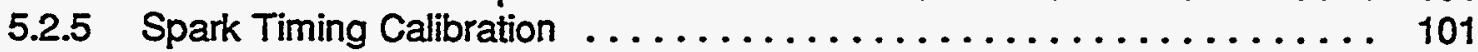

5.2 .6 Turbocharger Test ............................ 101

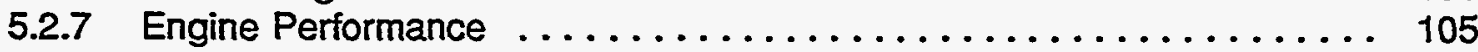

5.2 .8 Emission Control Development ..................... 105 
TABLE OF CONTENTS (Continued)

$5.3 \cdot$ DURABILITY TEST $\ldots \ldots \ldots \ldots \ldots \ldots \ldots \ldots \ldots \ldots \ldots \ldots \ldots \ldots \ldots \ldots$

5.3.1 Spark Plug Life .............................. 126

5.3 .2 Valve Recession ............................. 127

6. FIELD EVALUATION OF PROTOTYPE SYSTEM $\ldots \ldots \ldots \ldots \ldots \ldots \ldots \ldots \ldots \ldots$

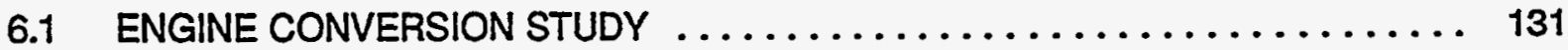

6.2 FUEL STORAGE SYSTEM DESIGN AND INSTALLATION $\ldots \ldots \ldots \ldots \ldots \ldots \ldots$

6.3 FIELD TESTING OF THE VEHICLE $\ldots \ldots \ldots \ldots \ldots \ldots \ldots \ldots \ldots \ldots \ldots \ldots \ldots \ldots$

7. CONCLUSIONS AND RECOMMENDATIONS $\ldots \ldots \ldots \ldots \ldots \ldots \ldots \ldots \ldots$

REFERENCES

APPENDIX 1

APPENDIX 2 


\section{LIST OF FIGURES}

3.1 More-Complete-Expansion Cycle Events .................... 5

3.2 Pressure vs. Volume Diagram of MCEC $\ldots \ldots \ldots \ldots \ldots \ldots \ldots \ldots \ldots \ldots$

3.3 Temperature vs. Entropy Diagram of MCEC $\ldots \ldots \ldots \ldots \ldots \ldots \ldots \ldots \ldots$

4.1 Detonation Limit for a Stationary Natural Gas Engine . . . . . . . . . . . . 10

4.2 Intake Process Simulation Output $\ldots \ldots \ldots \ldots \ldots \ldots \ldots \ldots \ldots \ldots \ldots \ldots \ldots$

4.3 Experimental Cam Lift vs. Crank Angle ..................... 13

4.4 Engine Induction Flow Model Prediction $\ldots \ldots \ldots \ldots \ldots \ldots \ldots \ldots \ldots \ldots$

4.5 Engine Performance Model Prediction $\ldots \ldots \ldots \ldots \ldots \ldots \ldots \ldots \ldots \ldots \ldots$

4.6 Engine Performance Model Prediction $\ldots \ldots \ldots \ldots \ldots \ldots \ldots \ldots \ldots \ldots$

4.7 Engine Induction Flow Model Prediction $\ldots \ldots \ldots \ldots \ldots \ldots \ldots \ldots \ldots \ldots$

4.8 Engine Performance Model Prediction $\ldots \ldots \ldots \ldots \ldots \ldots \ldots \ldots \ldots$

4.9 Engine Performance Model Prediction $\ldots \ldots \ldots \ldots \ldots \ldots \ldots \ldots \ldots \ldots \ldots \ldots$

4.10 Engine Induction Flow Model Prediction $\ldots \ldots \ldots \ldots \ldots \ldots \ldots \ldots \ldots \ldots \ldots$

4.11 Engine Performance Model Prediction $\ldots \ldots \ldots \ldots \ldots \ldots \ldots \ldots \ldots \ldots \ldots \ldots$

4.12 Engine Performance Model Prediction $\ldots \ldots \ldots \ldots \ldots \ldots \ldots \ldots \ldots \ldots \ldots$

4.13 Engine Induction Flow Model Prediction $\ldots \ldots \ldots \ldots \ldots \ldots \ldots \ldots \ldots \ldots$

4.14 Engine Performance Model Prediction $\ldots \ldots \ldots \ldots \ldots \ldots \ldots \ldots \ldots \ldots \ldots$

4.15 Engine Performance Model Prediction $\ldots \ldots \ldots \ldots \ldots \ldots \ldots \ldots \ldots$

4.16 Engine Performance Model Prediction $\ldots \ldots \ldots \ldots \ldots \ldots \ldots \ldots \ldots \ldots \ldots \ldots$

4.17 Spark Plug Adapter for Navistar DTA-466 Engine ................. 30

4.18 Spark Plug Adapter for Navistar DTA-466 Engine (Alternate) $\ldots \ldots \ldots \ldots \ldots$. . . 31

4.19 Prechamber Design $\ldots \ldots \ldots \ldots \ldots \ldots \ldots \ldots \ldots \ldots \ldots \ldots \ldots \ldots \ldots \ldots \ldots$

4.20 Distributorless Ignition System $\ldots \ldots \ldots \ldots \ldots \ldots \ldots \ldots \ldots \ldots \ldots \ldots \ldots \ldots \ldots$ 


\section{LIST OF FIGURES (Continued)}

4.21 Schematic of Engine Set-up in Dynamometer Test Facility . . . . . . . . . . 37

4.22 Comparison of Test Data and Model Prediction .................. 38

4.23 Engine Performance $-\mathrm{TE160,}$ C.R. $=16.5, \phi=1.00 \ldots \ldots \ldots \ldots \ldots \ldots \ldots, 41$

4.24 Engine Performance -TE160, C.R. $=16.5, \phi=0.91 \ldots \ldots \ldots \ldots \ldots \ldots \ldots, 42$

4.25 Comparison of Test Data and Model Prediction ................... 44

4.26 Comparison of Test Data and Model Prediction .................. 45

4.27 Engine Performance -TE180, C.R. $=16.5, \phi=1.00 \ldots \ldots \ldots \ldots \ldots \ldots \ldots$

4.28 Engine Performance $-T E 180, C . R .=16.5, \phi=0.91 \ldots \ldots \ldots \ldots \ldots \ldots \ldots$

4.29 Comparison of Test Data and Model Prediction .................. 48

4.30 Comparison of Test Data and Model Prediction ................... 49

4.31 Comparison of Test Data and Model Prediction $\ldots \ldots \ldots \ldots \ldots \ldots \ldots \ldots \ldots$

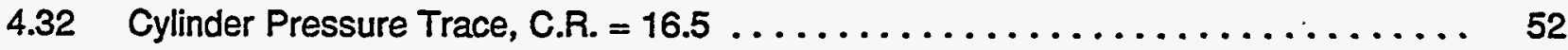

4.33 Engine Performance vs. Spark Timing $\ldots \ldots \ldots \ldots \ldots \ldots \ldots \ldots \ldots \ldots \ldots \ldots \ldots \ldots \ldots$

4.34 Cylinder Pressure Trace, C.R. $=13.9$ with Prechamber $\ldots \ldots \ldots \ldots \ldots \ldots .65$

4.35 Cylinder and Prechamber Pressure Trace, C.R. $=13.9$ with Prechamber $\ldots \ldots \ldots 56$

4.36 Engine Performance $-T E 180, C . R .=13.9, \phi=1.00 \ldots \ldots \ldots \ldots \ldots \ldots \ldots$

4.37 Engine Performance $-\mathrm{TE180}, \mathrm{C} . \mathrm{R}_{.}=13.9, \phi=0.91 \ldots \ldots \ldots \ldots \ldots \ldots \ldots \ldots \ldots \ldots$

4.38 Engine Performance - TE180, C.R. $=13.9, \phi=0.91 \ldots \ldots \ldots \ldots \ldots \ldots \ldots \ldots$

4.39 Engine Performance - TE180, C.R. $=13.9, \phi=0.91$, Cold Spark Plug $\ldots \ldots \ldots 61$

4.40 Comparison of Test Data and Model Prediction .................... 62

4.41. Comparison of Test Data and Model Prediction ................... 63

4.42 Comparison of Test Data and Model Prediction ................... 64

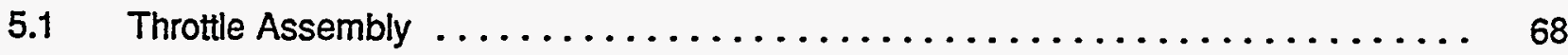

5.2 Crankshaft Position Sensing System for Ignition $\ldots \ldots \ldots \ldots \ldots \ldots \ldots \ldots$

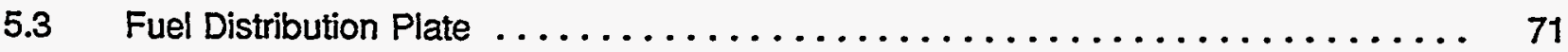




\section{LIST OF FIGURES (Continued)}

$5.4 \quad$ Fuel Injector Rail $\ldots \ldots \ldots \ldots \ldots \ldots \ldots \ldots \ldots \ldots \ldots \ldots \ldots \ldots \ldots \ldots$

$5.5 \quad$ Flow Characteristics of Bosch Fuel Injector $\ldots \ldots \ldots \ldots \ldots \ldots \ldots \ldots \ldots$

$5.6 \quad$ Half-Speed Sensing System for Fuel Injection $\ldots \ldots \ldots \ldots \ldots \ldots \ldots \ldots \ldots$

5.7 Engine Performance with Garrett T300 Turbocharger . . . . . . . . . . . . . 76

5.8 Heat Soak Test - Temperatures of Turbocharger Center Section

5.9 Heat Soak Test - Temperatures of Turbocharger Center Section

Without Water Cooling . . . . . . . . . . . . . . . . . . . . . . . 79

5.10 Heat Soak Test - Temperatures of Turbocharger Center Section

Without Water Cooling ............................ 80

5.11 Heat Soak Test - Temperatures of Turbocharger Center Section

With Water Cooling ................................ 81

5.12 Mechanical Speed Governing System ...................... 82

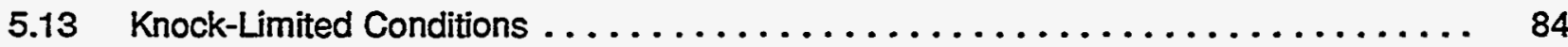

5.14 Maximum Allowable Intake Manifold Pressure .................. 85

5.15 Maximum Allowable Intake Manifold Pressure $\ldots \ldots \ldots \ldots \ldots \ldots \ldots$

5.16 Mass Air Flow Meter Calibration $\ldots \ldots \ldots \ldots \ldots \ldots \ldots \ldots \ldots \ldots \ldots$

5.17 Fuel Flow Calibration $\ldots \ldots \ldots \ldots \ldots \ldots \ldots \ldots \ldots \ldots \ldots \ldots \ldots \ldots$

5.18 External Auxiliary Gap Design for Spark Plugs $\ldots \ldots \ldots \ldots \ldots \ldots \ldots \ldots$

5.19 Spark Plug Selection Test $\ldots \ldots \ldots \ldots \ldots \ldots \ldots \ldots \ldots \ldots \ldots \ldots \ldots \ldots$

5.20 Spark Plug Selection Test $\ldots \ldots \ldots \ldots \ldots \ldots \ldots \ldots \ldots \ldots \ldots \ldots \ldots \ldots$

5.21 Spark Plug Selection Test $\ldots \ldots \ldots \ldots \ldots \ldots \ldots \ldots \ldots \ldots \ldots \ldots \ldots \ldots \ldots$

5.22 Spark Plug Selection Test $\ldots \ldots \ldots \ldots \ldots \ldots \ldots \ldots \ldots \ldots \ldots \ldots \ldots$

5.23 Spark Plug Selection Test $\ldots \ldots \ldots \ldots \ldots \ldots \ldots \ldots \ldots \ldots \ldots \ldots \ldots$

5.24 Spark Plug Selection Test $\ldots \ldots \ldots \ldots \ldots \ldots \ldots \ldots \ldots \ldots \ldots \ldots \ldots \ldots$

5.25 Spark Plug Selection Test . . . . . . . . . . . . . . . . . . . . . . 99

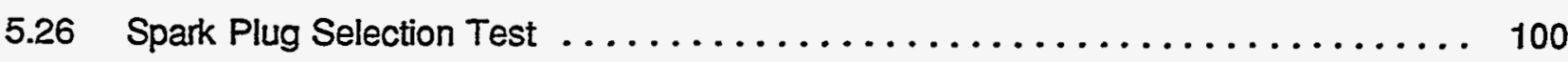




\section{LIST OF FIGURES (Continued)}

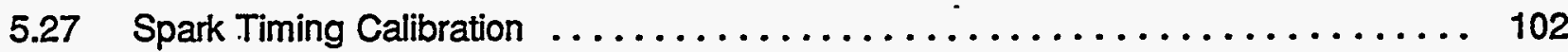

5.28 Engine Performance - Garrett T300 Turbocharger Without Wastegate ......... 103

5.29 Engine Performance - Garrett T300 Turbocharger With Integral Wastegate ...... 104

5.30 T300 Turbocharger Performance, With and Without Integral Wastegate ....... 106

5.31 Engine Performance - Power vs. Speed ...................... 107

5.32 Engine Performance -Torque vs. Speed $\ldots \ldots \ldots \ldots \ldots \ldots \ldots \ldots \ldots \ldots$

5.33 Engine Performance - BSFC vs. Speed ..................... 109

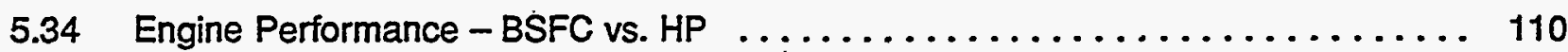

5.35 Engine Emission Test Data $\ldots \ldots \ldots \ldots \ldots \ldots \ldots \ldots \ldots \ldots \ldots \ldots \ldots \ldots \ldots \ldots \ldots \ldots$

5.36 Engine Emission Test Data $\ldots \ldots \ldots \ldots \ldots \ldots \ldots \ldots \ldots \ldots \ldots \ldots \ldots \ldots \ldots \ldots \ldots \ldots$

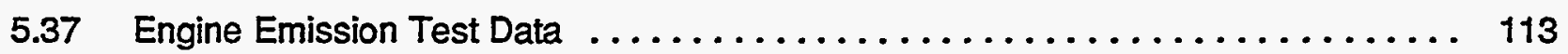

5.38 Engine Emissions vs. Relative Injection Period ................... 115

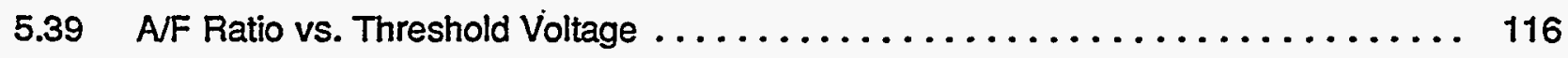

5.40 Engine Emission vs. Threshold Voltage $\ldots \ldots \ldots \ldots \ldots \ldots \ldots \ldots \ldots \ldots \ldots \ldots$

5.41 Engine Emission vs. Threshold Voltage $\ldots \ldots \ldots \ldots \ldots \ldots \ldots \ldots \ldots \ldots \ldots$

5.42 Engine Emission vs. Threshold Voltage $\ldots \ldots \ldots \ldots \ldots \ldots \ldots \ldots \ldots \ldots \ldots$

5.43 Cylinder to Cylinder A/F Ratio Distribution .................... 120

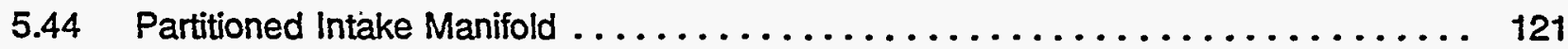

5.45 Cylinder to Cylinder A/F Ratio Distribution - Partitioned Manifold ........... 122

5.46 Engine Emissions With Partitioned Manifold $\ldots \ldots \ldots \ldots \ldots \ldots \ldots \ldots \ldots . \ldots \ldots$

5.47 Engine Emissions With Partitioned Manifold ................... 124

5.48 Engine Emissions With Partitioned Manifold ................... 125

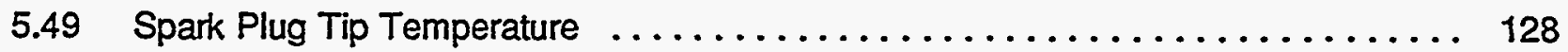

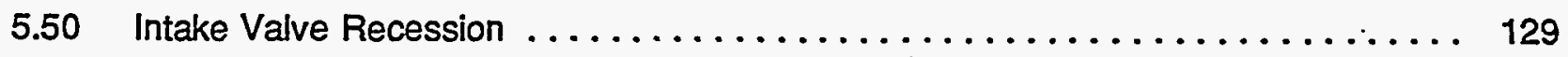

5.51 Exhaust Valve Recession .............................. 130 


\section{EXECUTIVE SUMMARY}

Tecogen has developed and applied a novel technique for converting turbocharged automotive diesel engines to operate as dedicated spark-ignition engines with natural gas as fuel. The conversion process changes the engine cycle to a more-complete-expansion cycle in which the expansion ratio of the original diesel engine is unchanged while the effective compression ratio is lowered, so that engine detonation is avoided. The converted natural gas engine, with an expansion ratio higher than that normally used for the conventional spark-ignition natural gas engine, offers thermal efficiency at wide-open-throttle conditions comparable to its diesel counterpart. This technique leaves the engine with the original diesel pistons and cylinder head and, therefore, allows field conversion of existing vehicle engines. Low exhaust emissions can be achieved when the engine is operated with precise control of the fuel air mixture at stoichiometry with a three-way catalyst.

A Navistar DTA-466 diesel engine with an expansion ratio of 16.5 to 1 was converted using this technique. The conversion process includes modifying the cam profiles, increasing the turbocharger boost pressure, incorporating an aftercooler if it does not already exist, and adding a spark-ignition system, a natural gas fuel management system, a throttle body for load control, and an electronic engine control system. Since the expansion ratio is unchanged, it is not necessary to replace the pistons and the cylinder head as in the convectional technique. The design of the cam profile to provide the appropriate valve timing was aided by computer simulation of the intake and exhaust processes. The criteria for the cam design and boost pressure requirement was based on the desired engine output and detonation-free operation.

A proof-of-concept engine converted from a Navistar DTA-466 diesel engine was used successfully to demonstrate the technical feasibility of the concept. It achieved a power level comparable to that of the diesel engine without detonation. It also demonstrated the practicality and economic advantages of this method of conversion, especially for retrofitting existing diesel engines. The proof-of-concept engine was also used to demonstrate the effectiveness of the computer simulation model as a tool to establish the required valve timing and turbocharger boost to achieve detonation-free performance of the engine without extended development testing.

After the completion of the proof-of-concept engine testing, a conversion system was developed for the Navistar DT 466 engine. The system was designed for stoichiometric operation of the engine, together with a three-way catalyst for emissions control. Steady state testing of the engine at full load and variable speeds showed expected power output and fuel consumption. $\mathrm{NO}_{X}$ emissions on the order of $1.5 \mathrm{gm} / \mathrm{bhp}-\mathrm{hr}$ have been measured at full load conditions.

The conversion system consists of the following major components: 1) a new camshaft with cam profile specifically designed for the Navistar 466 engine to operate with stoichiometric fuel mixture is the only engine component that requires removal of the gear cover to install; 2) a turbocharger with integral wastegate replaces the existing turbocharger to provide higher inlet boost and its control; 
3) the ignition system is a three coil waste spark system adopted from an automotive engine; 4) the spark plugs are off-the-shelf $12 \mathrm{~mm}$ plugs modified to fit in the diesel fuel injector well; 5) the fuel system is electronic, sequential-port fuel injection, which provides precise metering of fuel to maintain close control of the fuel-air ratio and cylinder-to-cylinder distribution; 6 ) an automotive engine throttle body is adopted for the engine, and it includes a mass air flow sensor, a throttle position sensor, and an idle control valve; 7) the engine controller is a production automobile PCM calibrated for this engine and also modified to incorporate additional software to control the intake manifold pressure and to govern the engine speed; and 8) the emissions control system consists of a closedloop fuel-air ratio control based on an exhaust oxygen sensor and a three-way catalyst.

The conversion system was installed on a school bus (used) for the purpose of establishing the practicality of retrofitting existing engines in the field. The school bus was also used to calibrate the PCM for driveability. A 3,700 mile cross country field test has been completed to obtain durability data for the various engine components. Valve recession rates and oil consumption were found to be comparable to those of the conventional spark ignition natural gas engines. Field testing of the conversion system on five additional vehicles will be carried out in California, and emissions certification for the conversion system will be obtained. 


\section{INTRODUCTION}

A legislated requirement for alternatives to diesel-fueled vehicles is developing in various geographical areas, particularly those urban centers which are not in compliance with mandated air quality standards. When confronted with this requirement, the operator of a fleet of diesel-powered vehicles will be forced to either purchase new vehicles powered by alternative fuels or, more likely, equip some of the existing fleet with engines designed or modified to run on an alternative fuel. If required to convert existing vehicles, the operator has the options of either replacing the existing engine, or modifying it to burn an alternative fuel.

The work described in this report addresses the problem of modifying an existing diesel engine to operate on an alternative fuel, in this case, natural gas.

Any technology for converting an existing diesel engine must be very cost effective, since there is the increasingly available alternative of purchasing a new, dedicated gas engine. There are 2 types of conversion techniques which have been applied. The first simply adds a gas mixing system to the intake of a diesel engine and relies on the injection of a small amount of diesel fuel for ignition. Controls for the fuel injection system are required and the intake air may or may not be throttled. The sophistication of this type of conversion system can vary, from simply adding a gas carburetor and injection system limit controls, to replacing the diesel injection system with electronically-controlled injection systems for both the pilot diesel fuel and the natural gas. This more sophisticated approach allows re-optimization of the injection timing for dual-fuel operation, which can be very important for meeting emission standards, avoiding detonation, and retaining diesel engine efficiencies at part load. The difficulties with this approach are particulate emissions from the diesel fuel, detonation due to the retention of a high compression ratio and consequent damage to pistons and valves, and, in the case of the more sophisticated system, high cost.

The second conventional conversion technique is to rebuild the engine with lower compression ratio pistons, modify the cylinder head to accept spark plugs, and add fuel supply and ignition systems, resulting in a dedicated natural gas engine. This conversion approach requires extensive development time to work out the proper piston configuration for performance and durability, and to ensure that the cylinder head and valves are capable of handling the higher thermal loading associated with lower compression ratios and generally richer mixtures. This component development effort must be carried out for each engine type to be converted.

The conversion technique described in this report is based on spark ignition, but retains the high expansion ratio of the diesel engine by utilizing the more-complete-expansion-cycle (MCEC, also known as the Miller cycle). This allows the basic engine to remain unmodified except for a camshaft change, which provides for detonation control. This conversion was explored as the basis for an aftermarket kit, hence an engine model in widespread use, the Navistar 466 series engine, was chosen on which to demonstrate the concept's feasibility. 
This development program was sponsored jointly by the Southern California Gas Company (SoCal), the Gas Research Institute (GRI), the U.S. Department of Energy (DOE), and Tecogen Division/Thermo Power Corporation. The program was carried out in 3 phases, namely:

Phase 1 Proof-of-Concept Engine Demonstration

Phase 2 Prototype Navistar DTA-466 Engine Development

Phase 3 Field Evaluation of Prototype Engine

The program has been successfully completed, and a commercially viable conversion kit for the DTA-466 engine has been developed. 


\section{PROGRAM OBJECTIVES}

The overall objective of this R\&D program was to develop the new diesel to natural gas conversion technology described briefly in the Introduction and more completely in Section 3 , and to demonstrate its advantages on a Navistar DTA-466 in-line 6 cylinder diesel engine, which is widely used to power school buses and trucks.

The objectives of Phase 1 (Proof-of-Concept Engine Demonstration) were to demonstrate the technical feasibility of the conversion method by applying the MCEC for detonation control, and to show that the converted engine is more efficient than conventional Otto cycle natural gas engines.

The objective of Phases 2 and 3 (Prototype Navistar DTA-466 Engine Development, Field Evaluation of Prototype Engine) was to develop a low cost conversion kit for the Navistar DTA-466 engine which could be retrofitted cost-effectively to existing diesel engines in the field. 


\section{DESCRIPTION OF THE CONVERSION TECHNIQUE}

The ideal indicated efficiency of the Otto cycle depends only on the expansion ratio and the relative fuel-air ratio (or equivalence ratio). The MCEC allows flexibility within the Otto cycle by the use of unconventional intake valve events (this is illustrated in the pressure-volume diagram shown in Figure 3.2, where the intake valve is closed well before bottom dead center (BDC) rather than after, as in a conventional Otto cycle engine). By early closing of the intake valve, the condition of the mixture at the end of compression can be manipulated to avoid detonation, while retaining a high mechanical expansion ratio.

Figure 3.1 illustrates the various stages of the intake and compression stroke. The corresponding pressure-volume and temperature-entropy diagram of the idealized MCEC are shown in Figures 3.2 and 3.3, respectively. Referring to Figure 3.1, the intake process is completed the point when the inlet valve closes and the piston reaches point $x$. From point $x$ to point 1 , as the piston descends to BDC, the air charge expands from the intake manifold pressure $p_{i}$ to a lower pressure $p_{1}$. This expansion process results in a drop in air temperature, which provides the same effect as externally cooling the air for an Otto cycle engine. After BDC, the air charge is recompressed back to point $x$, at which time the pressure in the cylinder returns to the intake manifold pressure. The piston then continues to compress the charge to the ignition condition $P_{2}$ at top dead center (TDC). The expansion and recompression part of the process, $x \rightarrow 1 \rightarrow x$, does not consume or produce any power. Since the condition of the air charge at point $x$ is the same as the intake manifold condition, the effective compression of the charge occurs between point $x$ and point 2 on the compression stroke. The effective compression ratio, defined as the volume ratio $v_{x} N_{2}$, is therefore lower than the mechanical expansion ratio $V_{1} N_{2}$. The idealized cycle is completed with the heat release of combustion occurring instantaneously at TDC, the power expansion stroke from 3 to 4 , and the exhaust stroke. The additional degrees of freedom (inlet valve closing time and turbocharger boost) in the MCEC over the Otto cycle is useful in obtaining high thermal efficiency, as well as circumventing the limit imposed by detonation.

This theoretical improvement is of little practical interest unless the manifold pressure can be raised to compensate for the loss in volumetric efficiency caused by the early intake valve closing. As the system schematic in Figure 3.2 shows, a turbocharger and aftercooler can be used to effect the first stage of the compression process with intercooling. The second stage of the compression process is then carried out in the engine cylinder.

Detonation is avoided by carrying out more of the compression process in the blower and less in the engine cylinder, rather than by lowering the expansion ratio by modifying the piston. Retention of the high expansion ratio means higher thermal efficiencies can be achieved with lower exhaust temperatures. The basic engine does not have to be disassembled using this technique, since the pistons are not modified. Conversion is accomplished by: 
$\frac{z}{5}$
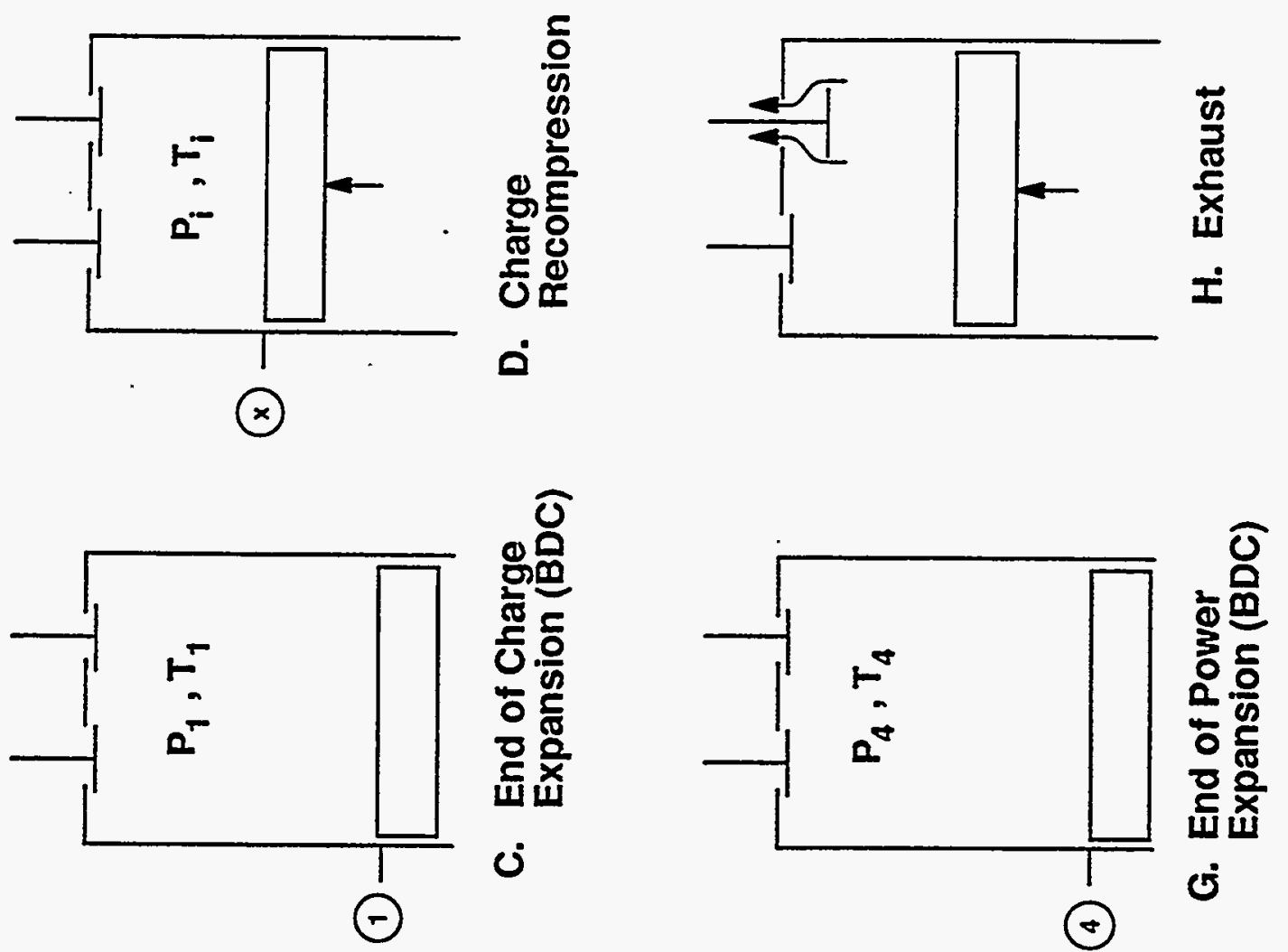

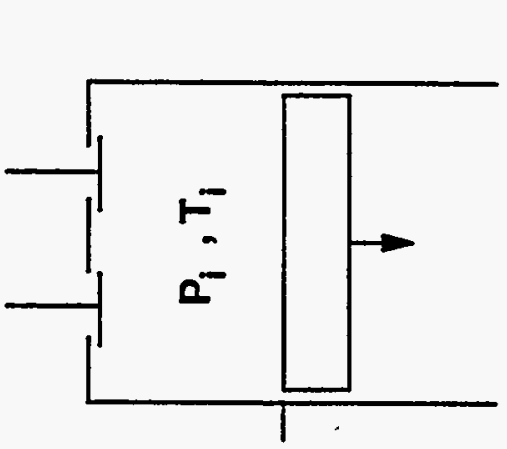

()
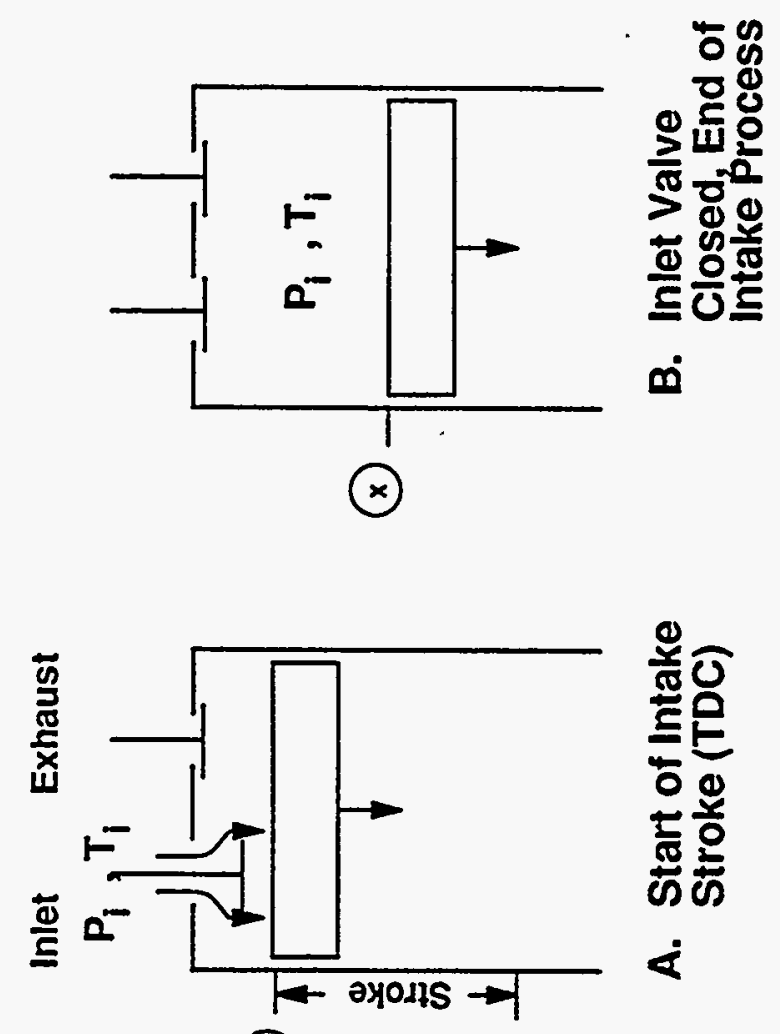

(ง)

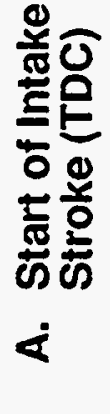

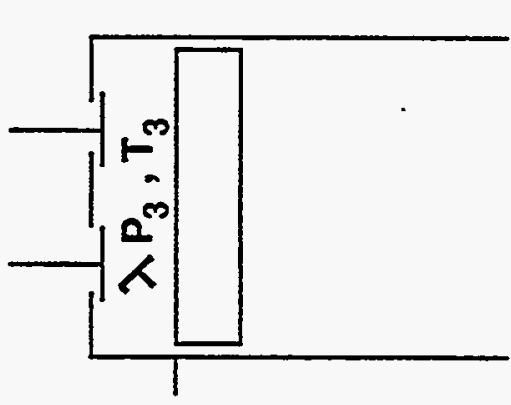

(๑)

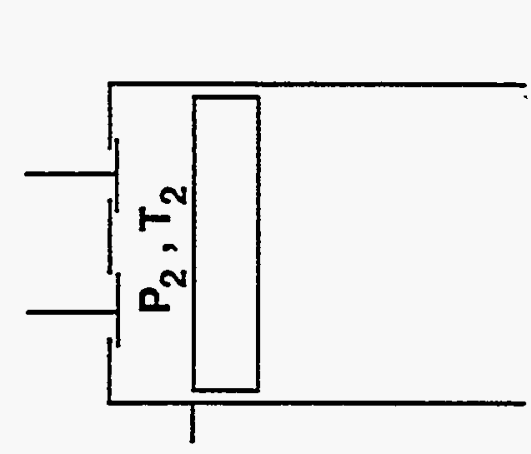

(ง)

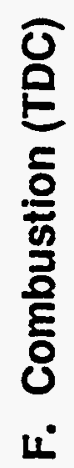

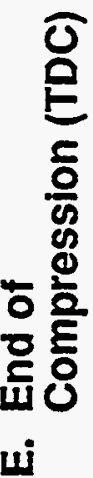

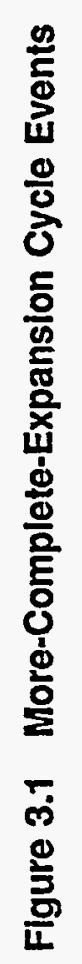




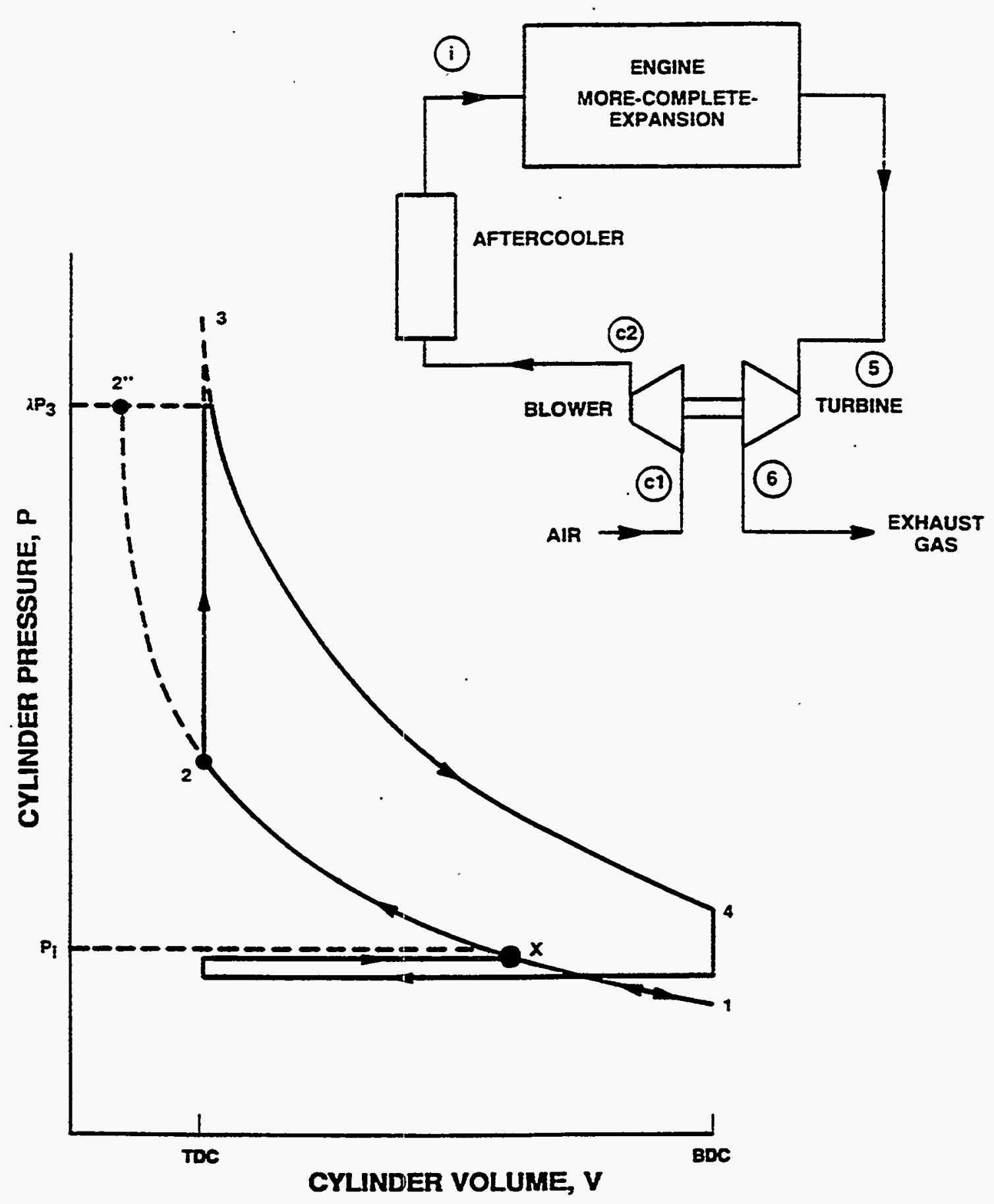

Figure 3.2 Pressure vs. Volume Diagram of MCEC 
TEMPERATUAE, T

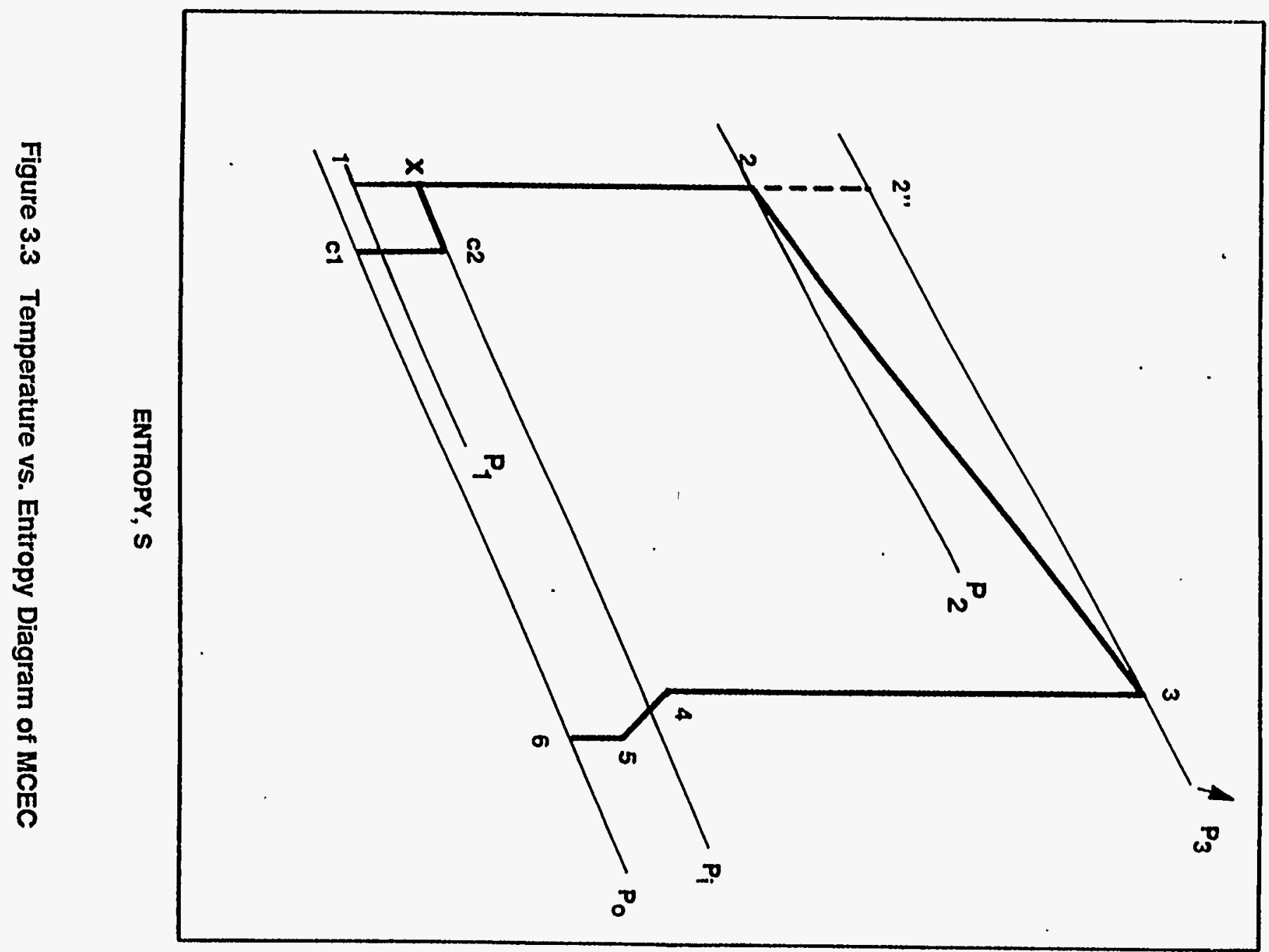

견 
- Replacing the camshaft

- Modifying the turbocharger

- Using an aftercooler
- Installing spark plugs and an ignition system

- Installing a fuel metering and mixing system

- Installing a throttle

This technique lends itself to either stoichiometric or lean-burn operation. Limits to the efficiency of the MCEC are imposed by the overall turbocharger efficiency and heat transfer to the incoming charge. BMEP is limited by blower pressure ratio and firing pressure, not by detonation. The MCEC system has been used for many years in larger stationary natural gas engines, where diesel efficiencies are routinely achieved (Refs. 1 and 2). This is the first time this technique has been proposed for converting existing diesel engines to spark ignition operation, as far as the authors are aware. 


\section{PROOF-OF-CONCEPT ENGINE DEMONSTRATION}

\subsection{PROOF OF CONVERSION METHOD}

To prove the technical feasibility of Tecogen's new method of converting the diesel engine to natural gas operation by applying the MCEC, a Navistar DTA-466 diesel engine was selected for the study. The proof of the conversion method constituted several aspects. The first was to show that the engine could be converted by a simple change of valive timing, to a spark ignition, MCEC natural gas engine without the risk of detonation. The second aspect was to demonstrate that such a converted engine could offer better fuel economy than a conventional Otto cycle engine by virtue of the high expansion ratio. The third was to show the integrity of the engine components required by the conversion. The final aspect was to prove that an analytical simulation model could be established as a universal design tool applicable to all engine conversions.

\subsection{DESIGN ANALYSIS}

The advantage of the MCEC is that the additional degree of freedom associated with the inlet valve closing time and the boost pressure level allows the cycle to be specifically designed such that the engine will produce the maximum power without exceeding the limiting conditions for detonation. Therefore, the key design factor is the detonation limit. It has been shown (Refs. 2 and 3 ) that the condition for auto-ignition of the end gas, which leads to detonation, can be correlated as a function of the temperature and pressure at the state point $2^{n}$ on the P-V and T-S diagrams shown back in Figures 3.3 and 3.4. Point $2 "$ is the condition of the charge adiabatically compressed from $\left(P_{1}, T_{1}\right)$ to the firing pressure $\lambda p_{3}$, and it represents the condition of the last portion of the unburned mixture (the end gas) prior to completion of the combustion process. The detonation limit of a given engine can therefore be expressed as a limiting curve in a plot of $T_{2}{ }^{\prime \prime}$ versus $\lambda p_{3}$, with $T_{2}$ " being the major factor, as shown in Figure 4.1. Detonation does not occur in an engine as long as the adiabatic end gas temperature, $T_{2}$ ", at the firing pressure $\lambda_{p_{3}}$, is kept below the limiting curve. Although this detonation-limited curve may vary from engine to engine due to turbulence and heat transfer conditions inside the combustion chamber, the general characteristics of the curve remain similar for most engines.

The design analysis involved the development and application of an engine simulation model to describe the various processes of the engine cycle. The engine parameters included:

- Turbocharger performance

- Valve lift profiles and timing

- Aftercooler effectiveness

- Engine configuration and speed

- Flow losses in various parts
- Combustion efficiency of the flow system

- Detonation characteristics of the engine

- Heat transfer between the charge and the various hot surfaces 


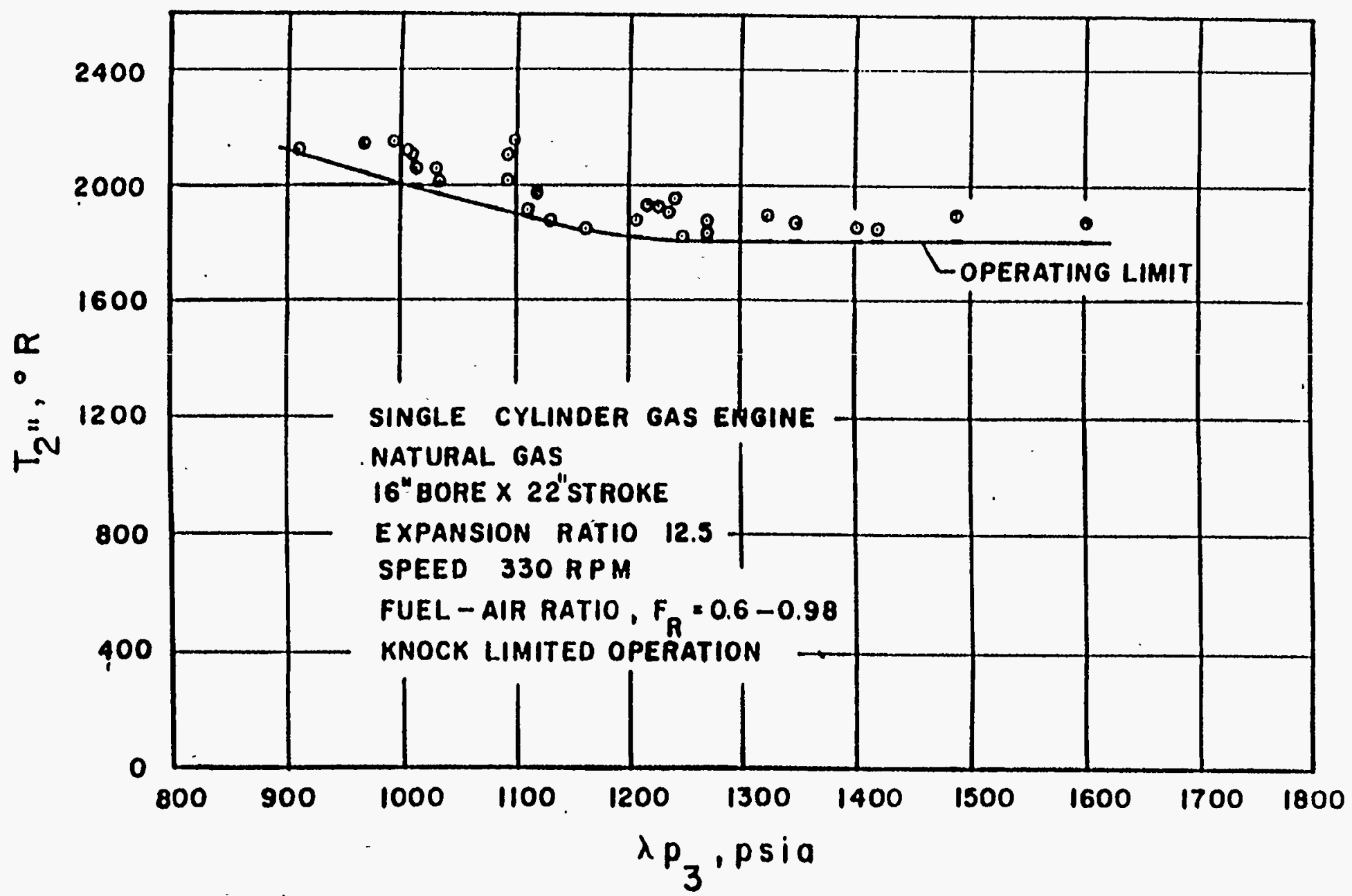

Figure 4.1 Detonation Limit for a Stationary Natural Gas Engine 
Tecogen's engine simulation analytical model included 2 parts. The first part was an in-house computer model which simulated the flow and thermodynamics of the mixture charge during the blowdown, scavenge, and intake process of the engine cycle. This was modified and adopted for the analysis of the Navistar 466 engine. The computer analysis provided the information on the effect of cam timing and valve lift on the trapped charge mass or volumetric efficiency, the effective compression ratio from the point where the cylinder pressure equals the inlet manifold pressure, the temperature and pressure of the charge at the BDC of compression stroke, the amount of residual gas remaining in the cylinder, and the potential scavenging and loss of the fresh charge when there is positive pressure differential across the engine. The flow characteristics of the gas through the valves and the heat transfer between the charge and the various surfaces inside the cylinder are importaint factors which vary from engine to engine. Figure 4.2 shows a typical output of the intake process at $5^{\circ}$ crank angle intervals starting from $60^{\circ}$ after TDC firing until the cylinder pressure reaches the intake manifold pressure.

The result of the intake process simulation was used in conjunction with the second model for cycle analysis to predict engine output, fuel consumption, peak firing pressure, and the end gas temperature at various engine speeds and inlet manifold conditions. The end gas temperature, $T_{2}$ ", and the peak firing pressure, $\lambda p_{3}$, would indicate the margin to detonation.

The flow coefficients through the valves and the heat transfer coefficients were first assumed and later calibrated against some preliminary engine data on mass flow rates.

For the Navistar DTA-466 engine, 3 experimental camshaft profiles were designed based on the results of the analysis, as shown in Figure 4.3. The analysis shows how the effective compression ratio, the volumetric efficiency, the pumping loss, the BMEP, the BSFC, $T_{2}{ }^{n}$, and $\lambda p_{3}{ }^{n}$ are affected by the inlet valve timing, the engine speed, and the intake manifold pressure.

Figure 4.4 shows a typical output of the intake process simulation for an intake cam with $180^{\circ}$ crank angle duration. The intake valve opens at $20^{\circ} \mathrm{BTC}$ and closes at $160^{\circ} \mathrm{ATC}$. The intake valve duration for the DTA-466 diesel engine is $242^{\circ}$. These curves show the effect of the intake manifold pressure, as well as the engine speed, on the various parameters, namely, the volumetric efficiency, the effective compression ratio, the trapped mass, and the increase of charge temperature over the manifold temperature when the cylinder pressure reaches the manifold pressure due to the combination of heat transfer and flow loss through the intake valve. The effective compression ratio is based on the cylinder volume at which the cylinder pressure equals the intake manifold pressure. It is seen that the volumetric efficiency, Ev, and the effective compression ratio, Rc, are reduced significantly due to the early closing of the valve. At higher speed, Rc is lower and therefore produces lower BMEP and lower peak pressure. However, since $\Delta T$ is higher for higher speeds, the adiabatic end gas temperature, $T_{2}$ ", remains about the same as for the lower speed conditions. It is also interesting to note that $R c$ and $\Delta T$ are not sensitive to manifold pressure, which means the same is true for $\mathrm{T}_{2}$ ". 


$$
\begin{aligned}
& E L=09200000 \times 02
\end{aligned}
$$

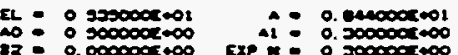

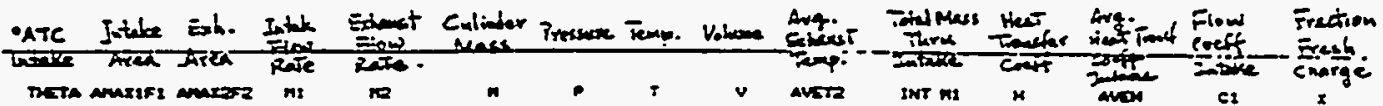

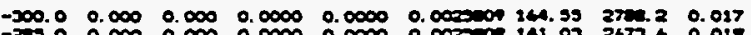

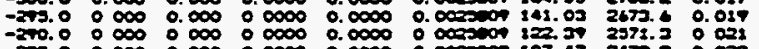

$00 \quad 0.0000000209 .920227 .0400$

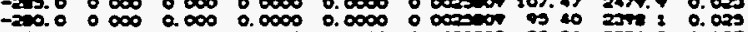

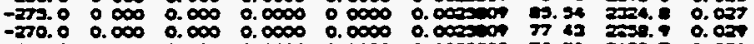

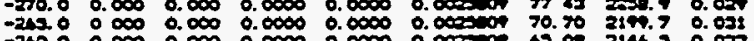

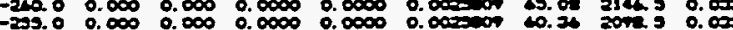

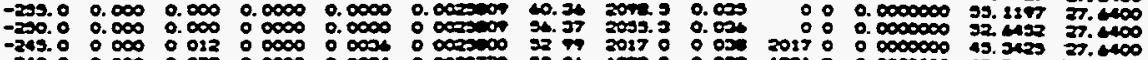

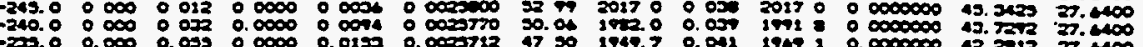

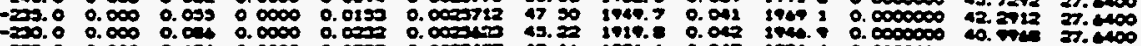

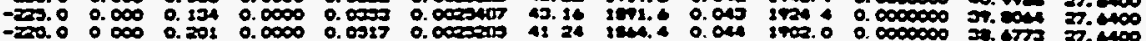

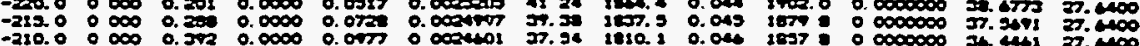

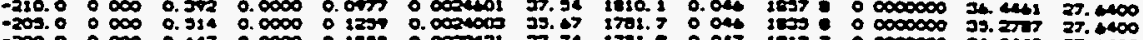

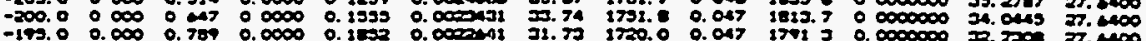

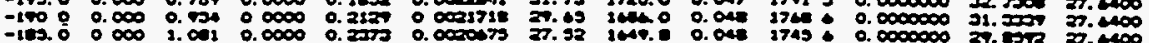

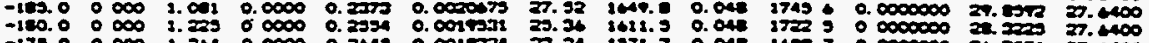

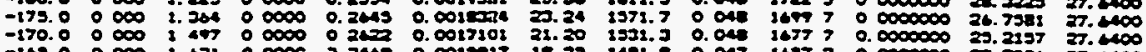

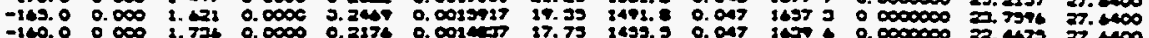

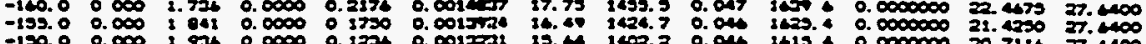

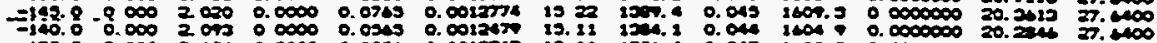

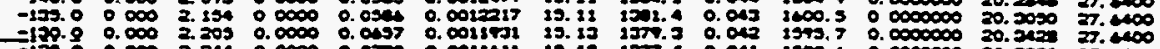

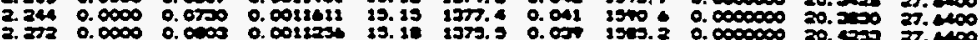

-

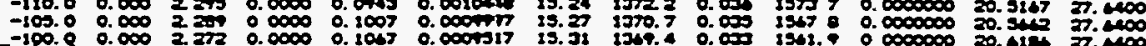

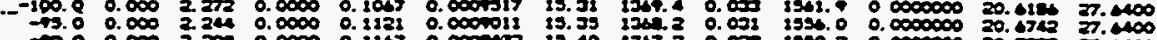

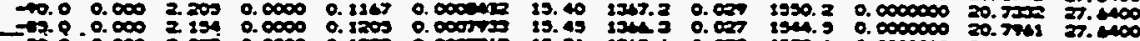

7.

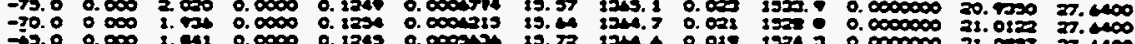

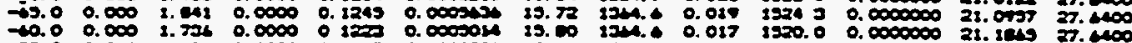

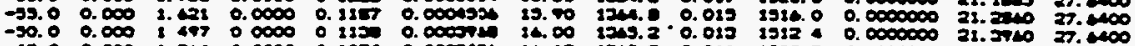

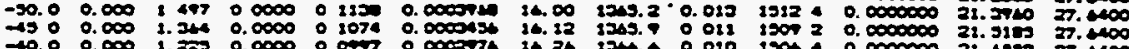

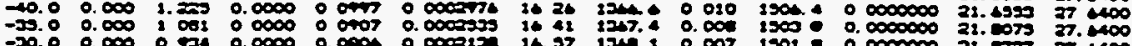

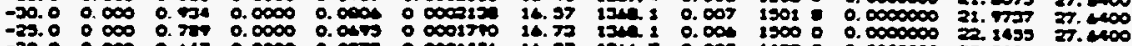

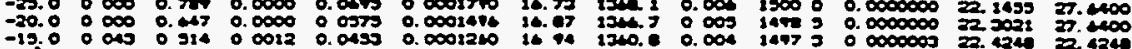

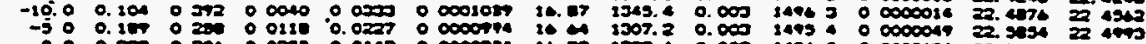

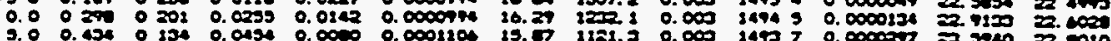

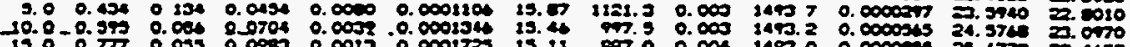

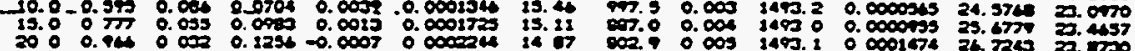

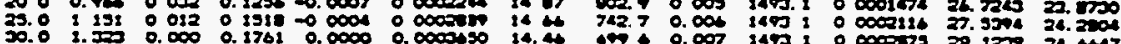

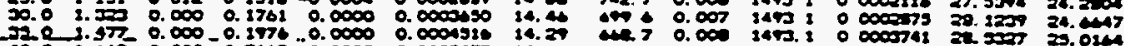

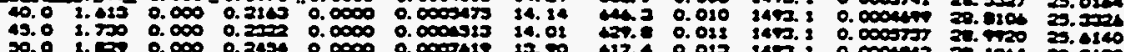

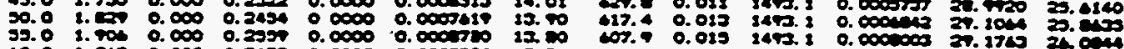

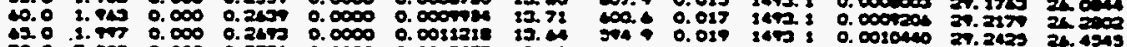

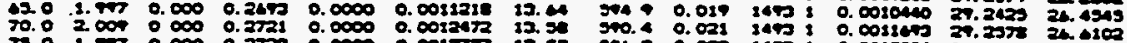

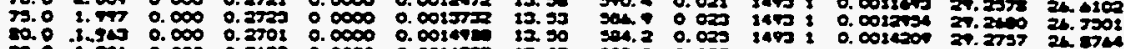

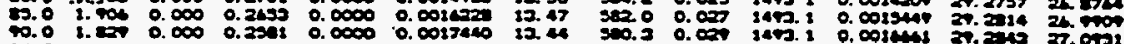

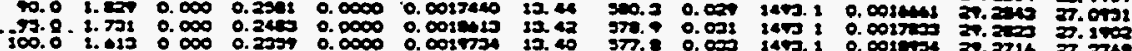

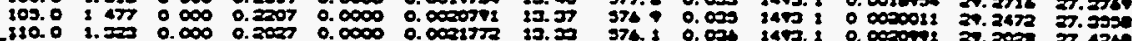

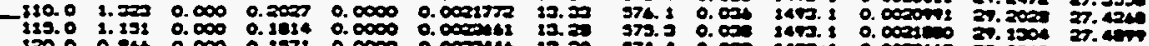

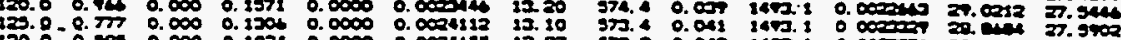

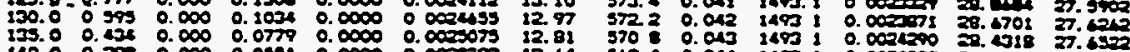

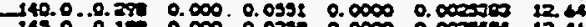

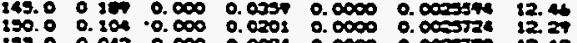
$\begin{array}{lllllllll}110.0 & 0.000 & 0.000 & 0.0000 & 0.0000 & 0.0003010 & 11.77\end{array}$

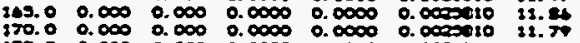

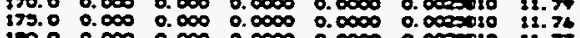

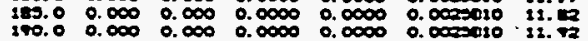

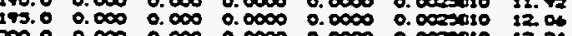

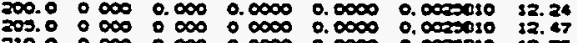
$210.0 \quad 0.000 \quad 0.000 \quad 0.0000 \quad 0.0000 \quad 0.000301012 .73$

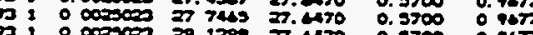

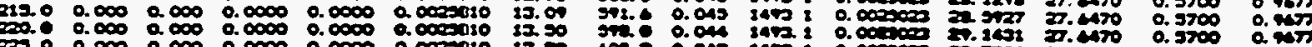

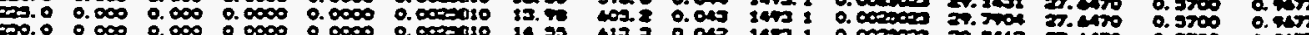

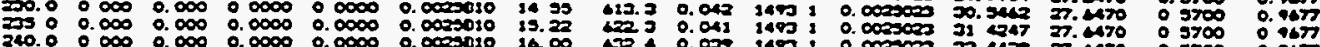

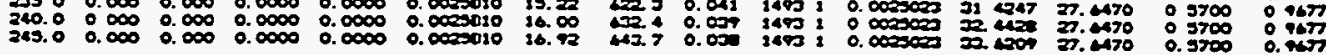

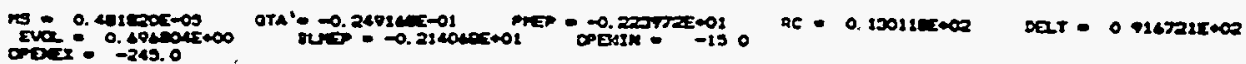




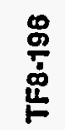

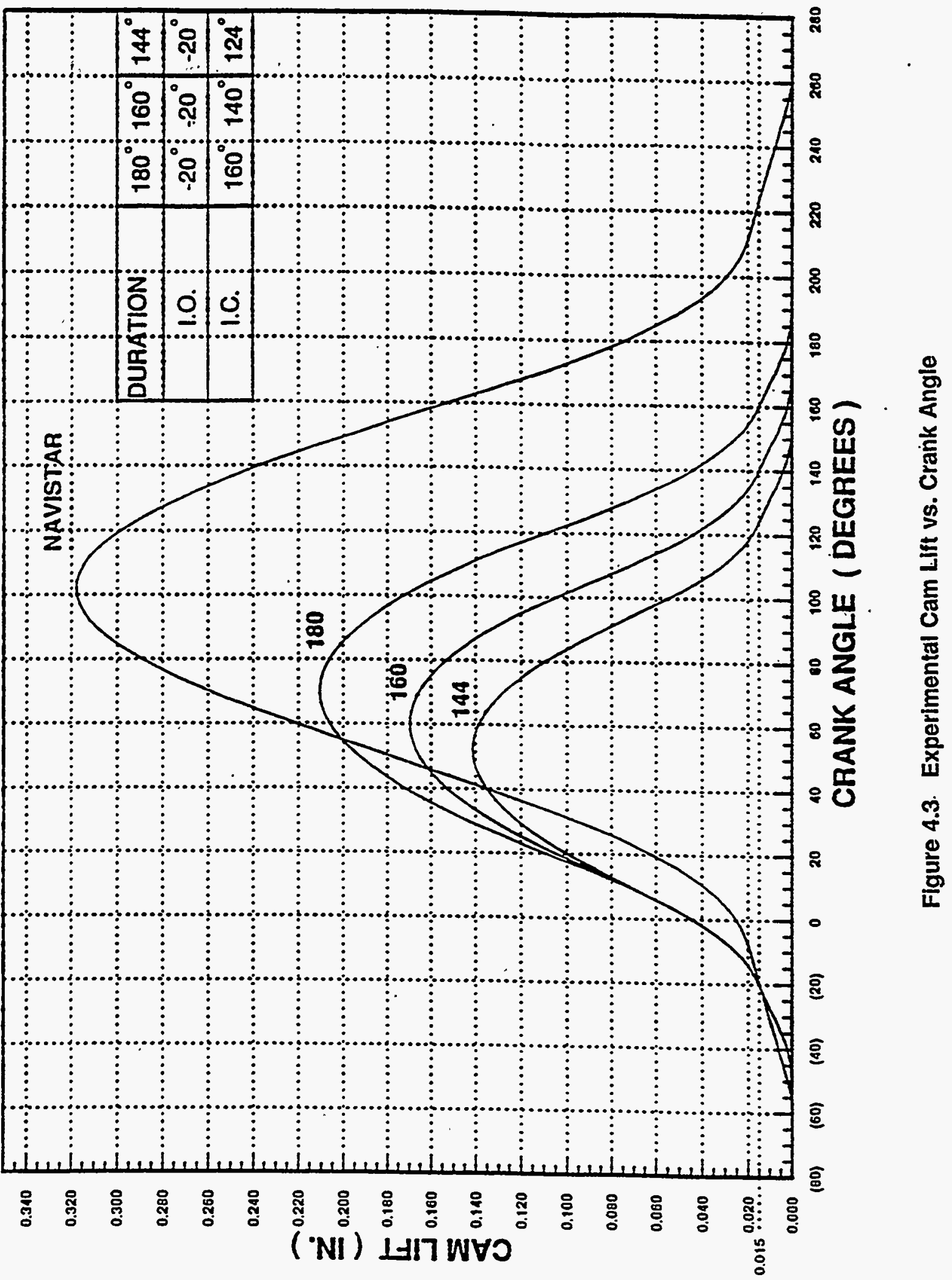


Engine: Navistar DTA-466. In-line 6 cylinders Bore: 4.30 in

Stroke: 5.35 in

Displacement: 455 cu.in.
Expansion Ratio: 16.5:1

Carrshatt: Tecogen $180 \mathrm{deg}$. Duraton intake

Fuol: Natural Gas
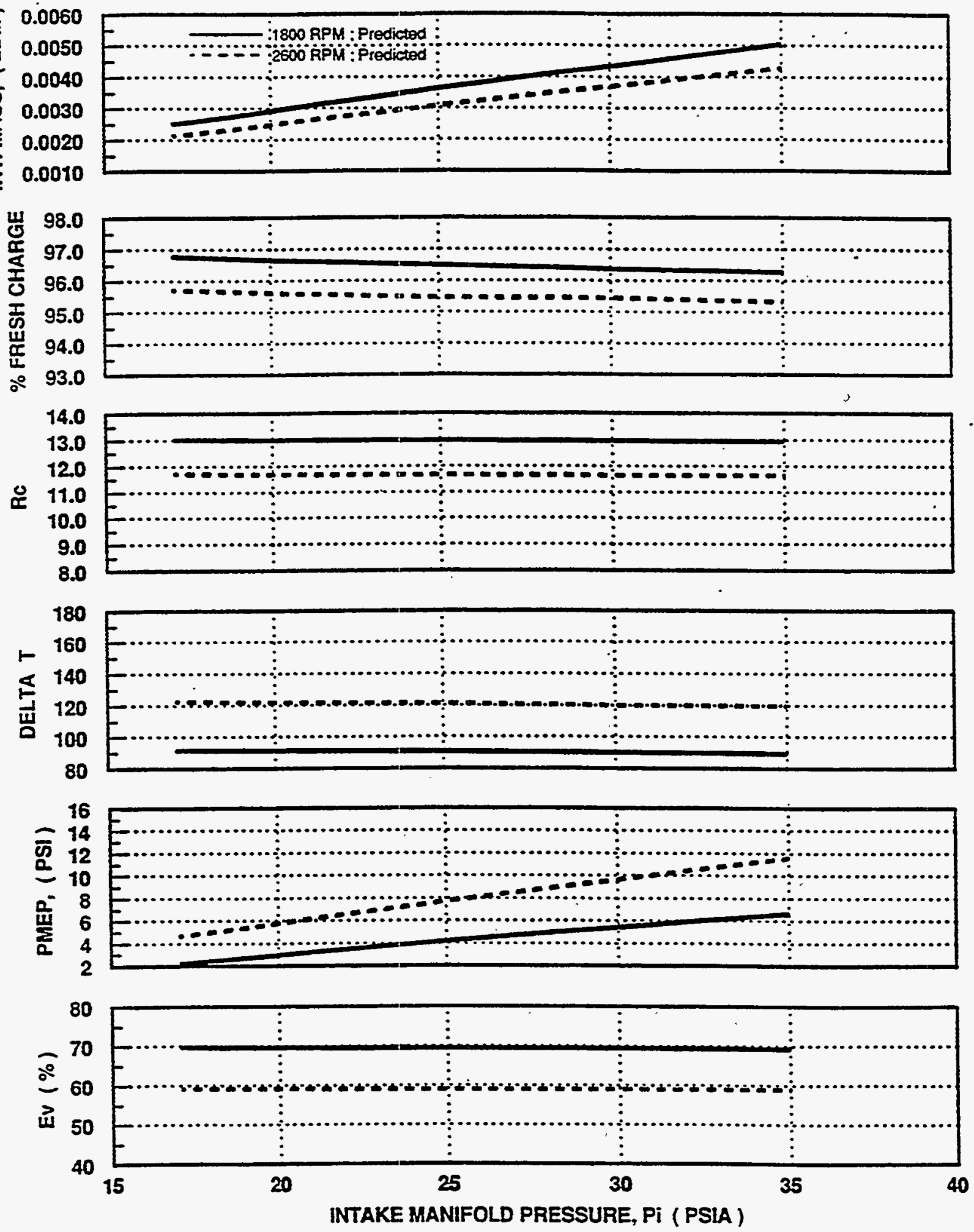

Figure 4.4 Engine Induction Flow Model Prediction 
Figure 4.5 is the predicted engine performance for different speeds and intake manifold pressures based on the results of the intake process simulation. The BSFC is significantly lower than a conventional Otto cycle natural gas engine due to the high expansion ratio of this engine. Figure 4.6 is a plot of $T_{2}$ " vs. peak pressure, for various engine speeds and manifold pressures. As pointed out above, $T_{2}$ " is insensitive to the operating conditions. Since the detonation limit of the engine is expected to be in the form similar to that shown in Figure 4.1, this means the engine will detonate when the peak firing pressure reaches a level above which the calculated $T_{2}{ }^{n}$ becomes higher than the detonation-limited $T_{2}$ ".

Figures $4.7,4.8$, and 4.9 are the analytical results for the engine with the same $180^{\circ}$ duration camshaft except that a prechamber is incorporated into the cylinder head. In this case, the expansion ratio is reduced to 13.9. Comparing to the previous case, the lower compression ratio resulted in lower $T_{2}$ " and peak firing pressure for the same BMEP. However, the BSFC is higher. The lower $T_{2}{ }^{n}$ and peak pressure should allow this engine to reach higher knock-limited BMẸP, provided that the detonation limit of this engine is not changed due to the addition of the prechamber.

Figures 4.10 through 4.15 are the analytical results for the $160^{\circ}$ crank angle duration intake with the 2 different expansion ratios, 16.5 and 13.9. Figure 4.16 shows a plot of the $T_{2}{ }^{n}, \lambda p_{3}{ }^{n}$, and $P_{j}$ vs. horsepower at $2600 \mathrm{rpm}$ for the 4 configurations, namely, $160^{\circ}$ and $180^{\circ}$ cam with C.R. $=16.5$ and $160^{\circ}$ and $180^{\circ} \mathrm{cam}$ with C.R. $=13.9$. The $144^{\circ}$ duration cam was found inadequate to produce the required power. The selection of the cam profile is based on a trade-off between the following criteria:

1. The adiabatic end gas temperature, $T_{2}{ }^{\prime \prime}$, is minimized.

2. The peak firing pressure, $\lambda p_{3}$, is minimized for a given engine speed and BMEP.

3. The intake manifold pressure is within the range that commercially-available turbochargers can attain, and it must also be within the pressure ratings for the aftercooler, fuel mixer, and the pipes and hoses.

The analysis showed that the earlier closing of the intake valve resulted in lower $T_{2}$ " and therefore was less prone to detonate at the same power output. However, because of the reduced volumetric efficiency, the intake manifold pressure must be boosted to a higher level to achieve the same power output. Three cam durations (see Figure 4.3) were selected for testing in the proof-ofconcept engine. Detailed cam profiles were designed to ensure adequate loading on the valve train components for durability. 
Engine: Navistar DTA-466. In-line 6 cytinders 8ore: 4.30 in

Stroke: 5.35 in

Displacoment: 466 cusin.
Expansion Ratio: 16.5:1

Camsnaft: Tecogen 180 deg. Duravon intake

Fuel: Natural Gas

Equivalence Ratio: 1.00
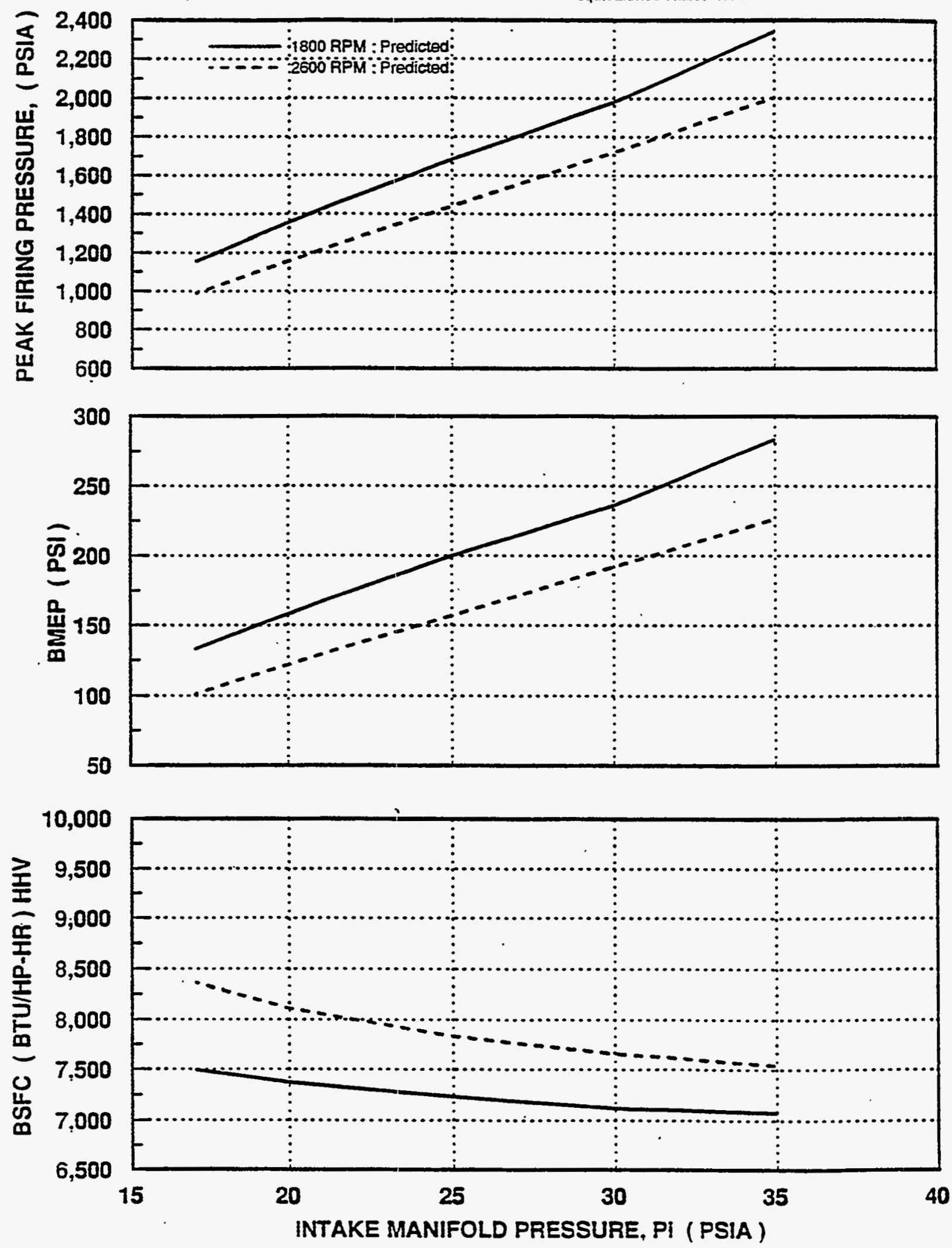

Figure 4.5 Engine Performance Model Prediction 


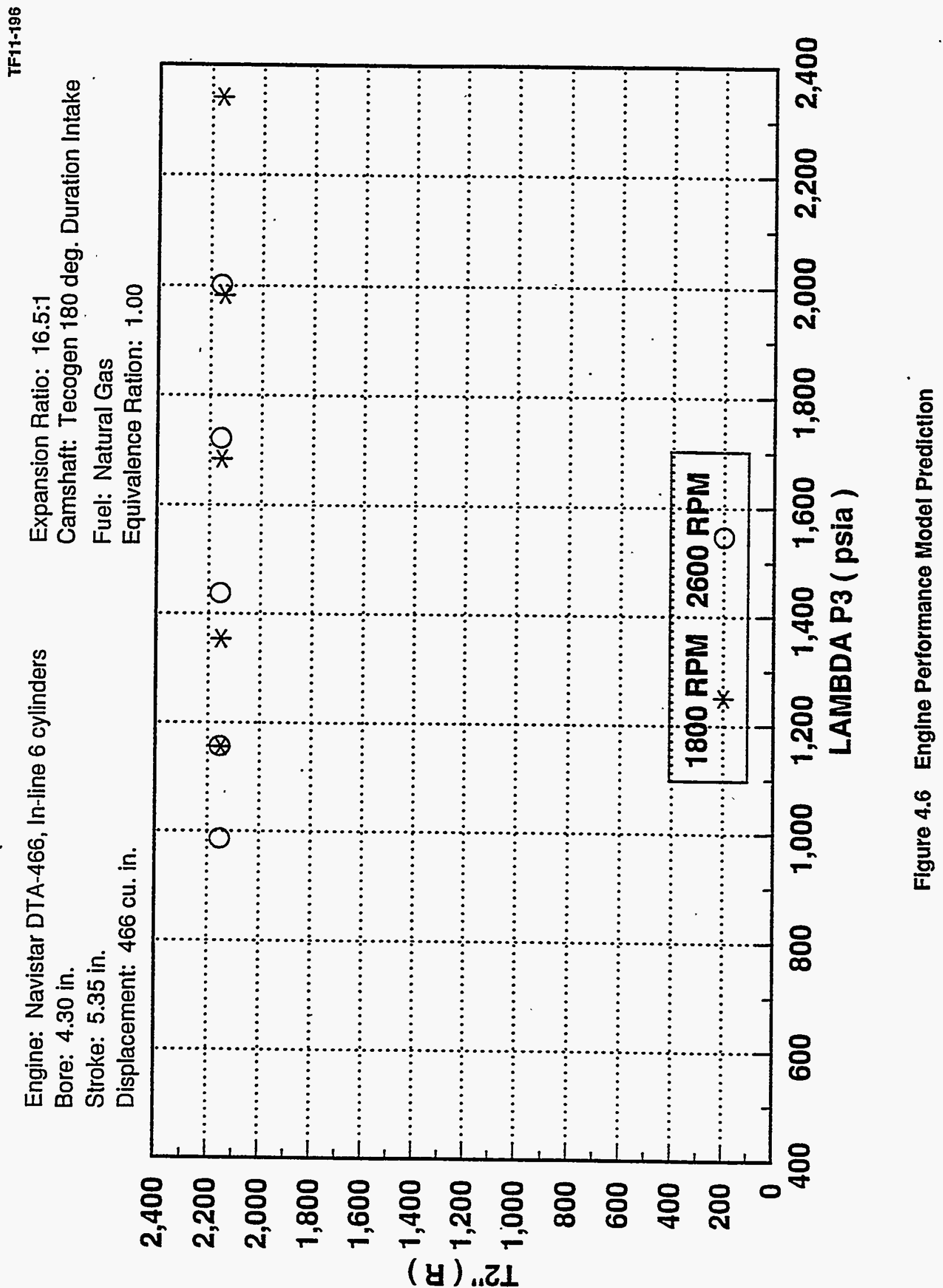


Engine: Navistar DTA-466. in-line 6 cylinders with Pre-Chamber

Bore: 4.30 in

Strok日: 5.35 in

Displacement: 466 cu.in
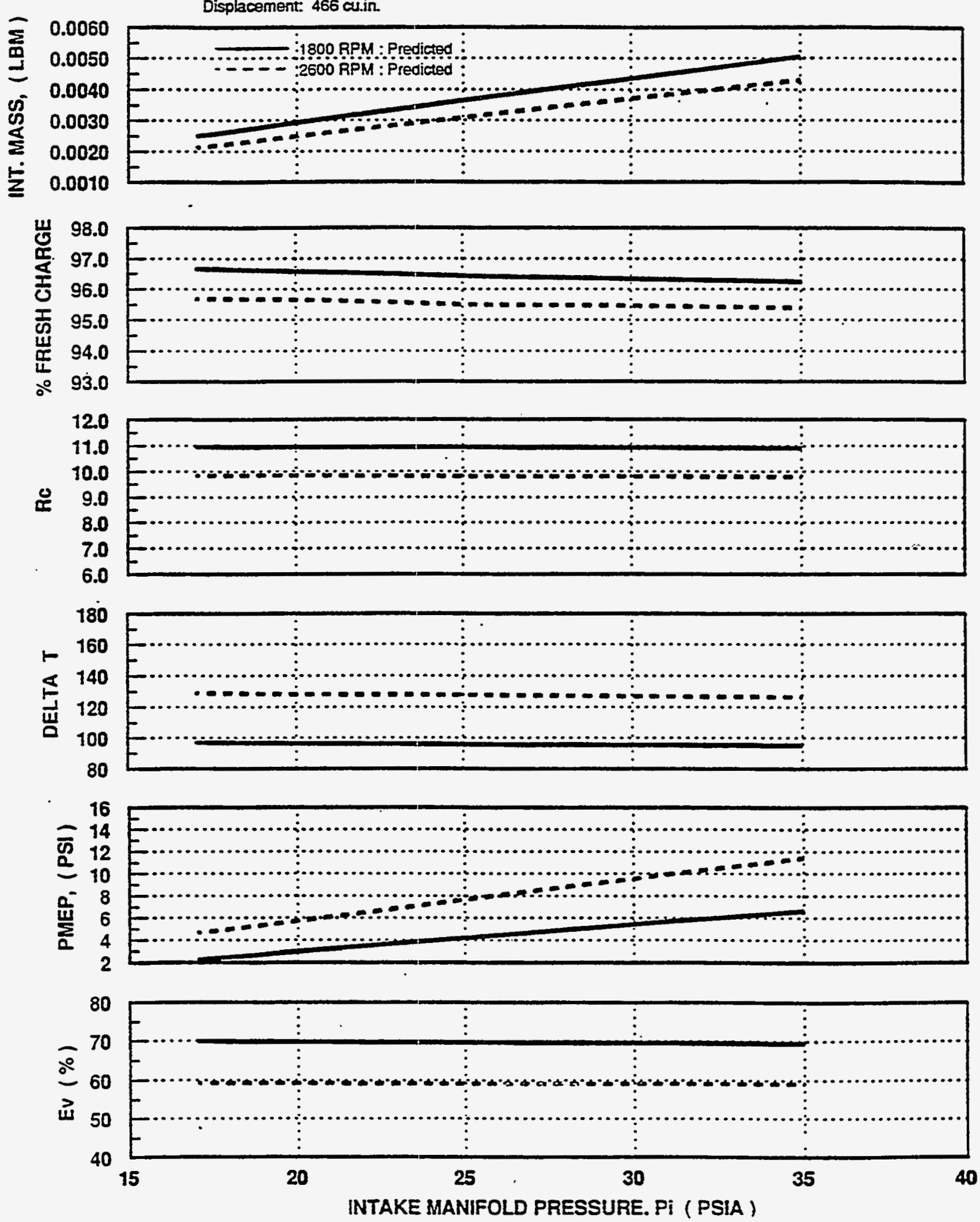

Figure 4.7 Engine Induction Flow Model Prediction 
Engine: Navistar DTA-465. In-line 6 cylinders with Pro-Chamber

Bore: 4.30 in

Stroke: 5.35 in

Displacament: 466 cus.in.
Expansion Ratio: 13.9:1

Camshatt Tecogen 180 deg. Duration intake

Fuel: Natural Gas

Equivalence Ratio: 1.00
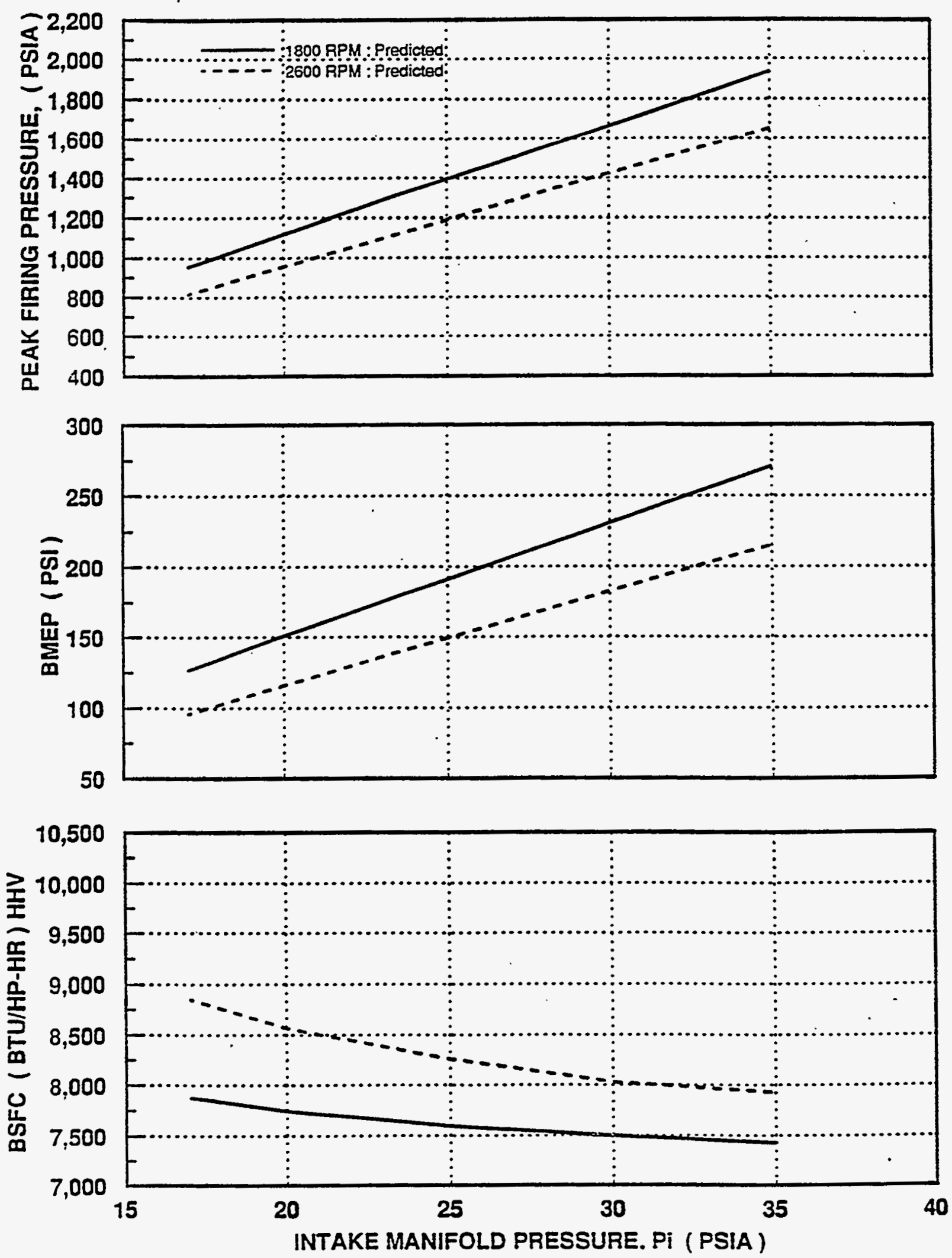

Figure 4.8 . Engine Performance Model Prediction 
$\stackrel{\circ}{\stackrel{\$}{+}}$
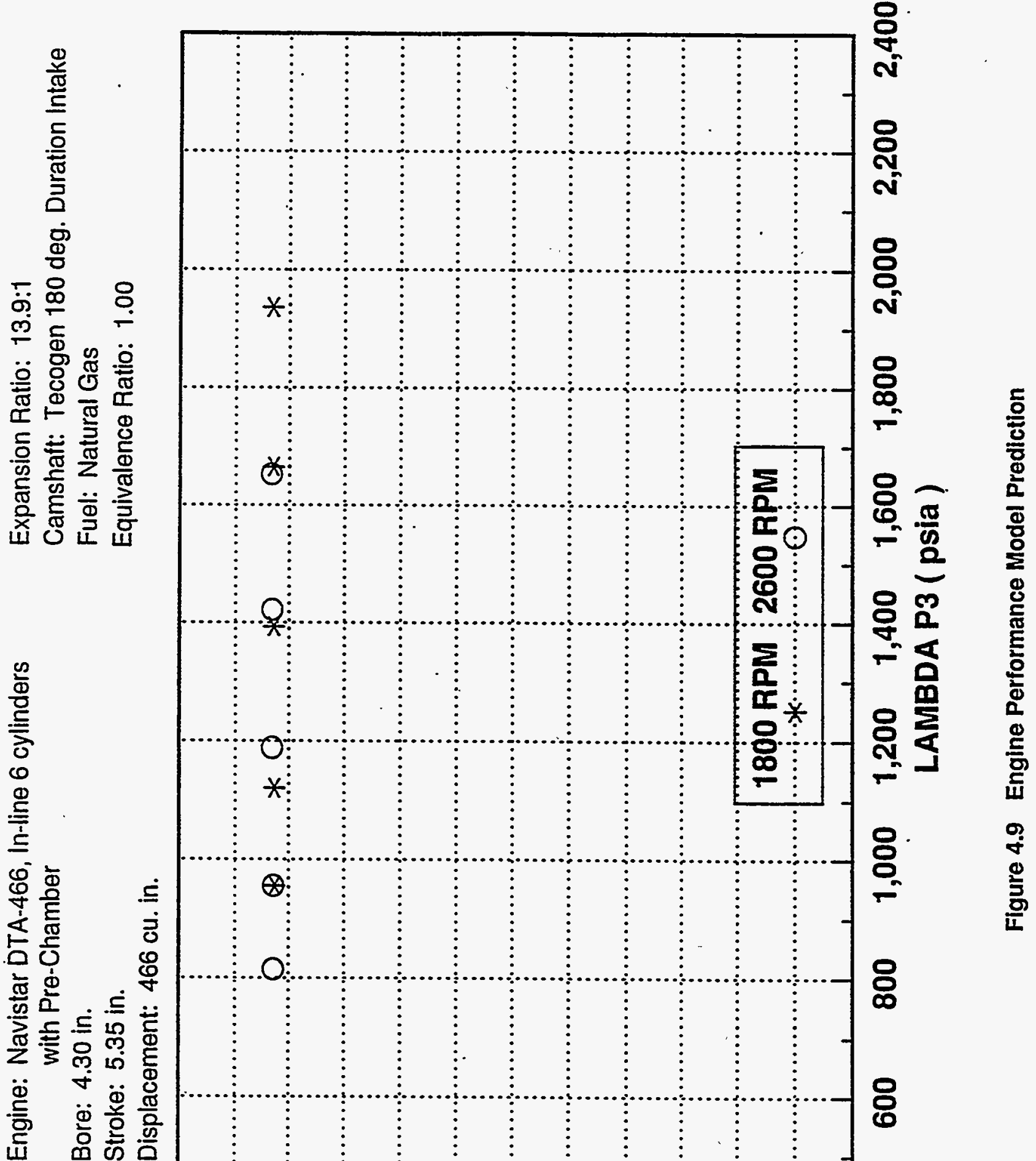
Engine: Navistar OTA-466. In-line 6 cylinders Bore: 4.30 in Stroke: 5.35 in

Displacement: 466 cu.in.
Expansion Ratio: 16.5:1

Camshatt: Tecogen 160 deg. Duraton intake

Fuel: Naturat Gas

$=$
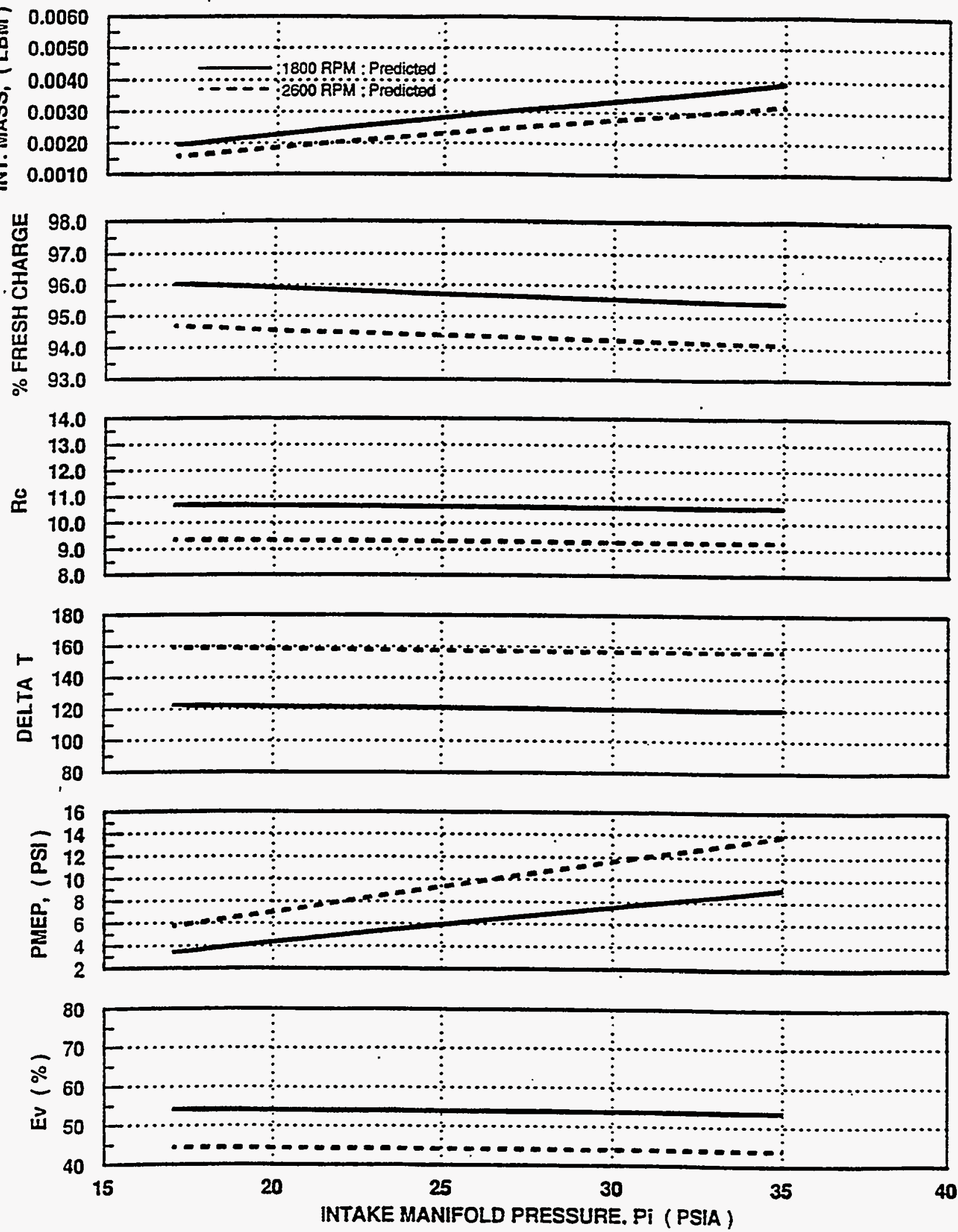

Figure 4.10 Engine Induction Flow Model Prediction 
Engine: Navistar OTA-466. In-line 6 cylinders Bore: 4.30 in

Stroke: 5.35 in

Displacement: 466 cus.1n.
Expansion Ratio: 16.5:1

Camshaft: Tecogen 160 deg. Duration intake

Fuel: Natural Gas

Equivalence Ratio: 1.00

$\frac{5}{0}$
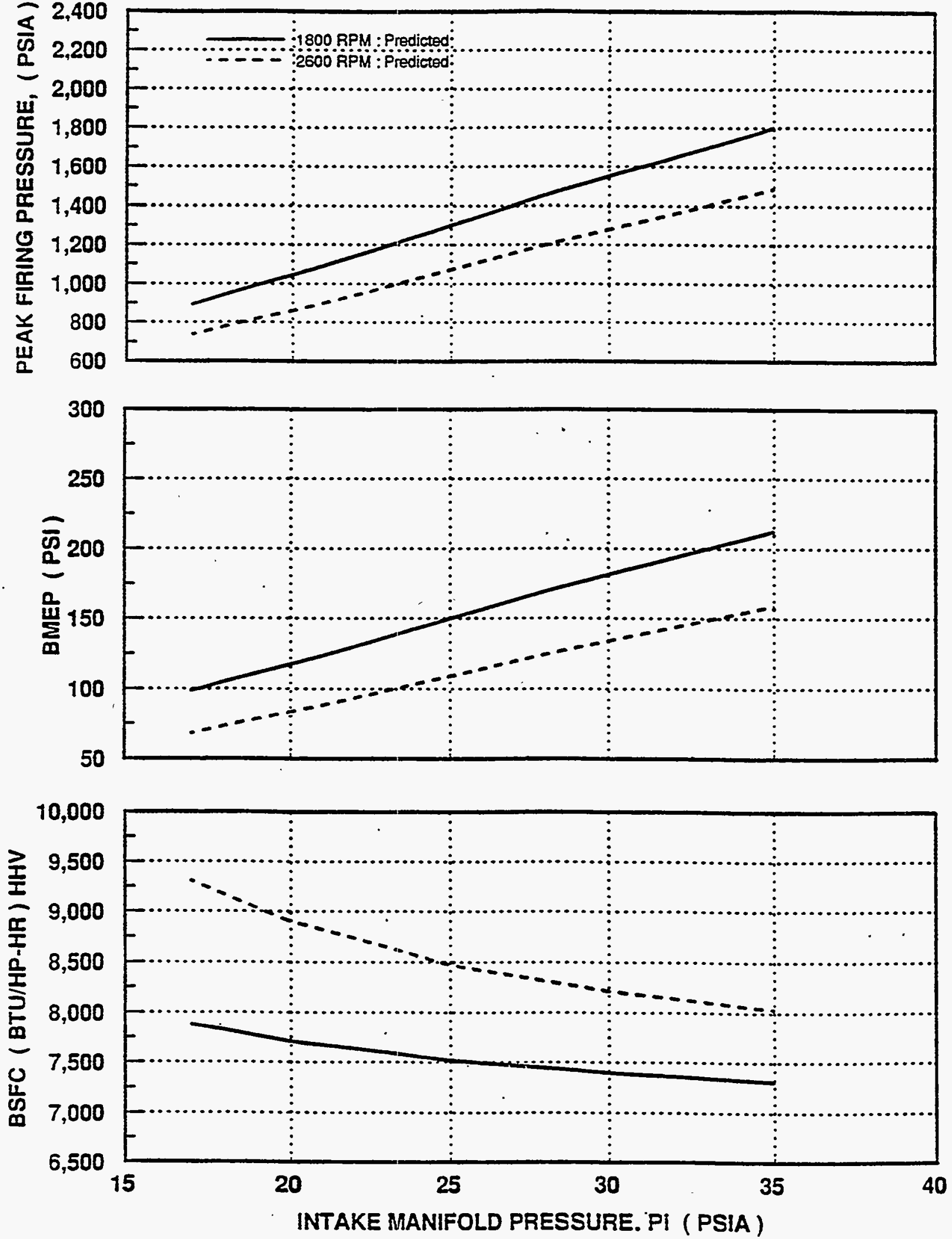

Figure 4.11 Engine Performance Model Prediction 


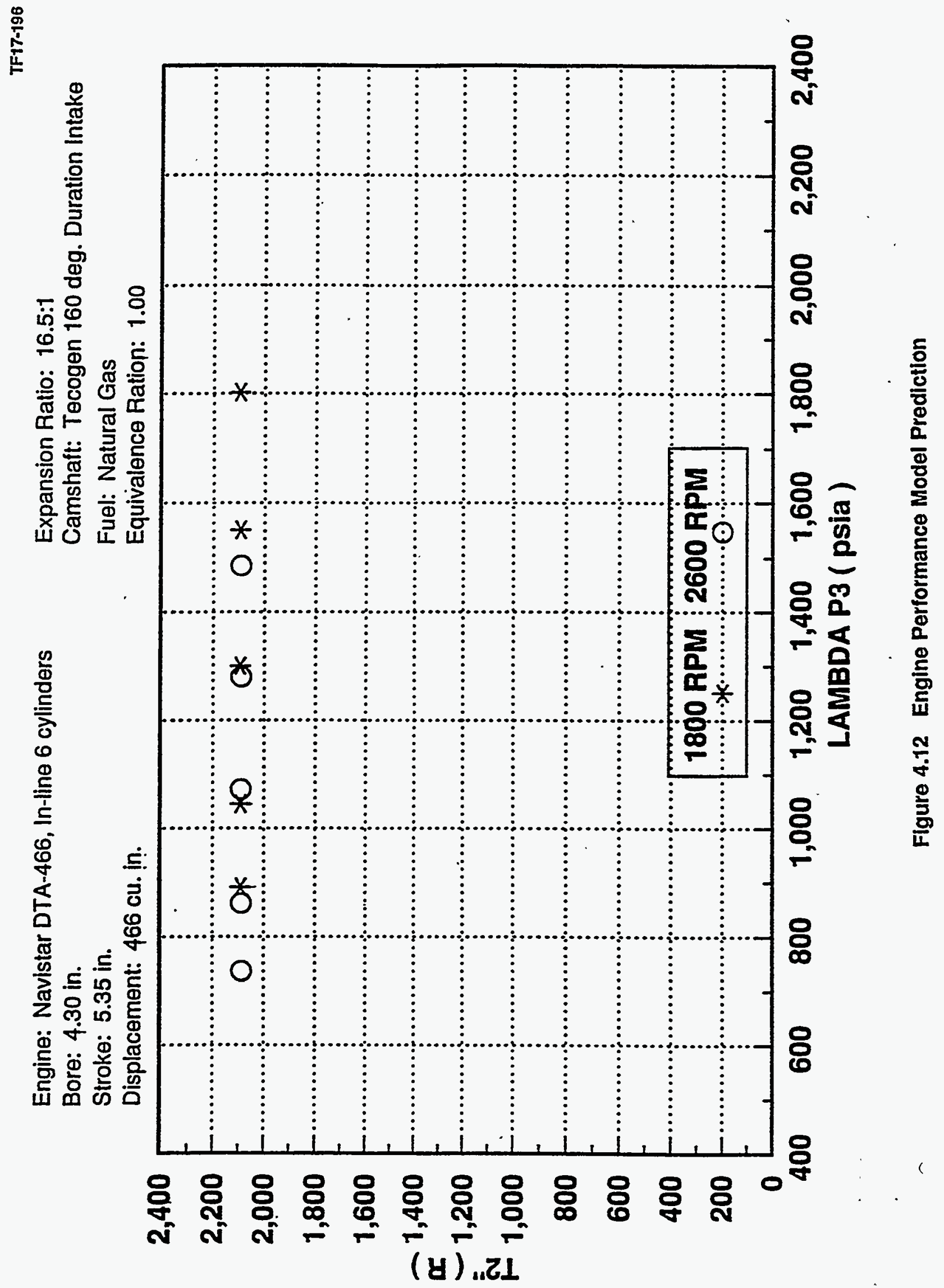


Engine: Navistar DTA-466. In-line 6 cylinders with Pre-Chamber

Bore: 4.30 in

Stroke: 5.35 in

Displacement: 466 cusin.
Expansion Ratio: 13.9:1

Camshaft: Tecogen 160 deg. Duration Intake Fuel: Natural Gas
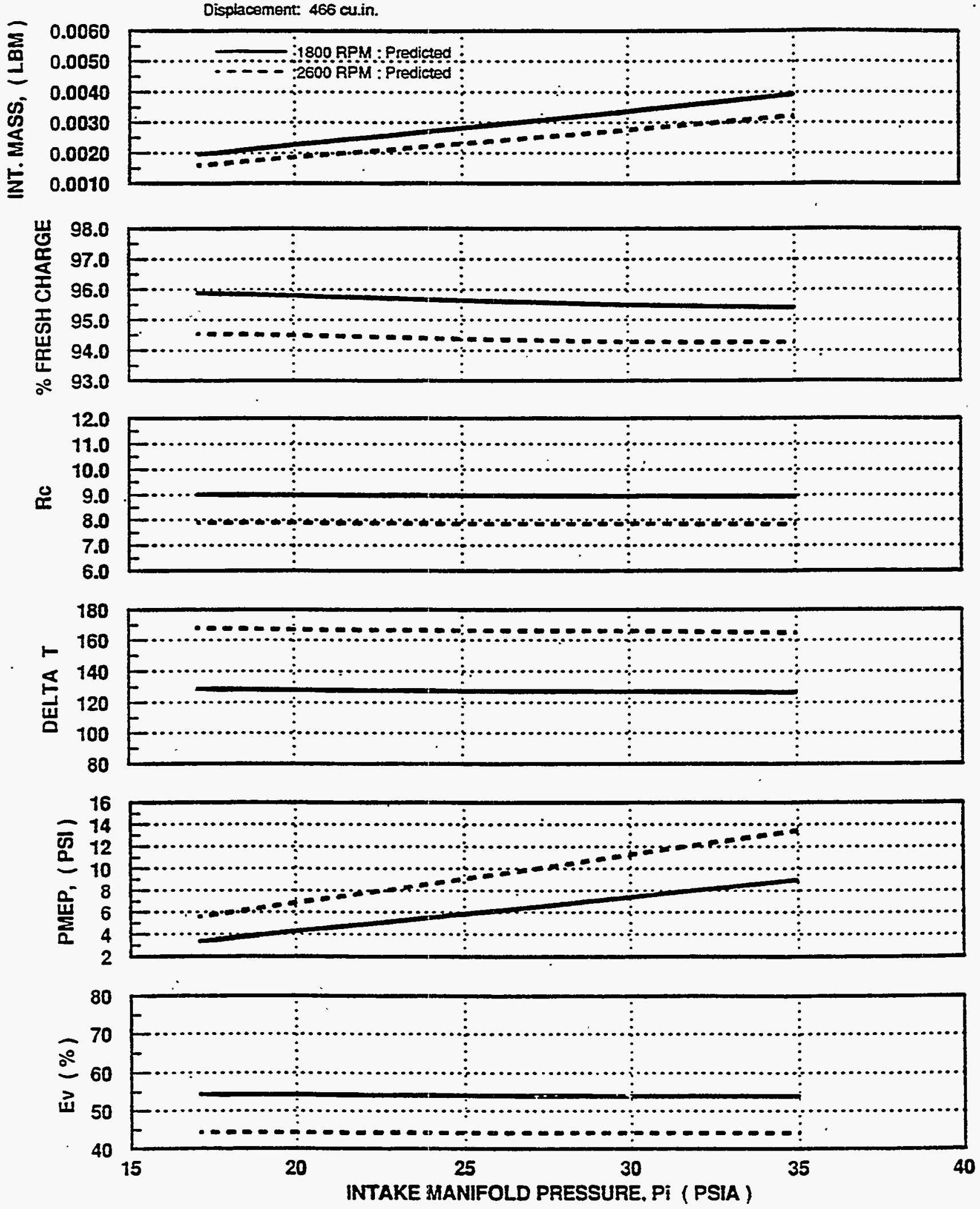

Figure 4.13 Engine Induction Flow Model Prediction 

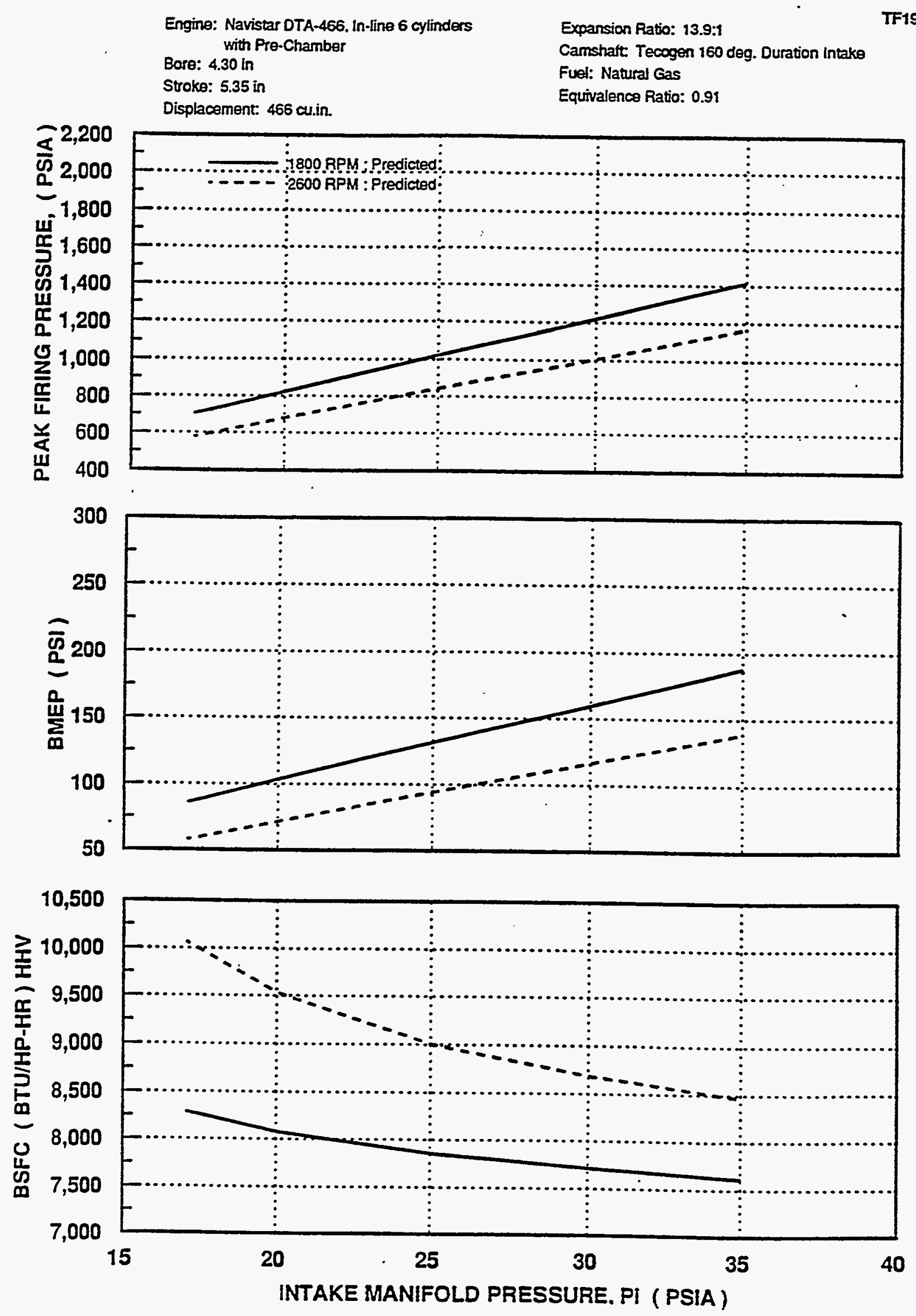

Figure 4.14 Engine Performance Model Prediction 


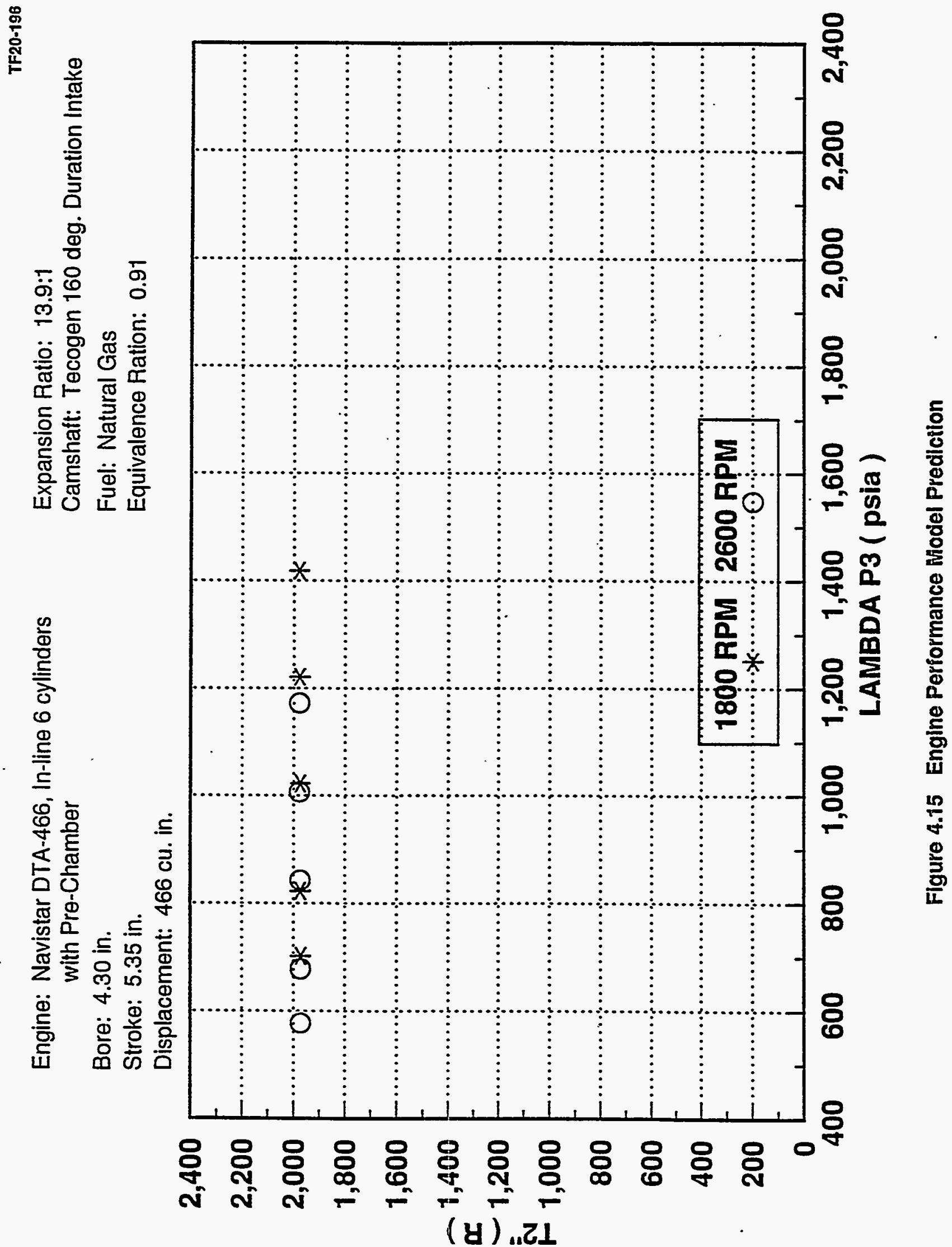


Engine: Navistar DTA-466. In-line 6 cylinders Bore: 4.30 in

Stroke: 5.35 in

Displacement: 466 cuin.
Engine Speed: 2600 RPM

Fual: Naural Gas

Equivalence Ratio: 1.00
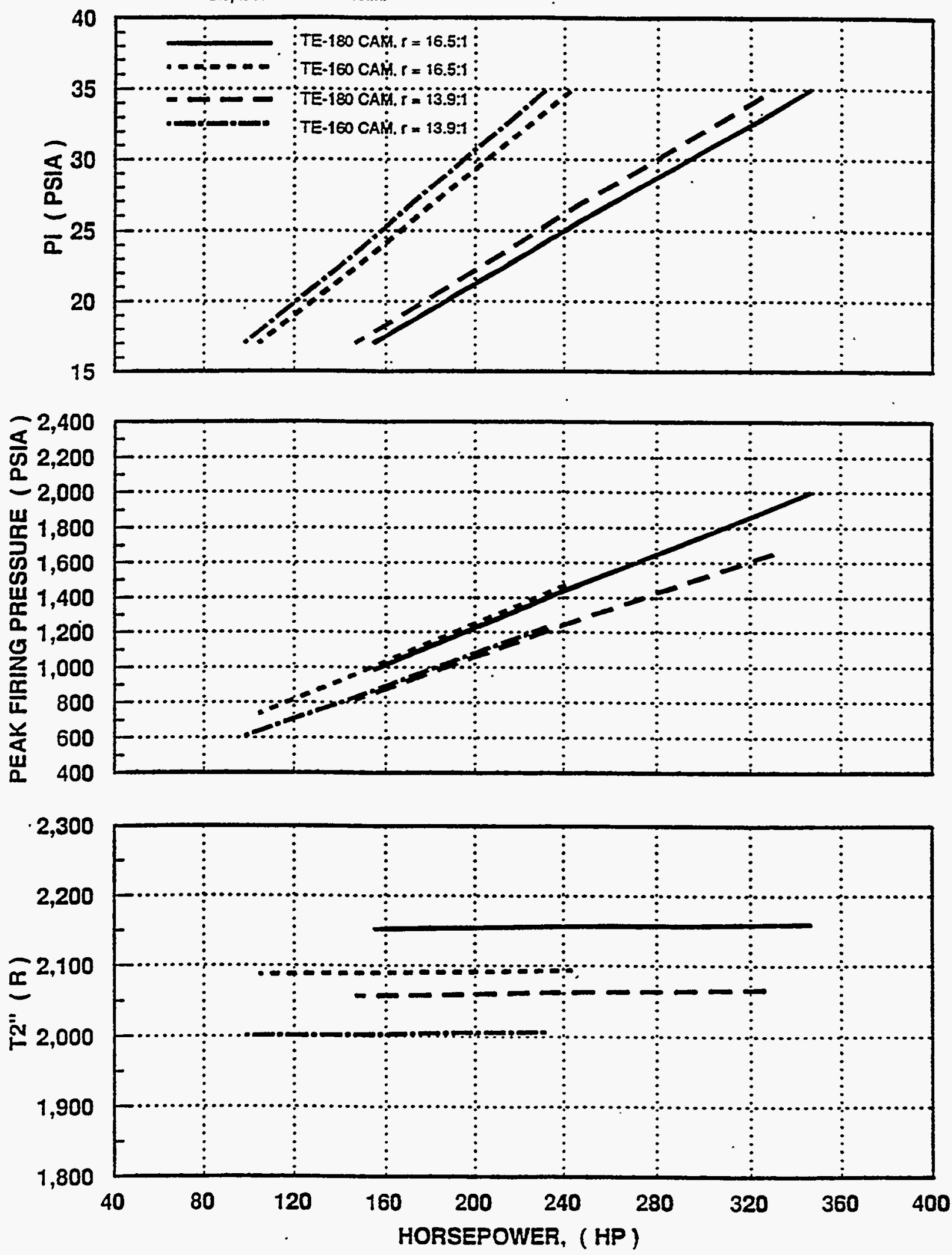

Figure 4.16 Engine Performance Model Prediction 


\subsection{DESIGN PROOF-OF-CONCEPT ENGINE}

The engineering specifications of the Navistar DTA-466 diesel engine are:

\begin{tabular}{||l|l|}
\hline \hline Engine Type & Diesel, 4-cycle \\
\hline Configuration & In line, 6-cylinder \\
\hline Displacement & $466.4 \mathrm{cu}$. in. \\
\hline Bore and Stroke & $4.301 \times 5.350$ in. \\
\hline Compression Ratio & $16.5: 1$ \\
\hline Aspiration & Turbocharged, Aftercooled \\
\hline Combustion System & Direct Injection \\
\hline Engine Weight (diry) & 1400 lbs. \\
\hline
\end{tabular}

\begin{tabular}{|c|c|c|}
\hline \multicolumn{3}{|c|}{ RATING OF FIVE MODELS } \\
\hline Model & HP & Peak Torque \\
\hline DT-466 E185 & 185 hp @ $2600 \mathrm{rpm}$ & 456 lb.ft. @ 1800 \\
\hline DT-466 E210 & 210 lip @ 2600 rpm & 513 lb.ft. @ 1800 \\
\hline DT-466 E220 & 220 hp @ 2400 rpm & 590 lb.ft. @1600 \\
\hline DT-466 E245 & 245 hp @ $2400 \mathrm{rpm}$ & 635 lb.ft. @1600 \\
\hline DTA-466 E270 & $270 \mathrm{hp} @ 2400 \mathrm{rpm}$ & 740 lb.ft. @1600 \\
\hline
\end{tabular}

The objective of the conversion was to achieve detonation-free operation of the engine on natural gas fuel with a maximum power output of 230 .hp @ 2400 rpm.

The design of the proof-of-concept engine involved 5 major areas, namely, 1) modification of the cylinder head to adopt spark plugs, 2) adaptation of a commercial ignition system, 3) incorporation of a natural gas fuel metering system and a throttle body for load control, 4) the design of a new camshaft for detonation-free operation on natural gas fuel, and 5) the selection of a turbocharger to provide the needed boost for the desired power output. Each of these topics are described below.

\subsubsection{Cylinder Head}

The approach used in adapting the spark plugs or precombustion chambers to the cylinder head was to avoid any modifications to the existing diesel cylinder head that would require machining operation. This approach would make the conversion process simple and less costly. 
The design of the spark plug arrangement is shown in Figure 4.17. A $12 \mathrm{~mm}$ spark plug is modified to fit into the exiting brass injector sleeve. A brass connector insulated with high dielectric plastic (PFA) is used to extend the plug above the cylinder head. The threads on the spark plug are machined off so that it fits through the injector hole. The hex on the plug is also machined off to fit into the brass sleeve. The spark plug is held down with a steel tube using the existing clamp for the diesel injector. Since the threads are removed, the cooling of the spark plug depends on the contact area through the brass sleeve. Whether or not the cooling is sufficient to prevent premature failure of the spark plug was to be determined by the test. An alternate design, Figure 4.18, for the spark plug was also suggested in which an aluminum collar is used as a heat conductor to increase the contact area between the spark plug and the brass sleeve.

A precombustion chamber was designed to fit into the head in place of the existing brass sleeve for the diesel fuel injector. Figure 4.19 shows the design of the prechamber which is held in place by means of a slight interference fit at the nozzle end and a clamp at the top similar to that for the diesel fuel injector. Since the prechamber is in the waterjacket, an "O" ring seal is needed at the top, and a copper gasket together with locktight is used at the nozzle end. A standard $14 \mathrm{~mm}$ taperedseat spark plug is inserted at the top of the chamber. Cooling of the spark plug was not anticipated to be a problem. The prechamber adds approximately $1.0 \mathrm{cu}$. in. to the clearance volume, which reduces the expansion ratio of the engine from 16.5 to 13.9 , which is one of the purposes of using the prechamber. The lower expansion ratio permits the engine to achieve higher output before reaching the knock limit. The second reason for the prechamber is to improve the ignition and combustion characteristics of the engine, because the high turbulence resulting from the squish configuration could cause the ignition with a conventional spark arc to be inconsistent and thus cause large cycle-to-cycle variations. The ignition of the mixture inside the prechamber should be more consistent due to the more regulated flow pattern, and the mixture in the main combustion chamber is ignited by the hot gas jet from the prechamber, which is several orders of magnitude higher in energy than that in the arc of a spark discharge.

\subsubsection{Fuel System}

Since it was not an objective in this proof-of-concept-engine demonstration phase to optimize the fuel control system, a simple mechanical-type fuel mixer (i.e., the IMPCO 425 mixer) was selected for the test engine. An adaptor was designed to fit between the throttle body and the intake manifold. We decided to place the mixer after the aftercooler for safety reasons because of the substantial volume between the blower and the engine, which includes the air-to-air aftercooler and the pipes joining the various components. The fuel supply from the gas utility has a maximum pressure limit of $24 \mathrm{psig}$, which was adequate for boost pressures up to $20 \mathrm{psig}$. The IMPCO 425 was modified to incorporate a pressure balance line between the air inlet chamber and the atmospheric chamber for the idle circuit, so that the idle diaphragm would operate properly and not be damaged under high boost pressure conditions. 


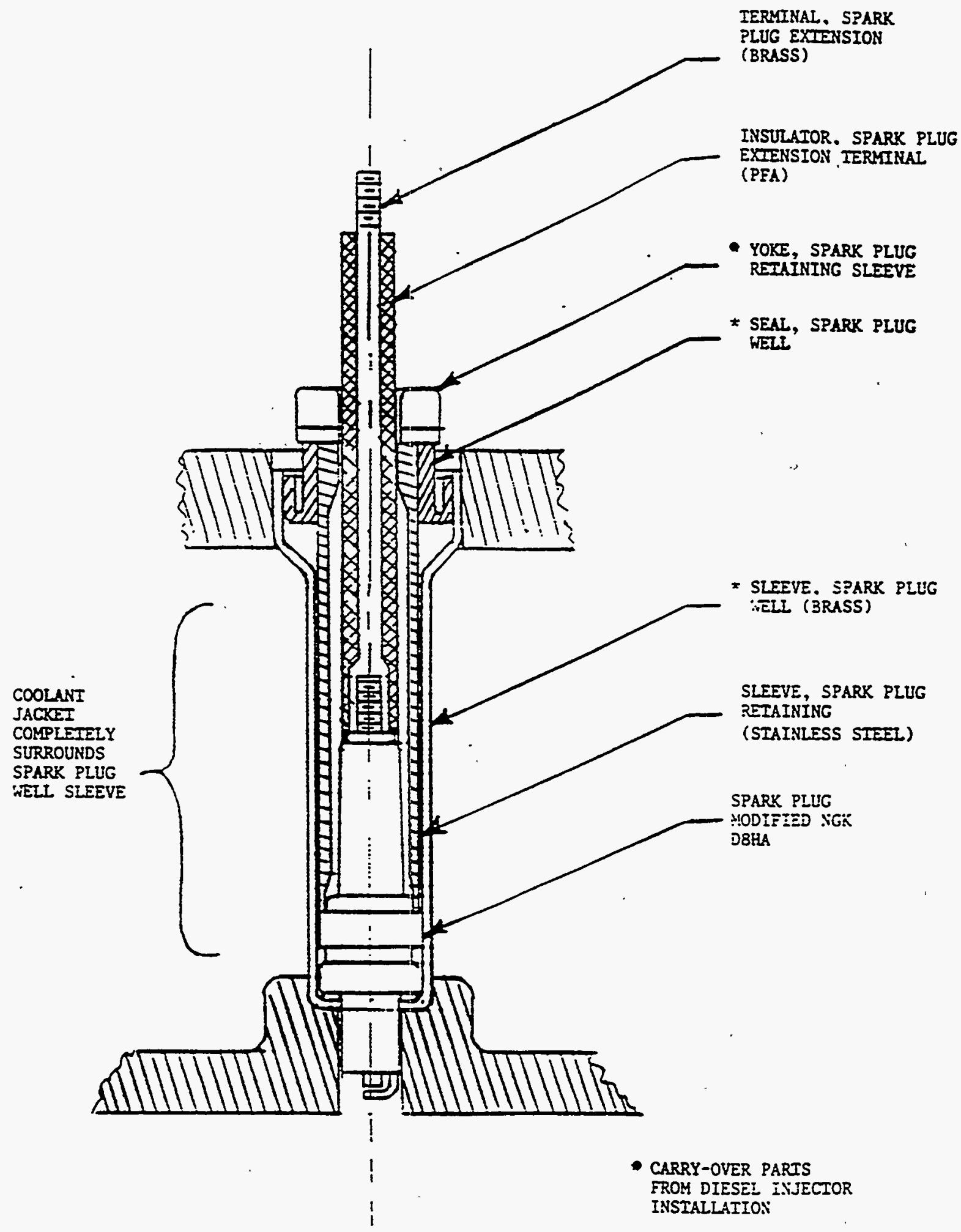

Figure 4.17 Spark Plug Adapter for Navistar DTA-466 Engine 


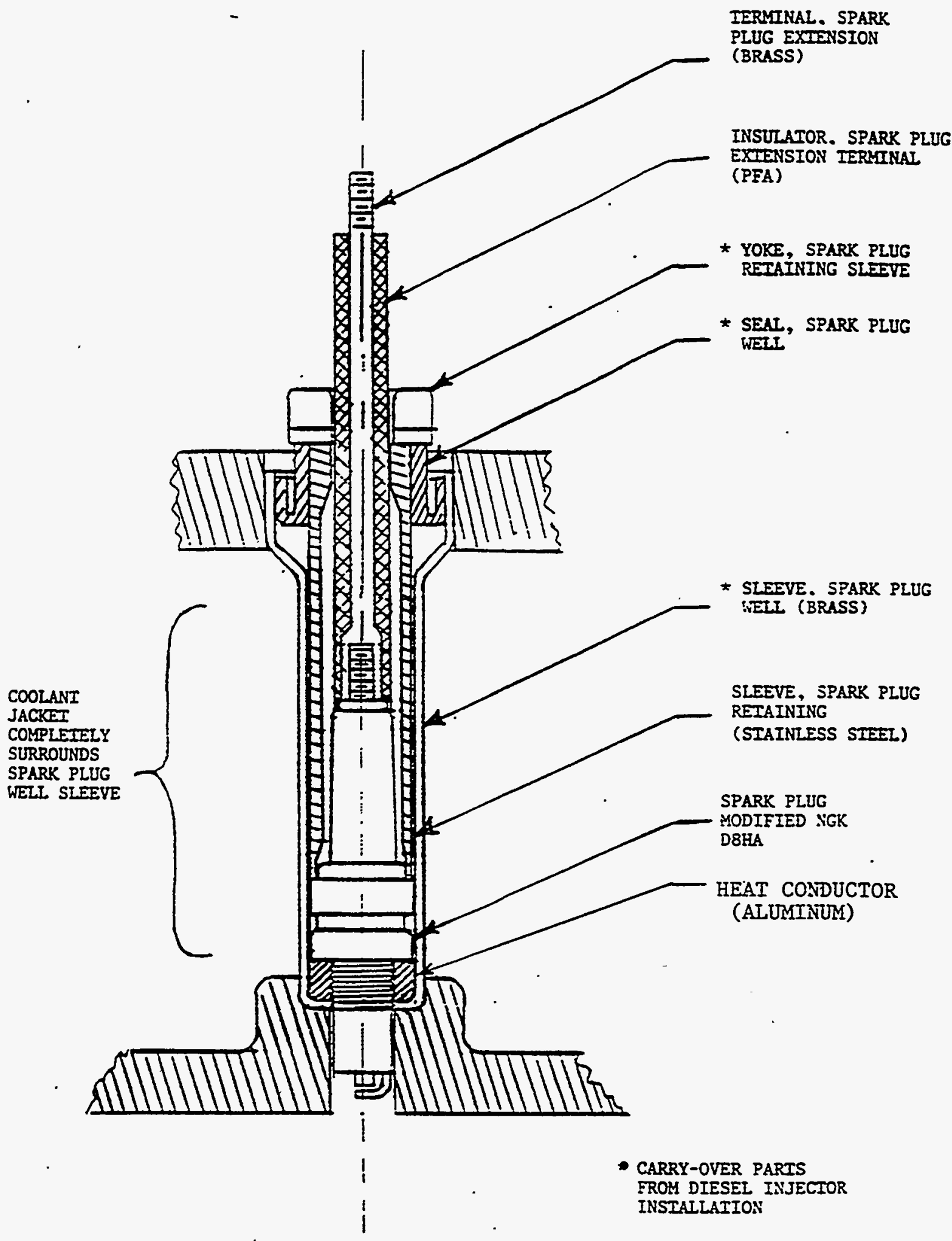

Figure 4.18 Spark Plug Adapter for Navistar DTA-466 Engine (Alternate) 


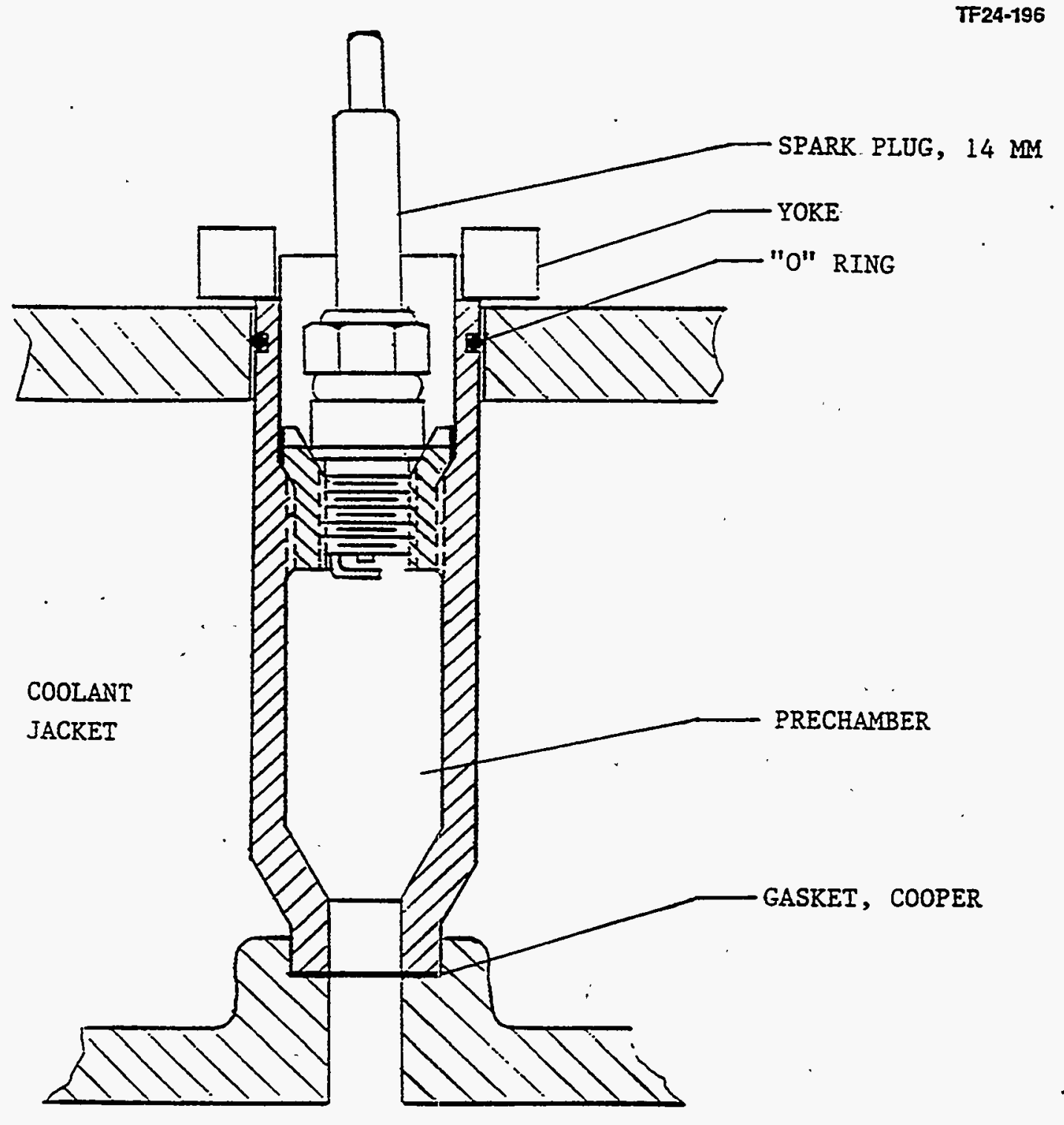

Figure 4.19 Prechamber Design 
Preliminary testing of the fuel system indicated that the fuel metering system did not provide constant fuel-air mixture when engine conditions were changed. Therefore, a motorized control of the mixture adjustment screw on the mixer was provided for adjusting the mixture during the steady state dynamometer testing.

\subsubsection{Ignition System}

Two approaches were considered for the ignition system. One approach was to adopt a distributorless ignition system with a magnetic pickup sensing signals from a disc attached to the pulley. With this arrangement, the spark plug in each cylinder fires with every revolution, i.e., at TDC compression and TDC exhaust. This approach is currently used in a number of automotive engines. The second approach was to utilize the half-speed shaft which is normally used to drive the fuel injection pump, and adapt a distributor-type ignition system, or to drive a timing disc for a distributorless system. The latter is preferred for the proof-of-concept engine, even though it may not be the optimum system from the standpoint of cost and reliability, because it is easier to diagnose any potential ignition problems during the development of the engine combustion system. However, we could not easily use this approach, because it was determined that the half-speed shaft was an integral part of the injection pump and the drive gear is actually cantilevered off the end of the pump shaft. Since the camshaft was also not easily accessible, we decided to use the distributorless ignition. An Altronic CD1 ignition system was selected for the engine. Due to space limitations, the disc to provide the magnetic pick-up signal could only be attached to the back face of the pulley. Provisions for adjusting the angular position of the disc were included for timing change, since the CD1 system only allows a limited range for spark timing adjustment.

The Altronics CD1 ignition system consists of a CD1 control unit, a 3-coil tower module, and a magnetic pick-up. Photographs in Figure 4.20 show the locations of these components. This ignition system fires 2 cylinders at the same time on each revolution of the camshaft. This means.that the spark fires at both TDC compression and TDC exhaust. Under normal conditions, firing the spark at TDC exhaust is inconsequential. However, it potentially could cause backfire if there is a misfire at TDC compression and the unburnt mixture is ignited at TDC exhaust when the intake valve is open. We chose to test this system, since it has been used successfully in a number of automobile applications.

\subsubsection{Camshaft Design}

Although the $144^{\circ}$ duration cam was not expected to produce the required power, it was included as a possible test cam in the event that the assumed flow coefficients and detonation limits were wrong and a short duration cam was needed to achieve the detonation-free operation.

The valve events for the 3 experimental cams and the original diesel cam were: 
TF25-196
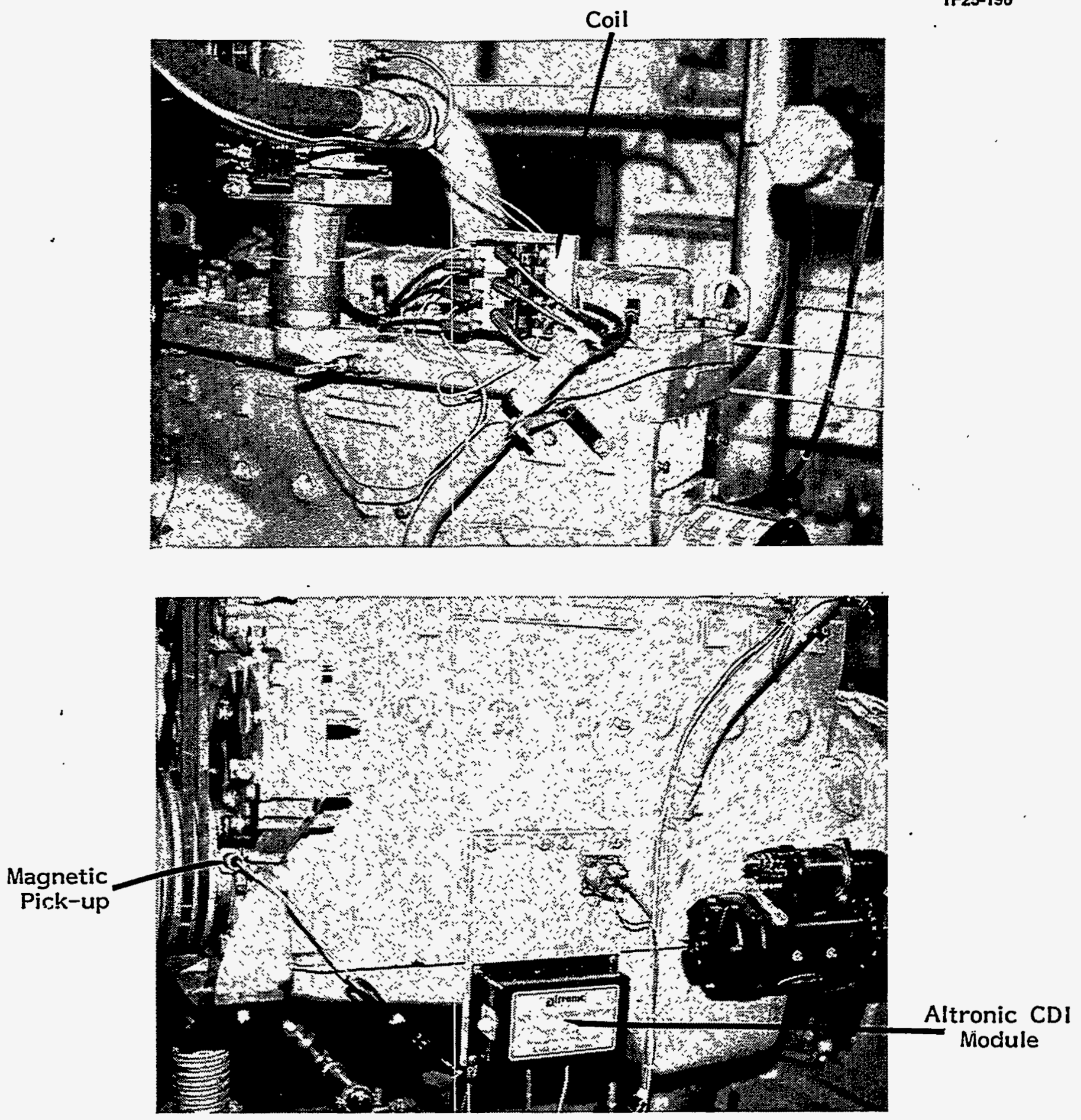

Figure 4.20 Distributorless Ignition System 


\begin{tabular}{|c|c|c|c|c|c|c||}
\hline \multirow{2}{*}{ CAMSHAFT } & \multicolumn{3}{|c|}{ INTAKE VALVE } & \multicolumn{3}{c|}{ EXHAUST VALVE } \\
\cline { 2 - 7 } & $\begin{array}{c}\text { I.O. } \\
\text { ( }{ }^{\text {ATC) }}\end{array}$ & $\begin{array}{c}\text { I.C. } \\
\text { ('ATC) }\end{array}$ & $\begin{array}{c}\text { MAX. LIFT } \\
\text { (Inches) }\end{array}$ & $\begin{array}{c}\text { E.O. } \\
\text { ('ATC) }\end{array}$ & $\begin{array}{c}\text { E.C. } \\
\text { ( }{ }^{\circ} \text { ATC) }\end{array}$ & $\begin{array}{c}\text { LIFT } \\
\text { (Inches) }\end{array}$ \\
\hline DTA-466 & -24 & 218 & 0.5273 & -252 & 24 & 0.4815 \\
\hline TE 180 & -20 & 160 & 0.3495 & -252 & 24 & 0.4815 \\
\hline TE 160 & -20 & 140 & 0.2816 & -252 & 24 & 0.4815 \\
\hline TE 144 & -20 & 124 & 0.2345 & -252 & 24 & 0.4815 \\
\hline
\end{tabular}

It can be seen that, for the shorter duration cam, the maximum lift is significantly reduced. The exhaust valve timing was varied in the analysis and the original exhaust valve closing time was found to provide the best result in conjunction with the $20^{\circ}$ BTC intake valve opening from the standpoint of minimizing the back flow of exhaust gas through the intake valve. The back flow of exhaust gas through the intake valve causes lower volumetric efficiency and higher charge temperature at the beginning of compression.

It should be pointed out that, until we ran the engine, the flow characteristics through the valves and the heat transfer characteristics inside the cylinder of this specific engine were approximated. These were calibrated as engine data became available. The most important parameter that determines the maximum engine power output is the detonation characteristics in terms of the limiting end gas temperature, $T_{2}{ }^{\prime \prime}$, and peak firing pressure, $\lambda p_{3}$. This was established in the engine test.

\subsubsection{Turbocharger and Aftercooler}

The DTA-466 E270 is equipped with a TO4E turbocharger with a 1.15 A/R turbine, which was not adequate to provide the required boost for the converted natural gas engine. Three additional turbochargers with smaller turbine nozzles were obtained and their specifications are:

\begin{tabular}{||l|l|l|l||}
\hline \multicolumn{1}{|c|}{ SUPPLIER } & \multicolumn{1}{|c|}{ P/N } & TURBINE & COMPRESSOR \\
\hline Navistar DTA-466 & PN 1817322C91 & TO4E 76 Trim, 1.15 A/R & T45 48-12 Trim, 0.33 A/R \\
\hline Navistar DTA-360 & PN 1819904C91 & TO4B 76 Trim, 0.84 A/R & TO4B 54 Trim, 0.50 A/R \\
\hline Turbonetics & P/N 10250-69 & TO4B 0-Trim, 0.69 A/R & TO4B S-3 Trim, 0.60 A/R \\
\hline Turbonetics & P/N 10250-58 & TO4B 0-Trim, 0.58 A/R & TO4B S-3 Trim, 0.60 A/R \\
\hline
\end{tabular}

The 2 small turbochargers required an adaptor to be mounted to the exhaust manifold. 
A standard aftercooler for the Navistar chassis was purchased, which was attached to the front of the coolant radiator. A high capacity fan normally available for high output duty engine applications was selected for the proof-of-concept engine due to the anticipated higher heat rejection when the boost pressure was increased.

\subsection{PROOF-OF-CONCEPT ENGINE TEST}

The engine was completely instrumented to measure pressure, temperature, and flow rates. Exhaust gas samples were taken for emissions measurement. The exhaust gas $\mathrm{O}_{2}$ measurement was used as an indicator for setting fuel-air mixture. A Kistler pressure transducer was inserted in the No. 6 cylinder head for in-cylinder pressure measurement, and the visual detection of engine detonation was from the pressure trace displayed on an oscilloscope. Figure 4.21 shows the schematic of the test set-up.

\subsubsection{Preliminary Engine Calibration Test}

The engine initially was run to check out the test system, and to compare the flow characteristics in the induction system of the engine to the assumptions made for flow coefficients, friction, and heat transfer coefficient in the computer simulation. This comparison allowed us to calibrate the constants used in the model, in order to match the calculated mass flow rate against the measured values at various engine speeds and inlet conditions.

During this series of tests, we established that the flow losses through the intake passage and valve were somewhat higher than we had anticipated. This higher flow loss or lower flow coefficient resulted in lower trapped mass per cycle or lower volumetric efficiency, and thus lower power output than those originally predicted by the computer model. In other words, to achieve the desired power, a higher boost of the inlet pressure was required. Consequently, we decided not to test the TE-144 Cam in this engine because the required boost pressure would have been too high to be practical.

Figure 4.22 shows the mass flow rate through the engine with the TE-160 Cam at 2 speeds, 1800 and $2600 \mathrm{rpm}$, and variable intake manifold pressure. The computer simulation with corrected flow coefficients is also plotted and shows good agreement.

\subsubsection{Selection of Turbocharger with TE-160 Cam}

The objective of this proof-of-concept engine test was to demonstrate the feasibility of the conversion method and, most importantly, to show that the engine can be operated at a reasonable power level without being knock-limited, even though the geometrical expansion ratio of the engine is $16.5: 1$, the same as in the original diesel engine. Therefore, matching of the turbocharger to the engine was not so critical. We needed to select a turbocharger that did not limit the maximum power output of the engine, nor did not produce boost pressures which required significant throttling, since 
ENGINE JACKET CODLANT

ENGiNE EXIIAUST

ENGINE OIL

- $-\cdots \cdots \cdots \cdots \cdots$ ENGIE.

- -..-...-.- heAT EXchanger CoOLANT

- nalualgas

(T) TEMPERMTUAE MEASUREMENT
(P) PRESSURE MEASUREMENT
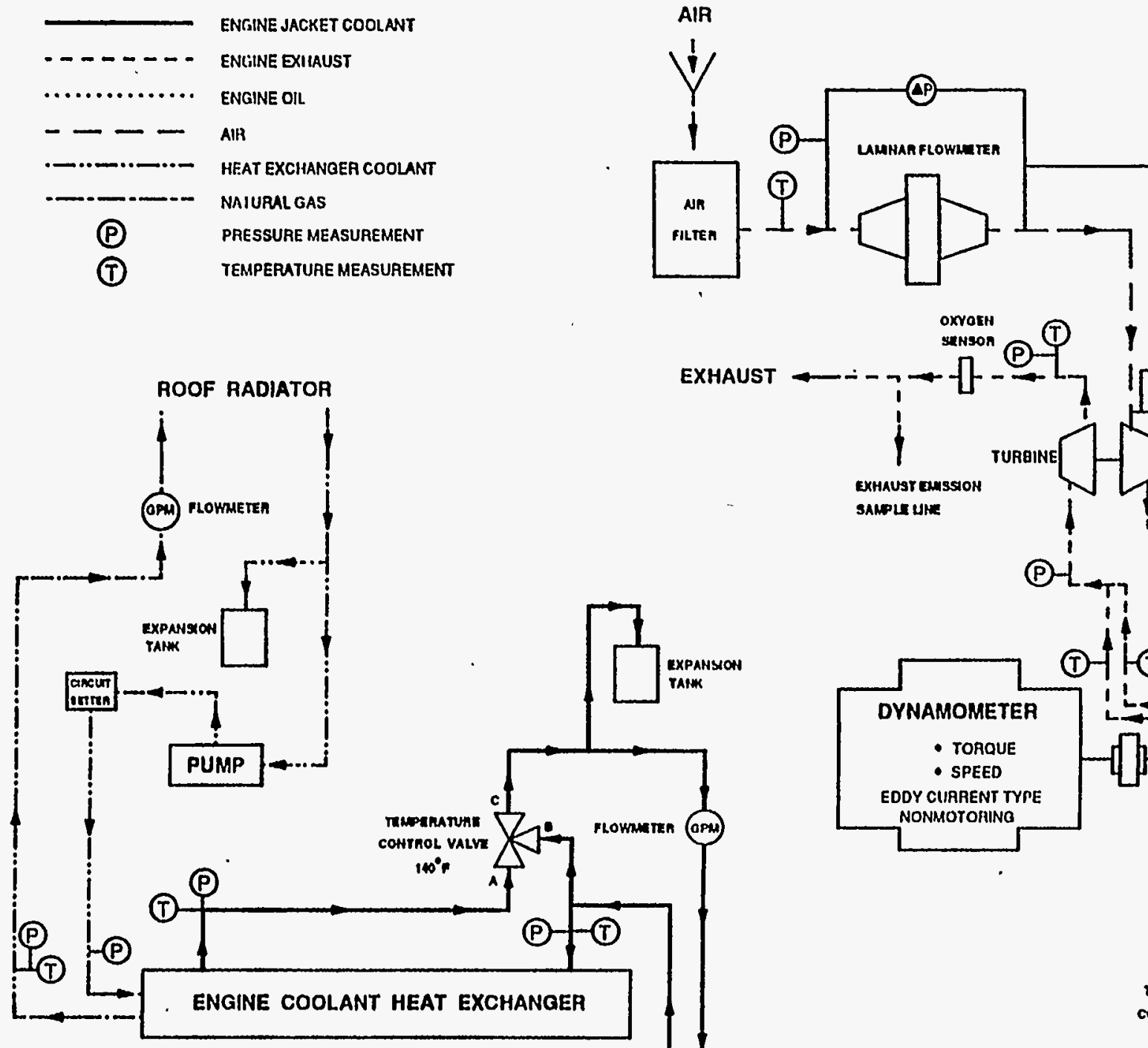
EXHAUST

senson (P)
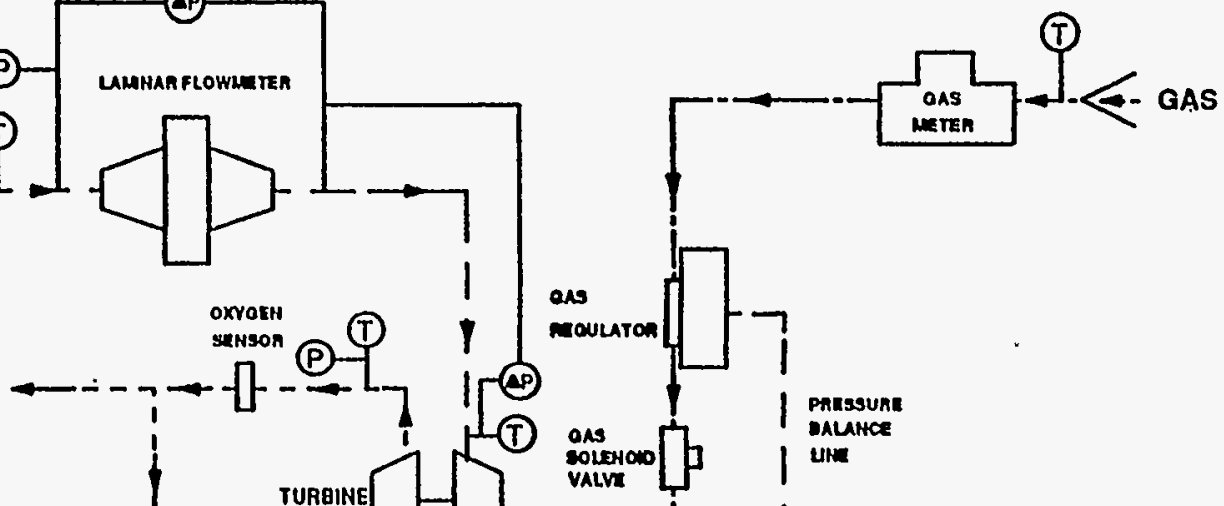

as (2)

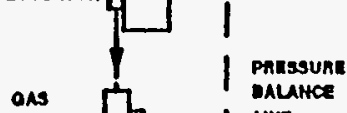

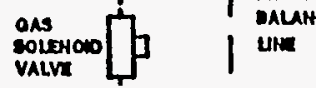

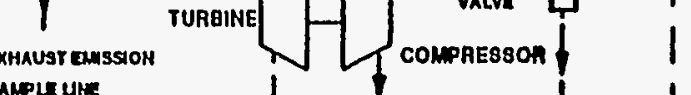

ExHAUST EMASSION sAlpLI URE

ralse

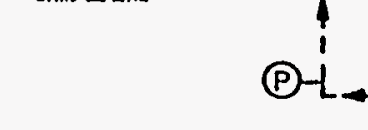

$--\rightarrow$<smiles>CC12CCC1CC2</smiles>

(1)

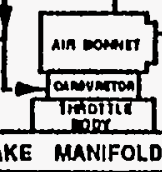

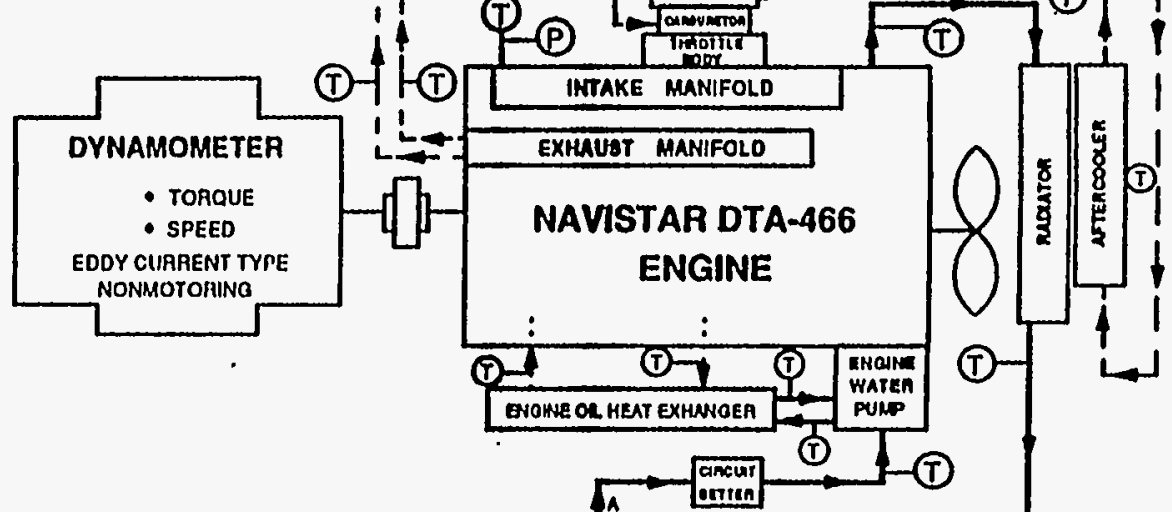
Timearatua $190 \%$

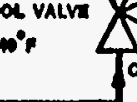

Figure 4.21 Schematic of Engine Set-up in Dynamometer Test Facility 


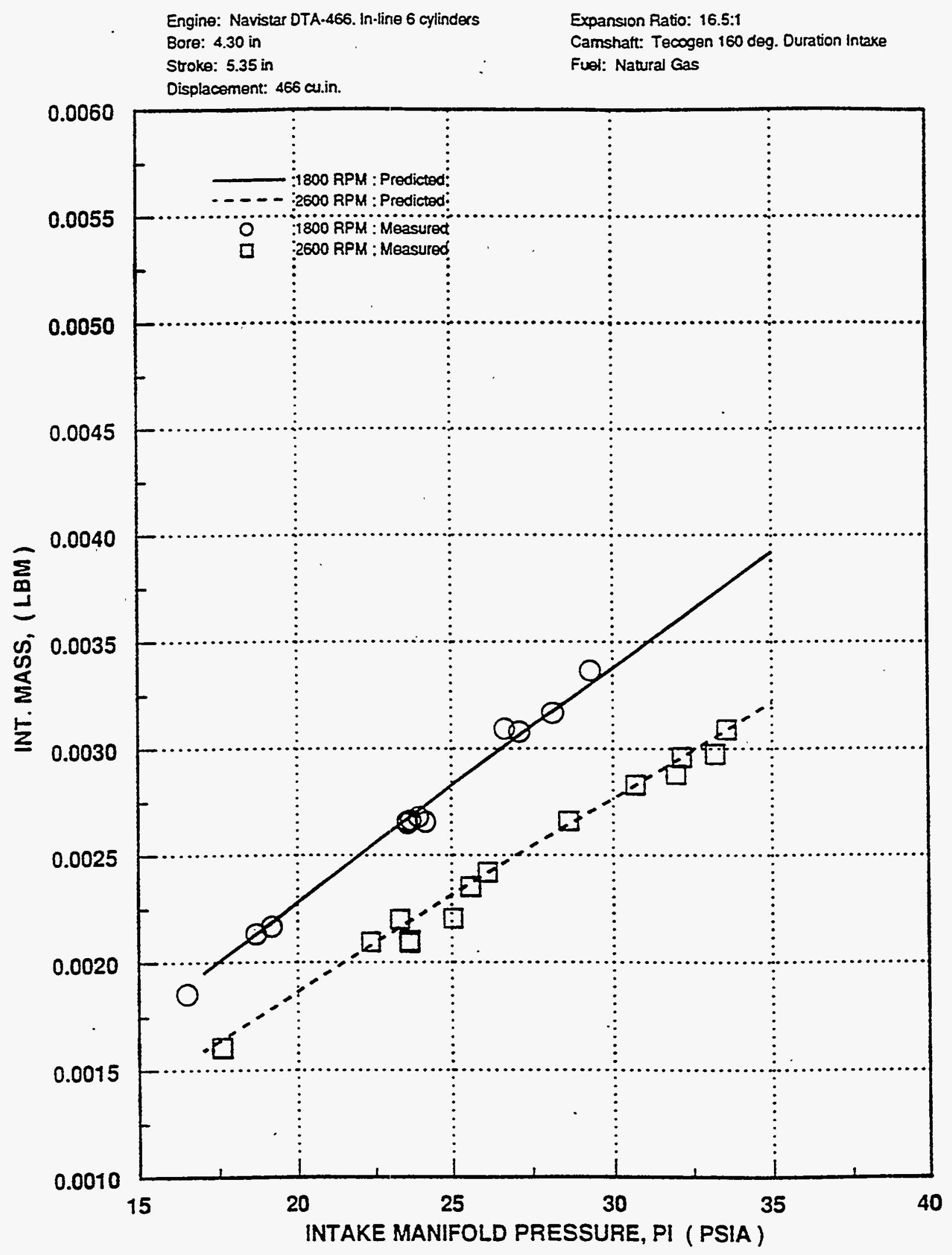

Figure 4.22 Comparison of Test Data and Model Prediction 
this could result in excessive back pressure on the engine. The high back pressure relative to the intake manifold pressure not only causes high pumping power, it also affects the intake flow process and the amount of residual gas retained in the cylinder. All of these could have an impact on the charge temperature, and ultimately, the detonation limit condition of the engine.

Three turbochargers were tested with the engine. The first tested was the stock turbocharger for the Navistar DTA-360 diesel engine. It has a TO4B 76 Trim, 0.84 A/R turbine and a TO4B 54 Trim, $0.5 \mathrm{~A} / \mathrm{R}$ compressor. The wide open throttle (WOT) performance of this engine at $1800 \mathrm{rm}$ and $2600 \mathrm{rpm}$ is:

\begin{tabular}{||l|l|l|}
\hline Speed, rpm & 1800 & 2600 \\
\hline Equivalence Ratio & 1.0 & 1.0 \\
\hline Intake Man. Press., " Hg abs. & 39.0 & 47.4 \\
\hline Torque, ft-lb & 335 & 320 \\
\hline BMEP, psi & 108 & 104 \\
\hline BHP & 112 & 156 \\
\hline BSFC, Btu/bhp-hr & 7651 & 7819 \\
\hline Peak Firing Press., psia & 970 & 983 \\
\hline
\end{tabular}

The engine operated very smoothly without any misfiring or erratic combustion at the above conditions. Since there were no signs of engine detonation, we decided to raise the boost pressure.

In order to bracket the conditions, we decided to test the turbocharger with the smallest nozzle, Turbonetics TO4B-0 Trim, 0.58 A/R turbine with the S-3 Trim, 0.60 A/R compressor. Because the turbine had an on-center configuration, an adapter had to be made to fit into the exhaust manifold flange. Modifications were also required for the compressor inlet and discharge because of the smaller sizes.

The turbocharger provided significantly higher boost to the point that the power output was limited because of fuel starvation. Since the maximum fuel supply from the utility line was about $24 \mathrm{psig}$, the flow became limited when the boost air pressure approached this level. As a result, we were not able to obtain higher power with this turbocharger than with the first turbocharger at $2600 \mathrm{rpm}$. However, at $1800 \mathrm{rpm}$, the engine performed without detonation up to the following conditions: 


\begin{tabular}{||l|l|}
\hline Speed, rpm & 1800 \\
\hline Equivalence Ratio & 0.91 \\
\hline Intake Man. Press., " Hg abs. & 59.7 \\
\hline Torque, ft-lb & 525 \\
\hline BMEP, psi & 169.7 \\
\hline BHP & 179.9 \\
\hline BSFC, Btu/bhp-hr & 7472 \\
\hline Peak Firing Press., psia & 1100 to 1300 \\
\hline
\end{tabular}

Achieving this high output and high peak pressure without detonation was extremely encouraging because it indicated that the cletonation limit of this engine was higher than our original estimate based on data from large stationary natural gas engines. This is probably due to the fast burning of the highly turbulent flame, which will be discusșed later. The maximum power obtained with this turbocharger at $2600 \mathrm{pm}$ was $188 \mathrm{hp}$ and the torque was $380 \mathrm{ft}-\mathrm{b}$.

The third turbocharger tested was the Turbonetics TO4B O-Trim, 0.68 A/R turbine with the S-3 Trim, $0.6 \mathrm{~A} / \mathrm{R}$ compressor. This turbocharger matched the engine reasonably well, except at the high speeds where the maximum output conditions exceeded the detonation limit of the engine. For experimental purposes, this was exactly what we needed in order to determine the detonation limit of this engine. The performance of this engine is shown in the next section.

\subsubsection{Performance of Engine with TE-160 Cam}

The performance of the 466 engine with the TE-160 cam timing and the TO4B O-Trim, 0.68 A/R turbine and the S-3 Trim, 0.60 A/R compressor is shown in Figures 4.23 and 4.24 for 2 different mixture ratios, equivalence ratio $=1.0$ and 0.91 . The data represents either WOT condition or knock-limited condition: With a stoichiometric mixture, the engine produced $525 \mathrm{ft}-\mathrm{b}$ of torque at $1800 \mathrm{rpm}$ and WOT. At speeds of $2000 \mathrm{rjm}$ and over, the data was taken at the condition slightly backed off from the detonating condition. Detonation was determined by observing occasional pressure spikes and oscillations on the in-cylinder pressure trace.

Several important points from the data are worth noting:

- The engine is capable of producing $232 \mathrm{hp}$ at $2400 \mathrm{rpm}$ without encountering detonation.

- The maximum torque obtained at $1800 \mathrm{rpm}$ was as high as $525 \mathrm{ft}-\mathrm{lb}$.

- Efficiency of the engine was as good as the analysis predicted. BSFC was below 6996 Btu/bhp-hr at low speeds and increased to $7312 \mathrm{Btu} / \mathrm{bhp}-\mathrm{hr}$ at $2600 \mathrm{rpm}$. 
Engine: Navistar DTA-466, In-line 6 cylinders Bore: 4.30 in

Stroke: 5.35 in

Displacement: 466 cu.in.

Expansion Ratio: 16.5:1

Fuel: Natural Gas

Equivalenco Ratio: 1.00
Camshaft: Tecogen 160 deg. Duration Intake

Turbocharger: Turbonetics

Turbine: O-Trim 0.69 AR On-Center

Compressor: TO4B S-3

Dyno Run \#. 36. 37. 38, 39. 40, 41. 42. 43

Note: Engine test data with low fan and water pump

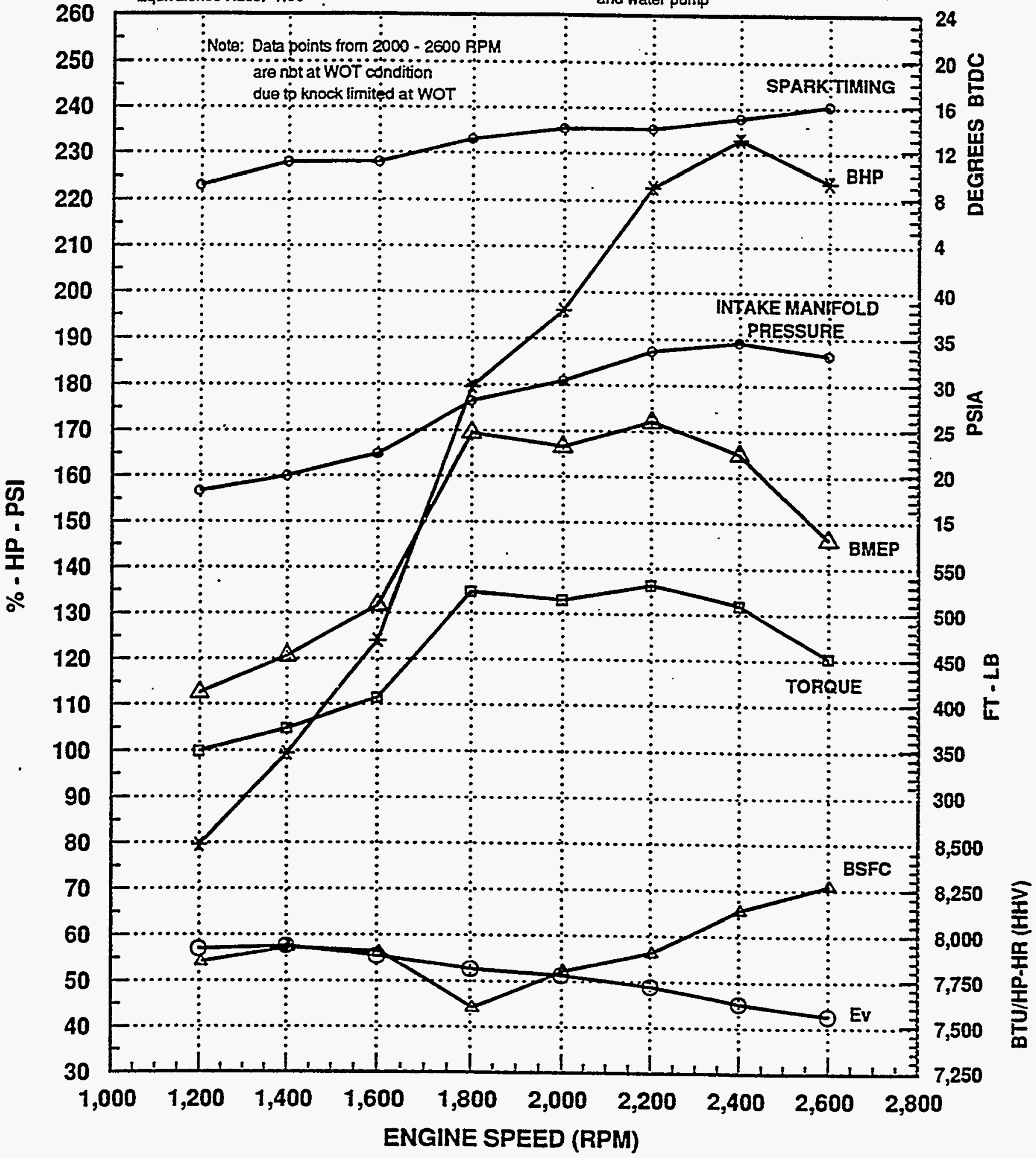

Figure 4.23 Engine Performance - TE160, C.R. $=16.5, \phi=1.00$ 
Engine: Navistar DTA-466, In-line 6 cylinders Bore: 4.30 in

Stroke: 5.35 in

Displacement 466 culin.

Expansion Ratio: 16.5:1

Fual: Natural Gas

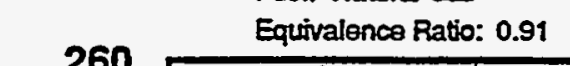

Camshaft: Tecogen $160 \mathrm{deg}$. Duration Intake Turbocharger: Turbonetics

Tuxbine: O-Trim 0.69 ANR On-Center

Compressor: TO48 S-3

Dyno Run \#. 31, 32, 33, 34, 46, 45, 30, 28

Note: Engine test data with low tan and water pump

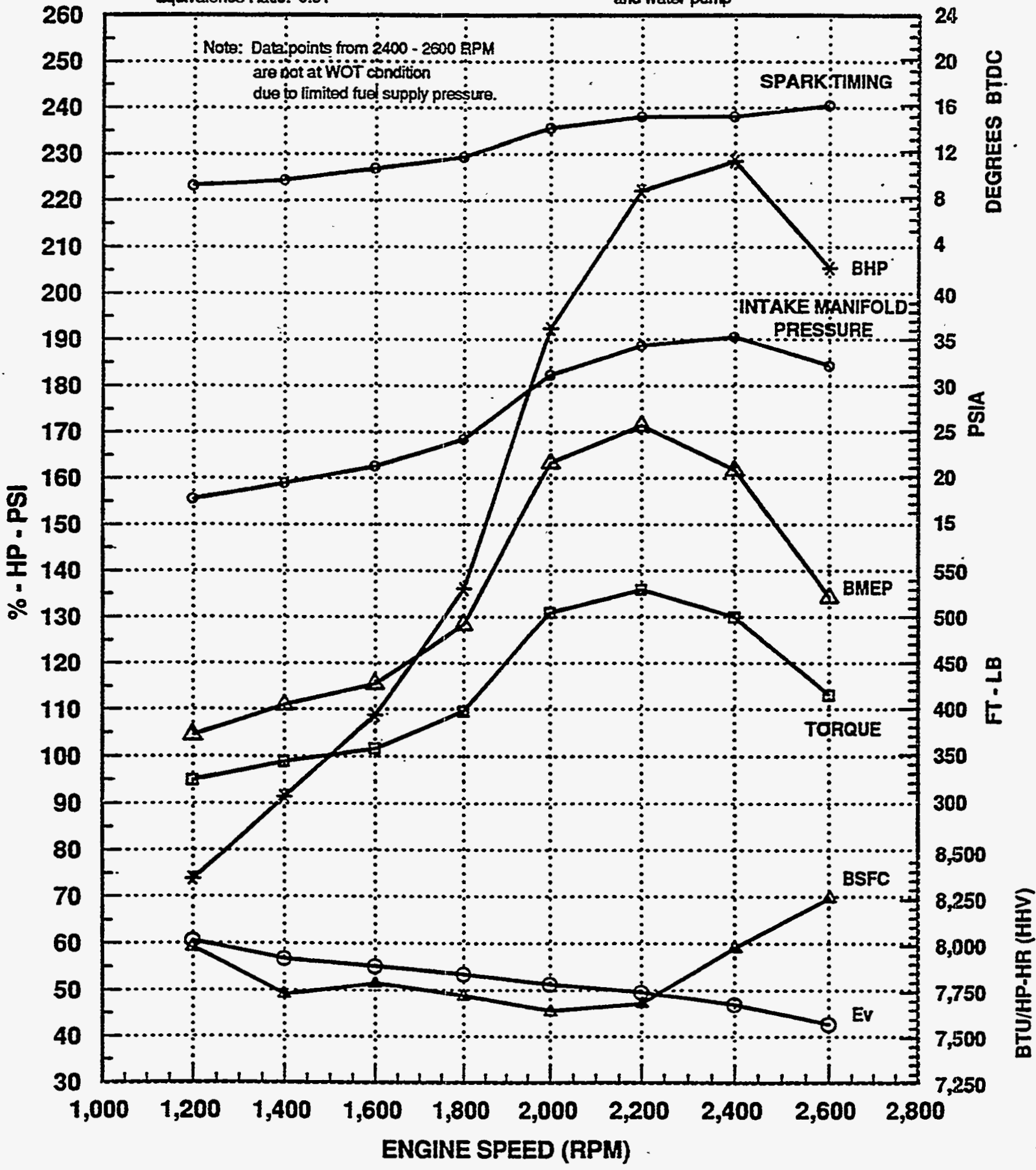

Figure 4.24 Engine Performance - TE160, C.R. $=16.5, \phi=0.91$ 
- Spark advance was low, $9^{\circ}$ to $16^{\circ}$ BTDC, compared to that for a conventional natural gas engine. This indicated very fast burning due to high turbulence.

- Based ori observation, the threshold for detonation appeared to be when the peak pressure exceeded 1400 psia for this particular configuration.

Figures 4.25 and 4.26 show the comparison of the measured and predicted BMEP and BSFC vs. intake manifold pressure at $1800 \mathrm{rpm}$ and $2600 \mathrm{rpm}$ for $\phi=1.00$ and 0.91 . The agreement is very good. The comparison of measured and calculated mass flow for the engine with the TE- 160 cam was shown back in Figure 4.22. It should be noted that the computer simulation was based on a constant blower inlet air temperature of $90^{\circ} \mathrm{F}$ and an aftercooler effectiveness of $95 \%$. A deviation of the actual intake manifold temperature from the calculated temperature could affect the BMEP and BSFC. A higher temperature would result in lower BMEP due to reduced mass flow. The minor effect on BSFC is due to the thermodynamics of the cycle.

In general, this engine performed very well with sufficiently high output and torque to meet our original objectives of the proof-of-concept engine demonstration program.

\subsubsection{Performance Testing of Engine with TE-180 Cam}

After testing the engine with the TE-160 cam, the camshaft was removed and the TE-180 camshaft was installed while the engine remained on the dynamometer stand. The radiator/aftercooler assembly had to be removed because the front gear cover had to be opened in order to slide the camshaft straight out the front. With the cylinder head in place, a wire and hook arrangement was devised to lift and hold the valve tappets so that the camshaft could be replaced. This exercise was conducted to gain some idea of what problems might arise in field conversion.

Since the TE-180 cam closes the intake valve later than the TE-160 cam and has higher maximum valve lift, it induces higher mass flow for the same intake manifold pressure. This means the $0.68 \mathrm{~A} / \mathrm{R}$ turbine will provide more boost than needed. The turbocharger with TO4B 76 Trim, 0.84 A/R turbine was therefore chosen to be tested with the TE-180 cam.

Figures 4.27 and 4.28 show the performance of the engine for the 2 mixtures, stoichiometric and $2 \% \mathrm{O}_{2}$, at either WOT or detonation-limited conditions over the speed range. It was seen that the BSFC is comparable to that with the TE-160 cam. The major difference between the TE- 180 and TE-160 cam was the lower detonation-limited BMEP with the TE-180 cam, which resulted in a maximum attained power output of $190 \mathrm{hp}$ at $2400 \mathrm{rpm}$, as compared to the $232 \mathrm{hp}$ for the engine with the TE-160 cam. The threshold of detonation for this engine was when the peak firing pressure reached about 1200 psia instead of 1400 psia for the engine with the TE-160 cam. This is because of the higher adiabatic end gas temperature, an increase of approximately $60^{\circ} \mathrm{F}$, due to higher effective compression ratio as predicted by the computer simulation. Figures 4.29 through 4.31 show the comparison of the measured data and the results of computer simulation. The agreement was not as good as that for the TE-160 case. 
Engine: Navistar DTA-466. In-line 6 cylinders Bore: 4.30 in

Stroke: 5.35 in

Displacement: 466 cu.in.

Expansion Ratio: 16.5:1
Camshaft: Tecogen 160 deg. Duraton Intake Fuel: Natural Gas

Equivalenco Ratio: 1.00

Note: Engine test data with low fan and water pump
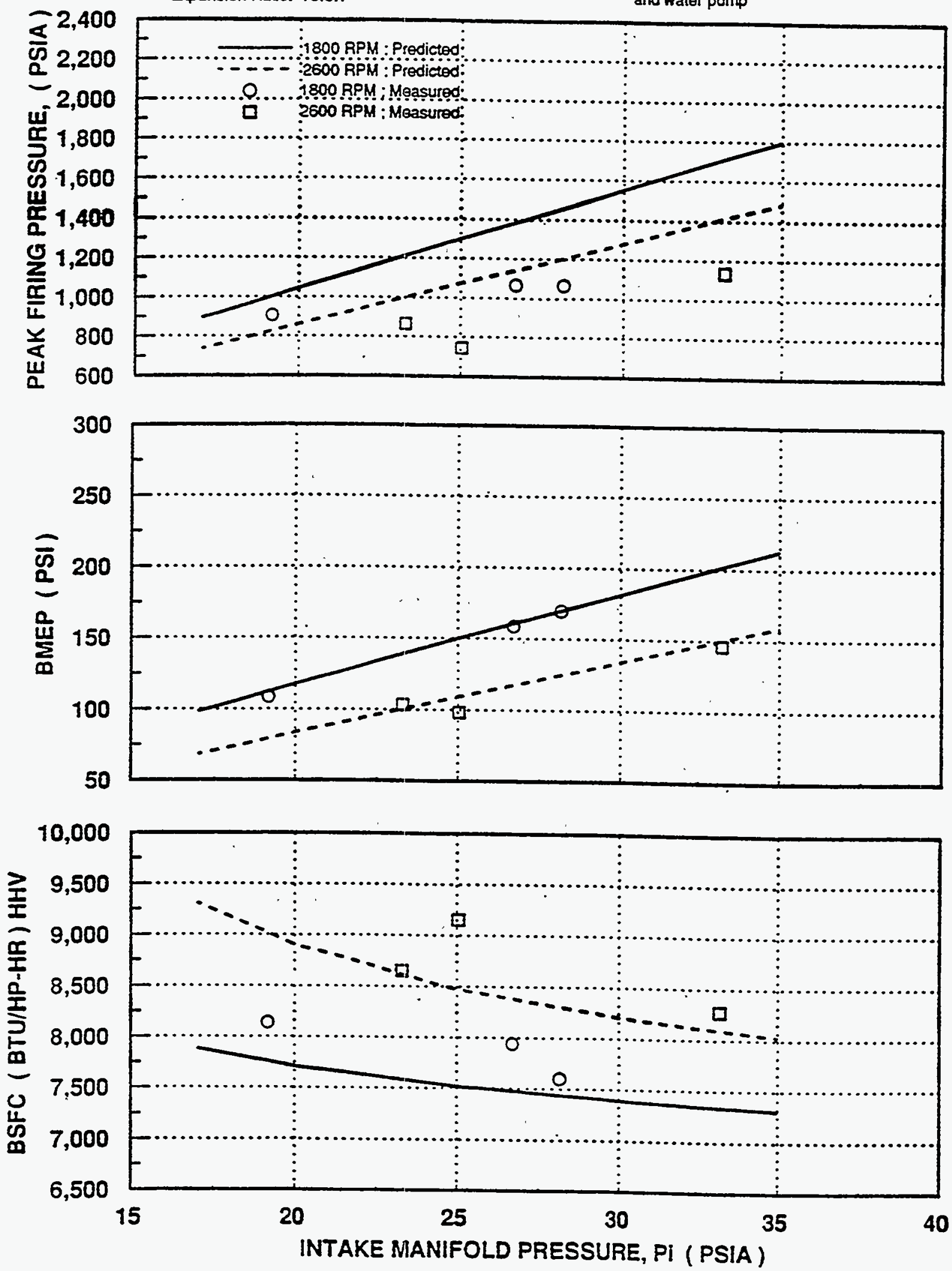

Figure 4.25 Comparison of Test Data and Model Prediction 
Engine: Navistar DTA-466. In-line 6 cylinders Bore: 4.30 in

Stroke: 5.35 in

Displacement: 466 cus.in.

Expansion Ratio: 16.5:1
Camshaft: Tecogen 160 deg. Duraton intake

Equivalence Ratio: 0.91

Note: Engine test data with low tan and water pump
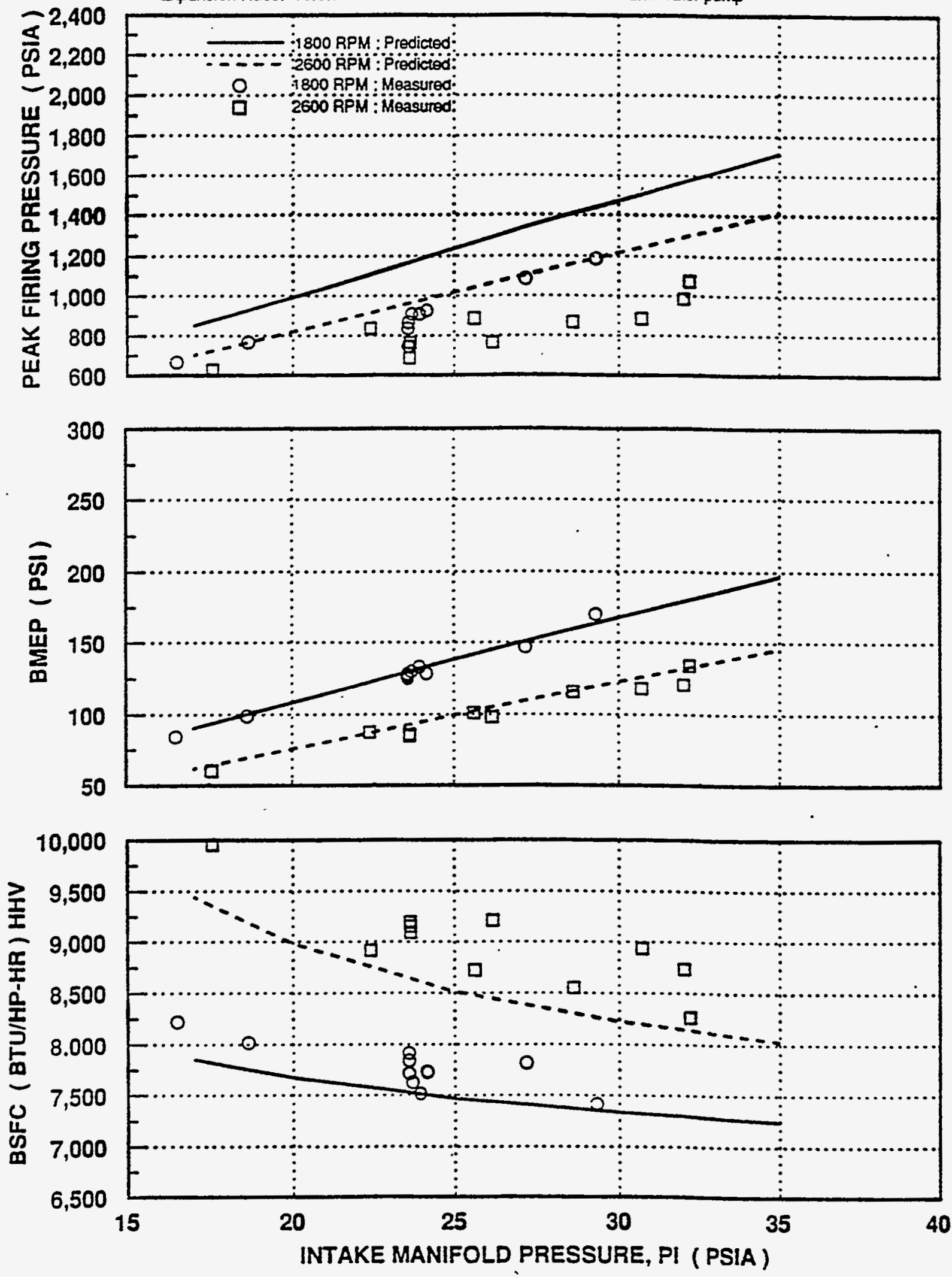

Figure 4.26 Comparison of Test Data and Model Prediction 
Engine: Navistar DTA-466, In-line 6 cylinders Bore: 4.30 in

Stroke: 5.35 in

Displacement: 466 cu.in.

Expansion Ratio: 16.5:1

Fuel: Natural Gas

Equivalence Ratio: 1.00
Camshaft. Tecogen $180 \mathrm{deg}$. Duration Intake

Turbocharger: Garrett

Turbine: 76 Trim 0.84 AR

Compressor: 54 Trim $0.50 \mathrm{ARR}$

Dyno Run \#. 57, 58, 61, 62, 76, 74, 68, 71

Note: Engine test data with low tan and water pump

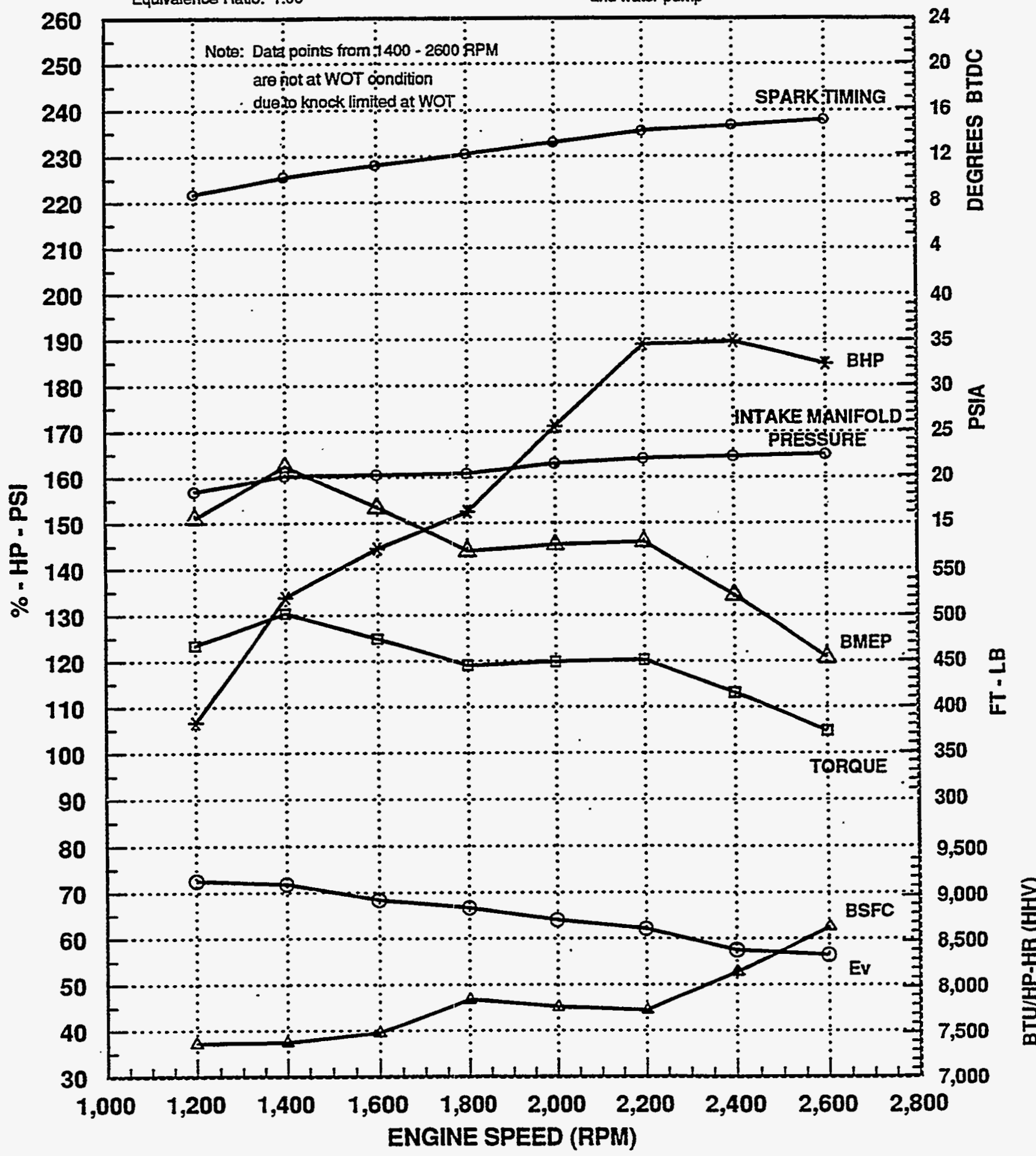

Figure 4.27 Engine Performance - TE180, C.R. $=16.5, \phi=1.00$ 
Engine: Navistar DTA-466, in-line 6 cylinders Bore: 4.30 in

Stroke: 5.35 in

Displacement: 466 cu.in.

Expansion Ratio: 16.5:1

Fuel: Natural Gas

Equivalence Ratio: 0.91
Camshaft: Tecogen 180 deg. Duration intake

Turbocharger: Garrett

Turbine: 76 Trim 0.84 AVR

Compressor: 54 Trim 0.50 A/R

Dyno Run \#. 56, 59, 60, 77, 75, 69, 70

Note: Engine test data with low fan and water pump

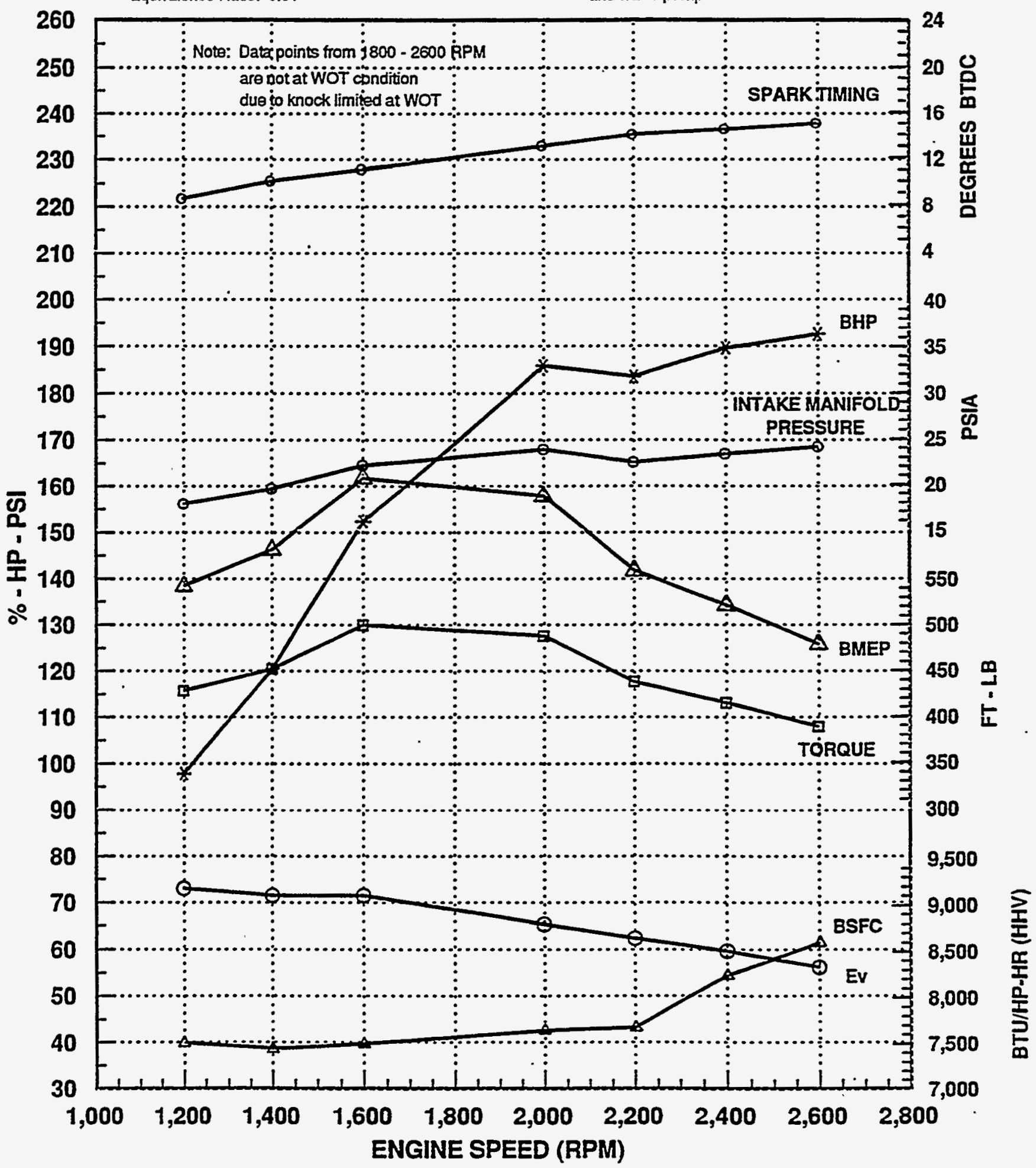

Figure 4.28 Engine Performance - TE180, C.R. $=16.5, \phi=0.91$ 
Engine: Navistar DTA-466. In-line 6 cylinders

Bore: 4.30 in

Sroke: 5.35 in

Displacement: 466 cus.n.
Expansion Ratio: 16.5:1

Camshaft: Tecogen $180 \mathrm{deg}$. Duration intake

Fuel: Natural Gas

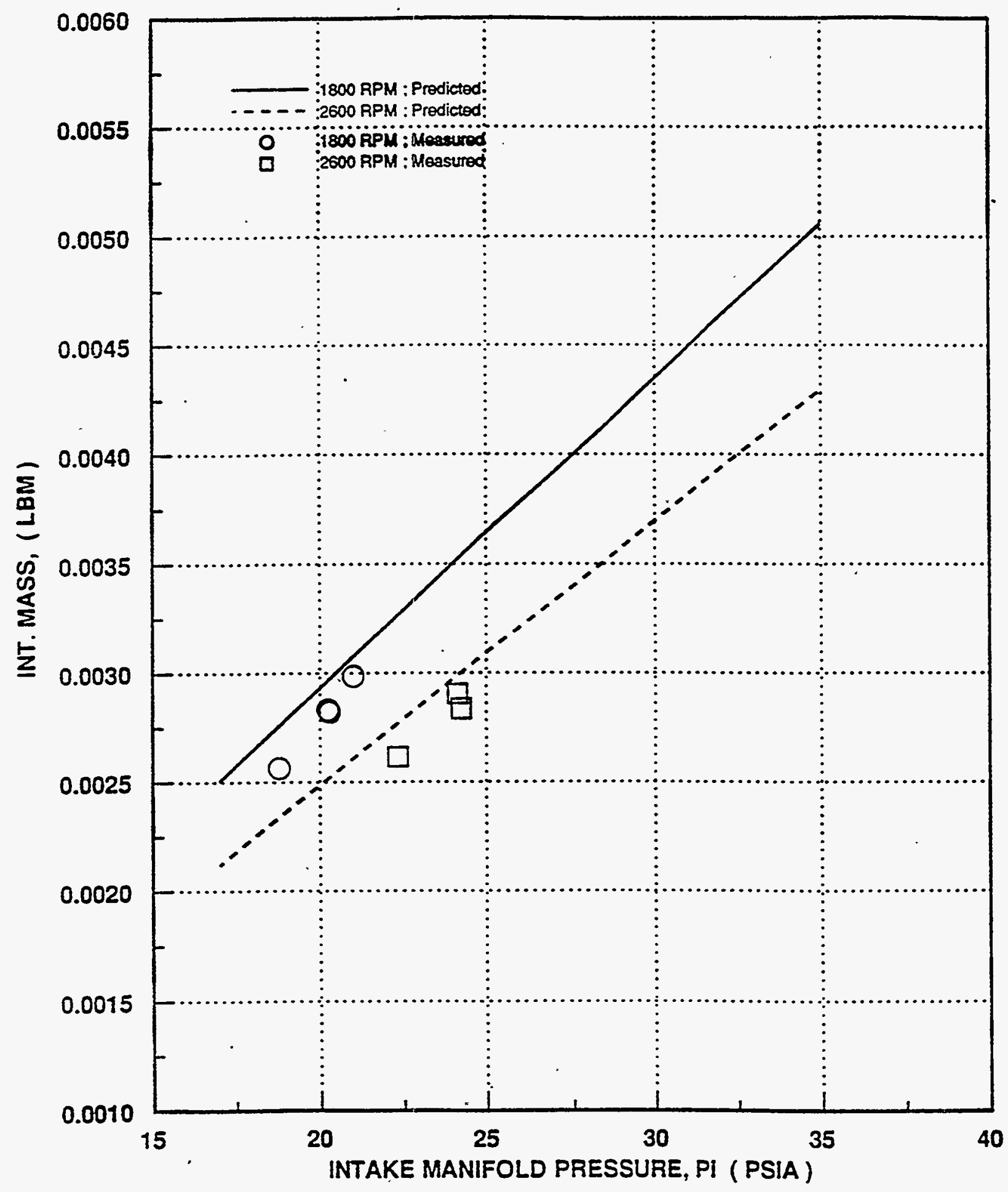

Figure 4.29 Comparison of Test Data and Model Prediction 
Engine: Navistar DTA-466. In-line 6 cylinders Bore: 4.30 in

Stroke: 5.35 in

Displacoment: 466 cu.in.

Expansion Ratio: 16.5:1
Camshat: Tecogen 180 deg. Duration intake

Fuel: Natural Gas

Equivalenco Ratio: 1.00

Note: Engine test data with low tan and water pump
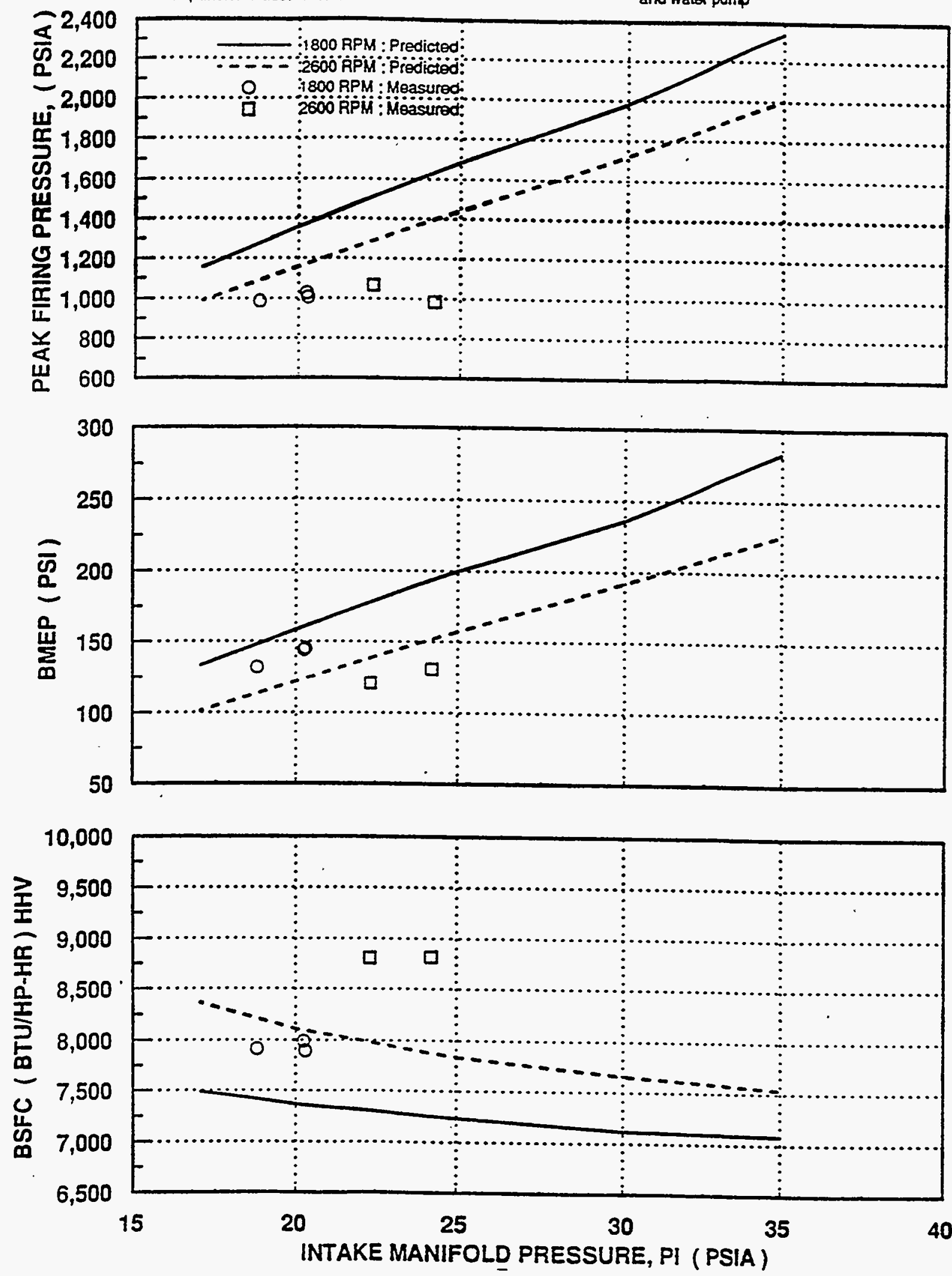

Figure 4.30 Comparison of Test Data and Model Prediction 
Engine: Navistar DTA-466. In-line 6 cylinders

Bore: 4.30 in

Stroke: 5.35 in

Displacement: 466 as.in

Expansion Ratio: 16.5:1
Camshaft: Tecogen 180 deg. Duraton Intake
Equivalence Ratio: 0.91

Note: Engine test data with low fan and water pump
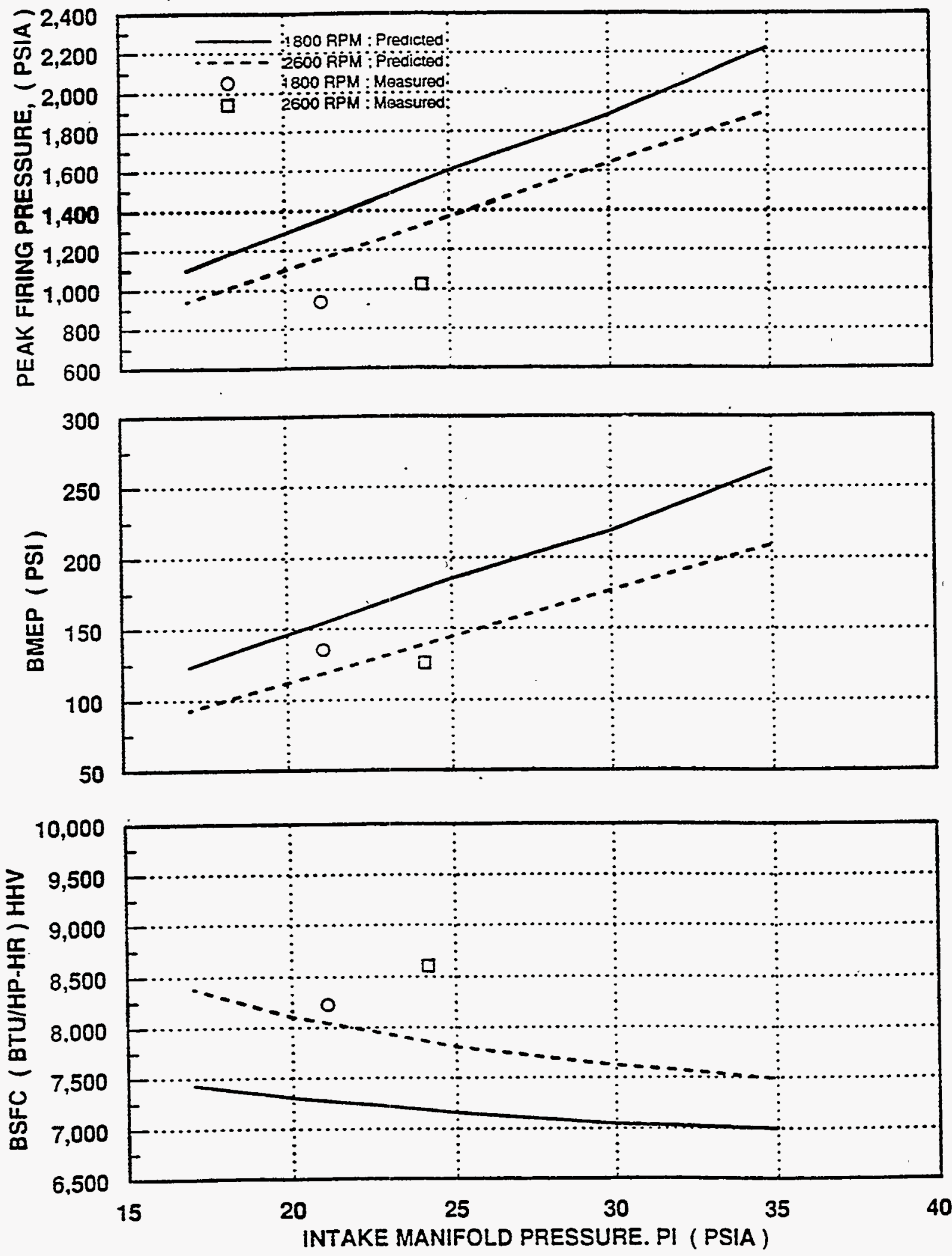

Figure 4.31 Comparison of Test Data and Model Prediction 
The engine configuration with the TE-180 camshaft is apparently not the preferred choice over that with the TE-160 camshaft due to the lower knock-limited power output at the high speeds. Lowering the expansion ratio by means of incorporating a prechamber in the cylinder head should theoretically reduce the adiabatic end gas temperature and, therefore, raise the detonation-limited peak firing pressure and BMEP. Therefore, the next step was to investigate the prechamber configuration.

\subsubsection{Combustion Characteristics}

The combustion chamber of the converted engine is basically the same as the diesel engine except the fuel injector is replaced by a spark plug. The location of the spark plug is slightly off center of the cup cavity in the piston. The swirl-type inlet passage plus the squish design generated strong turbulent flow at the time of combustion. The spark gap was slightly recessed to avoid the arc being exposed and quenched by the high velocity gas flow. The high turbulence was evident by the fast burning process which called for a considerably retarded spark timing. The BPSA was $13^{\circ}$ BTDC at $1800 \mathrm{rpm}$ and $16^{\circ} \mathrm{BTDC}$ at $2600 \mathrm{pm}$. A conventional natural gas engine normally requires a spark advance of 30 to $36^{\circ}$ BTDC. Figure 4.32 shows a typical trace of the cylinder pressure, with little pressure rise up to TDC followed by a steep pressure gradient.

The spark gap was first set at $0.015^{n}$. As the boost pressure increased, misfiring occasionally occurred. The gap was reduced to $0.012^{\prime \prime}$, and misfiring no longer was observed.

Figure 4.33 is a plot of BMEP and BSFC vs. spark advance for the 2 speeds, 1800 and $2600 \mathrm{pm}$, at a fuel-air mixture of $2 \% \mathrm{O}_{2}$ in the exhaust. It is seen that the BMEP and BSFC varied only slightly over this range of spark timing, while the peak firing pressure changed significantly. This is important in view of the fact that the detonation limit is directly related to the peak firing pressure. It means that the detonation-limited BMEP of the engine could be raised without sacrificing significantly on the BSFC if the spark timing were purposely retarded from the BPSA.

With the Altronic CD1 ignition system, which fires the spark plug on every revolution, a misfire sometimes resulted in back firing into the intake manifoid. The theory was that, when misfire occurred with our relatively late spark timing, the second spark firing could ignite the unburned mixture in the cylinder while the intake valve was already partially open. If this theory is correct, then it is not suitable to employ this type of ignition system for the engine if the fuel is introduced upstream of the intake manifold. A half-speed shaft should be used to provide the timing signal for the ignition system. To adapt such a shaft at the location of the diesel fuel injection pump has been investigated and has been found feasible.

\subsubsection{Spark Plug Durability}

The spark plug was an externally modified, standard $12 \mathrm{~mm}$ spark plug. Because the design and the method of fastening the plug to the cylinder head were significantly different from that of a 


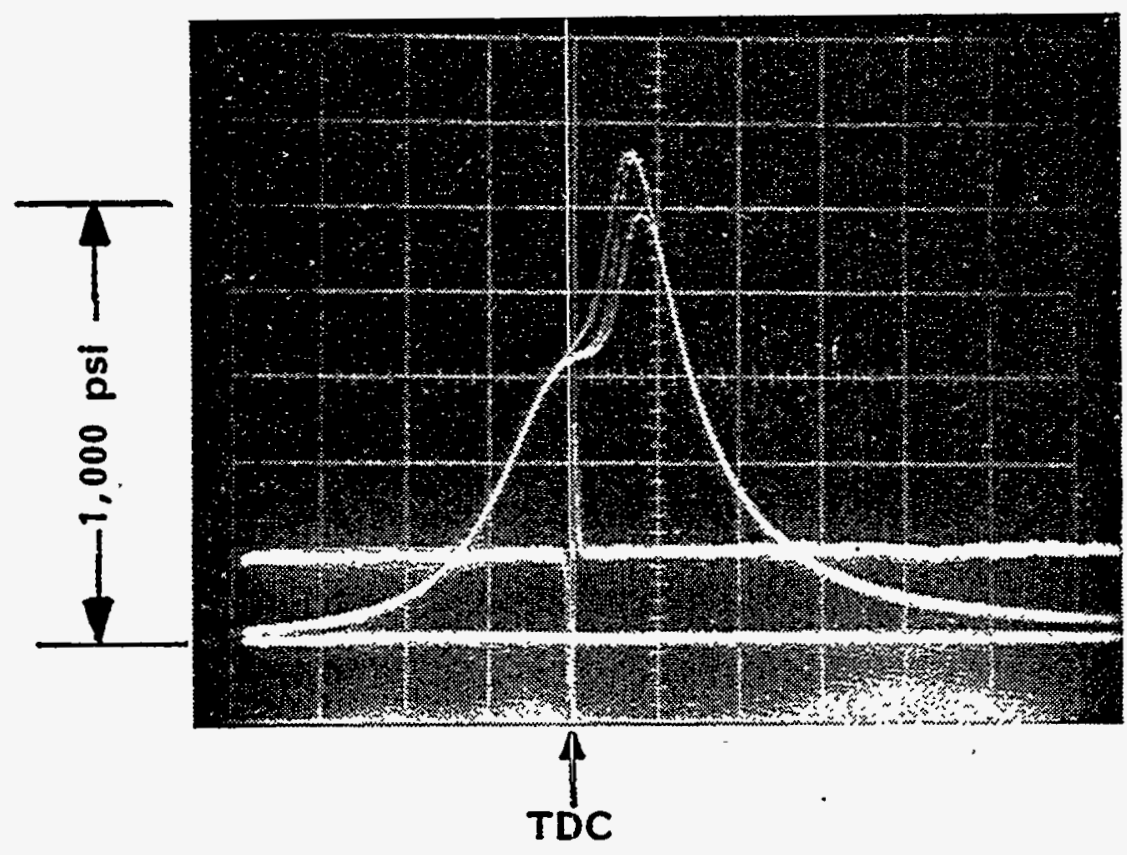

Figure 4.32 Cylinder Pressure Trace, C.R. $=16.5$ 
Engine: Navistar OTA-466. in.line 6 cylinders Bore: 430 in

Stroke: 5.35 in

Displacement: 466 cu.in.

Expanston Ratio: 16.5:1

Equivalenco Ratio: 0.91
Camshat: Tecogen $160 \mathrm{deg}$. Duraton Intake

Dyno Run *: 48, 49. 47.50

Dyno Run *: 54.55.53.52

Nota: Engine test data with low tan and water pump
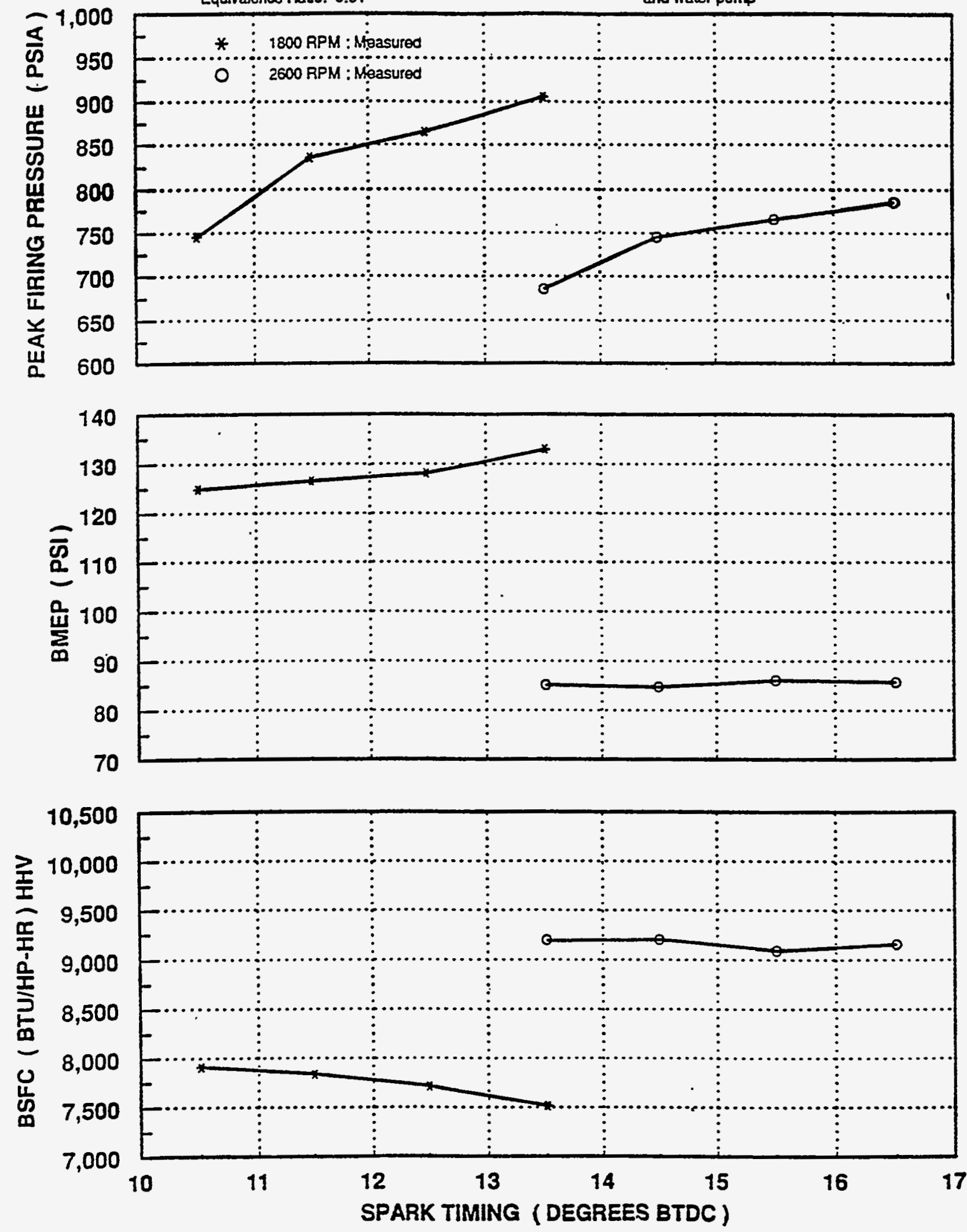

Figure 4.33 Engine Performance vs. Spark Timing 
standard plug, a number of questions had to be addressed. The most controversial one was the cooling of the plug, since there was no threaded engagement to provide a heat flow path. Examination of the spark plugs by the manufacturer after 140 hours of engine operation showed no signs of overheating or excessive wear of the electrodes. The clamping arrangement provided sufficient hold down force to collapse the gasket and effectively seal the high pressure gas. The insulator tube used between the spark plug extension rod and the plug retaining sleeve was adequate to prevent any arcing. in general, the spark plugs performed well, even though the cylinder pressure was significantly higher than that of a conventional low compression ratio engine.

\subsubsection{Engine Test with Prechamber}

The prechamber design was shown back in Figure 4.19. The volume of the prechamber is approximately $1.0 \mathrm{cu}$. in., which reduces the expansion ratio of the engine from 16.5 to 13.9 . The lower expansion ratio should, according to the analytical model, lower the adiabatic end gas temperature from $2150^{\circ} \mathrm{R}$ to $2000^{\circ} \mathrm{R}$, a net reduction of $150^{\circ} \mathrm{F}$. This should allow the peak firing pressure to reach a higher level before detonation occurs. Of course, this is true only if there are no negative effects introduced by the prechamber. The objective of testing an engine with the prechamber was to determine the characteristics of such a combustion system and its net effect on the engine performance.

A new cylinder head modified with the prechamber was installed on the engine for the test. The spark plugs initially selected were the AC R41TS and the spark gap was set at $0.012 "$.

The first noticeable characteristic of this combustion system was the very fast burning rate, which required the spark timing to be further retarded than the previous engine. At $2600 \mathrm{rpm}$, the required spark advance was only $8^{\circ} \mathrm{BTDC}$, and at $1800 \mathrm{pm}$ it was $5^{\circ} \mathrm{BTDC}$. The fast burning rate and steep pressure rise caused the engine to be noticeable more noisy than the engine without the prechamber. Figure 4.34 is a typical cylinder pressure trace showing the very sharp pressure gradient similar to that in a typical diesel engine.

Another unusual characteristic was the pressure oscillation which began after the sharp pressure rise. It was, at first, thought to be related to engine detonation. But, upon further observation, we decided that it could not be detonation since the oscillation existed at all engine speeds and load. It appeared to be a pressure oscillation induced by the sharp pressure rise as a result of the fast burning in such a combustion system. This combustion system is somewhat unique for a spark ignition natural gas engine because of the relatively large precombustion chamber. To make certain that the observed oscillation was not caused by the passage leaking to the pressure transducer, we also installed a second pressure transducer in the prechamber through a special spark plug. Both transducers recorded pressure oscillations, as shown in Figure 4.35. The pressure oscillation in the prechamber is at twice the frequency of that in the main chamber. The estimated maximum amplitude of the pressure fluctuation was almost 50 psi. 
TF39-196

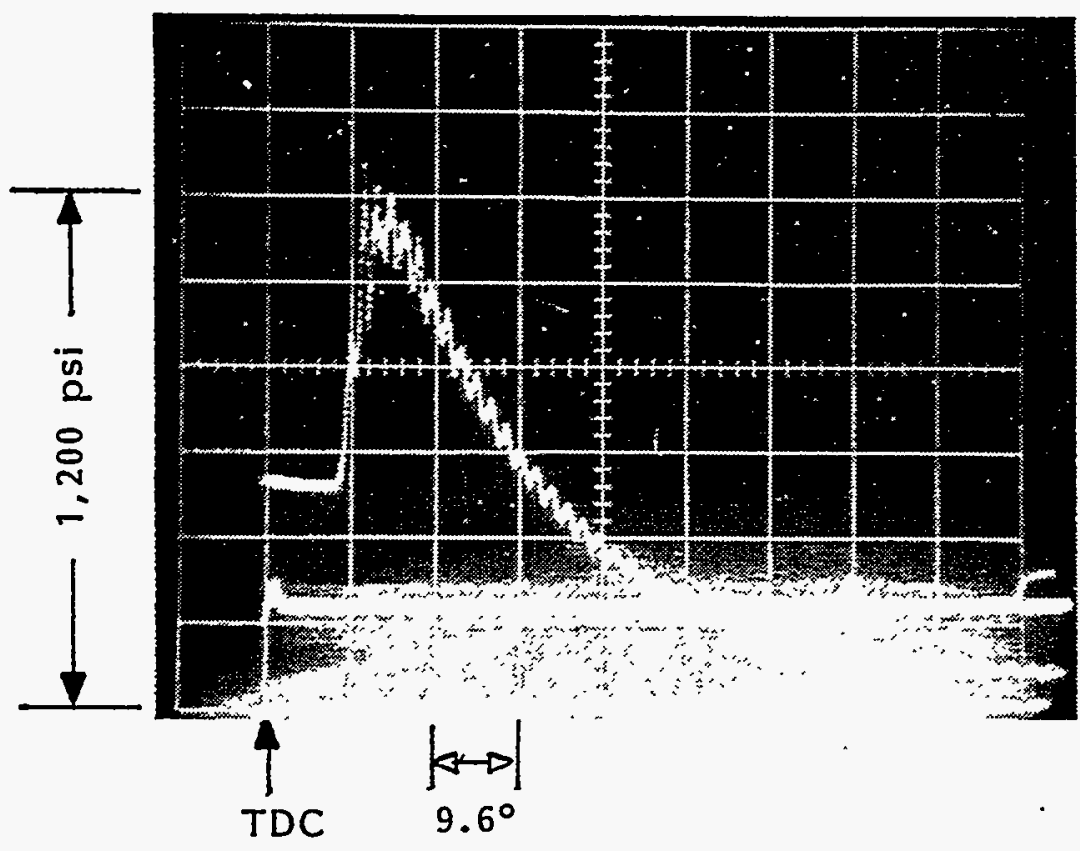

Figure 4.34 Cylinder Pressure Trace, C.R. $=13.9$ with Prechamber 
TF40-196

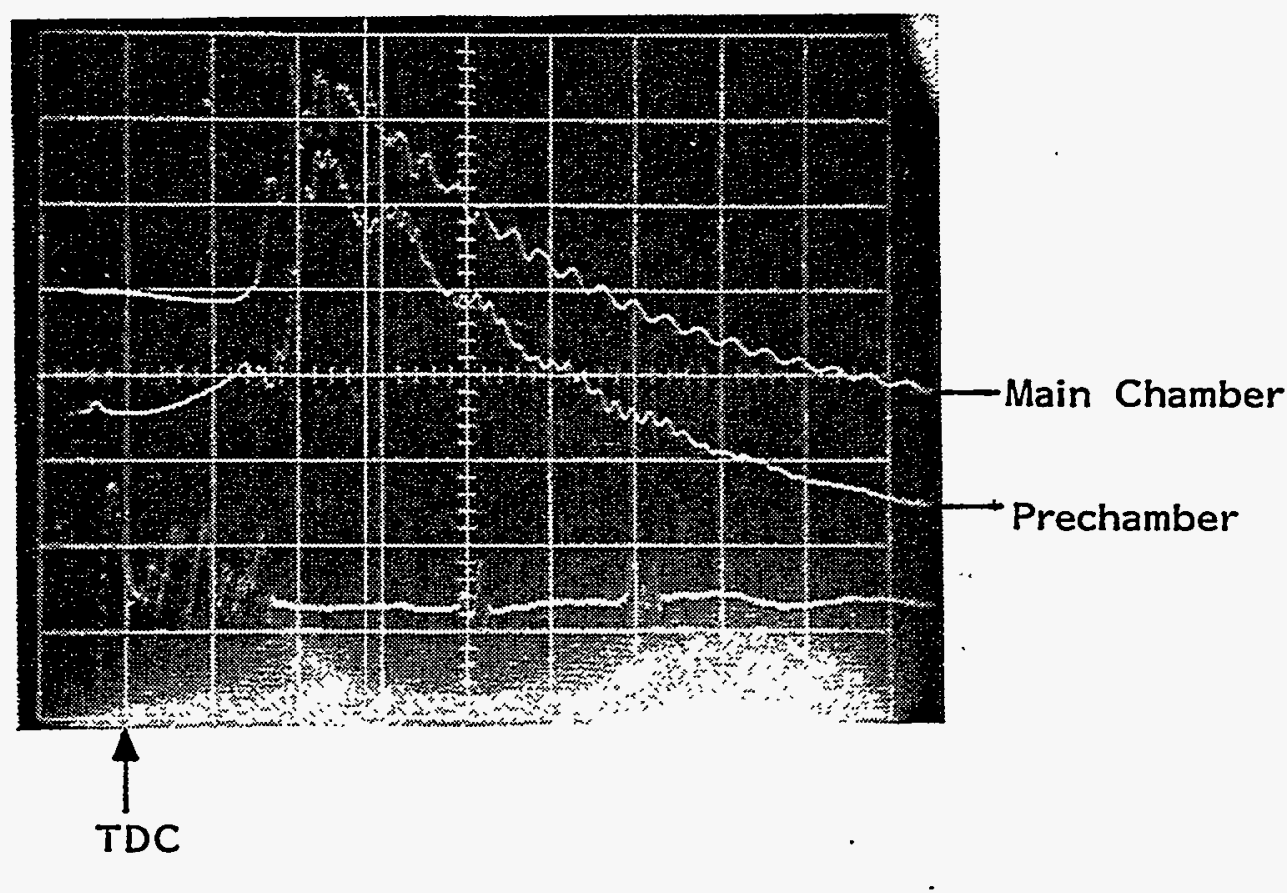

Figure 4.35 Cylinder and Prechamber Pressure Trace, C.R. = 13.9 with Prechamber 
As the torque of the engine was increased, pre-ignition occurred at some point. We interpreted that a pre-ignition had occurred when the point of sharp pressure rise shifted and occurred significantly earlier, sometimes before TDC. Depending on the peak firing pressure, the pre-ignition might or might not be accompanied by detonation. In any case, we decided that this was the operating limit of the engine. Figures 4.36 and 4.37 show the maximum output for the 2 mixture ratios, stoichiometric and $2 \% \mathrm{O}_{2}$, either at WOT, or at a condition limited by the pre-ignition. It is seen that, at low speeds, the BMEP at WOT is lower than the engine without the prechamber (see Figures 4.23 and 4.24) due to the lower expansion ratio. At higher speeds, the power is also lower because of the pre-ignition-limited conditions. The original objective of using a prechamber to lower the expansion ratio and raise the detonation-limited BMEP was, therefore, not demonstrated.

The cause for the pre-ignition was investigated by examining the combustion chamber with a borescope. No evidence of hot spots were found on the piston crown and internal surfaces of the prechamber. The conclusion was that the spark plug ran very hot and acted as an ignition source. This was somewhat surprising to us in view of the fact that the prechamber was completely surrounded by coolant and the heat conduction path from the spark plug to the coolant is comparable to that in a conventional spark ignition engine. However, there are 2 factors that could increase the heat transfer from the hot gas to the spark plug. The first factor is that the operating pressure is higher than a conventional spark ignition engine. The second factor is that the pressure oscillation with a significant amplitude, as indicated by the pressure trace, could generate secondary flow conditions that drastically increase the heat transfer coefficient. The first factor is less likely to be the major cause, since we did not experience any problems with pre-ignition in the first engine without the prechamber, in which the peak pressure was just as high. Nevertheless, the logical next step was to test a colder heat range spark plug. The plug selected for the next test was NGK R5763-10.

With the colder spark plug, the engine was capable of reaching higher BMEP before reaching the detonation limit. Pre-ignition was rarely observed. The test results are shown in Figures 4.38 and 4.39. The peak firing pressure reached as high as 1600 psia before detonation was observed on the pressure trace. This was the result of lower adiabatic end gas temperature as predicted by the analytical model.

Figure 4.40 shows that the actual mass flow agreed reasonably well with the predicted values. Although this engine produced a maximum output of $215 \mathrm{hp}$ at $2600 \mathrm{rm}$, it is still lower than that obtained with the engine using the TE-160 camshaft without the prechamber. This is contrary to the model prediction. The loss of power was also reflected in the higher BSFC in comparison to the model prediction as shown in Figures 4.41 and 4.42 . The loss in efficiency and power may also be related to the inordinately high heat transfer associated with this combustion system.

Based on the test results obtained to date, we conclude that, while the use of a prechamber is effective in reducing the expansion ratio and raising the knock-limited power output of the engine, the negative effects associated with this combustion system make it unattractive overall. The apparent increase in heat transfer in the combustion chamber caused overheating of the spark plug and might 
Engine: Navistar DTA-466, In-line 6 cylinders with Pre-Chamber

Bore: 4.30 in

Stroke: 5.35 in

Displacement: 466 cu.in.

Expansion Ratio: 13.9:1

Fuel: Natural Gas

Equivalence Ratio: 1.00
Camshaft: Tecogen 180 deg. Duration Intake

Turbocharger: Garrett

Turbine: 76 Trim 0.84 AR

Compressor: 54 Trim 0.50 AR

Dyno Run \#. 100, 101, 103, 108, 109, 110, 111, 114

Note: Engine test data with low fan and water pump

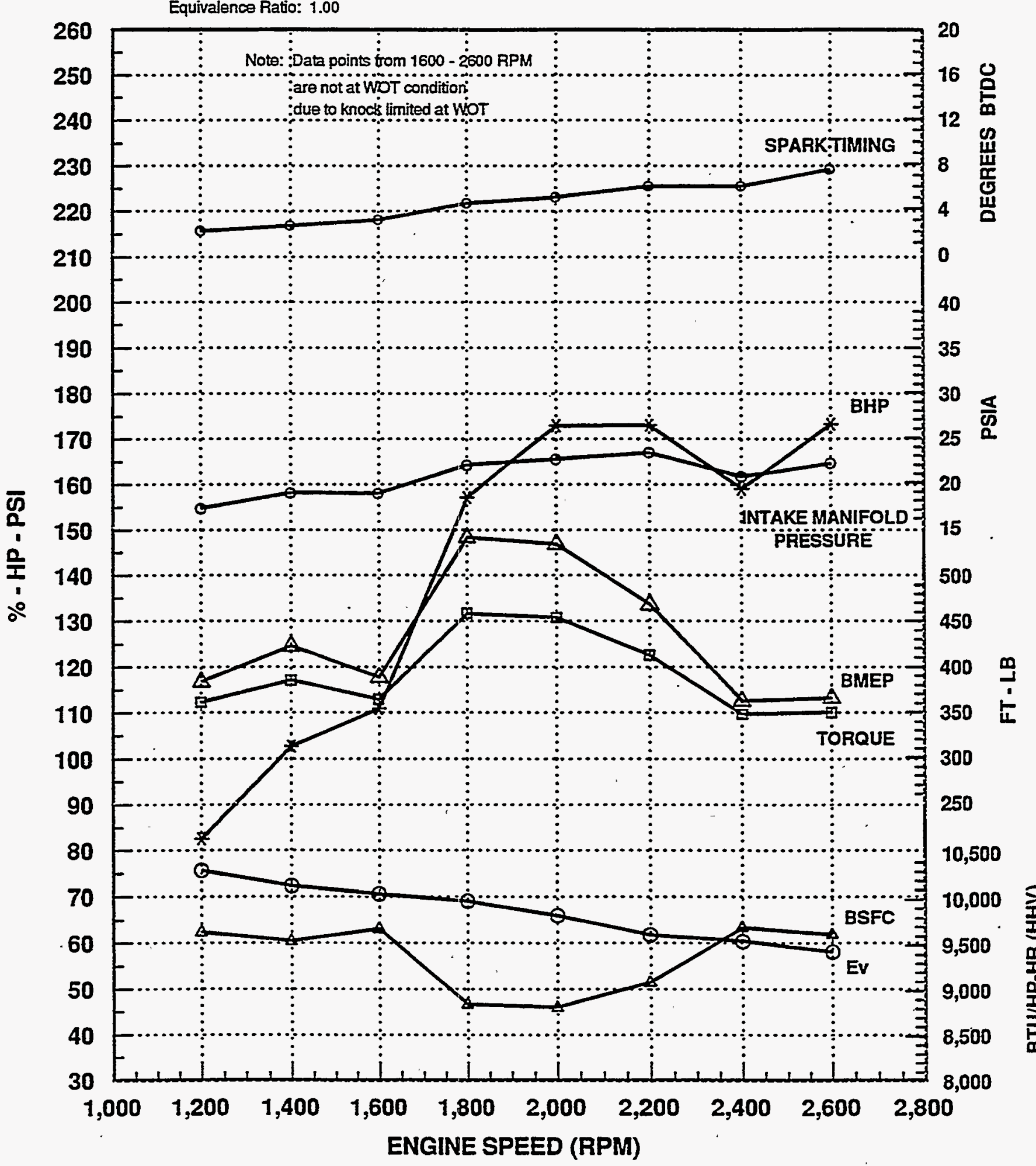

Figure 4.36 Engine Performance - TE180, C.R. $=13.9, \phi=1.00$ 
Engine: Navistar DTA-466, In-line 6 cylinders with Pre-Chamber

Bore: 4.30 in

Stroke: 5.35 in

Displacement: 466 culin.

Expansion Ratio: 13.9:1

Fuel: Natural Gas

Equivalence Ratio: 0.91
Camshaft: Tecogen 180 deg. Duration Intake

Tumbocharger: Garrett

Turbine: 76 Trim $0.84 \mathrm{ARR}$

Compressor: 54 Trim $0.50 \mathrm{~A} / \mathrm{R}$

Dyno Run \#. 106, 87, 98, 85, 107, 89, 90, 126

Note: Engine test data with low fan and water pump

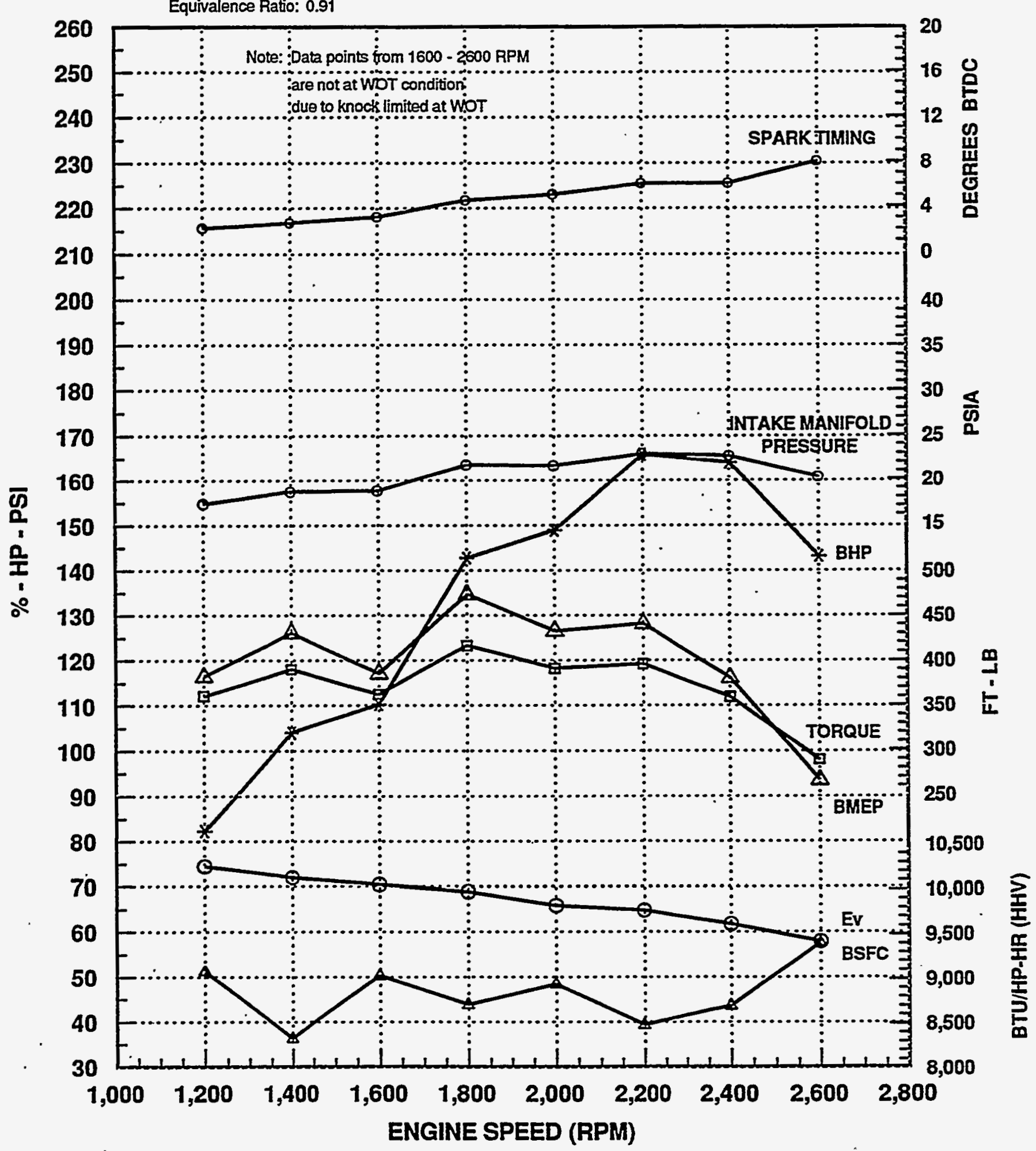

Figure 4.37 Engine Performance - TE180, C.R. $=13.9, \phi=0.91$ 
Engine: Navistar DTA-466. in-line 6 cylinders with Pre-Chamber

Bore: 4.30 in

Stroke: 5.35 in

Displacement: 466 cusin.

Expansion Ratio: 13.9:1

Fural: Natural Gas

Equivalence Ratio: 1.00
Camshaft: Tecogen 180 deg. Duration intake Turbocharger: Garrett

Turbine: 76 Trim 0.84 AR

Compressor: 54 Trim 0.50 AR

Dyno Run \#: 141, 136, 138, 143

Note: Engine test data with low fan and water pump

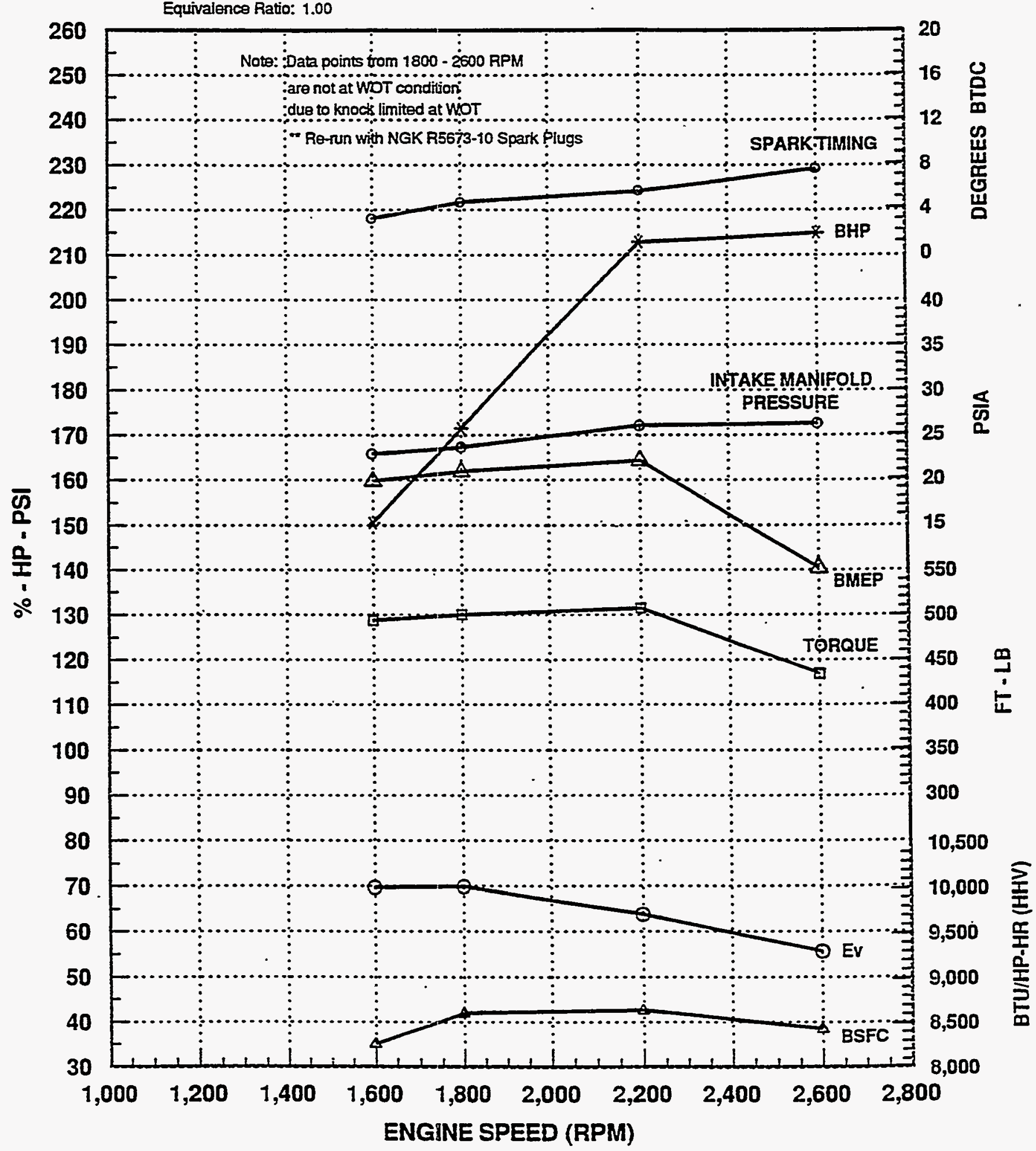

Figure 4.38 Engine Performance - TE180, C.R. $=13.9, \phi=0.91$ 
Engine: Navistar DTA-466. In-line 6 cylinders with Pre-Chamber

Bore: 4.30 in

Stroke: 5.35 in

Displacement: 466 cu.in.

Expansion Ratio: 13.9:1

Fuel: Natural Gas

Equivalence Ratio: 0.91
Camshaft: Tecogen 180 deg. Duration Intake

Turbocharger: Garrett

Turbine: 76 Trim 0.84 AR

Compressor: 54 Trim 0.50 AVR

Dyno Run \#. 142, 137, 139, 140

Note: Engine test data with low ian and water pump

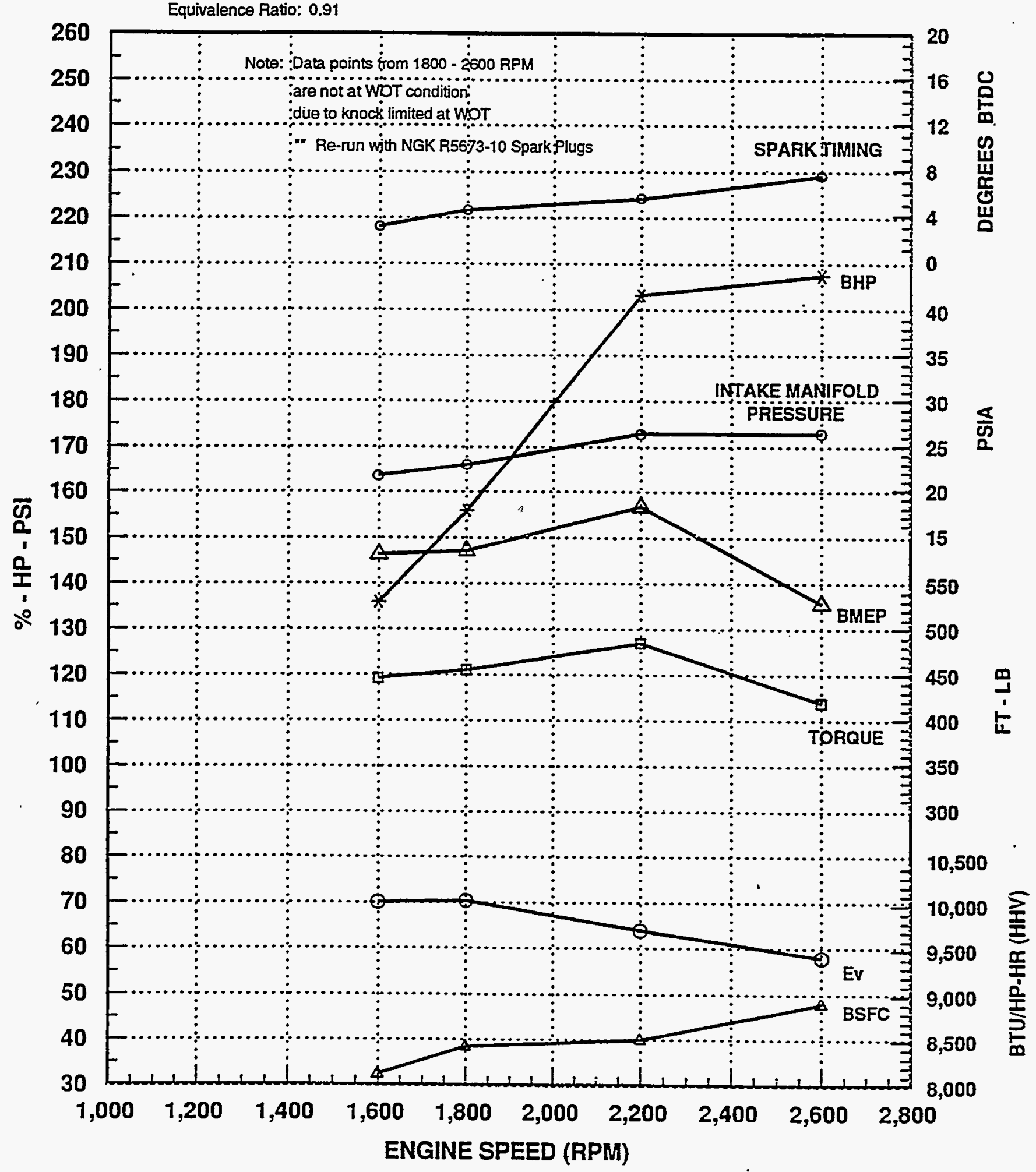

Figure 4.39 Engine Performance - TE180, C.R. $=13.9, \phi=0.91$, Cold Spark Plug 
Engine: Navistar DTA-466. In.line 6 cylinders with Pre-Chamber

Bore: 4.30 in

Stroke: 5.35 in

Displacement: 466 cu.In.
Expansion Ratio: 13.9:1

Camshatt: Tecogen 180 deg. Duraton Intake

Fuel: Natural Gas

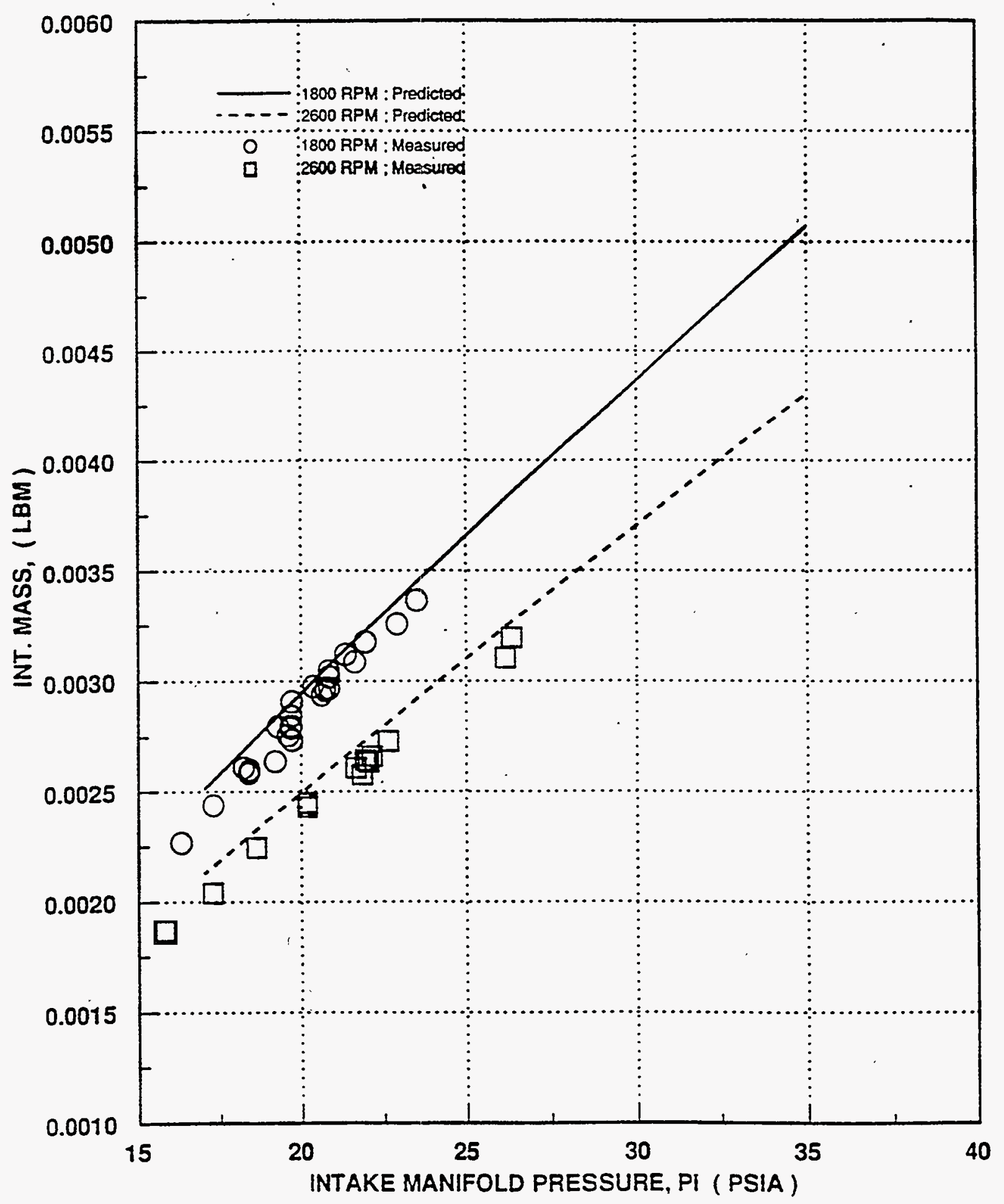

Figure 4.40 Comparison of Test Data and Model Prediction 
Engine: Navistar OTA-466. In-line 6 cylinders whth Pre-Chamber

Bore: 4.30 in

Stroke: 5.35 in

Displacement: 466 cu.in.

Expansion Ratio: 13.9:1
Camshaft: Tecogen 180 deg. Duraton Intake

Equivalenco Ratio: 100

Note: Engine test data with low fan and water pump
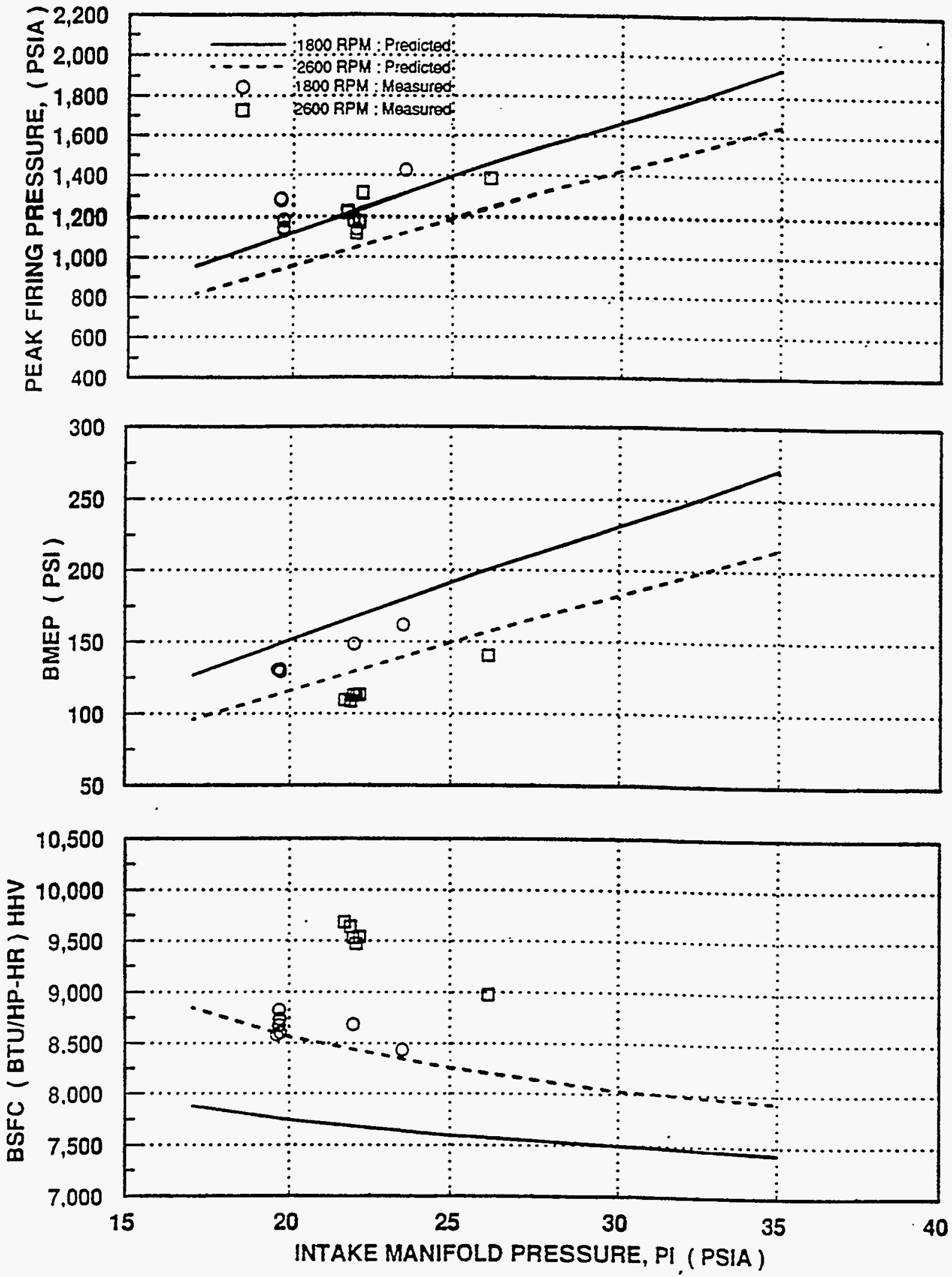

Figure 4.41 Comparison of Test Data and Model Prediction 
Engine: Navistar DTA-466. In-line 6 cylinders mth Pre-Chamber

Bore: 4.30 in

Stroke: 5.35 in

Displacoment: 466 cu.in.

Expanston Ratio: 13.9:1
Camshatt: Tecogen 180 deg. Duration Intake

Fuel: Natural Gas

Equivalence Ratio: 0.91

Note: Engine test data with low fan and water pump
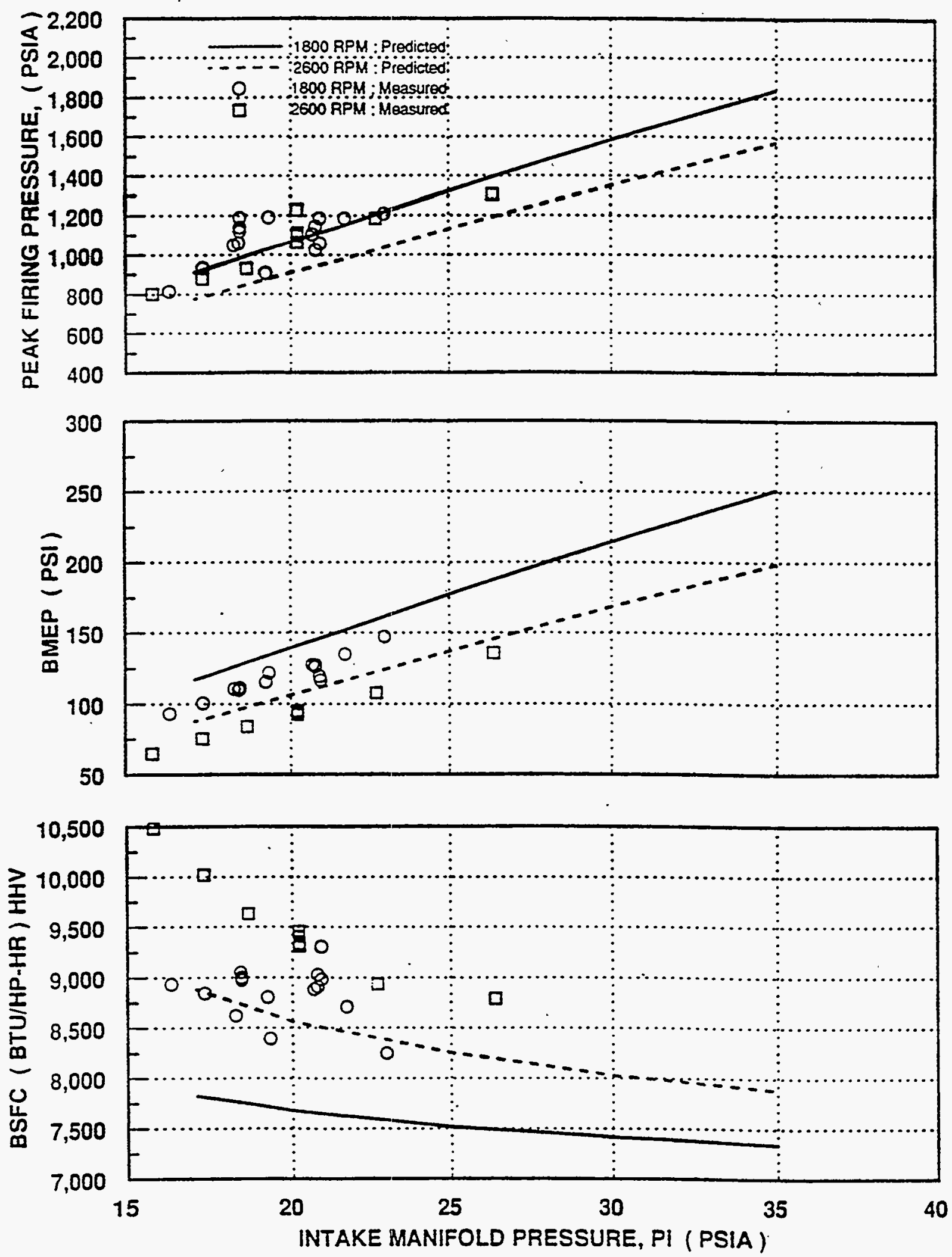

Figure 4.42 Comparison of Test Data and Model Prediction 
also have contributed to the decrease in the thermal efficiency. Until further studies on the prechamber system are made, we do not at this time recommend the prechamber approach for the conversion of the Navistar 466 engine.

\subsection{CONCLUSIONS FROM PROOF-OF-CONCEPT ENGINE DEMONSTRATION}

The following general conclusions can be summarized based on the proof-of-concept engine demonstration:

1. The method of converting the Navistar 466 diesel engine to a spark ignition natural gas engine, which consists of changing the cam profile to avoid detonation and adapting spark plugs to the existing cylinder head without alteration, is technically feasible.

2. With a properly designed camshaft profile and a properly matched turbocharger, the engine can deliver comparable power output without encountering engine detonation and overheating of the pistons and valves.

3. The conversion process is simple and straightforward, and it is retrofitable to existing diesel engines or can be applied to OEM engines.

4. The computer model, which was used to simulate the exhaust and intake process and the engine performance, correctly predicted the mass flow through the engine

- and the power and efficiency of the engine. It is an essential tool in the selection and optimization of the intake valve timing.

5. The proof-of-concept engine has demonstrated that it can deliver $232 \mathrm{hp}$ at $2600 \mathrm{mpm}$ and a maximum torque of $530 \mathrm{ft}-\mathrm{lb}$ without engine detonation. The different models of the Navistar 466 diesel engine are rated between $185 \mathrm{hp}$ to $270 \mathrm{hp}$.

6. The engine provides a BSFC of $7000 \mathrm{Btu} / \mathrm{bhp}$-hr, which is significantly better than the $7853 \mathrm{Btu} / \mathrm{bhp}-\mathrm{hr}$ for a conventional natural gas engine with 9.2 compression ratio.

7. The combustion system performed well without any difficulty in misfiring or erratic combustion.

8. The modified spark plug performed well without gas leakage or signs of inadequate cooling.

9. The incorporation of a prechamber effectively reduced the expansion ratio and raised the detonation limit of the engine. However, unexpectedly high heat flux caused the spark plug to be overheated and to act as a source for pre-ignition. The engine also produced lower power and lower efficiency than the computer prediction.

10. The $\mathrm{NO}_{X}$ and $\mathrm{CO}$ emissions are comparable to conventional gas engines, but the THC emissions are higher.

11. The engine is capable of running at a lean-burn condition of $8 \% \mathrm{O}_{2}$ in the exhaust gas, with low $\mathrm{NO}_{\mathrm{X}}$ emissions (below $3.0 \mathrm{gm} / \mathrm{bhp}-\mathrm{hr}$ ). 


\section{DEVELOPMENT OF PROTOTYPE SYSTEM FOR NAVISTAR DTA-466 ENGINE}

With the successful completion of Phase 1 , which demonstrated the feasibility of operating the Navistar DTA-466 engine on the More-Complete-Expansion-Cycle, the next step was to define, design, and fabricate or procure hardware which could be considered production prototype, and satisfy the requirement of a vehicle duty cycle. These requirements implied fuel, ignition, and control systems quite different from those used to demonstrate feasibility of the concept.

\subsection{PROTOTYPE CONVERSION SYSTEM}

The following sections describe the process of identifying the components of the conversion system and their characteristics.

\subsubsection{Electronic Control System Selection}

Tecogen's first step in the process of selecting a control system was to contact a number of potential suppliers for the fuel and ignition management system and supply them with our detailed requirements. The potential suppliers were asked to quote as follows:

- One lab prototype system with engineering support

- Two systems for field testing in vehicles

- Production version pricing

The initial field was narrowed to 4 suppliers, as follows:

- Clean Air Partners/BKM

- Fuel Management Systems (FMS)

- Mesa Environmental (GEM)

- Stewart \& Stevenson-GFI

All of these suppliers proposed closed loop adaptive learn, speed/density, pulse width modulated systems. They all proposed to use the Altronic PM1, 6 coil single fire capacitive discharge ignition system.

An assessment of the quotations from these suppliers revealed the following:

- None of the proposed systems are in quantity production

- The ability to control overspeed, idle speed, and manifold pressure required special development effort by all bidders

- The projected quantity pricing of all bidders exceeded the targeted material costs which could result in a marketable diesel to natural gas conversion kit 
We concluded that our best chance at getting a marketable system was to develop the control system ourselves with help from General Motors (GM). General Motors agreed to do the software development required to transfer the CNG vehicle software to a new controller, the PCM-6. This advanced PCM- 6 is capable of firing 6 fuel injector drivers, allowing the use of sequential port injection. This, in turn, allowed the use of the GM 6-cylinder distributorless ignition system with waste spark, since the backfire problem we experienced in Phase I would be eliminated with port injection. Additional software could be added by GM Delco to handle the needs for controlling overspeed, idle speed, and manifold pressure.

\subsubsection{Air Induction System}

Several approaches to throttling were investigated. These were:

- Modify existing Rochester TBI system to handle positive pressures. This TBI incorporates a speed governor motor, idle air control, and throttle position sensor.

- Design a new throttle body incorporating the Rochester TBI hardware (i.e., governor, IAC), but compatible with high charge air pressures and adaptable to the Navistar intake manifold.

- Use another GM throttle body.

Tecogen selected the third alternative as the most cost effective when it became apparent that we needed a mass air flow sensor for compatibility with the PCM-6 controller.

The throttle assembly must also include the throttle valve with a throttle position sensor (TPS) and an idle air control valve. The unit selected for this engine is a standard GM part used in its 3.8 liter engine (see Figure 5.1). The mass air flow sensor provides an accurate and repeatable measurement of the air flow rate, upon which the PCM selects the fuel flow rate and the pulse signal for the fuel injector. The mass air flow sensor system has the advantage over the speed-density approach for mass flow measurement in that the error is significantly reduced during transient operation. With the speed-density system, the manifold pressure generally lags behind the mass flow increase after a sudden opening of the throttle. The mass flow rate calculated, based on manifold pressure, temperature and speed, is also affected by the engine coolant temperature during warm-up. With the mass air flow sensor, we anticipate a better control of the fuel air ratio and, consequently, the emissions.

\subsection{3 lgnition System}

The ignition system selected for this engine is the 3-coil inductive system used on GM 3.8 liter engines. The system consists of an ignition module, 3 coils, a trigger wheel with 2 interrupt discs, and a sensor unit with dual Hall sensors. The ignition module is an interface between the sensors, the coil, and the PCM. It performs the sequencing function for the 3 coils according to the crankshaft position identified from the signals generated by the Hall sensors. It also provides the backup ignition signal 
TF48-196

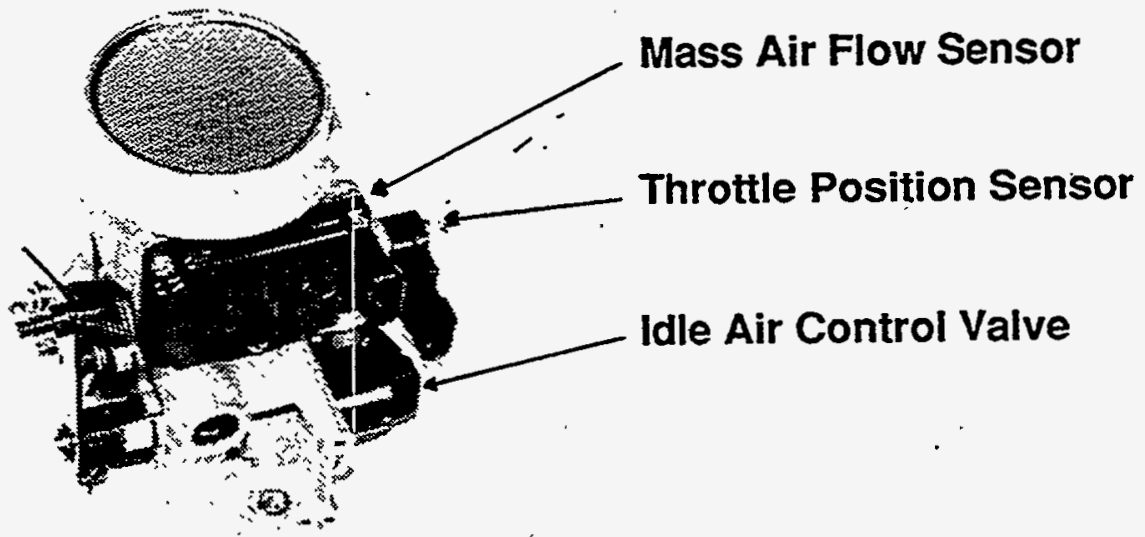

Figure 5.1 Throttle Assembly 
during starting and warm-up. The interrupt discs provide the timing and crank position signals. One disc has 3 notches and the other has 18 notches. Figure 5.2 shows the trigger wheel and the Hall sensor unit. The trigger wheel is mounted on the back of the main drive pulley at the front of the engine. To establish the notch sizes for the interrupt discs and their phase angles relative to the top-dead-center crank position for \#1 cylinder, a bench test was carried out to determine the characteristics of the notch/sensor system.

The spark timing is controlled by the PCM, and it is calibrated as a function of engine speed and flow rate of charge air per engine revolution.

The same spark plug design used on the Phase I proof-of-concept engine is adopted for the prototype engine. The spark gap required optimization since the ignition system will produce a different voltage and energy level from the Altronic CD1 system used in the proof-of-concept engine test.

\subsubsection{Fuel System}

The fuel is injected in a sequential manner according to the air flow rate and engine speed at the inlet of the intake passage in the cylinder head. A plate which incorporates the 6 injectors is sandwiched between the intake manifold and the cylinder head. The fuel injectors are held in place between the sandwich plate and gas fuel rail which also carries the gas pressure and temperature sensor. Figures 5.3 and 5.4 show the detail design of the plate and the fuel rail. As shown in Figure 5.3, the fuel is directed through a small passage at an inclined angle towards the intake passage. This is done to avoid the gas being delivered into the intake manifold during a portion of the injection period when the inlet valve is closed and there is no air flow to carry the gas into the cylinder. Based on the flow characteristics of the injectors, it is anticipated that, at high speed and high load conditions, the injection will be on for as much as $75 \%$ of the duty cycle, while the inlet valve is open for only $22 \%$ of the time. Obviously, we rely on the swirl action and turbulence during the intake process to mix the fuel and air.

The injector characteristics in terms of flow rate as a function of pulse period of the electrical signal was obtained from the supplier, Bosch (see Figure 5.5). This curve was incorporated into the software of the PCM- 6 controller.

A GFI pressure regulator has been chosen for controlling fuel supply pressure. It is a single body, 2-stage regulator with water passages for heating and an integral high pressure shut-off. This regulator provides relatively constant pressure with a maximum deviation of $7 \mathrm{psi}$.

A half speed sensor is required for sequencing the fuel injectors. Two approaches were examined. One approach is to use a Hall sensor to pick up the magnetic field from a magnet imbedded in the cam gear, and the other is to mount a Hall sensor to sense the motion of the rocker arm. Initially, the rocker arm arrangement appeared to be the preferred approach because of the easy 


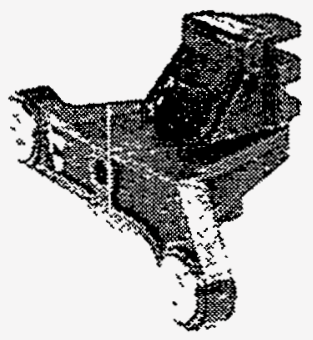

Double

Hall Sensor

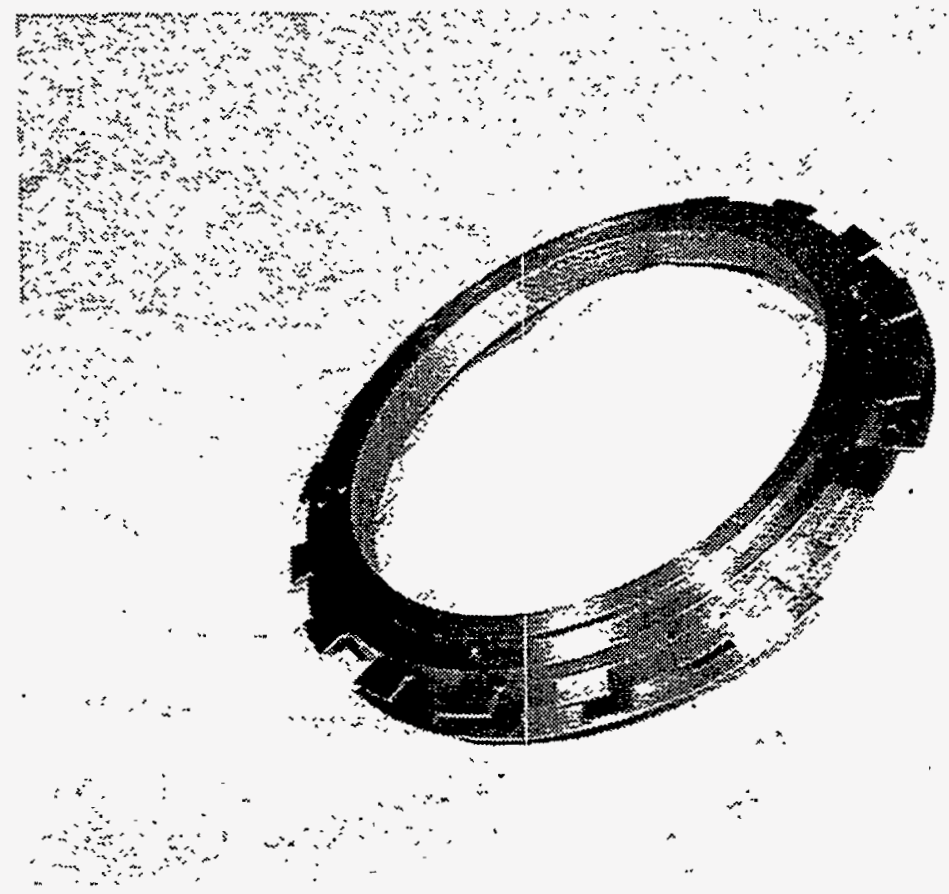

Figure 5.2 Crankshaft Position Sensing System for Ignition 
号
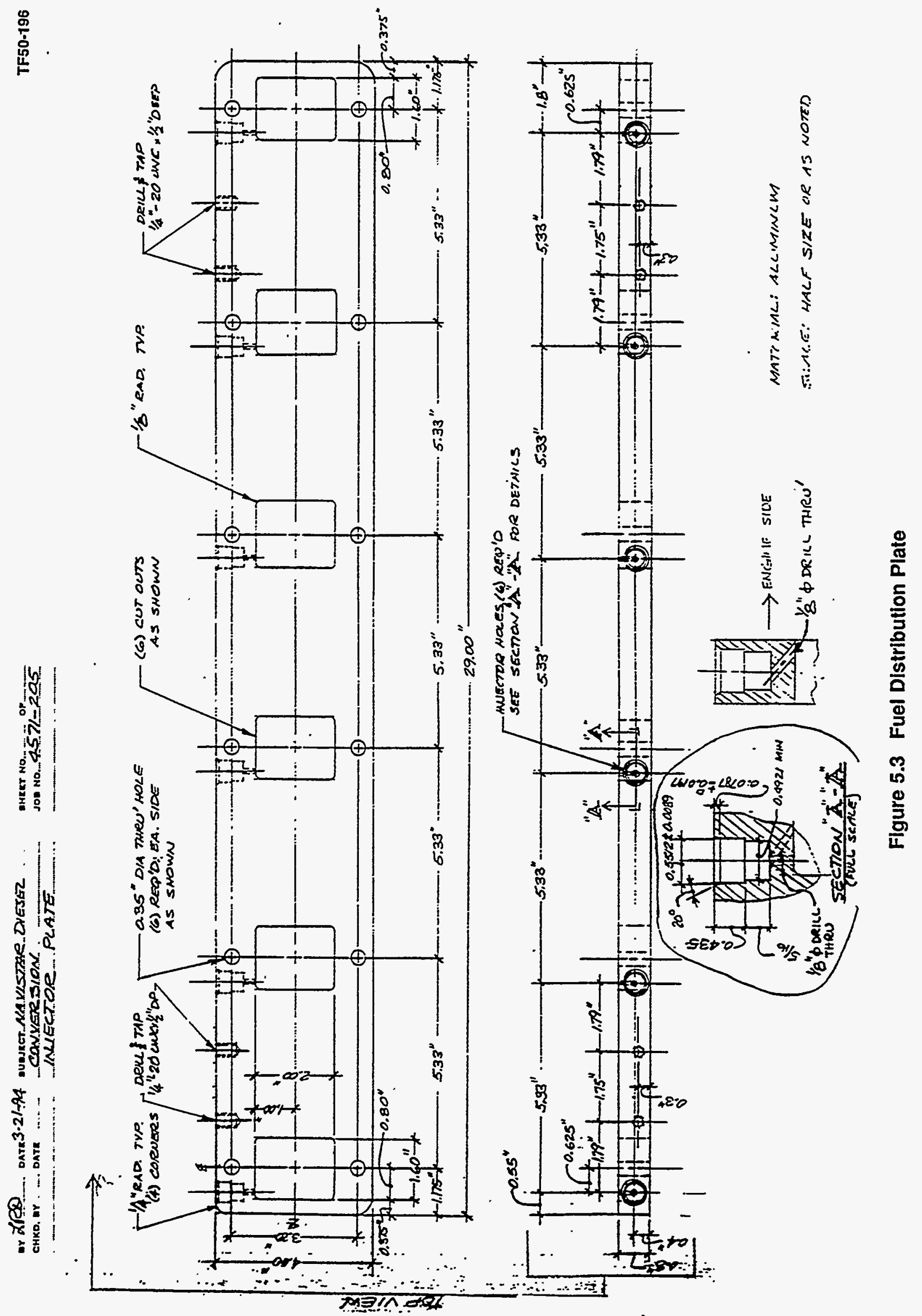
跡
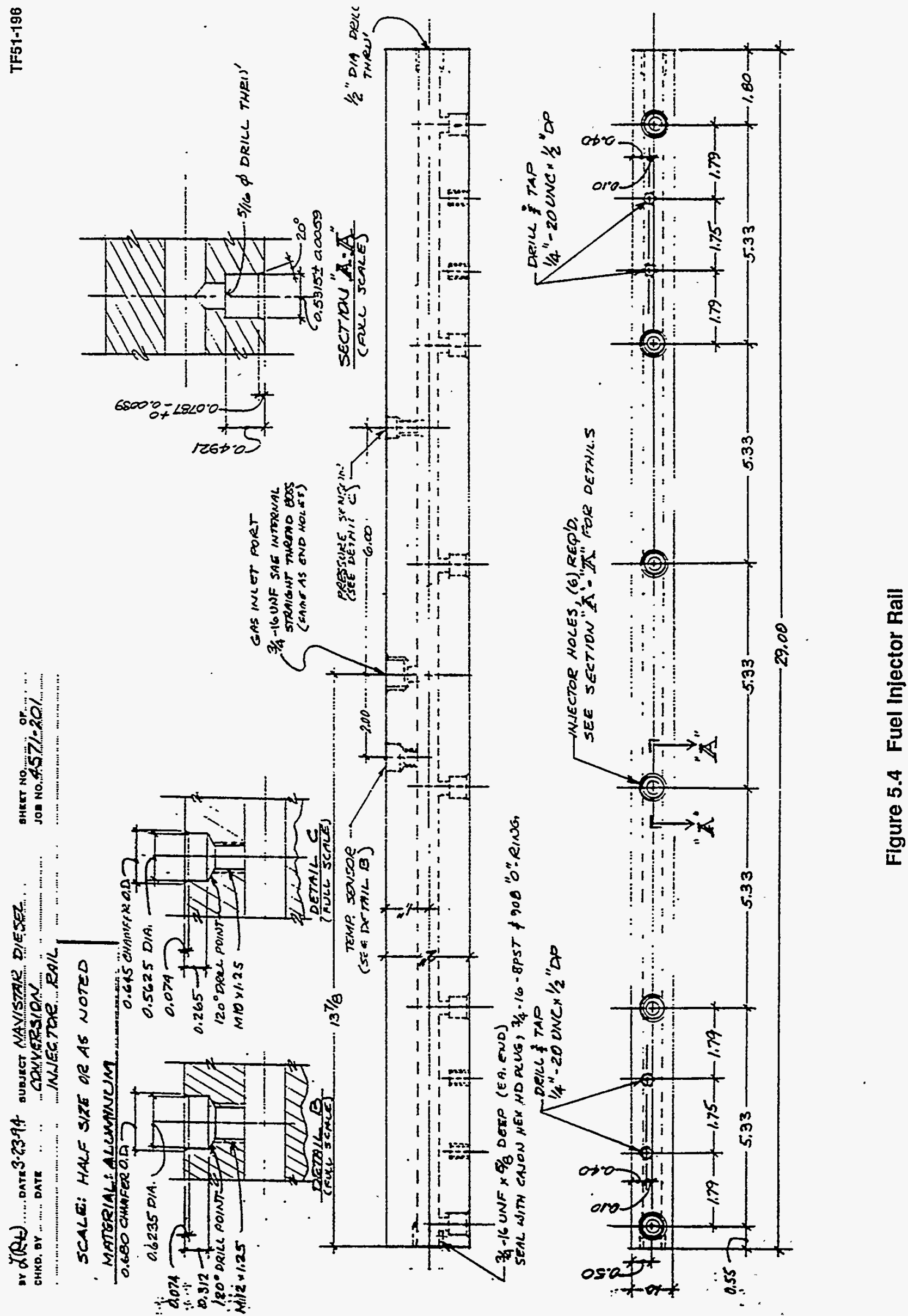


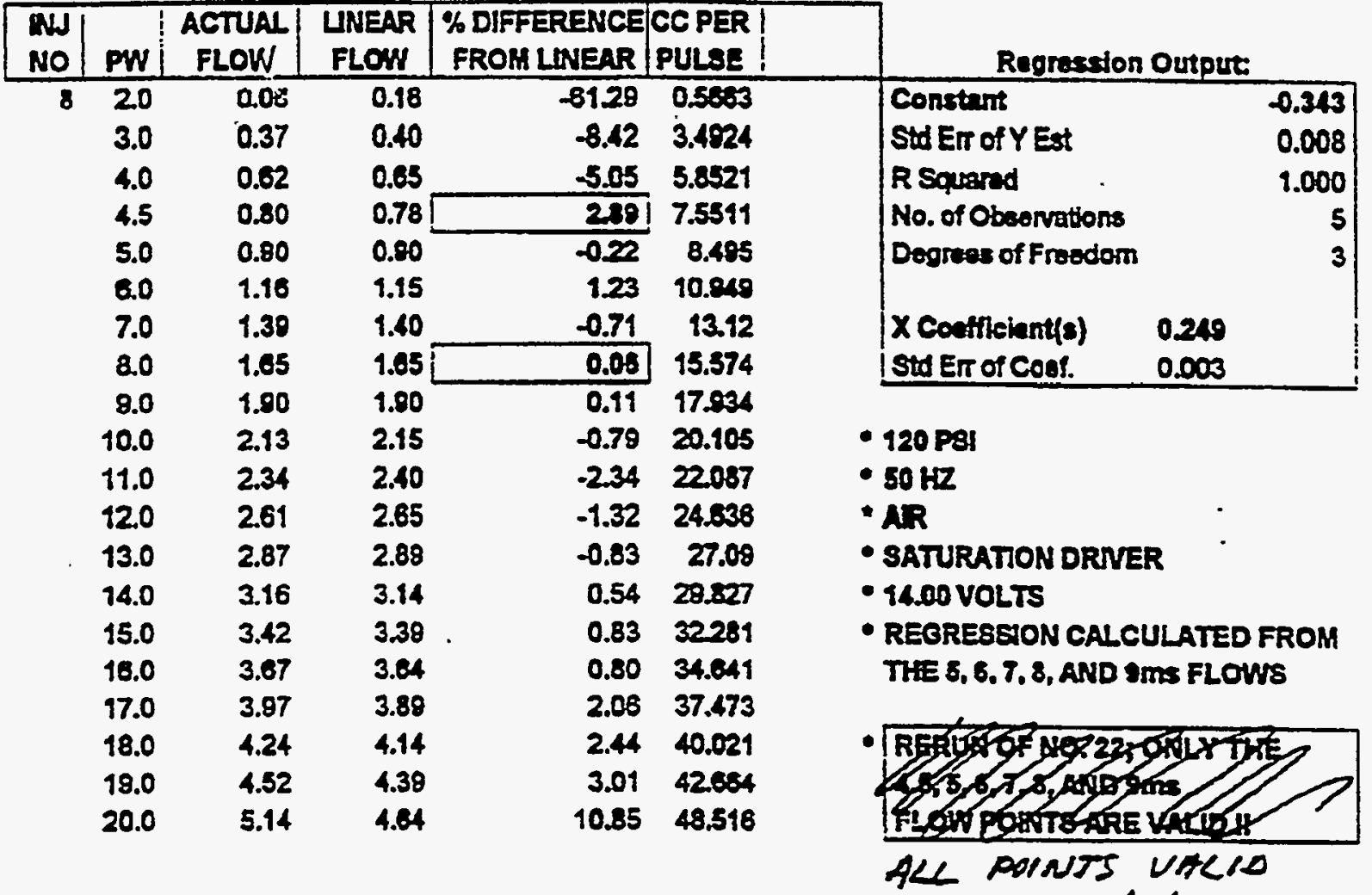

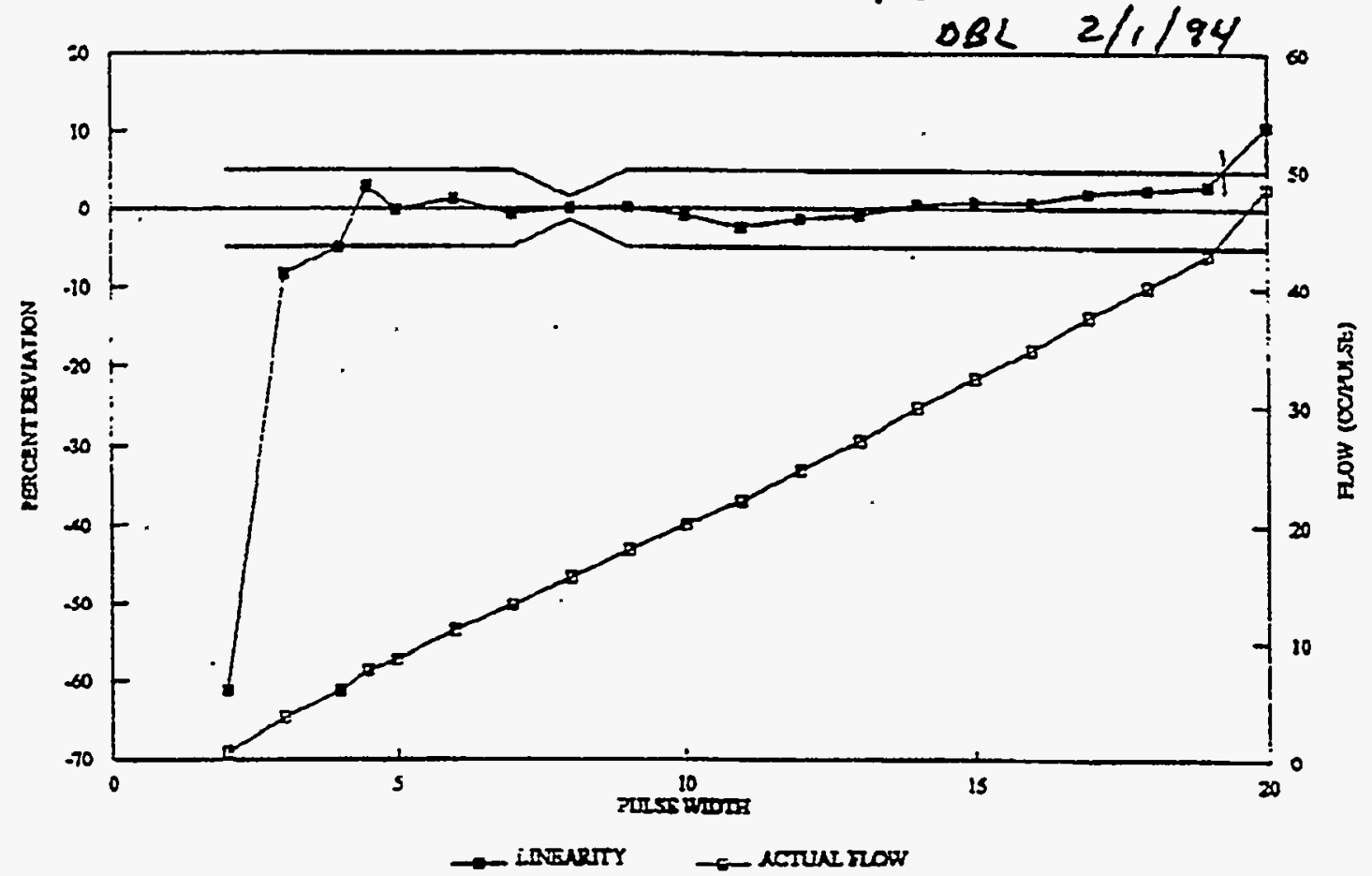

UORENG3_DL

Figure 5.5 Flow Characteristics of Bosch Fuel Injector 
accessibility. However, after conducting an exploratory test, it was determined that, while the signal generated was consistent and repeatable, it was extremely difficult to fix the sensor to within a few mils of the correct position. The signal generated by the sensor must be within $10^{\circ}$ crank angle of a specified timing. It was also anticipated that, even though the sensor can be located accurately relative to the rocker arm, variability of the sensor element within the sensor body may cause the timing to be out of specification. Consequently, this approach was abandoned, and the alternate approach was taken.

The design adopted was to have a magnet imbedded in the front face of the camshaft gear and the Hall sensor inserted through the front gear cover. To determine the appropriate locations of the magnet and the Hall sensor, a bench test was first carried out to establish the characteristics of this system. After the system was installed on the engine, further adjustment on the sensor clearance was found necessary to ensure consistent triggering of the sensor. Figure 5.6 shows the gear with the magnet and the GM Hall sensor.

\subsubsection{Turbocharger With Integral Wastegate and Water-Cooled Center Section}

The turbocharger used on the proof-of-concept engine was an aftermarket unit supplied by Turbonetics Inc. Even though it was reasonably well matched with the engine with the $160^{\circ}$ inlet cam, there were a number of drawbacks that call for searching for a better alternative. One drawback is the on-center configuration which did not permit it to be directly bolted to the exhaust manifold flange. An adapter was needed to displace the turbine away from the engine block. Therefore, a tangential inlet configuration is needed so that it can directly replace the current turbocharger on the diesel engine. The Turbonetics unit tended to under-boost at the low speeds and over-boost above $2000 \mathrm{rpm}$.

It was decided that what was needed was a turbocharger to provide higher boost at speeds around $1600 \mathrm{rpm}$. A turbocharger with this capability would automatically over-boost at higher speeds. This means we must employ certain means to limit the boost at high speeds. There are 2 ways to accomplish the boost control. One way is to by-pass the exhaust gas through a wastegate which is controlled according to the intake manifold pressure. The second approach is to recirculate a portion of the compressed air through a dump valve back to the inlet of the compressor.

The wastegated turbine was chosen because it can be packaged as an integral part of the turbine housing. The compressed air bypass system is also anticipated to be less efficient because of the higher turbine power required to compress more air than that required by the engine.

Garrett selected a non-wastegated turbocharger for us to test on the engine to verify the boost capability at low speeds. Figure 5.7 shows the performance at either WOT or knock-limited operation. It is seen that the maximum torque obtained at $1600 \mathrm{rpm}$ was about $600 \mathrm{ft}-\mathrm{lb}$, which is significantly higher than the $400 \mathrm{ft}-\mathrm{lb}$ obtained with the proof-of-concept engine. Based on this test, a newly configured turbocharger with integral wastegate was designed and provided by, Garrett. 


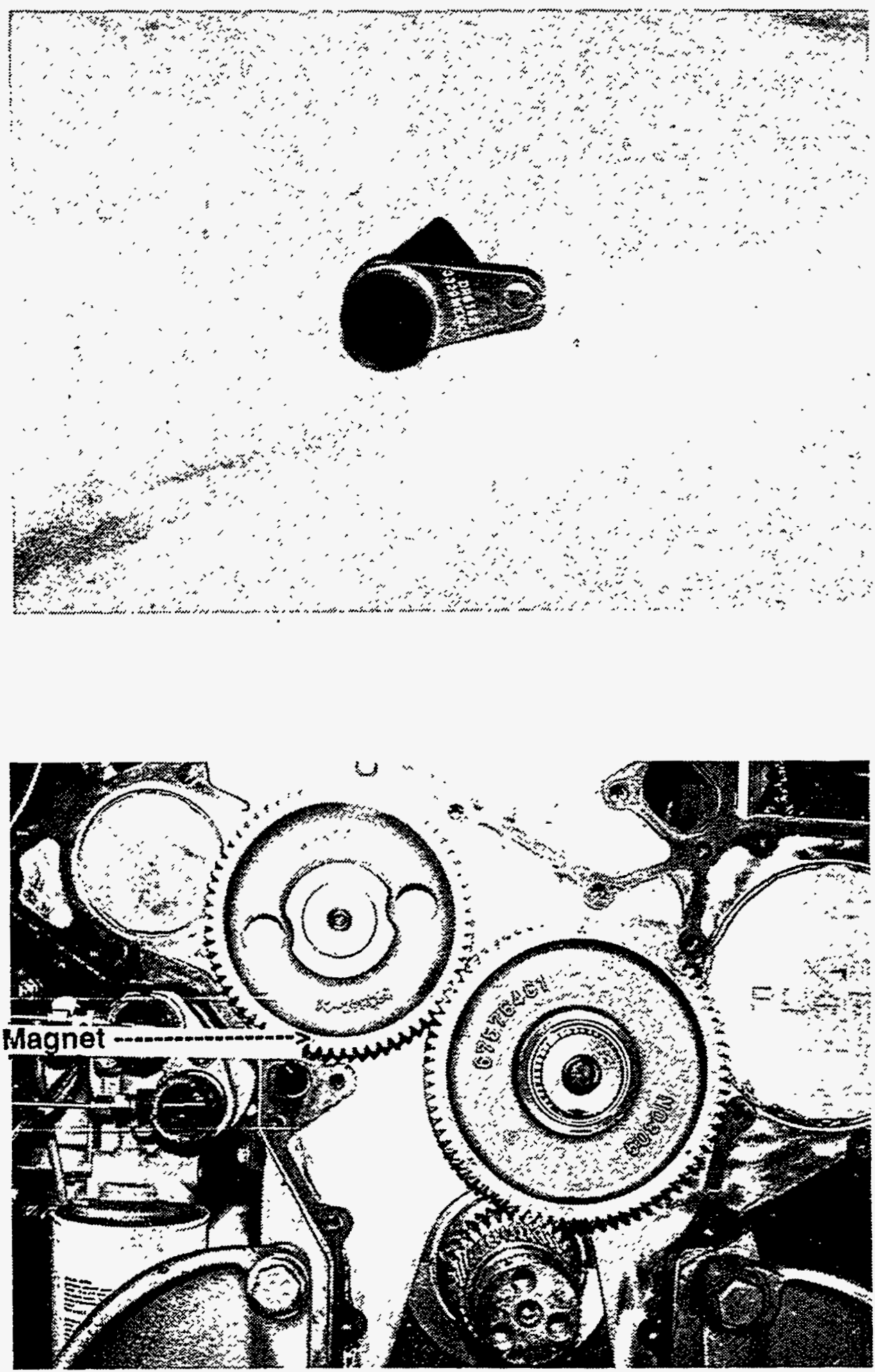

Figure 5.6 Half-Speed Sensing System for Fuel Injection 
Engine: Navistar DTA-466, In-line 6 cylinders Bore: 4.30 in

Stroke: 5.35 in

Displacement: 466 cu.in.

Expansion Ratio: 16.5:1

Fuel: Natural Gas

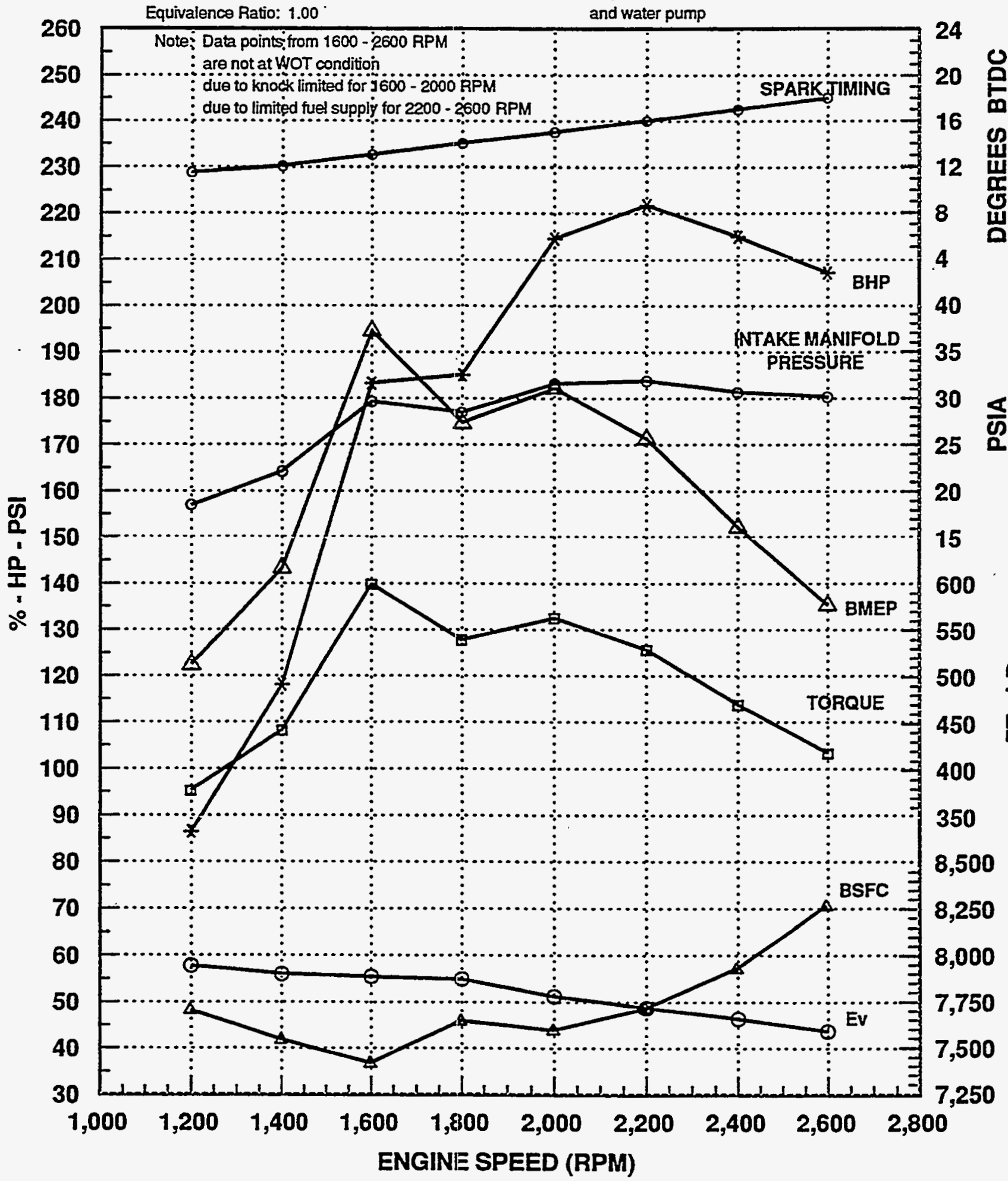

Camshaft: Tecogen 160 deg. Duration Intake

Turbocharger: Garrett

Turbine: T300 79 Trim 0.96 AVR VTF

Compressor: T300 44 Trim BCCWBD 0.50 AR

Dyno Run \#: 158, 159, 157, 152, 153, 154, 155, 156

Note: Engine test data with low fan and water pump 
This turbocharger has the same A/R ratio and trim as the one tested, except that the turbine housing was modified to incorporate a wastegate which is controlled by a diaphragm actuator. The diaphragm actuator is communicated to the blower discharge through a solenoid valve, which is controlled by the PCM according to the intake manifold pressure and temperature in comparison to the maximum set values. The solenoid is normally open so that, in case of electrical fault, the wastegate will be opened to avoid over-boosting of the intake pressure and causing damage to the engine due to detonation.

The original turbocharger for the DTA-466 diesel engine does not have a water-cooled center section. For the converted engine, the turbine inlet temperature is higher, maximum at $1400^{\circ} \mathrm{F}$, due to stoichiometric operation. Therefore, it was necessary to determine whether or not a water-cooled center section was needed. An instrumented-center section with water-cooling passage prepared by Garrett was installed for testing. Three thermocouples were installed at locations specified by Garrett. After the engine was operated at maximum output for a sufficiently long period of time to reach steadystate condition in the turbine housing, it was then abruptly shut down without idling. Temperatures of the 3 thermocouples were recorded on a strip chart. Figures 5.8, 5.9, and 5.10 are temperature records for 3 operating conditions without the coolant. Figure 5.11 shows the temperature when coolant was introduced. It is seen that, without coolant, the maximum temperature reached in the center section was $670^{\circ} \mathrm{F}$ during heat soak. The steady-state temperature was also as high as $566^{\circ} \mathrm{F}$. With water cooling, the steady-state temperature was only $280^{\circ}$, even though the maximum temperature during heat soak reached $540^{\circ} \mathrm{F}$. Based on this data, it was concluded that a water-cooled center section is necessary for this engine.

\subsubsection{Speed Governing System}

A speed governing system was designed and incorporated into the throttle assembly. It consists of a spring-loaded section to be inserted between the throttle cable and throttle linkage. The throttle linkage is also connected to a DC torque motor. When the DC motor is actuated, it pulls the throttle towards the closing position opposite to the direction of the throttle cable. The springloaded section would allow the throttle to close even if the drive keeps the cable position fixed. Figure 5.12 shows a schematic of the speed governing system.

The mechanical speed governing system was found to perform satisfactorily in controlling the maximum engine speed. However, Tecogen felt that it is a complex and costly component to be included in the conversion kit.

The new speed governing system was developed, which involved modification of the software in the PCM such that the engine will switch to open loop operation when the maximum set speed is reached. The controller causes the fuel-air mixture to ramp from stoichiometric to lean at a prescribed rate of change. This causes the engine output to reduce and engine speed to drop. If the speed continues to rise to a top limit, the fuel will be cut off completely. A hysteresis loop is provided to ensure a smooth and stable transition. Testing was conducted with this speed governing system, and adjustments were made to establish the calibration constants for safe speed governing and smooth 


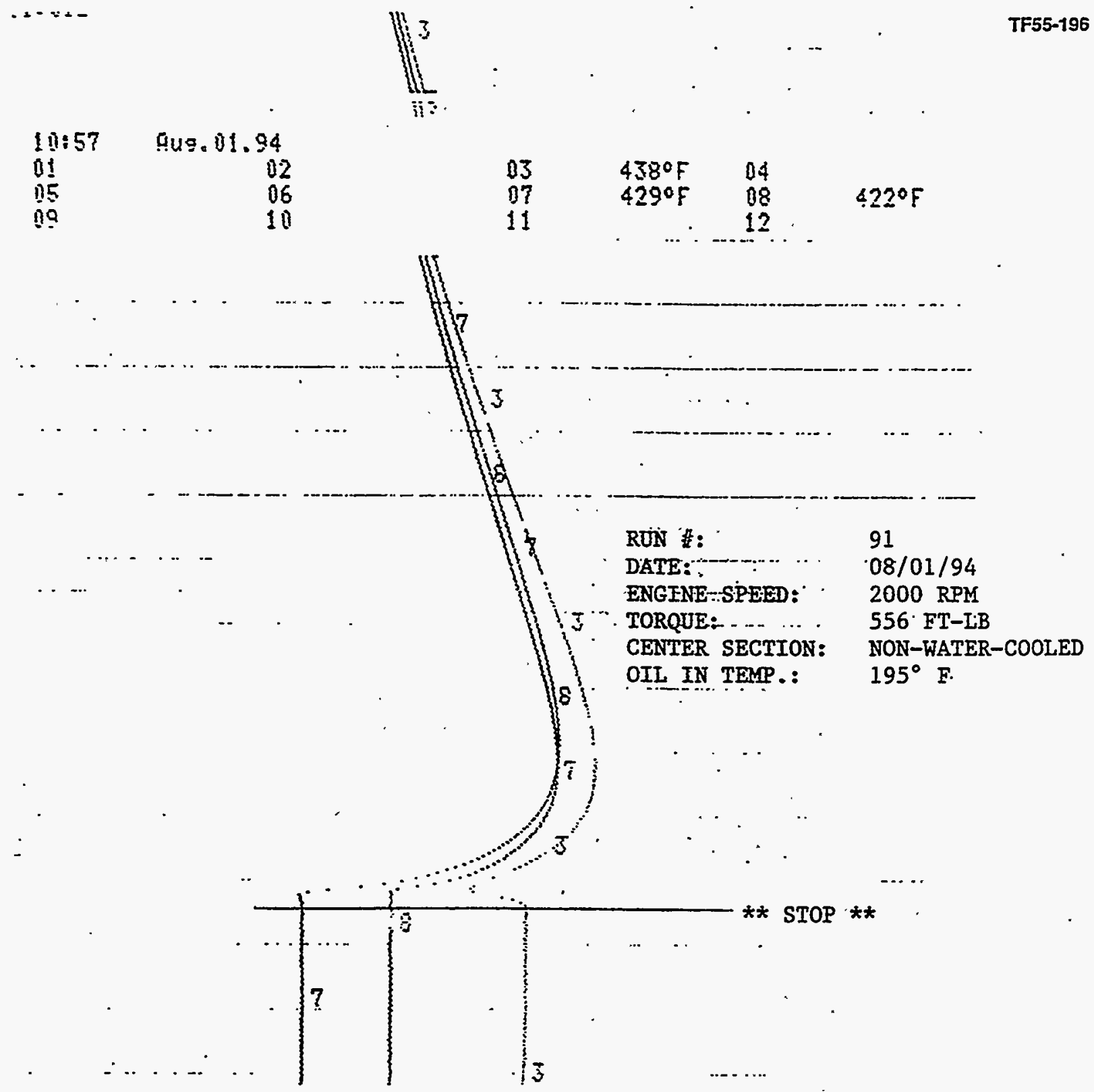

$10: 31$ Aนะ. 01.34

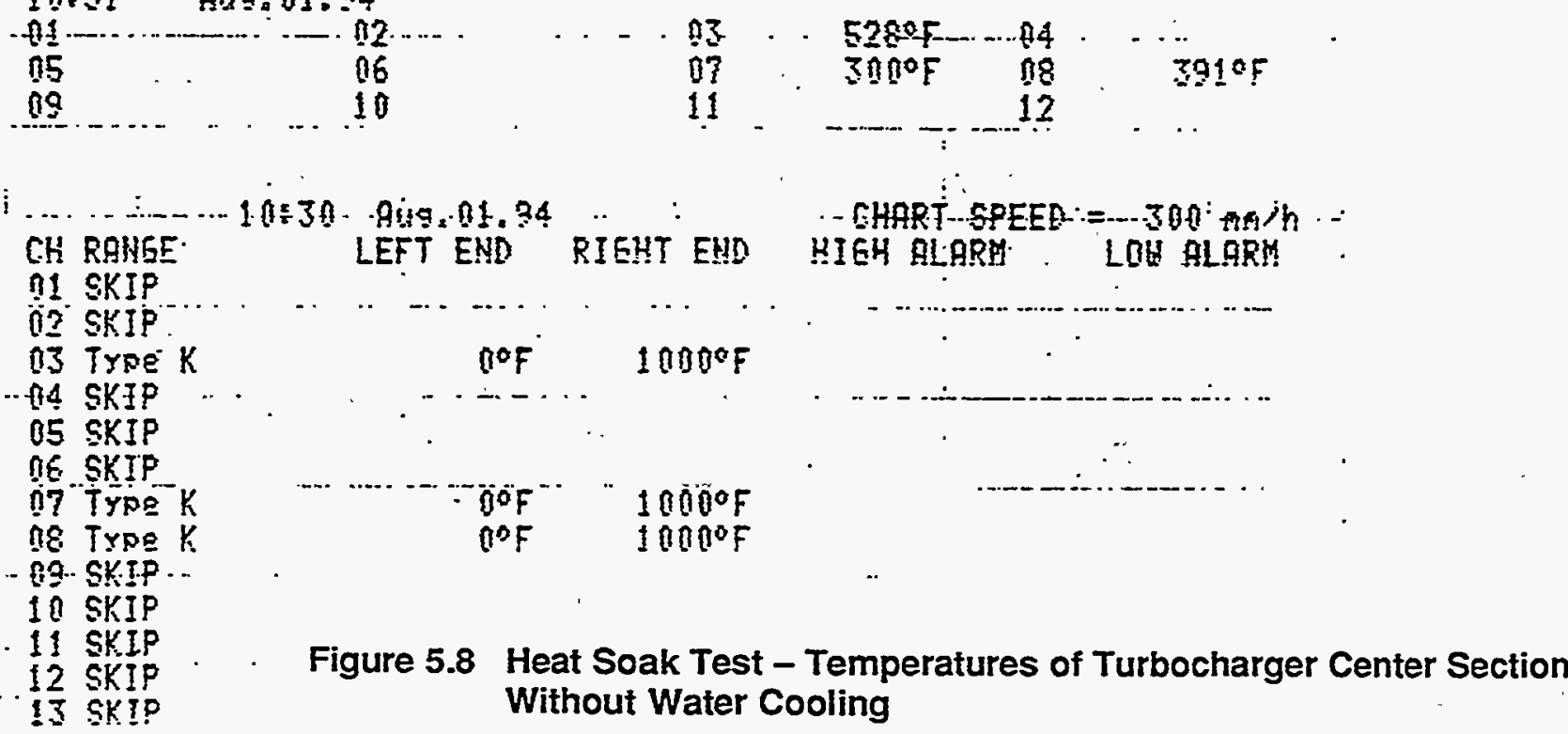




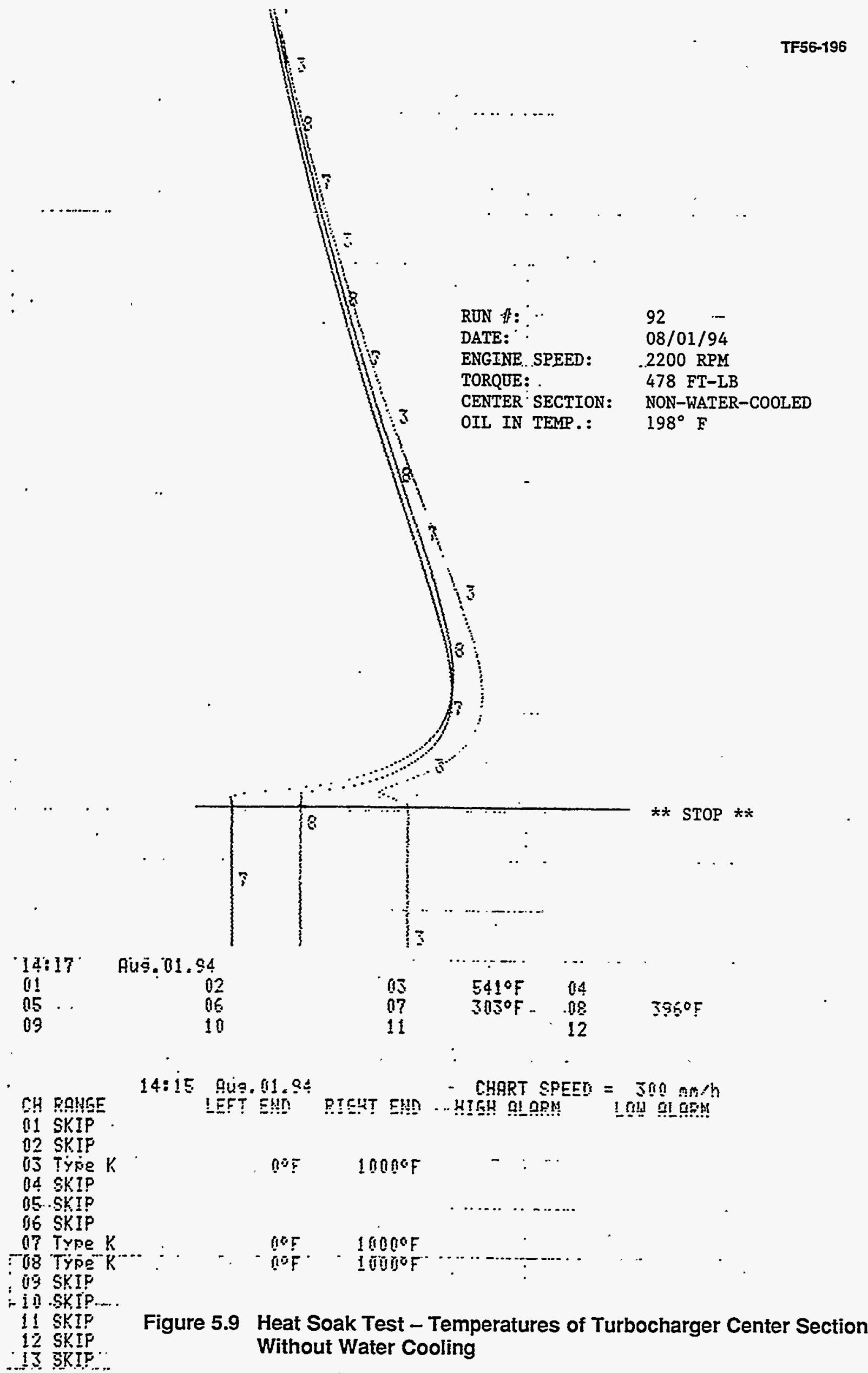




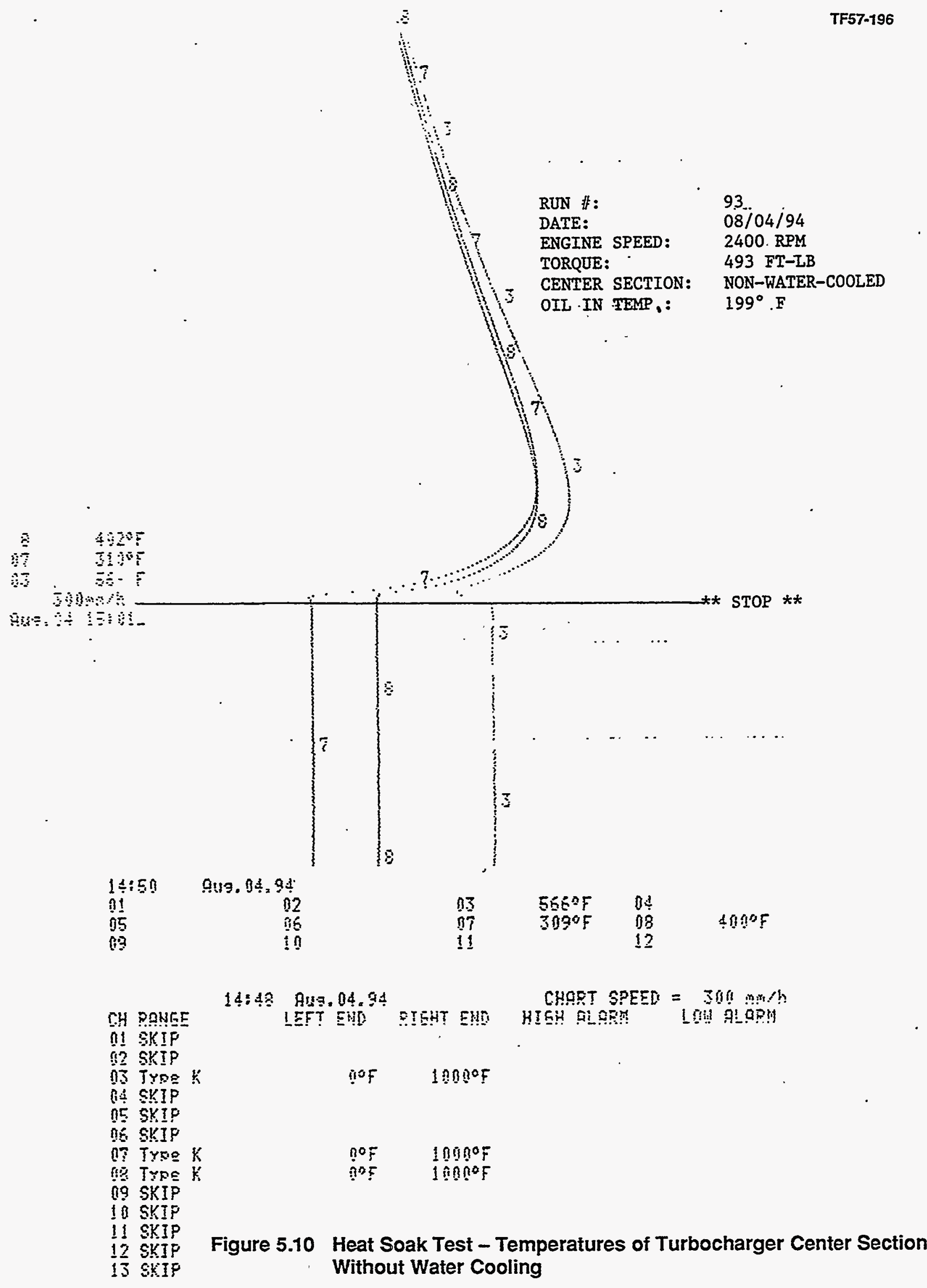




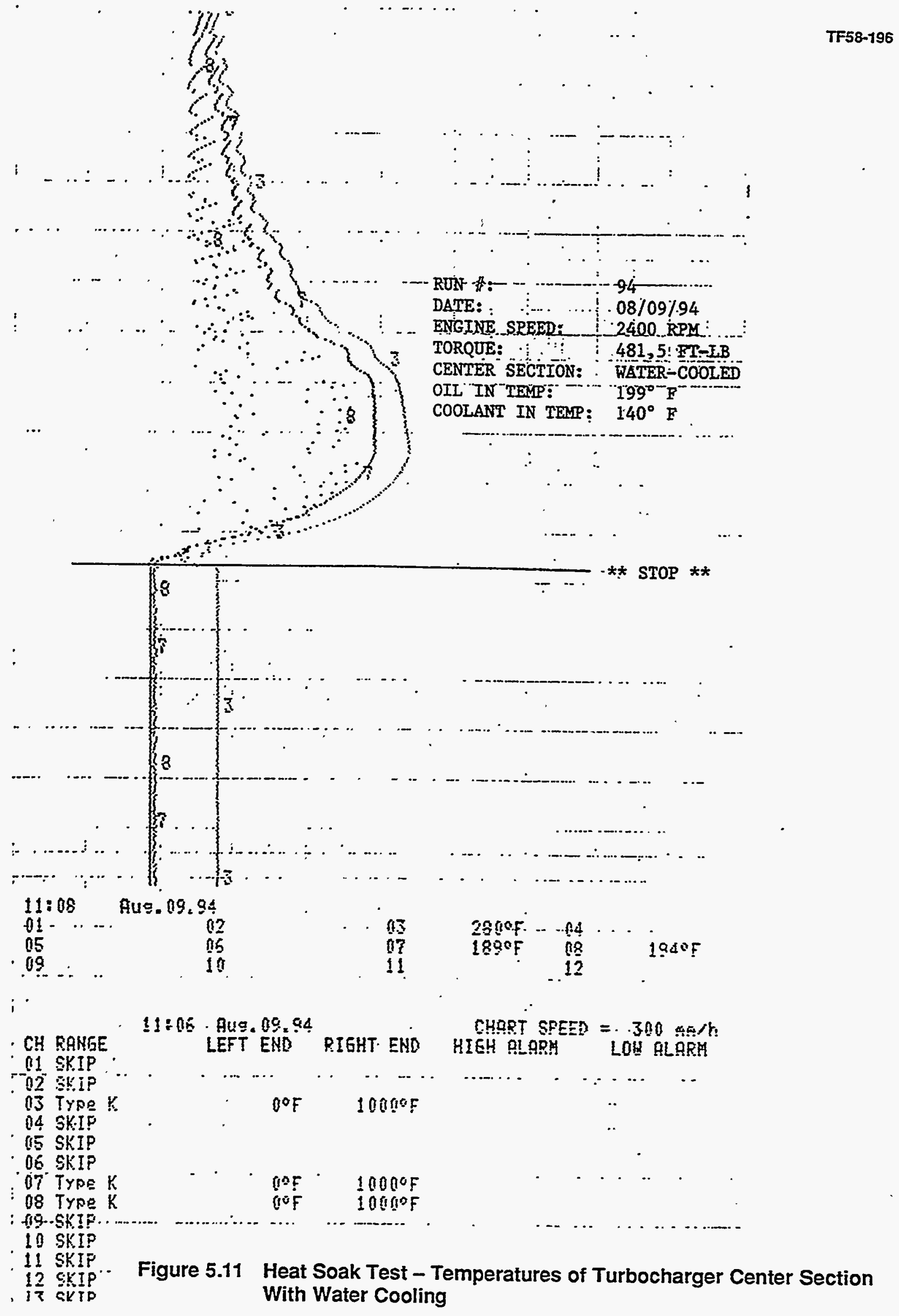




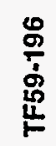

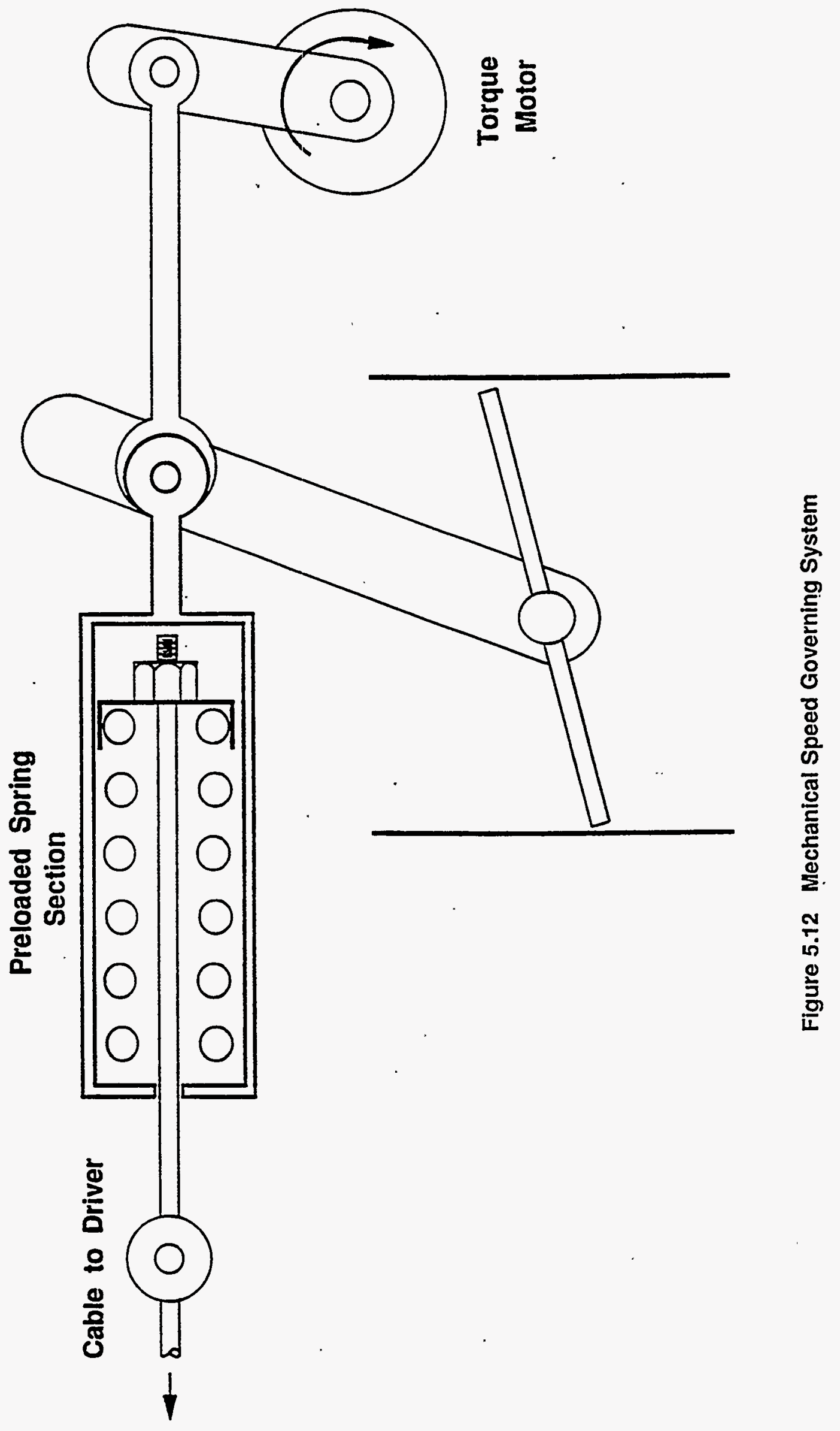


operation of the engine. It was decided that this system be adopted in place of the mechanical speed governor.

\subsubsection{Detonation Control System}

Test data for the knock-limited conditions, including both stoichiometric and $\phi=0.92$, were analyzed using the computer simulation model. The adiabatic end gas temperature, $T_{2}{ }^{\prime \prime}$, and the peak firing pressure, $\lambda p_{3}$, for each test point was calculated. In addition to the test data with the standard set up, the data also included several tests which were conducted with an additional air to water aftercooler in series with the air-to-air aftercooler. By using ice water, the inlet air temperature in these tests was reduced to about $43^{\circ} \mathrm{F}$. The lower charge temperature permitted the engine to reach a higher firing pressure before detonation occurred. Figure 5.13 shows the knock-limited test points on a plot of $T_{2}$ " vs. $\lambda p_{3}$. A line is drawn near the upper limit of the point to represent the "detonation limit" of the Navistar 466 engine. The scatter of the points is due to the amount of throttling that we chose to back away from the incipient detonation condition for data recording. The incipient detonation was detected by observing the pressure trace before it became audible. Generally at this condition, detonation occurred about once in every 100 cycles in cylinder \#6, in which a pressure transducer was installed.

Once we defined the "detonation limit" in terms of a function of $T_{2}$ " and $\lambda p_{3}$, the computer simulation model was used to establish the maximum allowable intake manifold pressure as a function of the engine speed and intake manifolded air temperature. Figure 5.14 shows a plot of maximum allowable $p_{i}$ vs. engine speed for various $T_{i}$. The same information is also shown in tabulated form in Figure 5.15. The table for maximum $p_{i}$ is incorporated in the controller software and it can be adjusted later if needed.

The method for limiting the maximum intake manifold pressure is to use a wastegate in the exhaust system to allow a portion of the exhaust gas to bypass the turbine, thus limiting the amount of boosting. Another method for limiting the maximum intake manifold pressure is to use a wastegate in the air line after the compressor. The wastegate is operated with a proportional solenoid. The blow-off air is recirculated back to the inlet of the compressor, which is similar to the by-pass scheme employed in some of the automotive supercharging systems. The first method was chosen for its lower cost and simplicity.

The new turbocharger with integral wastegate was tested on the engine to check the control for limiting the intake manifold pressure. A spring with 20.7-25.3 lbf/in spring rate was selected for the diaphragm actuator for the wastegate. A preload was set such that it requires a pressure of $7.5 \mathrm{psi}$ on the diaphragm to open the wastegate. The pre-load was necessary to prevent the wastegate from opening by the force acting on it due to the high pressure differential across the wastegate at high speed and high load conditions. The $7.5 \mathrm{psi}$ is sufficiently lower than the anticipated pressure limit for the intake manifold. 


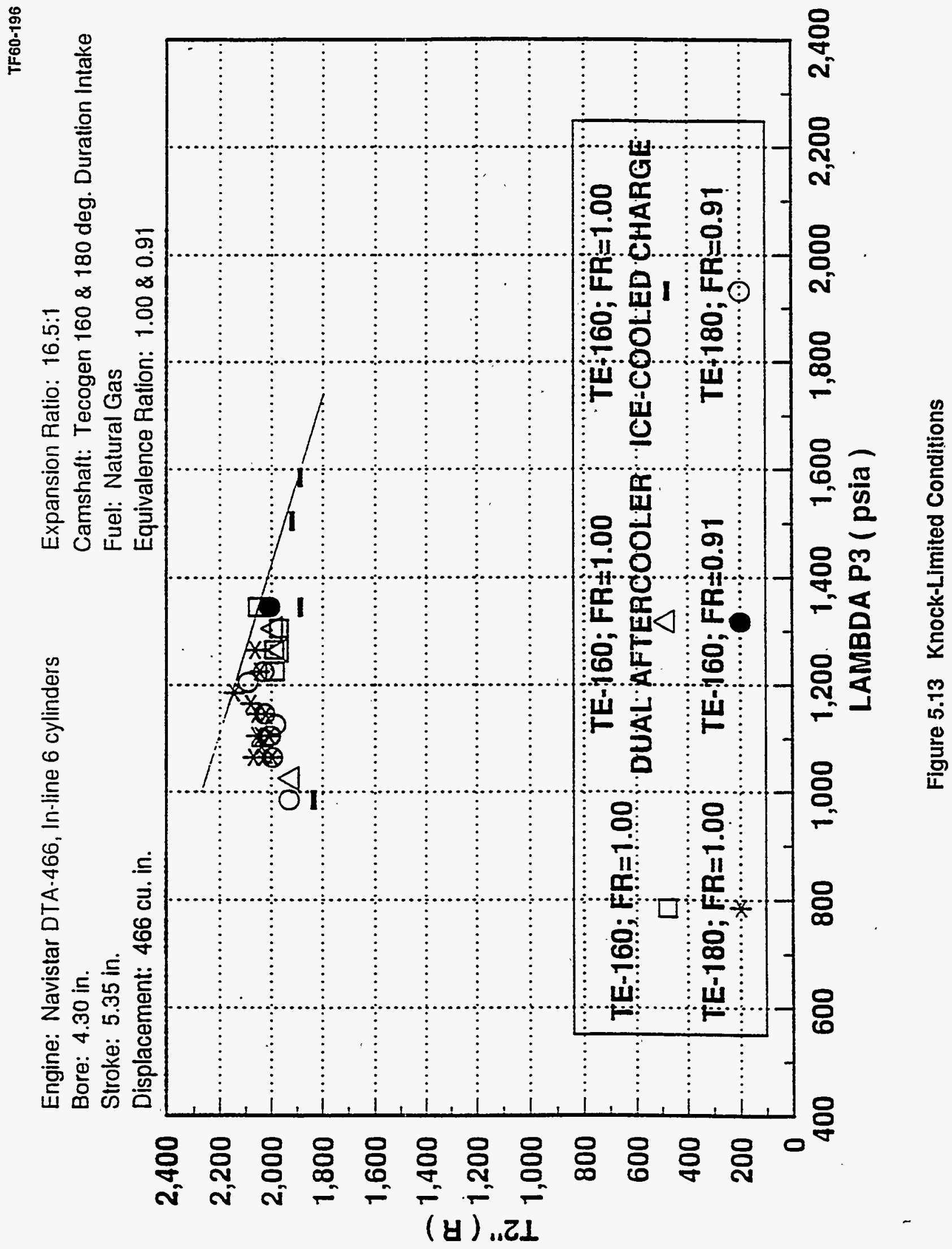


Engine: Navistar DTA-466, In-line 6 cylinders Bore: 4.30 in.

Stroke: 5.35 in.

Displacement: $466 \mathrm{cu}$. in.
Expansion Ratio: $16.5: 1$

Camshaft: TE - 160

Fuel: Natural Gas

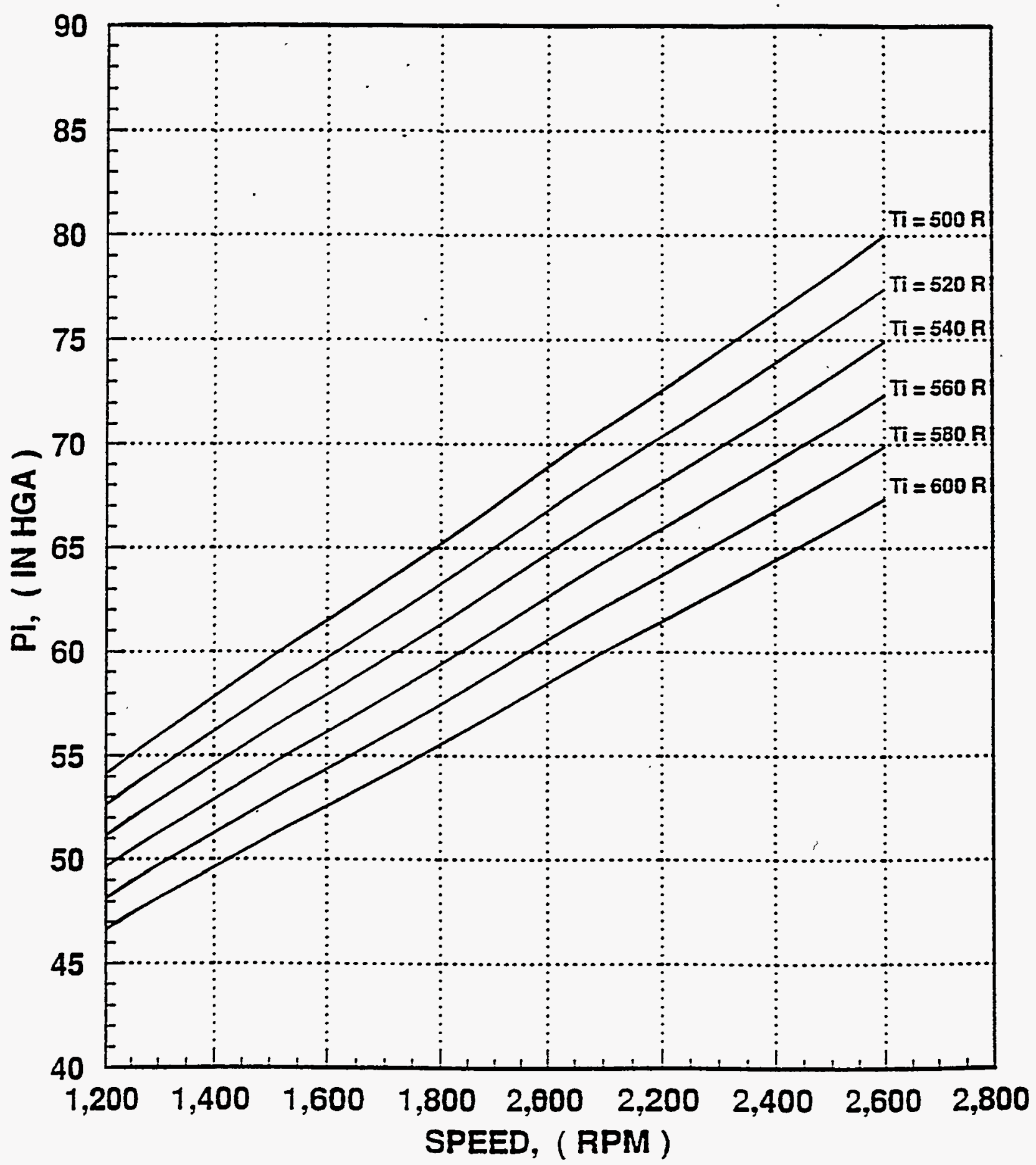

Figure 5.14 Maximum Allowable Intake Manifold Pressure 


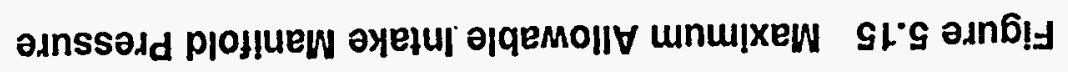

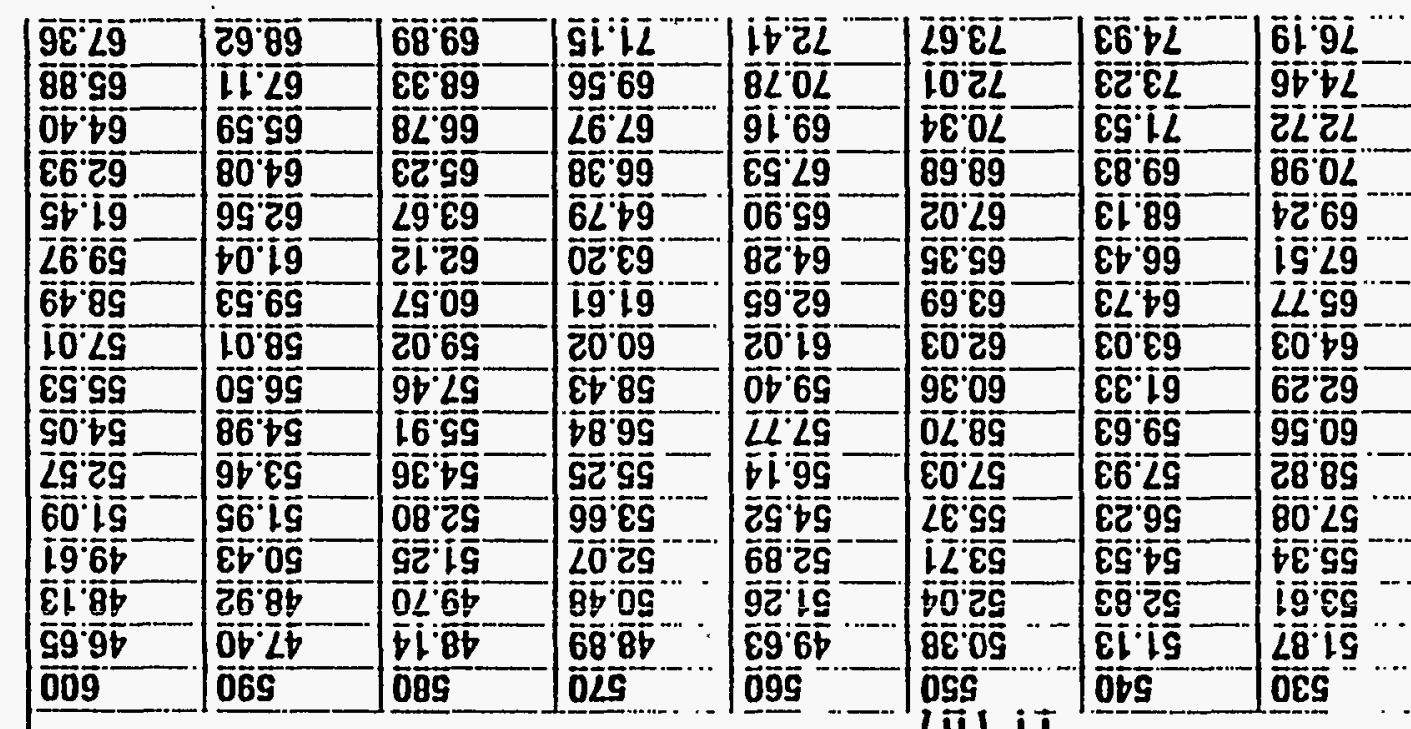

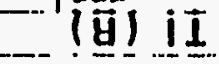

\begin{tabular}{|c|c|}
\hline $\mathbf{S E} 2 \mathbf{L}$ & $\bar{Z} \bar{L} \bar{B}$ \\
\hline $89 . \overline{G L}$ & $\overline{0} \overline{6} \overline{9} \bar{L}$ \\
\hline $16 \cdot 2 L$ & 6092 \\
\hline $\bar{E} L \bar{L}$ & $82 \varepsilon L$ \\
\hline $9 \varepsilon 0 L$ & 2612 \\
\hline 899 & 9969 \\
\hline 1899 & $98 \angle 9$ \\
\hline 0099 & 6099 \\
\hline 9289 & $E 2+9$ \\
\hline $6 \overline{6} \overline{9}$ & 2629 \\
\hline$I \leq 69$ & $\overline{0} \overline{9} \overline{0} \overline{9}$ \\
\hline 66.29 & $6 L 89$ \\
\hline 9199 & $86 \overline{6} \overline{9}$ \\
\hline 585 & LISS \\
\hline 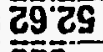 & $9 \varepsilon \varepsilon$ \\
\hline 025 & 019 \\
\hline
\end{tabular}

\begin{tabular}{|c|c|}
\hline$\overline{8} \overline{6}: \overline{6} \bar{L}$ & 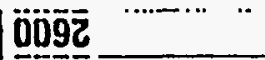 \\
\hline $\bar{E} \bar{L} \overline{8} \bar{L}$ & $\overline{0} \overline{\bar{s}} \overline{\mathrm{s}} \overline{\mathrm{z}}$ \\
\hline$\overline{8} \bar{C} \overline{9} \bar{L}^{-}$ & $\overline{0} \overline{0} \overline{\bar{z}} \overline{\mathrm{C}}$ \\
\hline$E \bar{t} \bar{L}$ & $\overline{0} \bar{\varepsilon} \bar{\varepsilon} \bar{Z}$ \\
\hline$\overline{6 S} \overline{2} \bar{L}$ & $\overline{0} \overline{0} \bar{z} \bar{z}$ \\
\hline $\bar{B} L \bar{O}$ & $\overline{0} \overline{0} \bar{i} \bar{c}$ \\
\hline$\overline{6} \overline{8} \overline{8} \overline{9}$ & $\overline{0} \overline{0} \overline{0} \bar{z}$ \\
\hline $60 \div 9$ & 0061 \\
\hline 61.99 & $\overline{0} 0 \overline{8} \overline{1}$ \\
\hline$\overline{\mathrm{G}} \bar{\varepsilon} \cdot \overline{\mathrm{\varepsilon}} \overline{9}^{-}$ & $002 i$ \\
\hline$\overline{0} \bar{q} i \overline{9}$ & ס̄ōi \\
\hline$\overline{\mathbf{g}} \overline{9}: \overline{6} \overline{\mathbf{S}}$ & $00 \underline{O Q} \mathbf{i}$ \\
\hline$\overline{0} \bar{Z}: \overrightarrow{\underline{s}}$ & 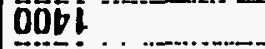 \\
\hline$\overline{\mathbf{G}} \mathbf{\underline { G }} \overline{\underline{S}} \underline{\underline{G}}$ & DOEI \\
\hline $11 \overline{9}$ & Dozl \\
\hline 005 & $(M d \theta) N$ \\
\hline
\end{tabular}

(VDH NI) Id

$\begin{array}{ll}\text { S0- } \exists 08899^{\circ}- & =\varepsilon 0 \\ 20-\exists 0 Z 69^{\circ} \varepsilon & =20 \\ 20-\exists 9920^{\circ} \varepsilon & =10 \\ 9 \angle 90^{\circ} \angle b & =00\end{array}$

$N \times[(Y) U \times \varepsilon O+Z O]+[(Y) U \times 10+0 O]=(\mathrm{HOH} N \|) l d$ 
The system was tested and the tables in the PCM software were calibrated for the limiting intake manifold pressures and temperatures which were specified based on the detonation characteristics of this engine. The engine was operated up to WOT at speeds above $1800 \mathrm{rpm}$ to make sure that the control system properly actuated the wastegate to limit the boost pressure and avoid engine detonation.

\subsubsection{Emissions Control System}

The basic strategy for emissions control is to operate the engine at stoichiometric ratio and use a catalytic converter to reduce the $\mathrm{NO}_{X}, \mathrm{CO}$, and $\mathrm{HC}$. The fuel-air ratio is to be controlled using a closed-loop control system with an oxygen sensor in the exhaust. The controller was calibrated for minimum emissions after the various engine component systems had been checked out and the specified engine performance had been achieved.

A prototype catalytic converter has been obtained from Johnson Matthey which was designed to meet the following emissions targets:

$\begin{array}{ll}\text { NOX } & 1.0 \mathrm{gm} / \mathrm{bhp}-\mathrm{hr} \\ \mathrm{CO} & 7.2 \mathrm{gm} / \mathrm{bhp}-\mathrm{hr} \\ \mathrm{NMHC} & 1.0 \mathrm{gm} / \mathrm{bhp}-\mathrm{hr}\end{array}$

The maximum pressure drop is $1.0 \mathrm{psi}$. The catalyst is $7.5^{\mathrm{n}}$ dia. $\times 6.9^{\mathrm{n}}$ long and is ceramic with 400 cells per square inch. The coating technology is JM51 and it includes Platinum and Rhodium at a 40 gram per cu. ft. level.

Although the catalyst unit is.reasonably compact, one of the difficulties uncovered during the bus conversion study (Section 6.1) was the lack of space for inserting the catalytic converter in the exhaust pipe between the turbocharger and the muffler. Also, the cost for adding this component is high because the exhaust pipe has to be either replaced or modified. A new approach was suggested by the manufacturer of the muffler to incorporate the catalytic reactor inside the muffler. Since the overall dimension of the muffler matches the original muffler on the vehicle, the original exhaust pipe would not have to be replaced. Using stainless steel for the muffler/catalyst unit, the system should have a life expectancy comparable to a conventional catalytic converter and considerably longer than a conventional muffler.

\subsection{PROTOTYPE ENGINE TEST}

\subsubsection{Shakedown Test}

The engine started very easily after only a few revolutions of cranking. This indicated that the fueling strategy incorporated in the controller software for starting was adequate. The starting is significantly easier than the proof-of-concept engine for which an IMPCO mixer was used. Apparently the IMPCO mixer did not maintain the required fuel-air ratio under cranking conditions. 
The engine was operated over the entire range of speed and torque to determine if all systems functioned properly. The ignition system, including the trigger signals and the ability to vary the spark timing, was found to behave as expected. The performance of the spark plug in terms of igniting the mixture at different engine operating conditions will be discussed later.

Initially, the fuel injection system did not sequence the injection correctly. Upon examining the trigger signal from the Hall effect sensor for the camshaft position, it was found that the signal was not consistent. The Hall sensor was modified to reduce the gap between the sensor and the magnet in the cam gear from $0.135^{\prime \prime}$ to $0.090^{\prime \prime}$, and the trigger signal became consistent. With the proper trigger signal, the fuel injection became properly sequenced.

The fuel injector flow rate was low, as expected. Consequently, at high speed and high torque operation, the fuel injection period was over $85 \%$ of the cycle period when the fuel supply fell below $120 \mathrm{psig}$. It is therefore important that the regulator maintains the fuel pressure above $120 \mathrm{psig}$ at the maximum output.

The timing of the fuel injection is such that the closing time of the injector is fixed in terms of crank angle position. Due to the fact that the software for the PCM was designed for gasoline, the injection timing was too early for natural gas operation. The only way to satisfy our need was to rotate the injector signal wire ahead by one cylinder, so that the end of injection time was delayed by $120^{\circ}$ of crank angle. This means the wire normally connected to No. 5 injector is now connected to No. 1 injector, since the firing order is 1-5-3-6-2-4. With this change, we can end the injection as late as $120^{\circ}$ ATDC, which was $20^{\circ}$ before inlet valve closing.

\subsubsection{Mass Air Flow Calibration}

The mass air flow meter generally requires calibration on a flow bench with the specific inlet piping connected to the throttle body. However, based on the calibration curve supplied with the PCM software, the engine maintained the fuel-air ratio to within a reasonably small variation over most of the flow range except in the low flow region. The small variation of fuel-air ratio is automatically corrected by the controller when it is operated in the closed-loop mode based on the output signal of an oxygen sensor in the exhaust stream. Figure 5.16 is a plot of the air flow data, calculated by three different methods, as compared to the calibration.curve for the mass air flow meter as a function of the frequency output from the meter. It is seen that the match is, in general, quite good. However, a slight adjustment of the mass air flow meter calibration was needed at the very low flow region in order to achieve constant fuel-air ratio over the entire range. This can be seen in a plot of air flow vs. fuel flow and the comparison to the constant fuel-air ratio line (see Figure 5.17).

\subsubsection{Spark Plug Selection}

The engine was operated over the full speed and torque range to determine the spark ignition characteristics of the engine. The spark plug, which was used for the proof-of-concept engine, was 


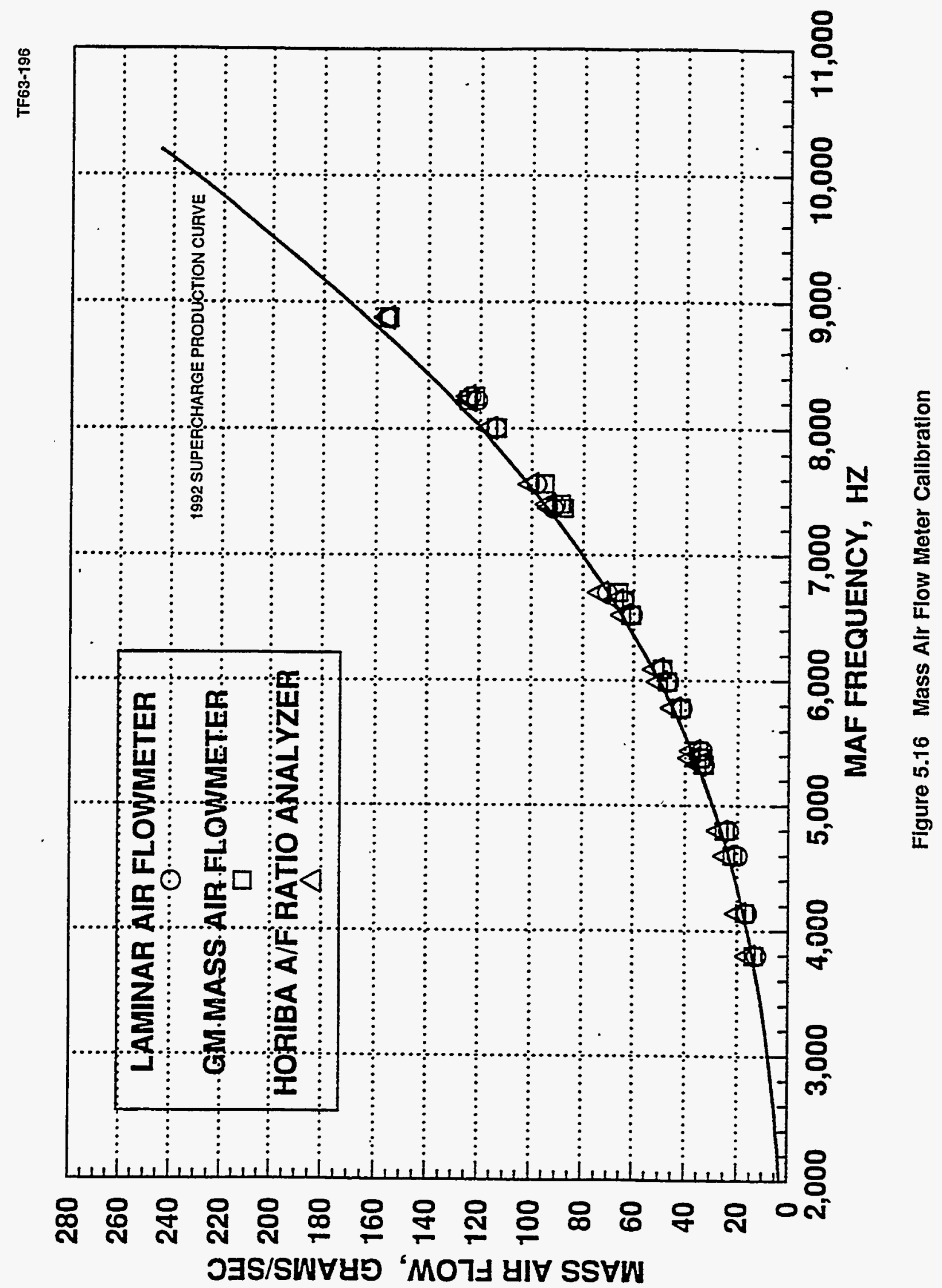




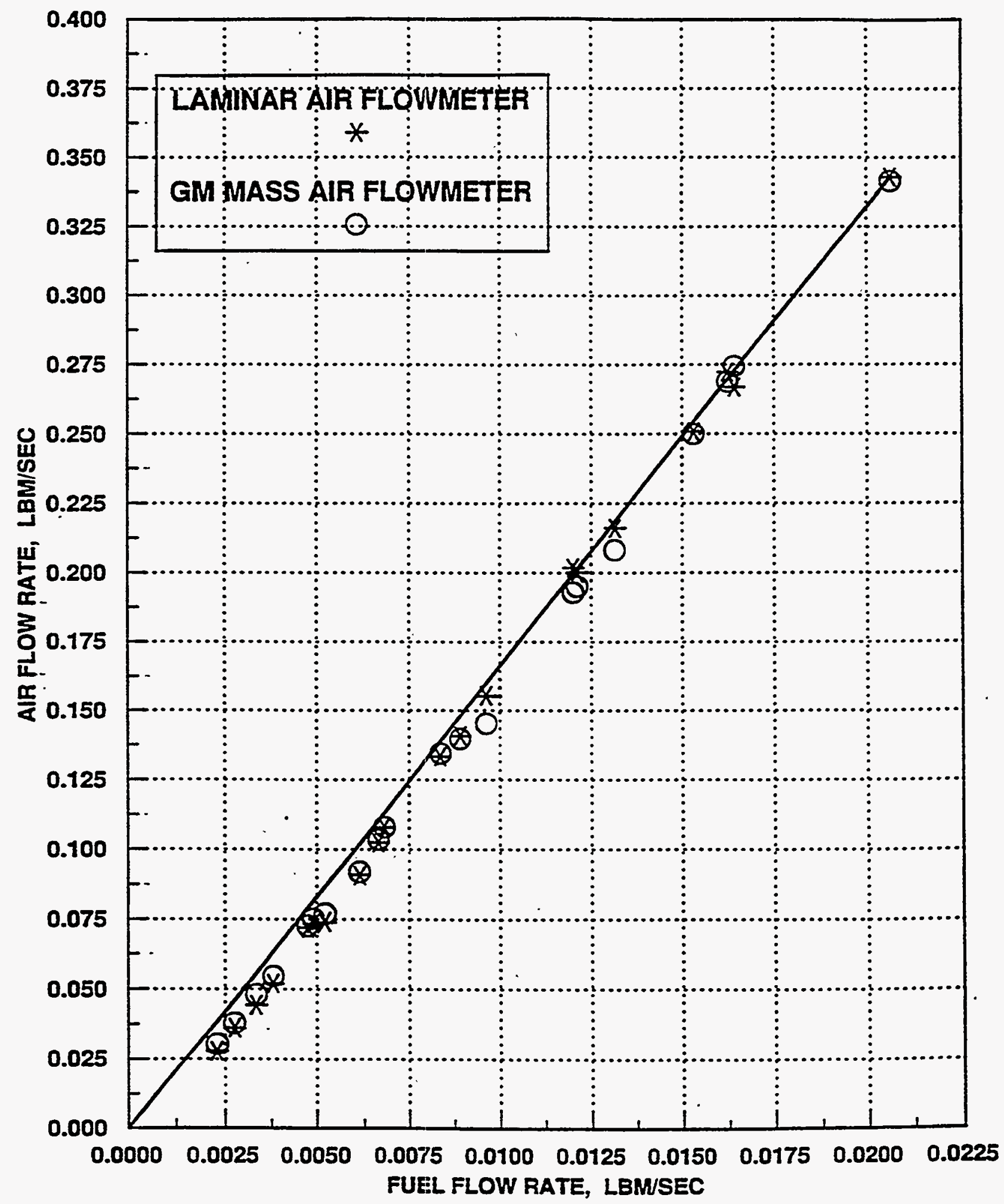

Figure 5.17 Fuel Flow Calibration 
the NGK D8HA $12 " \mathrm{~mm}, 1 / 2^{\prime \prime}$ reach plug modified to fit into the diesel injector well. The plug is clamped down with a steel sleeve in the same manner as the diesel injector. The spark gap was set at 0.012 " because of the high compression pressure at high torque conditions.

The performance of the spark plug in terms of ignition and combustion was satisfactory over the majority of the operating conditions. However, at speeds below $1000 \mathrm{rpm}$ and near zero throttle condition, the engine misfires frequently. This could be detected from the in-cylinder pressure trace, as well as from the fact that the engine controller tended to drive the mixture to the rich side when operating in the closed-loop mode. The unburned free oxygen would make the controller believe that the fuel-air mixture was too lean and therefore increase the fuel flow.

The first explanation of the misfire condition at low power condition was that the spark energy was too low due to the small spark gap. One approach to increase the spark energy was to provide an auxiliary gap in the external lead. Figure 5.18 shows a design sketch to incorporate a gap in the spark plug extension terminal. This design was tested on the No. 6 cylinder which had the pressure transducer to measure in-cylinder pressure. Results showed marginal improvement, but was not acceptable.

A number of spark plug electrode configurations were tested in No. 1 cylinder, and the in-cylinder pressure traces were examined to determine the consistency of the ignition. Figures 5.19 through 5.26 show the results of the test. Figure 5.19 shows the NGK D8HA spark plug which has been used so far to give good performance and life at high output conditions. However, at idle condition, we can see complete misfire of some cycles. Figure 5.20 shows the same spark plug, except that the ground electrode was modified to be tapered at the end so that the quenching area as reduced to nearly a point. The plug in Figure 5.21 is basically the same as that in Figure 5.20, except it has a 0.75 " reach instead of 0.5 ". Both of these plugs performed well at high load as well as at idle and lean-burn condition. The test results clearly showed that the major factor contributing to misfire at low load was the quenching effect by the electrodes. The low spark energy due to the small spark gap at low pressure creates a relatively weak flame kernel which must sustain and grow in the narrow space between the 2 heat sinks formed by the electrodes. The tapered ground electrode reduces the heat sink area significant.

Having the basic criteria in mind, we tested 5 different off-the-shelf spark plugs. The plugs in Figures 5.22 and 5.23 are with a thin wire center electrode. Figure 5.24 shows a combination of a thin wire center electrode and a tapered ground electrode. Figures 5.25 and 5.26 are 2 different size plugs with dual ground electrodes. The NGK D8EVX $12 \mathrm{~mm} \mathrm{0.75"} \mathrm{reach} \mathrm{plug,} \mathrm{as} \mathrm{shown} \mathrm{in}$ Figure 5.24, appeared to give the best performance.

The NGK D8EVX was installed in all cylinders for the remaining spark timing calibration tests, and also tests for the lean-burn idle condition. 


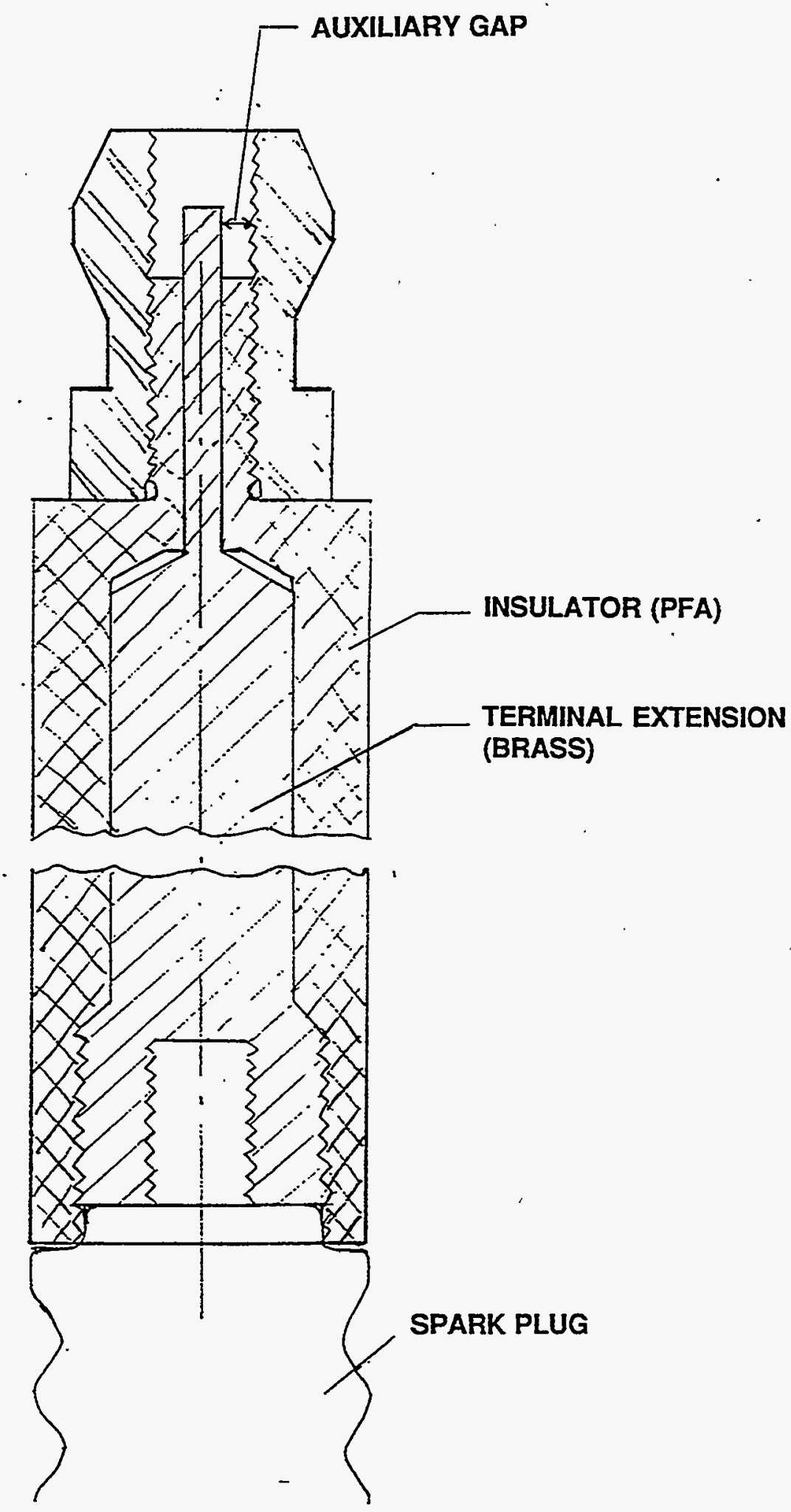

Figure 5.18 External Auxiliary Gap Design for Spark Plugs 
号
d.
占
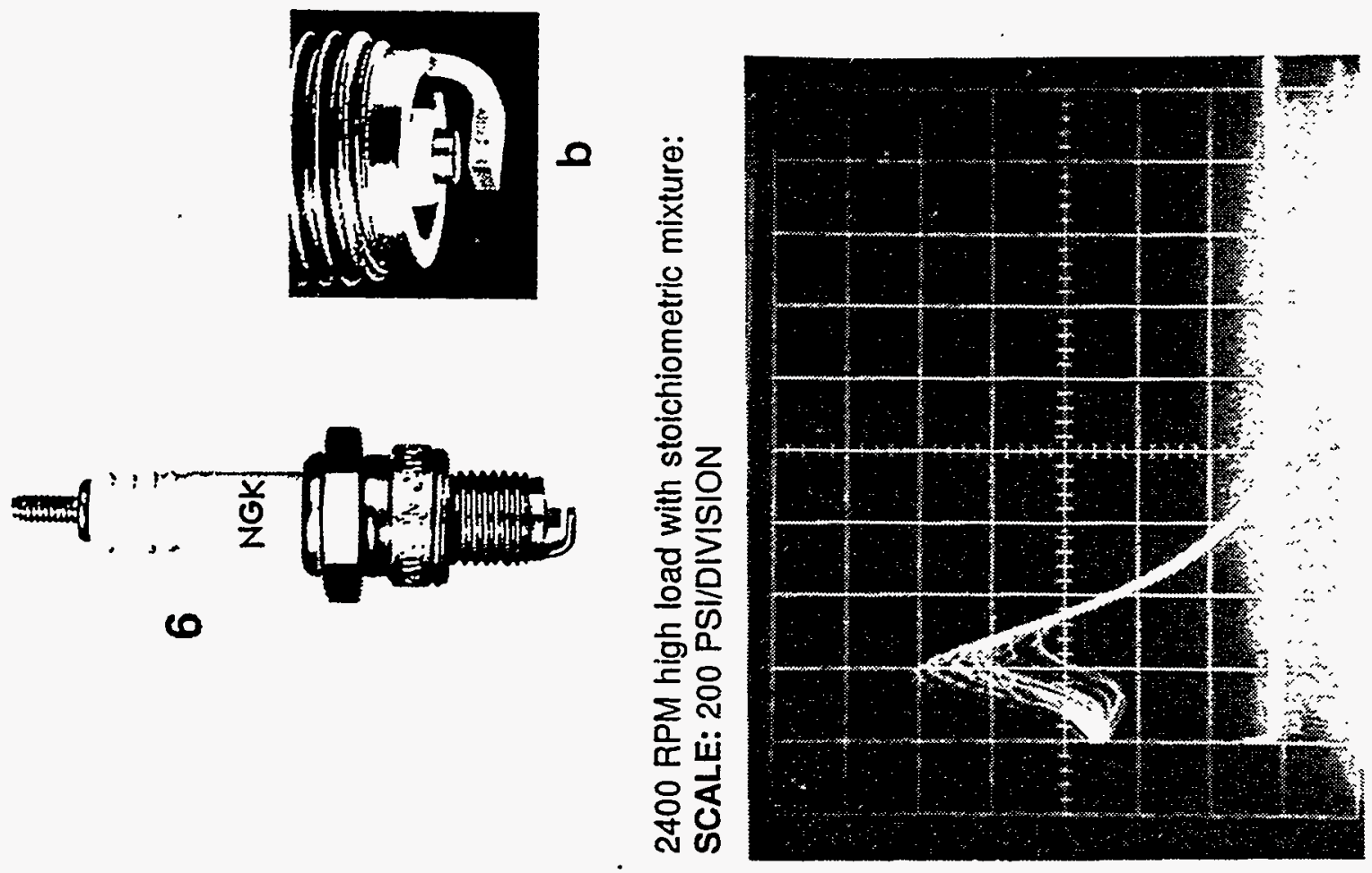

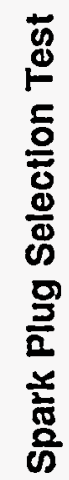
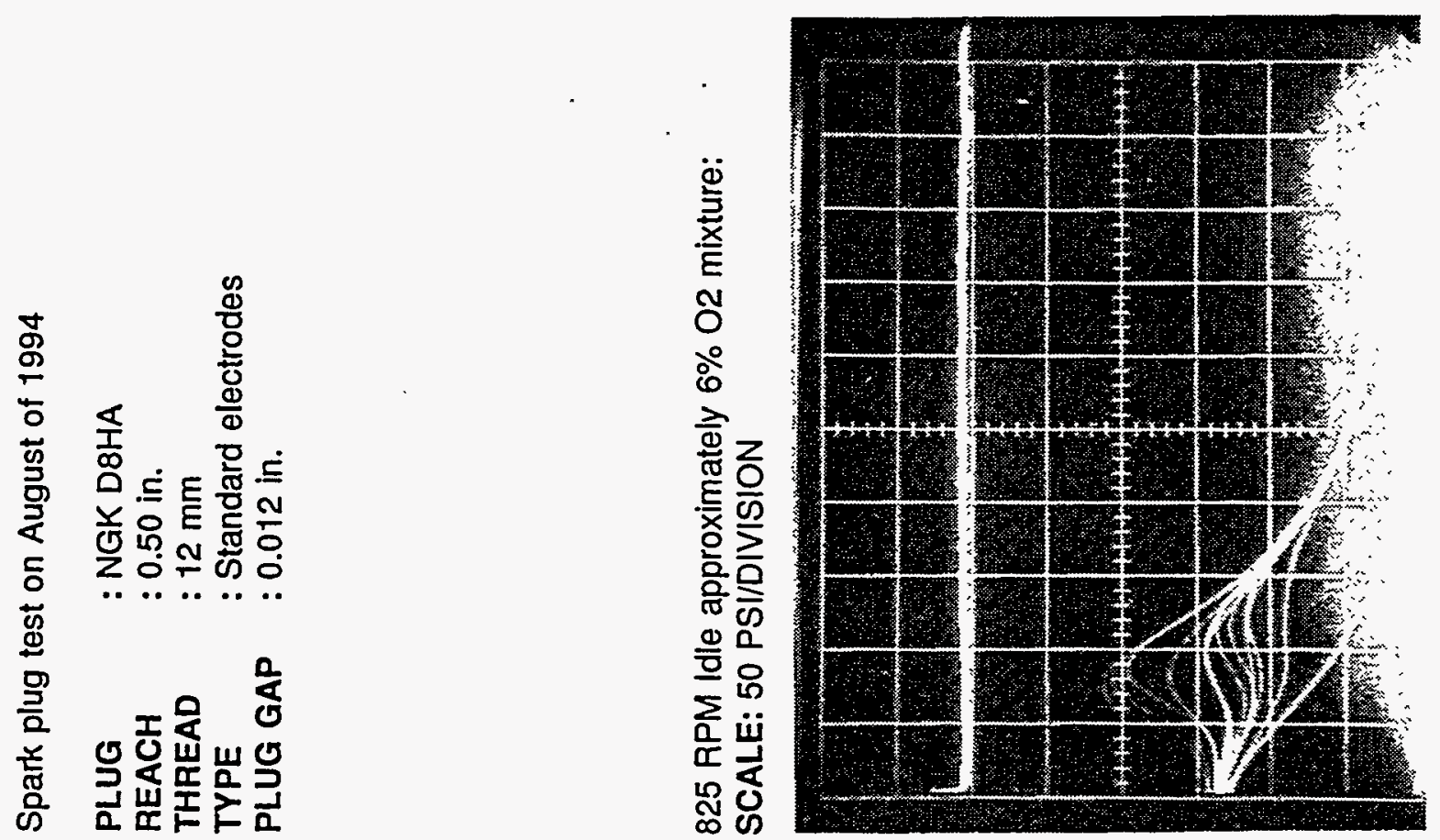

운 
Spark plug test on August of 1994

PLUG : NGK D8HA

REACH : $0.50 \mathrm{in}$.

THREAD $: 12 \mathrm{~mm}$

TYPE : Modified taper ground electrode

PLUG GAP $: 0.013$ in.

825 RPM Idle approximately $6 \%$ O2 mixture:

SCALE: 50 PSI/DIVISION

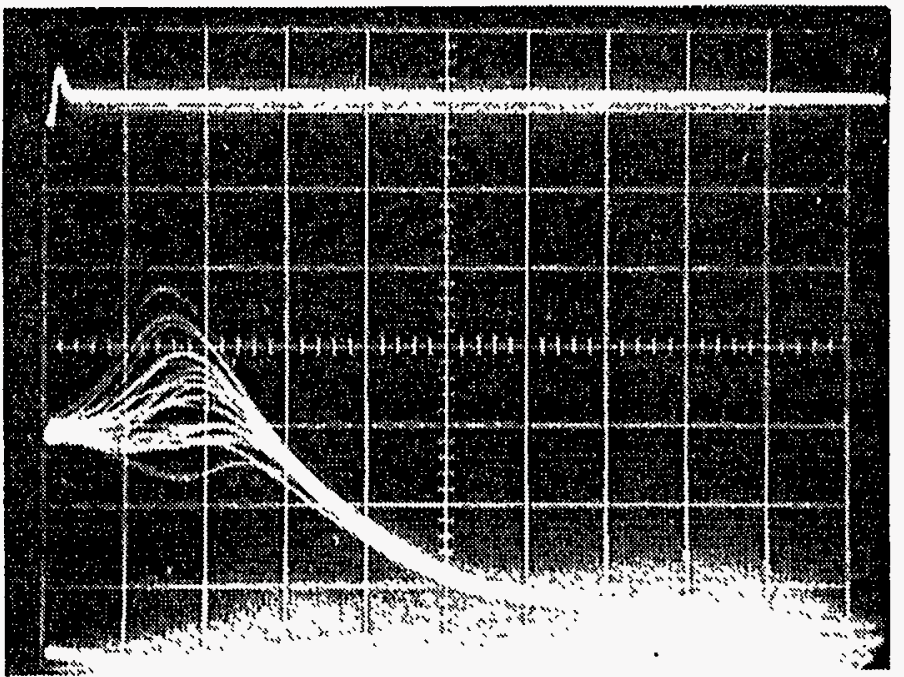

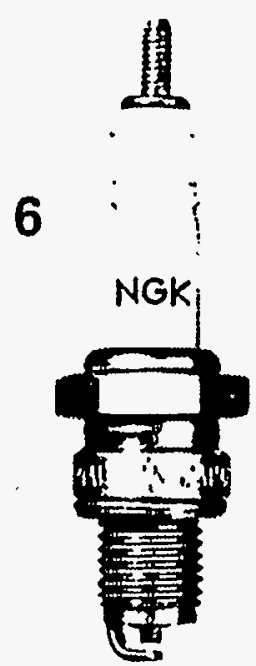

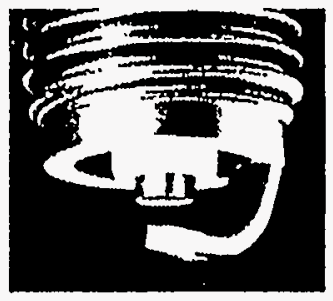

b

1600 RPM full-load with stoichiometric mixture:

SCALE: 200 PSI/DIVISION

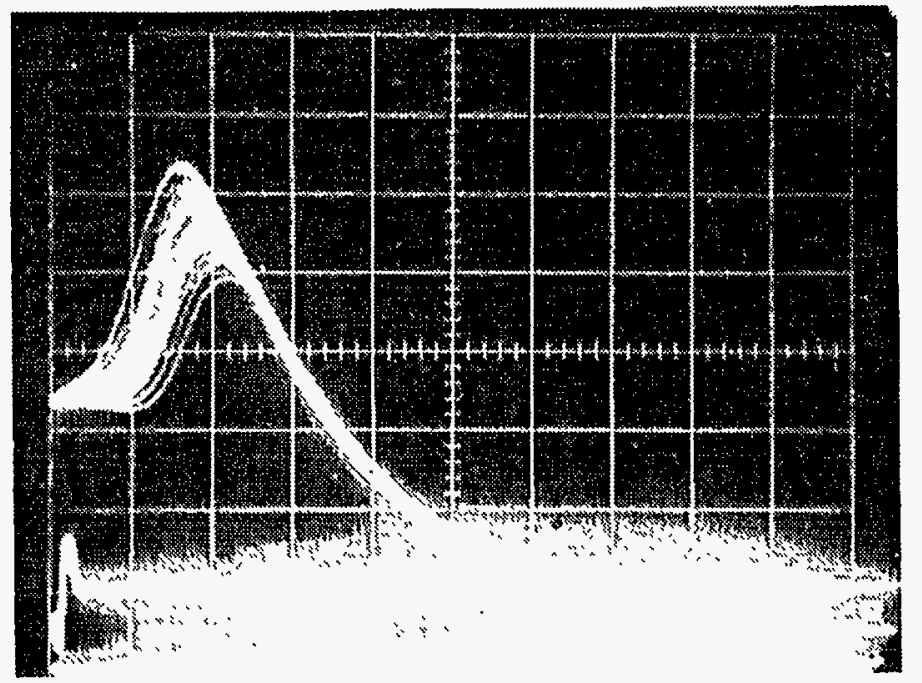

Figure 5.20 Spark Plug Selection Test 
Spark plug test on August of 1994

$$
\begin{array}{ll}
\text { PLUG } & : \text { NGK D9EA } \\
\text { REACH } & : 0.75 \mathrm{in} . \\
\text { THREAD } & : 12 \mathrm{~mm} \\
\text { TYPE } & : \text { Modified taper ground electrode } \\
\text { PLUG GAP } & : 0.013 \mathrm{in} .
\end{array}
$$

825 RPM Idle approximately $6 \%$ O2 mixture: SCALE: 50 PSI/DIVISION

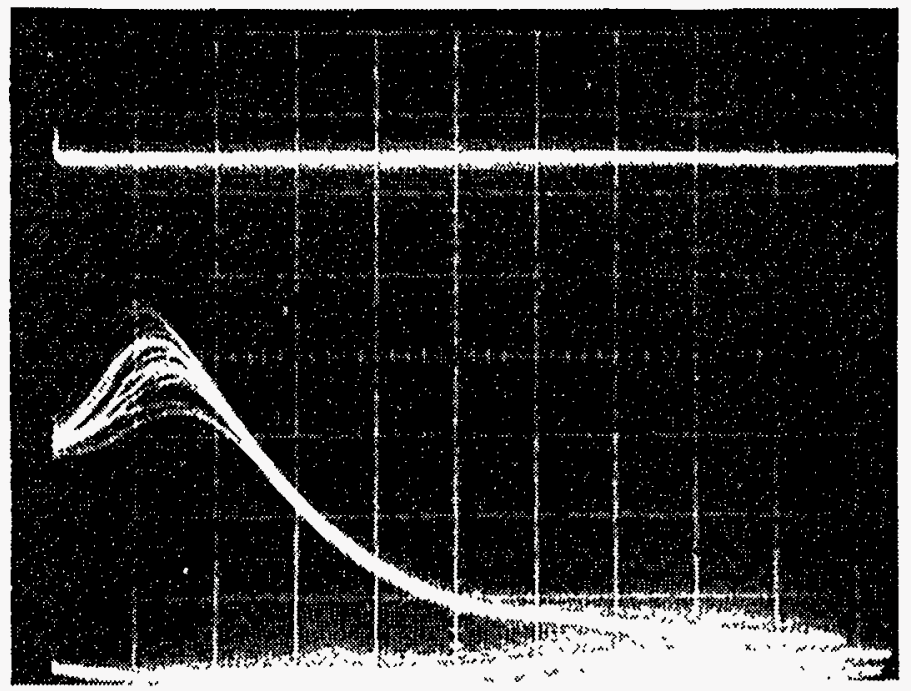

4 NGK
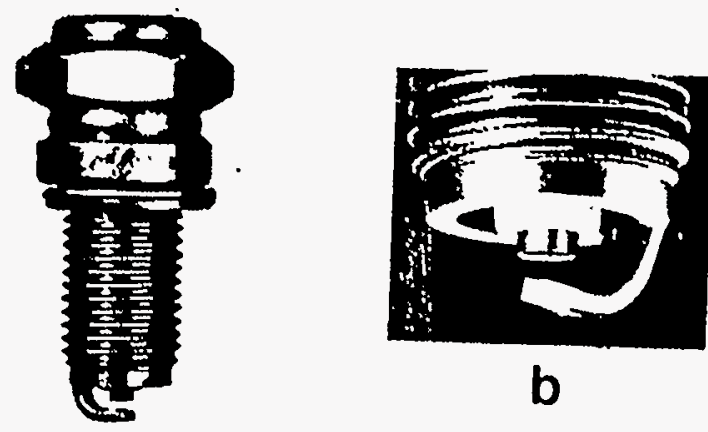

b

1600 RPM full-load with stoichiometric mixture: SCALE: 200 PSI/DIVISION

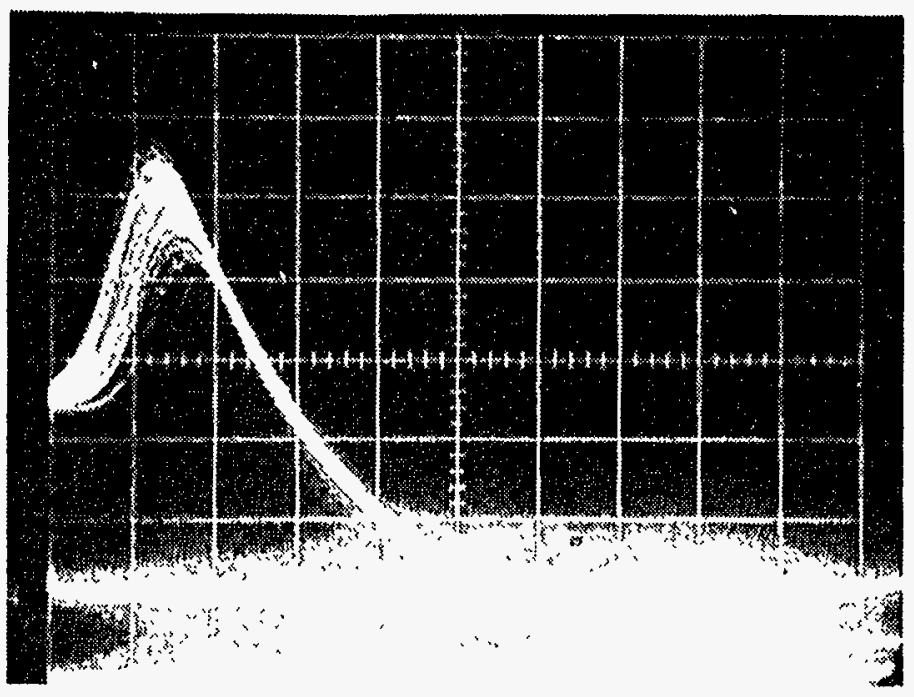

Figure 5.21 Spark Plug Selection Test 


\section{哀}
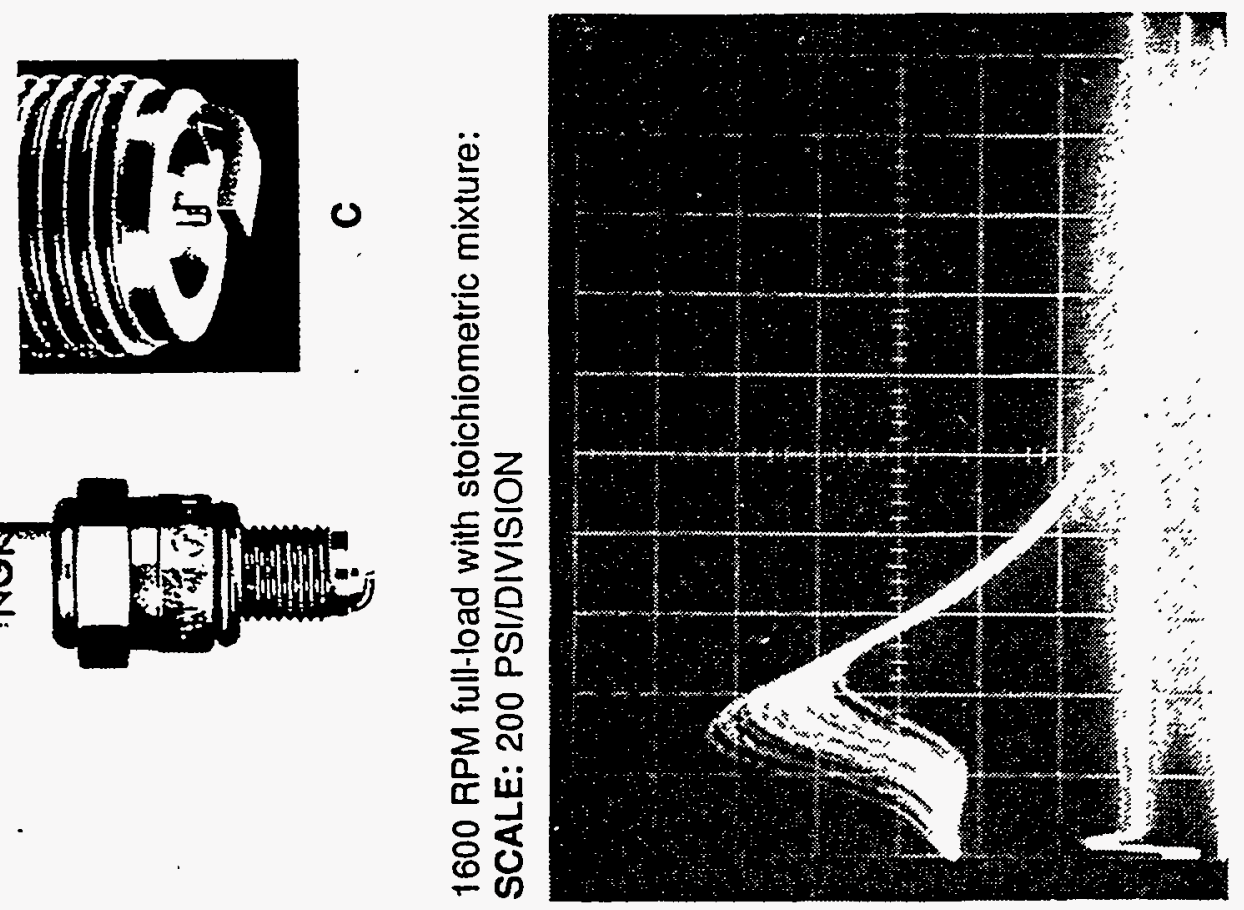

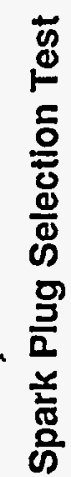
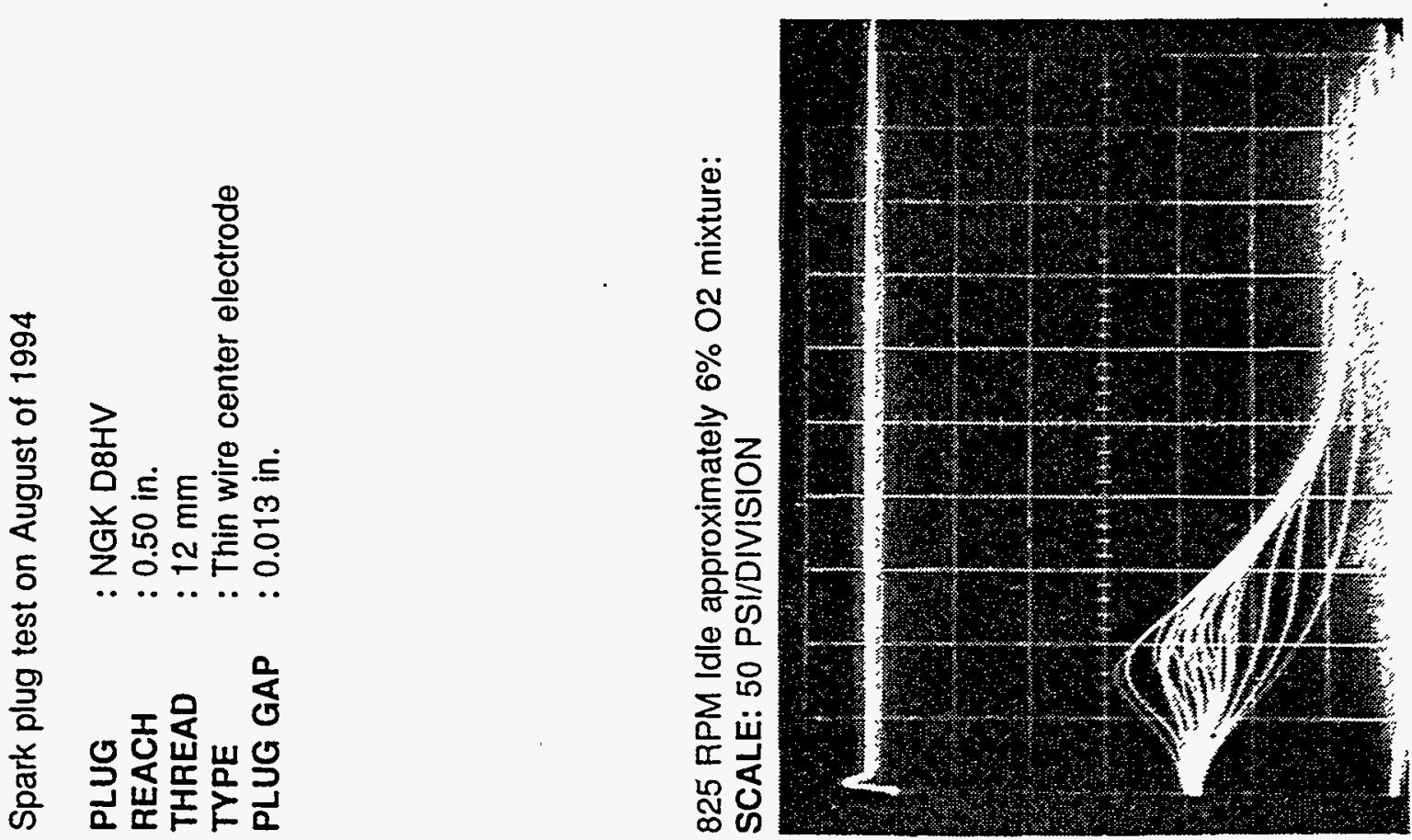

సั 
Spark plug test on August of 1994

\section{PLUG : Champion P-7G}

REACH : 0.50 in.

THREAD $: 12 \mathrm{~mm}$

TYPE : Thin wire center electrode

PLUG GAP $: 0.013$ in.

825 RPM Idle approximately $6 \% 02$ mixture:

SCALE: 50 PSI/DIVISION

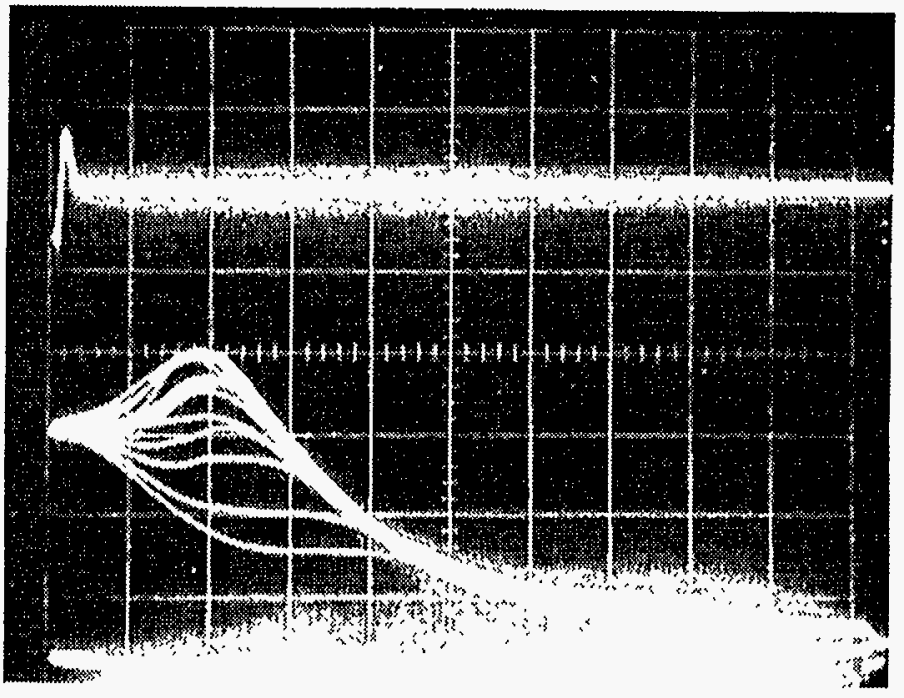

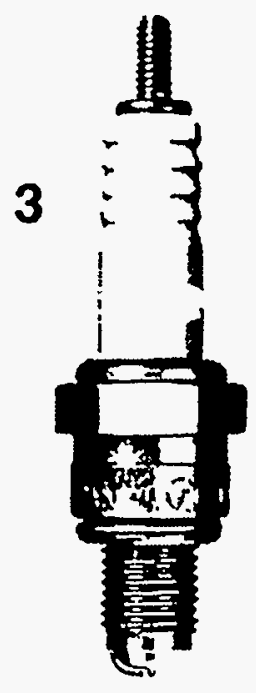

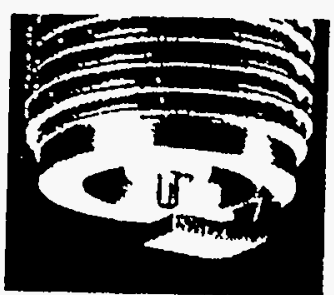

C

1600 RPM full-load with stoichiometric mixture. SCALE: 200 PSI/DIVISION

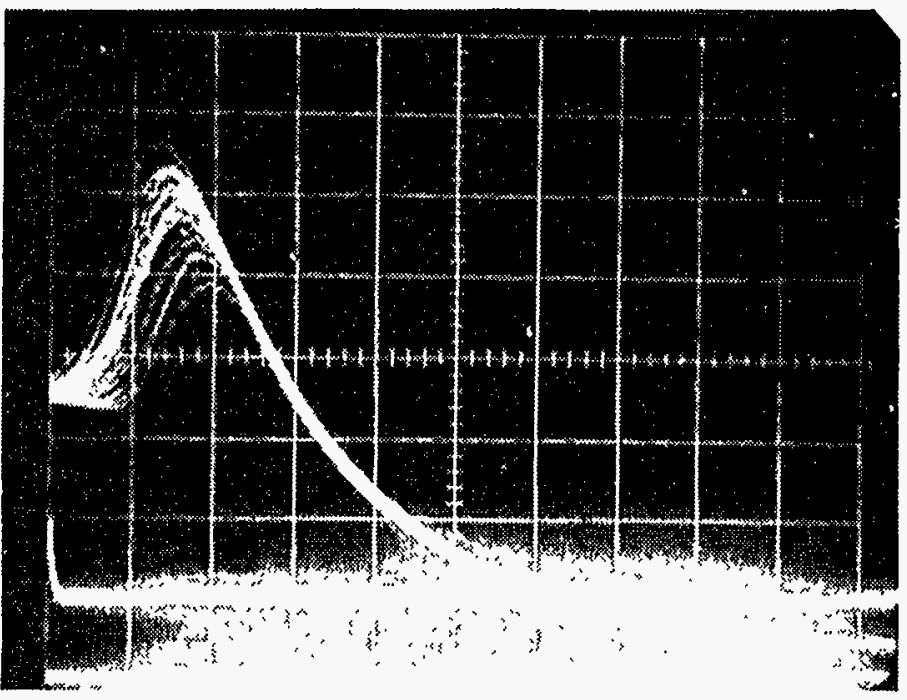

Figure 5.23 Spark Plug Selection Test 
Spark plug test on August of 1994

PLUG : NGK D8EVX

REACH $: 0.75 \mathrm{in}$.

THREAD $: 12 \mathrm{~mm}$

TYPE : Taper ground electrode and thin wire center electrode

PLUG GAP $\quad: 0.013$ in

825 RPM Idle approximately $6 \% 02$ mixture:

SCALE: 50 PSI/DIVISION

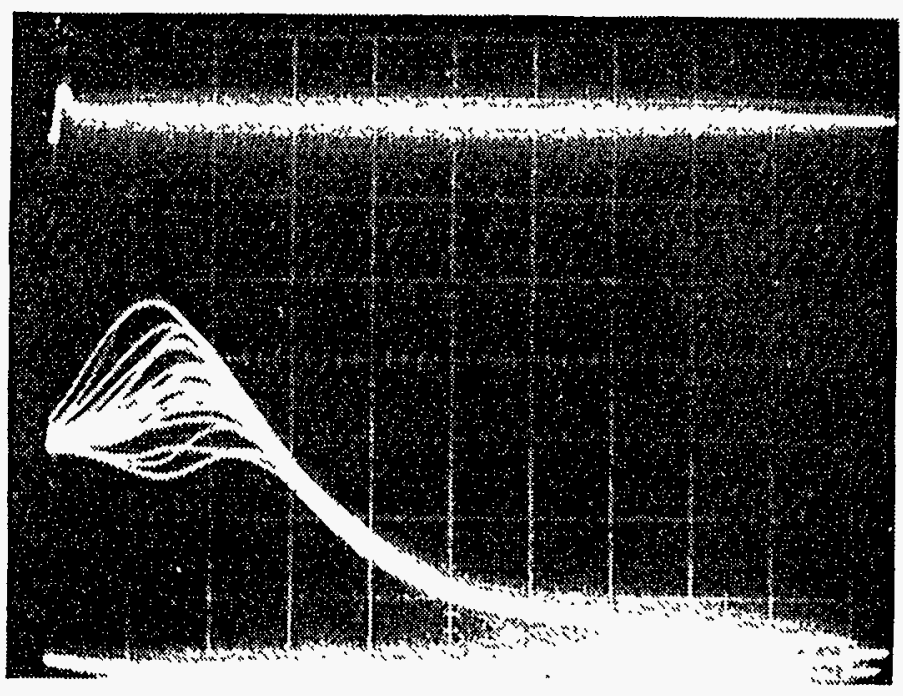

悬

7
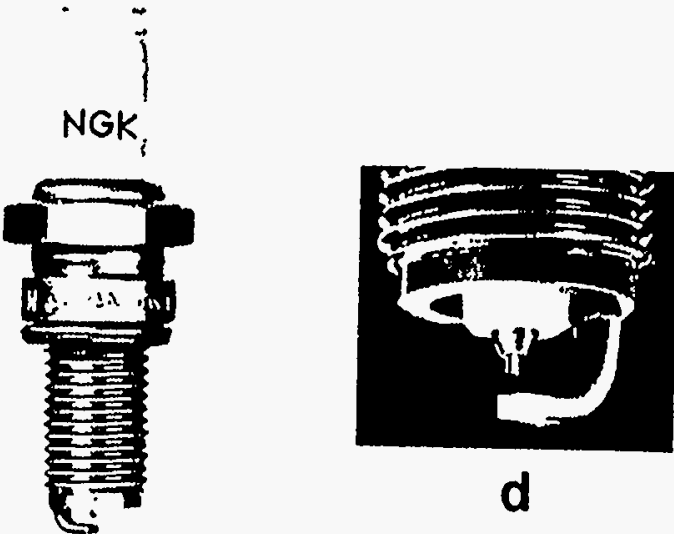

d

Figure 5.24 Spark Plug Selection Test

1600 RPM full-load with stoichiometric mixture: SCALE: 200 PSI/DIVISION

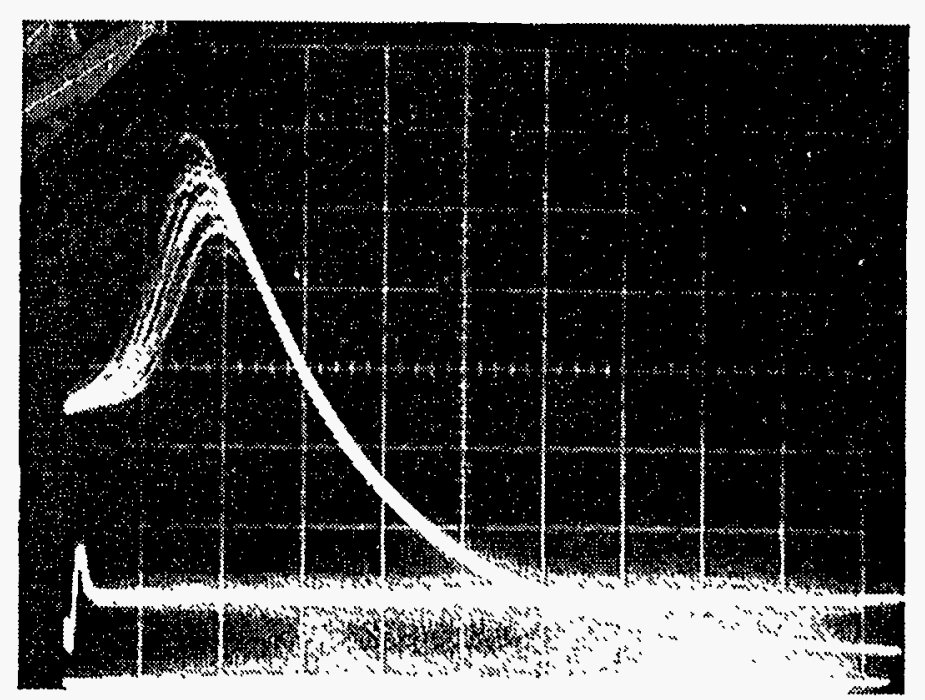


Spark plug test on August of 1994

\section{PLUG : NGK CR10EK}

REACH $: 0.75$ in.

THREAD $: 10 \mathrm{~mm}$

TYPE : Dual ground electrodes

PLUG GAP $: 0.013$ in.

825 RPM Idle approximately $6 \%$ O2 mixture:

SCALE: 50 PSI/DIVISION

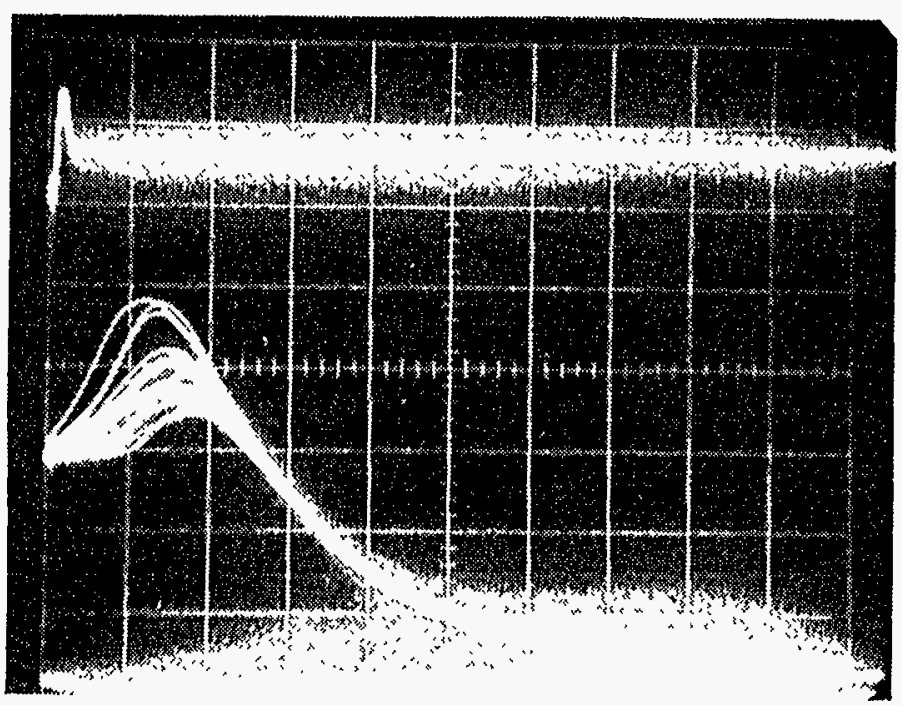

4 NGK
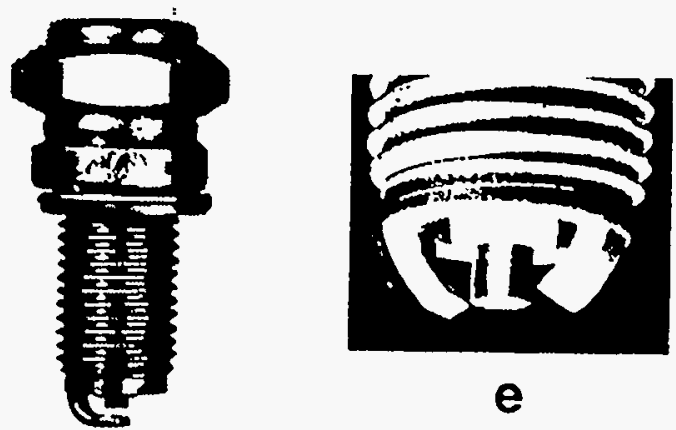

e
1600 RPM full-load with stoichiometric mixture: SCALE: 200 PSI/DIVISION

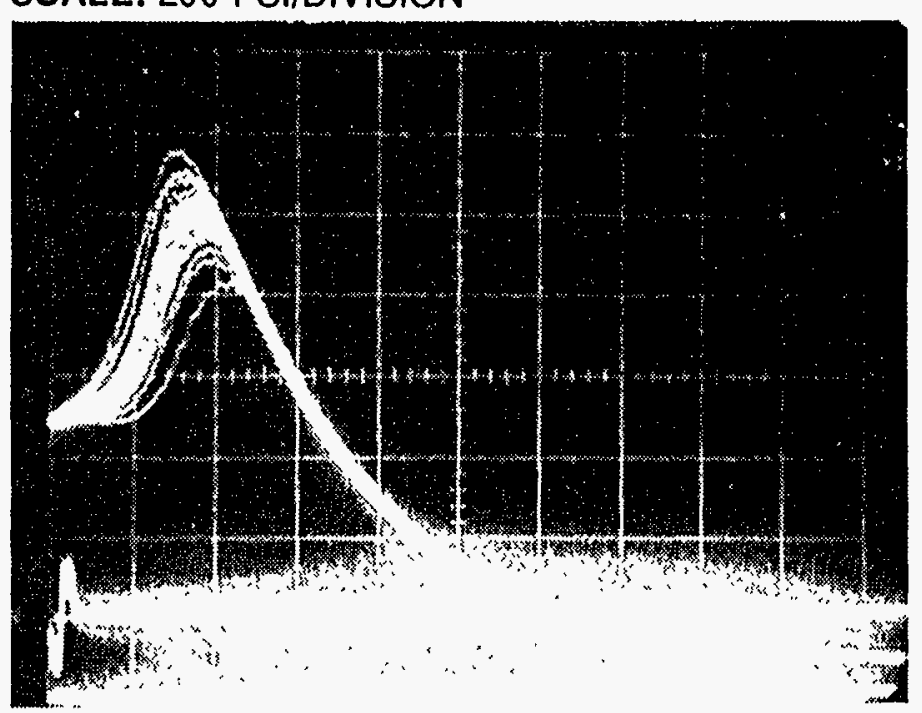

Figure 5.25 Spark Plug Selection Test 
Spark plug test on August of 1994

$\begin{array}{ll}\text { PLUG } & : \text { NGK JR9C } \\ \text { REACH } & : 0.75 \mathrm{in} . \\ \text { THREAD } & : 12 \mathrm{~mm} \\ \text { TYPE } & : \text { Dual ground electrodes } \\ \text { PLUG GAP } & : 0.013 \mathrm{in} .\end{array}$

825 RPM Idle approximately $6 \%$ O2 mixture:

SCALE: 50 PSI/DIVISION

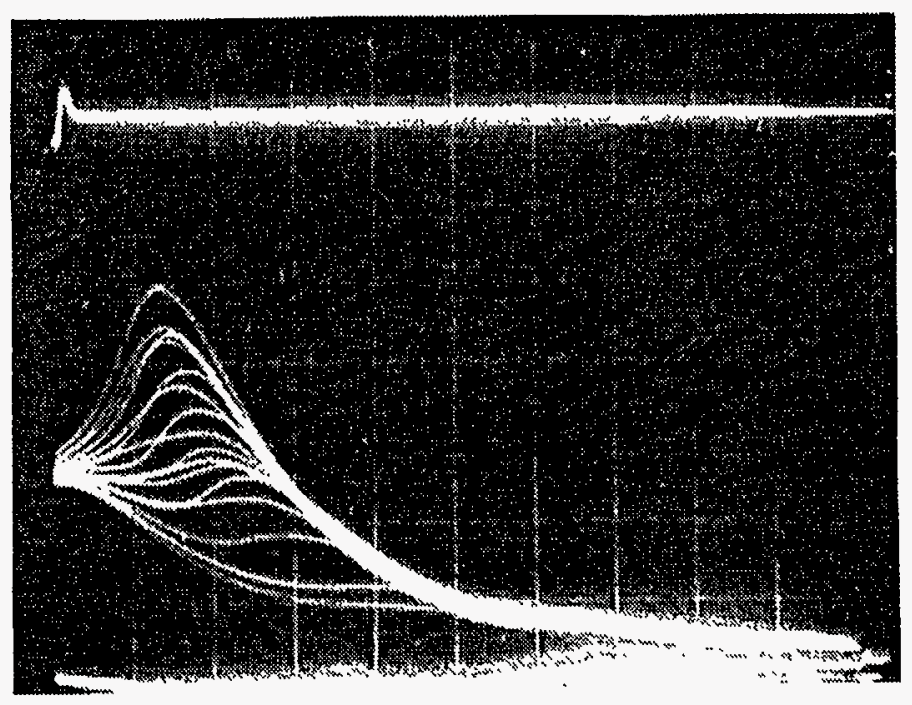

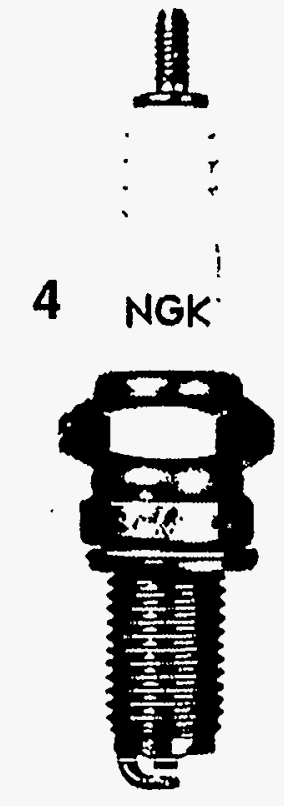

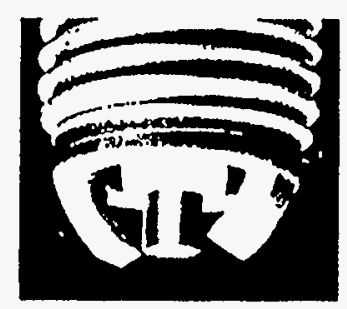

e

1600 RPM full-load with stoichiometric mixture: SCALE: 200 PSI/DIVISION

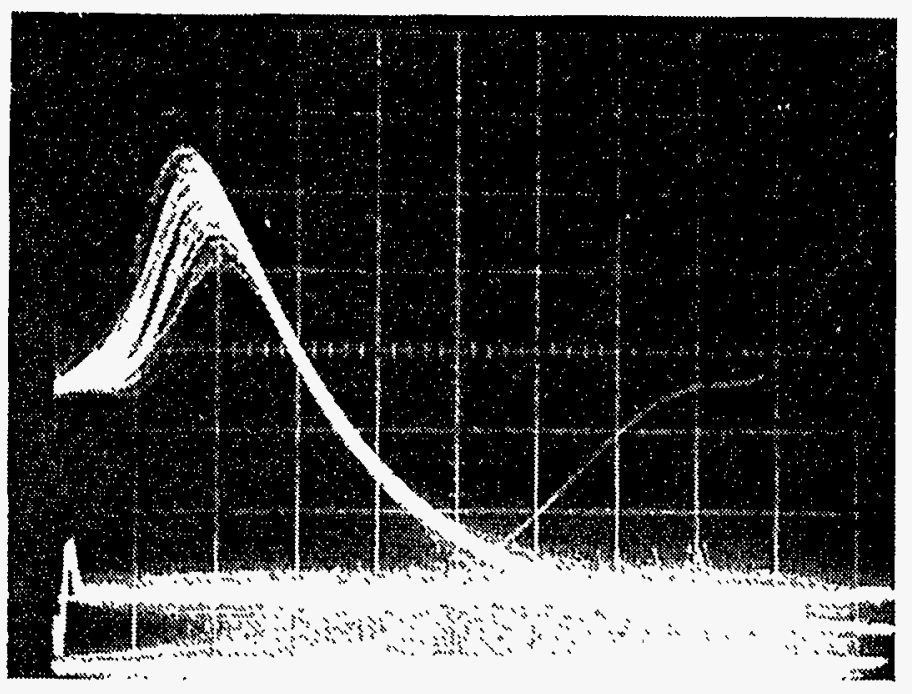

Figure 5.26 Spark Plug Selection Test 


\subsubsection{Low Load and Idle Operation}

One of the major concerns for the converted natural gas engine was the high oil blow-by during low load and idle conditions. This is caused by the low cylinder pressure during the intake process when the throttle is nearly closed, which results in oil being drawn past the piston rings into the cylinder. The piston rings in diesel engines are generally not designed to handle this level of adverse pressure gradient conditions. The MCEC employed in this engine reduces the level of intake manifold vacuum at low load conditions because of the early intake valve closing. However, the intake pressure is still not high enough to prevent the high oil blow-by. Tests showed that, when the intake manifold vacuum on the converted Navistar 466 engine exceeded about $14^{n} \mathrm{Hg}$, oil blow-by became high enough that visible white smoke appeared in the exhaust.

To avoid oil blow-by, the strategy was to operate the engine in lean-burn mode when the throttle was nearly closed. To accomplish this, the controller was programmed to switch from closedto open-loop fueling when the TPS (throttle position sensor) was reduced to below $1 \%$ and to resume closed-looped fueling when TPS was increased to above $3 \%$. The fuel-air mixture was set at an equivalence ratio of approximately $\phi=0.72$, which was sufficiently lean to limit the intake manifold vacuum to within 14" $\mathrm{Hg}$ at idle condition. This strategy would not have been possible without a spark plug that could consistently ignite a lean mixture at low load and idle conditions. Therefore, the spark plug study reported above was an integral part of this effort to eliminate oil blow-by.

\subsubsection{Spark Timing Calibration}

The optimum spark timing was determined by varying the spark timing while keeping the intake manifold pressure constant. This is a somewhat time-consuming procedure because the spark timing affects the turbocharger performance and consequently, the boost pressure and intake manifold pressure. Therefore, the throttle must be adjusted for each spark timing setting. At near WOT conditions, the criteria was different, since the throttle position is no longer effective in setting the intake manifold pressure. Also, at these conditions, the spark timing has a very strong effect on the engine output due to its effect on the turbocharger performance. Generally, retarding the spark timing results in higher turbocharger boost and therefore, higher engine output. In this case, we selected the spark timing to have the peak firing pressure occurring at about $15^{\circ}$ ATDC. Further retardation of spark timing would result in a loss in fuel economy. Figure 5.27 is the optimum spark timing calibration. The sharp increase in spark advance at low speed and low output conditions was due to the lean-burn conditions chosen for these conditions, which will be discussed below.

\subsubsection{Turbocharger Test}

Testing of the new turbocharger showed that the performance of the turbine was deficient at low speed, which resulted in lower boost pressure and lower maximum torque at WOT conditions. Figures 5.28 and 5.29 show the engine performance with the T300 turbocharger with and without the integral wastegate. 
TF74-196

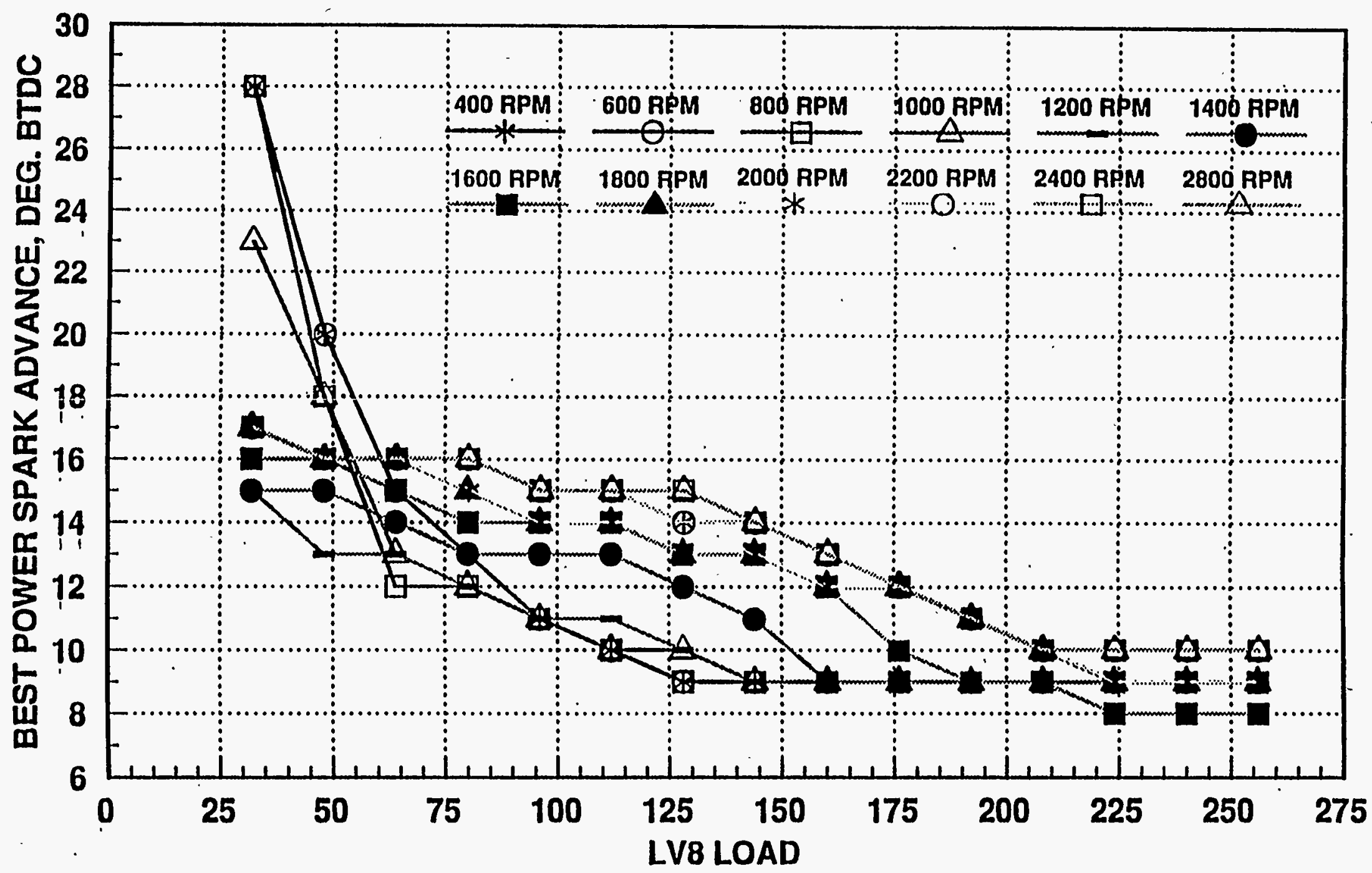

Figure 5.27 Spark Timing Calibration 
Engine: Navistar DTA-466, In-line 6 cylinders Bore: 4.30 in

Stroke: 5.35 in

Displacement: 466 cu.in.

Expansion Ratio: 16.5:1

Fuel: Natural Gas

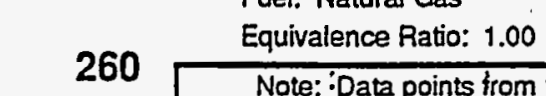

Camshat: Tecogen 160 deg. Duration Intake

TF75-196 Turbocharger: Garrett

Turbine: T300 79 Trim 0.96 AVR VTF

Compressor: T300 44 Trim BCCW8D 0.50 AR

Dyno Run \#: 87, 88, 89, 90, 91, 92, 93

Note: Engine test data with high fan and water pump

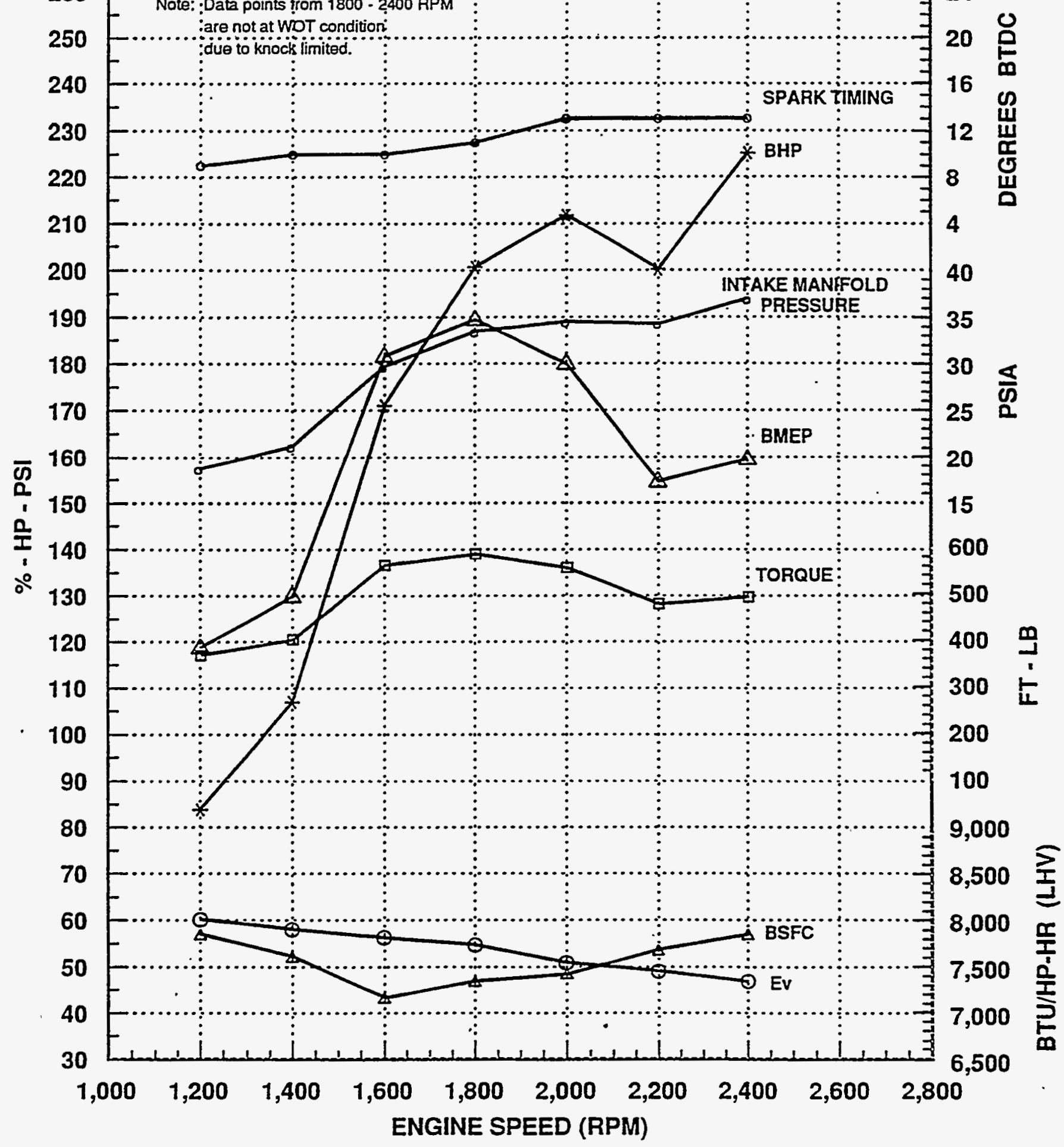

Figure 5.28 Engine Performance - Garrett T300 Turbocharger Without Wastegate 
Engine: Navistar DTA-466, In-line 6 cylinders Bore: 4.30 in

Stroke: 5.35 in

Displacement: 466 cu.in.

Expansion Ratio: 16.5:1

Fuel: Natural Gas

260 Equivalence Ratio: 1.00

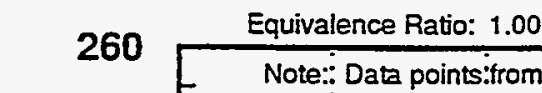

250

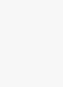

230

220



:

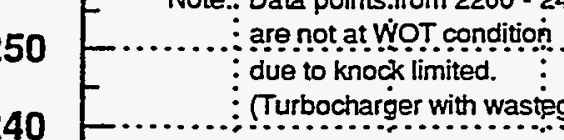

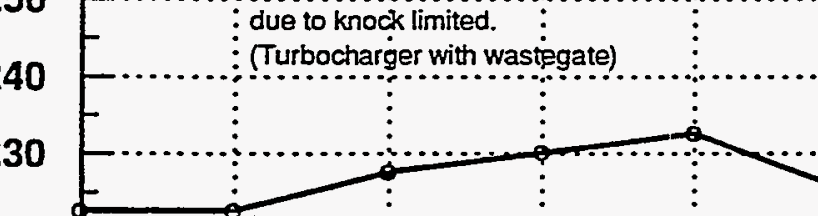

200

190

180

170

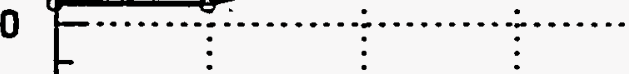

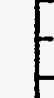

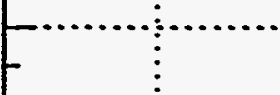

$E$

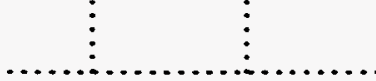

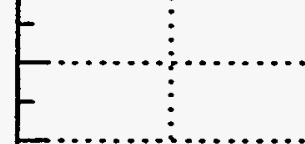

150

140

130

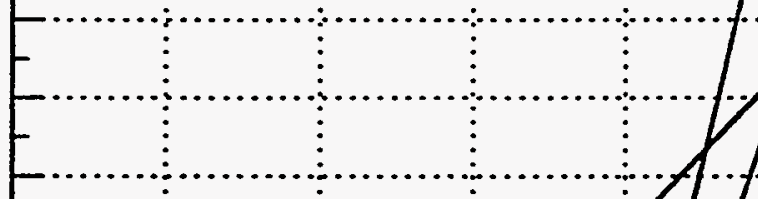

120

110

100

90

80

70

60

$\vdots \begin{aligned} & \vdots \\ & \vdots\end{aligned}$

Turbocharger: Garrett

Turbine: T300 79 Trim 0.96 ARR VTF ( with wastegate)

Compressor: T300 44 Trim BCCW8D 0.50 AR

Dyno Run \#: $179.178,177,176,175,174,173.172$

Note: Engine test data with high fan

and water pump

15

600

500

400

$\frac{m}{1}$

200

100
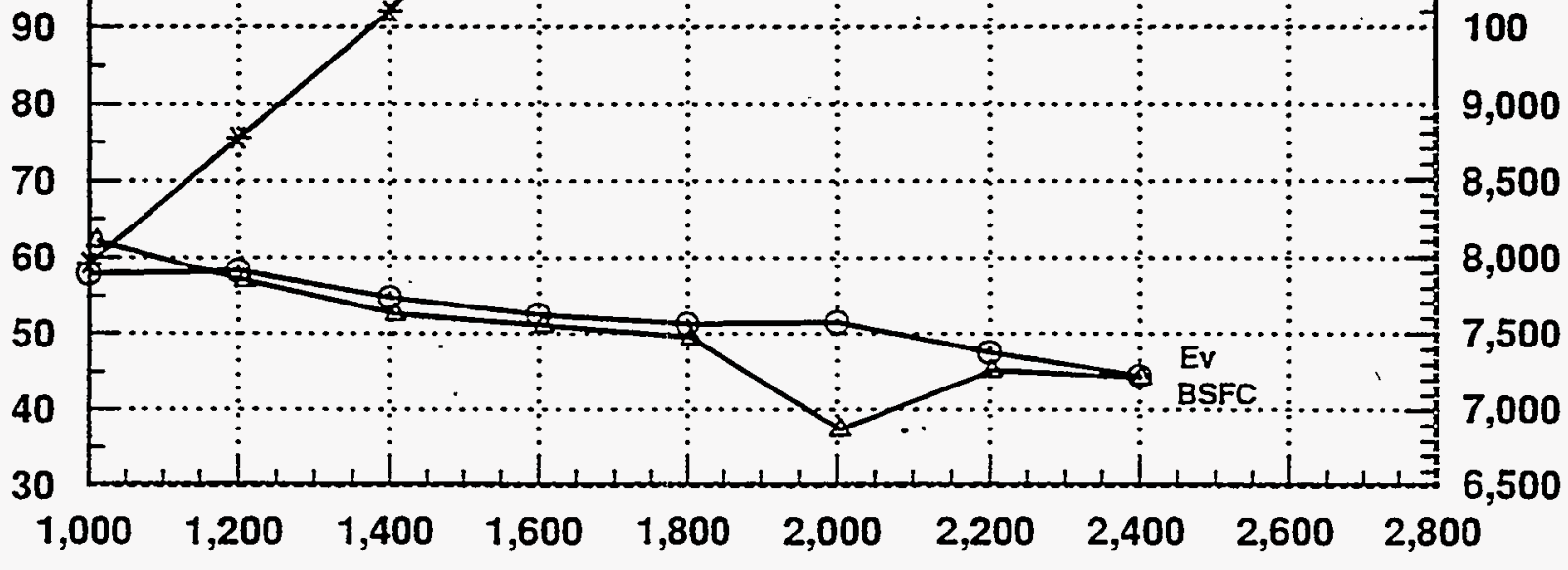

9,000

ENGINE SPEED. (RPM)

Figure 5.29 Engine Performance - Garrett T300 Turbocharger With Integral Wastegate 
To examine the turbine characteristics, the corrected turbine mass flow is plotted vs. the turbine pressure ratio for the 2 cases in Figure 5.30. This comparison definitely showed a difference between the 2 turbines. Garrett examined the turbines and determined that there are no geometrical differences due to manufacturing tolerance. It was concluded that the addition of the wastegate could have affected the aerodynamics of the turbine. The turbine was modified for a different trim to improve the boost in the low speed region.

\subsubsection{Engine Performance}

With the optimized spark timing calibrated, the engine was operated over the entire speed and torque range to establish its performance in output and fuel consumption. Figures 5.31, 5.32, and 5.33 are plots of hp, torque, and BSFC for variable speed and intake manifold pressures. Figure 5.34 is a plot of BSFC vs. hp. It is seen that the fuel efficiency at full load is very good due to the MCEC with an expansion ratio of 16.5 to 1 . However, the BSFC increases very fast at part load conditions, particularly when the engine speed is high. This loss of efficiency at part load is the result of the increased pumping loss due to throttling and the increased proportion of the power required to overcome the component friction. Therefore, we can safely conclude that, unless the part load efficiency of a dedicated spark ignition gas engine is improved, it would be difficult for it to become a commercially-viable alternative to diesel engines based on economics alone in the medium- and heavy-duty bus and truck market.

\subsubsection{Emission Control Development}

The emissions control system for the engine consists of the closed-loop fuel-air ratio control based on a heated oxygen sensor at the discharge of the turbine and a 3-way catalytic converter supplied by Johnson Mathey. The oxygen sensor is a stock GM part. The engine controller adjusts the fuel-air ratio to match the voltage output from the oxygen sensor to a pre-set rich/lean threshold voltage. The rich/lean threshold can be adjusted to change the air-fuel ratio to achieve maximum conversion of $\mathrm{NO}_{X}, \mathrm{CO}$, and $\mathrm{HC}$ in the catalytic reactor.

The engine was operated at maximum torque, either at WOT or at knock-limited conditions, for various speeds. The emissions measured at the turbine outlet and at the converter outlet are plotted in Figures 5.35, 5.36, and 5.37. It is seen that the $\mathrm{NO}_{X}$ emission increased from a minimum of $1.4 \mathrm{gm} / \mathrm{hp}$-hr at low load to a maximum of $7.5 \mathrm{gm} / \mathrm{hp}-\mathrm{hr}$ at $2400 \mathrm{rpm}$. The CO emission from the engine increased sharply at high loads, but it dropped to a very low value after the converter. The HC emission after the converter also increased with load. This result suggested that, as the load was increased, there were increased amount of free oxygen present in the exhaust gas, which effectively converted the $\mathrm{CO}$, but caused the conversion of $\mathrm{NO}_{X}$ to $\mathrm{N}_{2}$ to be ineffective.

The observation suggested that the fuel-air ratio distribution became poor at high load. This is conceivable in view of the long duration of the fuel injection relative to the time period that the intake valve is open. The theory was that, even though the fuel was directed into the intake passage towards 
Engine: Navistar DTA-466. In-line 6 cylinders Bore: 4.30 in

Stroke: 5.35 in

Displacement: 466 cu.in.

Expansion Ratio: 16.5:1

Fuel: Natural Gas

Equivalence Ratio: 1.00
Camshaft: Tecogen 160 deg. Duration intake

Turbocharger: Garrent

Turbine: T300 79 Trim $0.96 \mathrm{~A} / \mathrm{R}$ VTF

Compressor: T300 44 Trim BCCW8D 0.50 AR

Dyno Run \#: $87,88,89,90,91,92,93$

Dyno Run \#. 179, 178, 177, 176, 175, 174, 173, 172

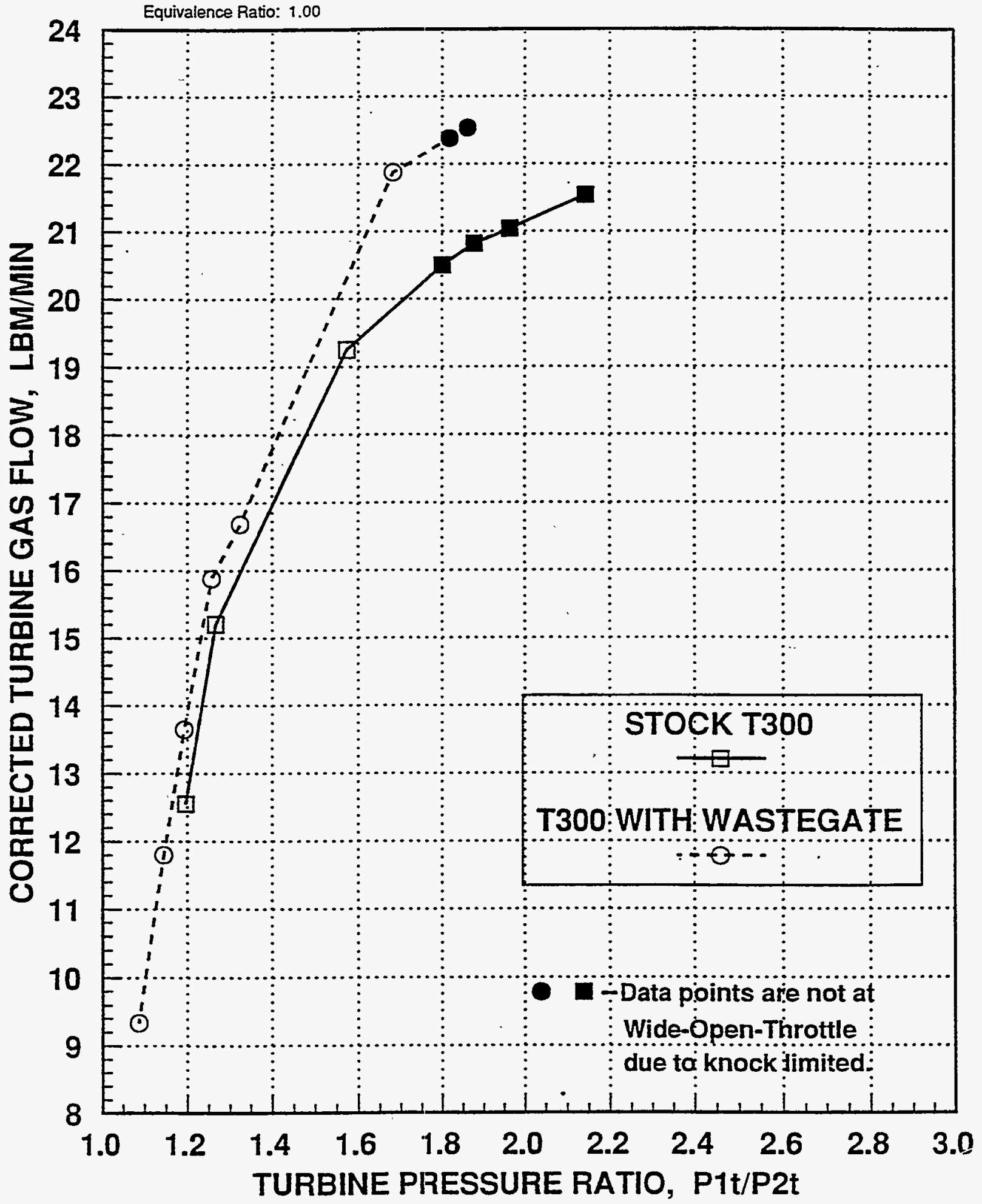

Figure 5.30 T300 Turbocharger Performance, With and Without Integral Wastegate 


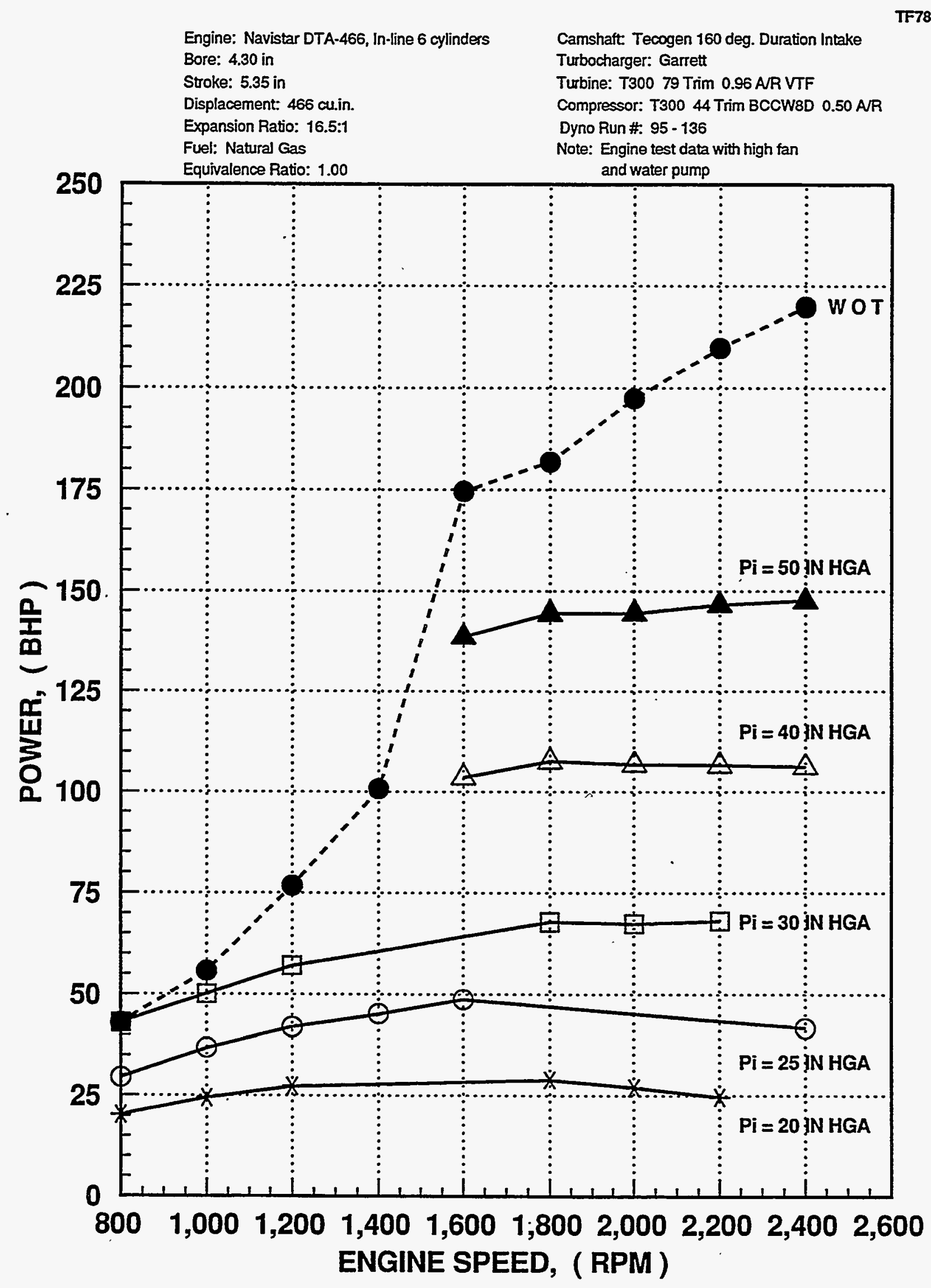

Figure 5.31 Engine Performance - Power vs. Speed 
Engine: Navistar DTA-466, In-line 6 cylinders Bore: 4.30 in

Stroke: 5.35 in

Displacement: 466 cu.in.

Expansion Ratio: 16.5:1

Fuel: Natural Gas

$600 \quad$ Equivalence Ratio: 1.00
Camshaft: Tecogen 160 deg. Duration Intake Turbocharger: Garrett

Turbine: T300 79 Trim 0.96 AR VTF

Compressor: T300 44 Trim BCCW8D 0.50 AVR

Dyno Run \#. 95 - 136

Note: Engine test data with high fan and water pump

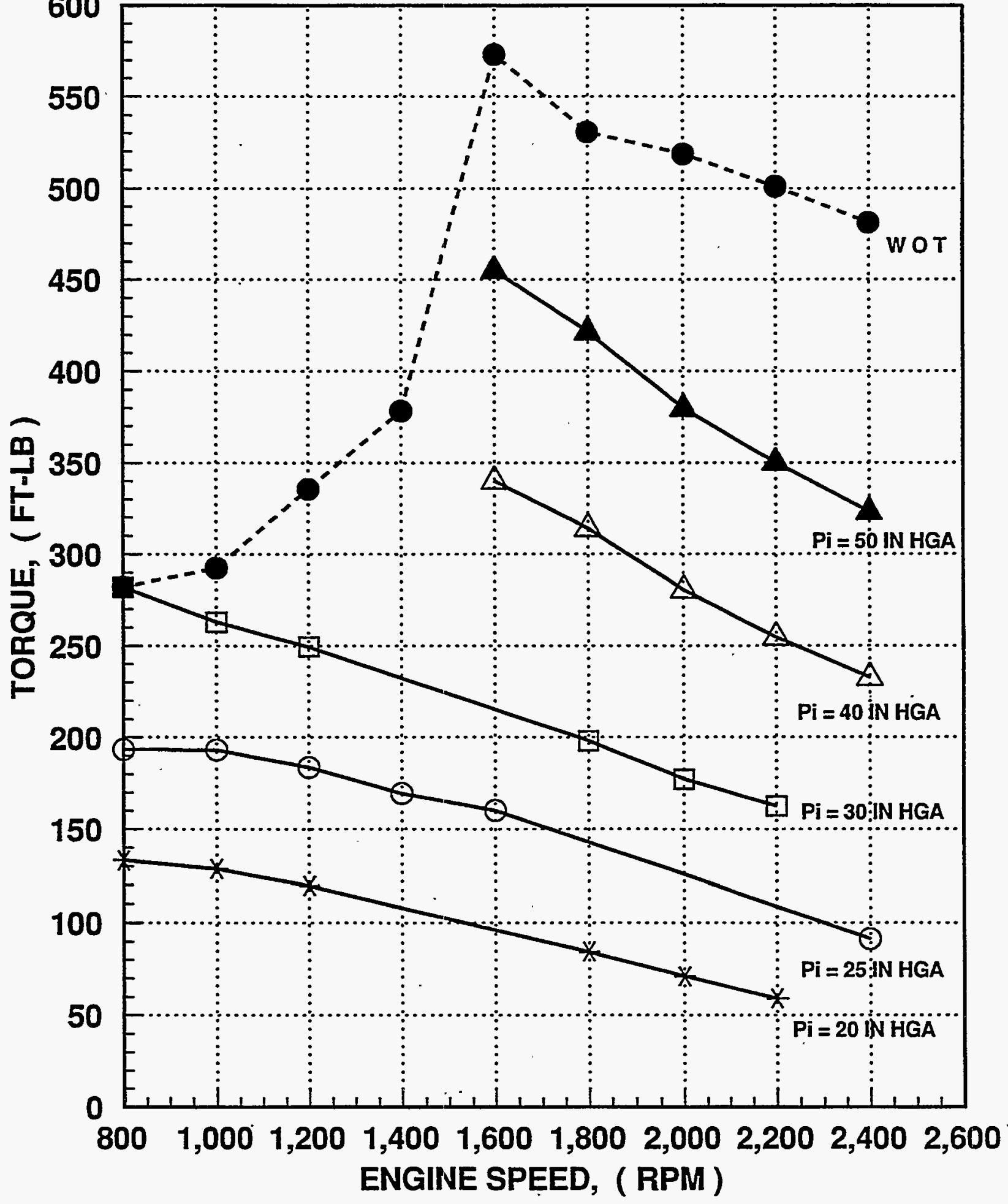

Figure 5.32 Engine Performance - Torque vs. Speed 
Engine: Navistar DTA-466, In-line 6 cylinders Bore: 4.30 in

Stroke: 5.35 in

Displacement: 466 cu.in.

Expansion Ratio: 16.5:1

Fuel: Natural Gas

Equivalence Ratio: 1.00
Camshaft: Tecogen 160 deg. Duration Intake

Turbocharger: Garrett

Turbine: T300 79 Trim 0.96 A/R VTF

Compressor: T300 44 Trim BCCW8D 0.50 AR

Dyno Run \#. 95 - 136

Note: Engine test data with high fan and water pump

Figure 5.33 Engine Performance - BSFC vs. Speed 


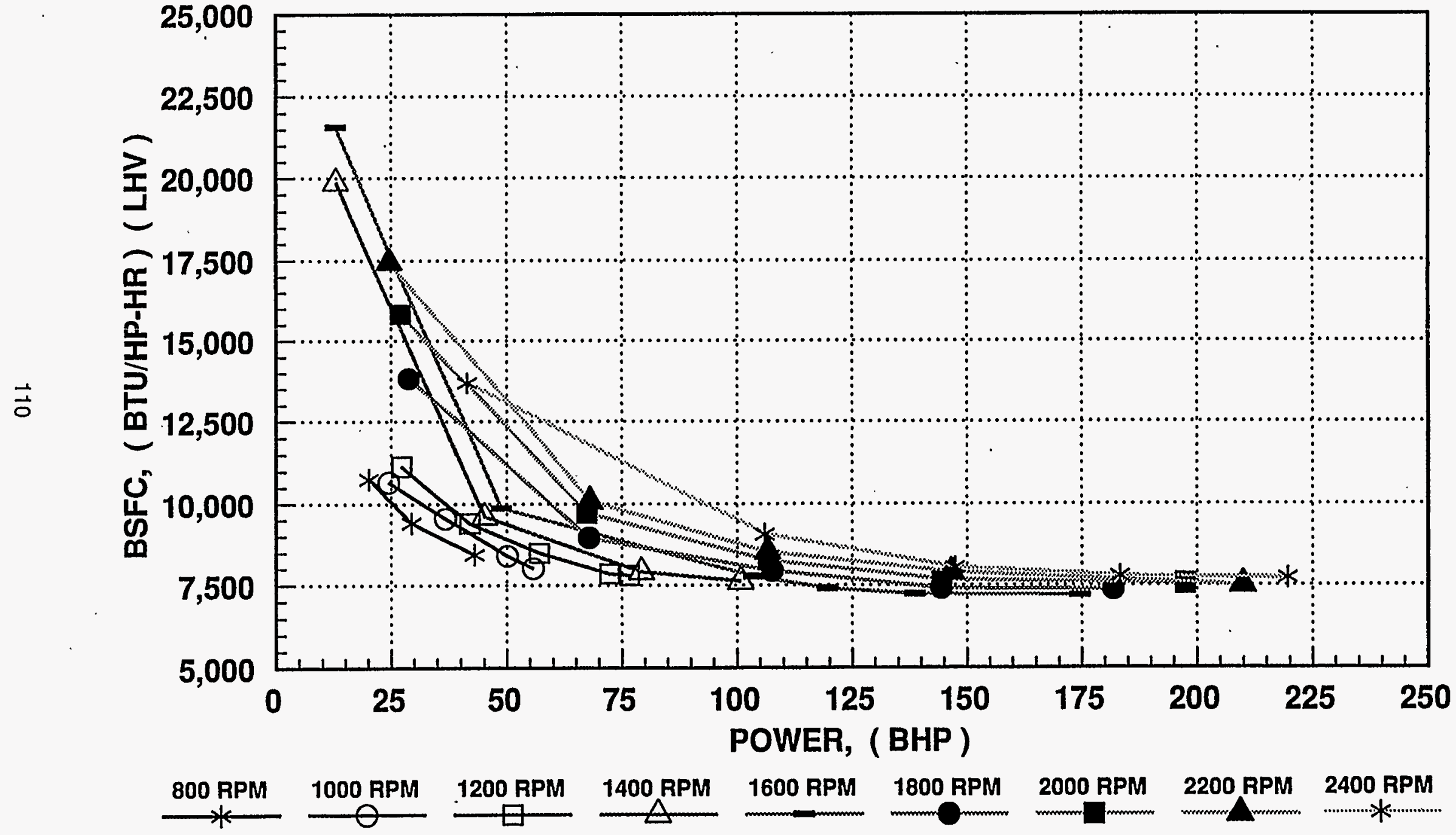

Figure 5.34 Engine Performance - BSFC vs. HP 
Engine: Navistar DTA-466. In-line 6 cylinders Bore: 4.30 in

Stroke: 5.35 in

Displacoment: 466 cusin.

Expansion Ratio: 16.5:1

Fuel: Natural Gas

Equivalence Ratio: Stoichiometric
Camshaft: Tecogen 160 deg. Duration Intake Turbocharger: Turtonetics

Turbine: O.Trim 0.69 AR On-Center

Compressor: TO4B S.3

Dyno Run \#: 137, 138. 139, 140, 141, 142, 143, 144

Note: Engine test data with high fan

and water pump

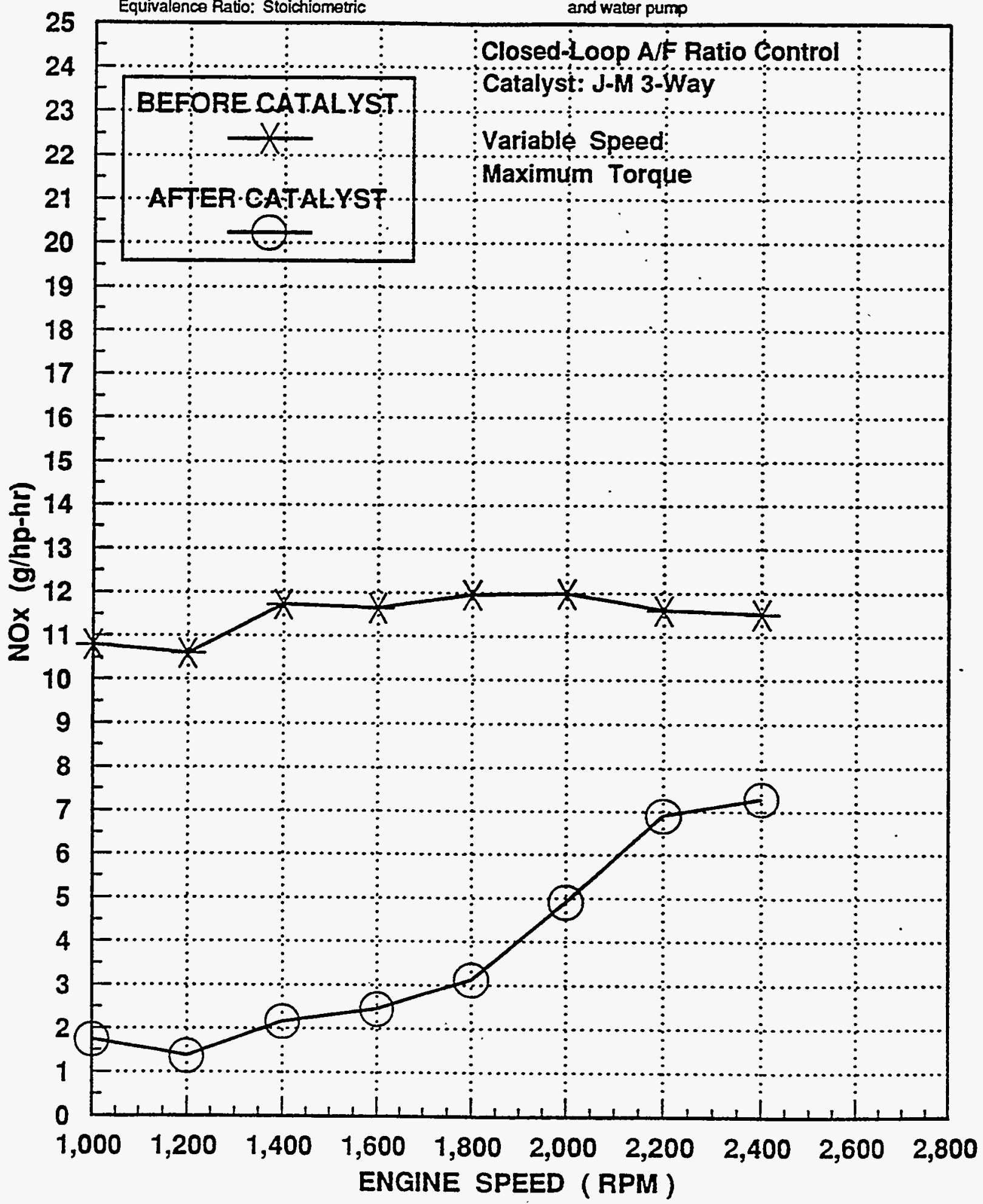

Figure 5.35 Engine Emission Test Data 
Engine: Navistar DTA-466. In-line 6 cylinders Bore: 4.30 in

Stroke: 5.35 in

Displacement: 466 cu.in.

Expansion Ratio: 16.5:1

Fuol: Natural Gas

Equivalenco Ratio: Stoichiometric
Camshaft: Tecogen 160 deg. Duration Intake

Turbocharger: Turbonetics

Turbine: O-Trim 0.69 AVR On-Center

Compressor: TO4B S.3

Dyno Run \#: 137, 138, 139, 140, 141, 142. 143, 144

Note: Engine test data with high fan and water pump

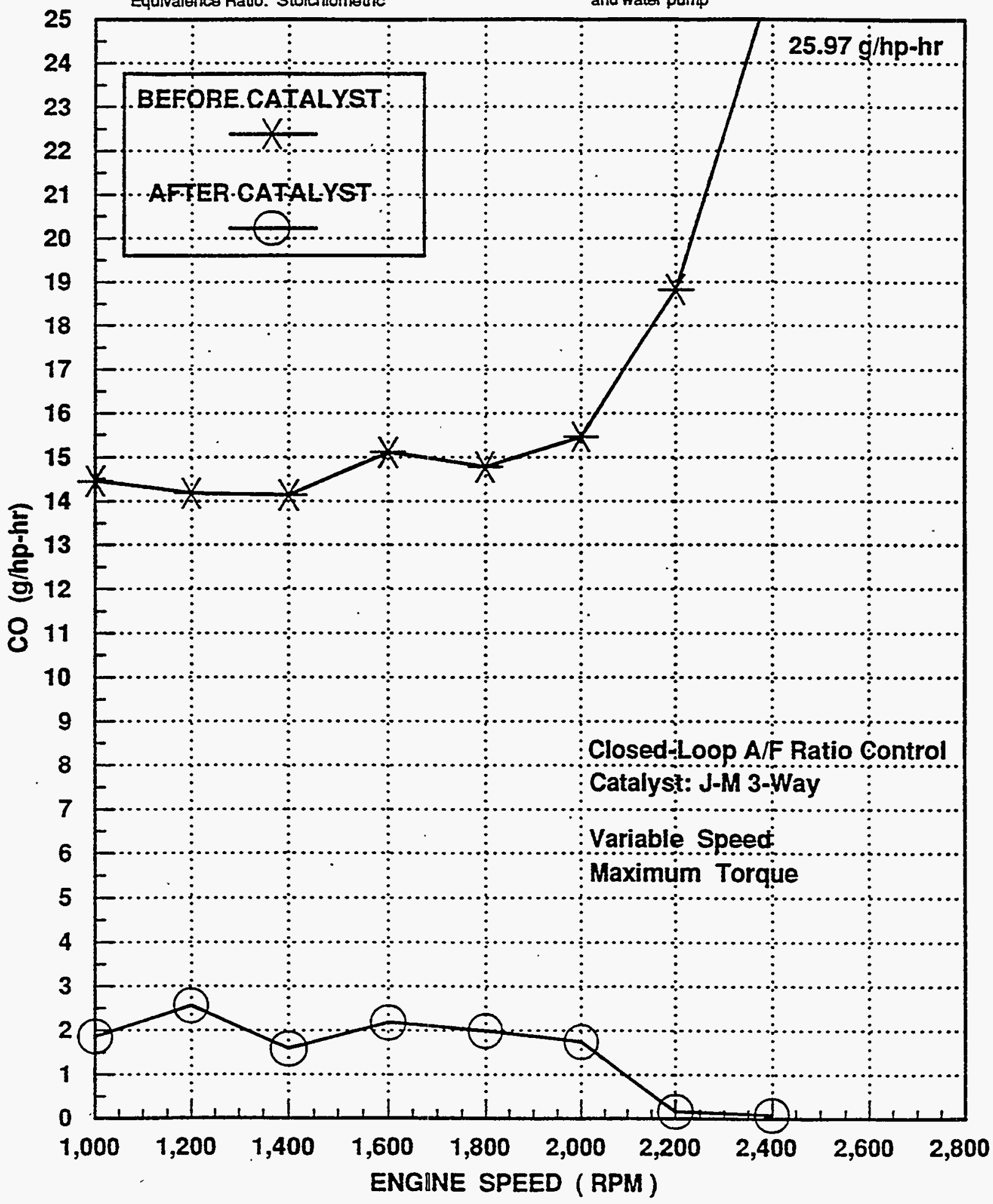

Figure 5.36 Engine Emission Test Data 
Engine: Navistar DTA-466. In-line 6 cylinders Bore: 4.30 in

Stroke: 5.35 in

Displacoment: 466 cu.in.

Expansion Ratio: 16.5:1

Fual: Natural Gas

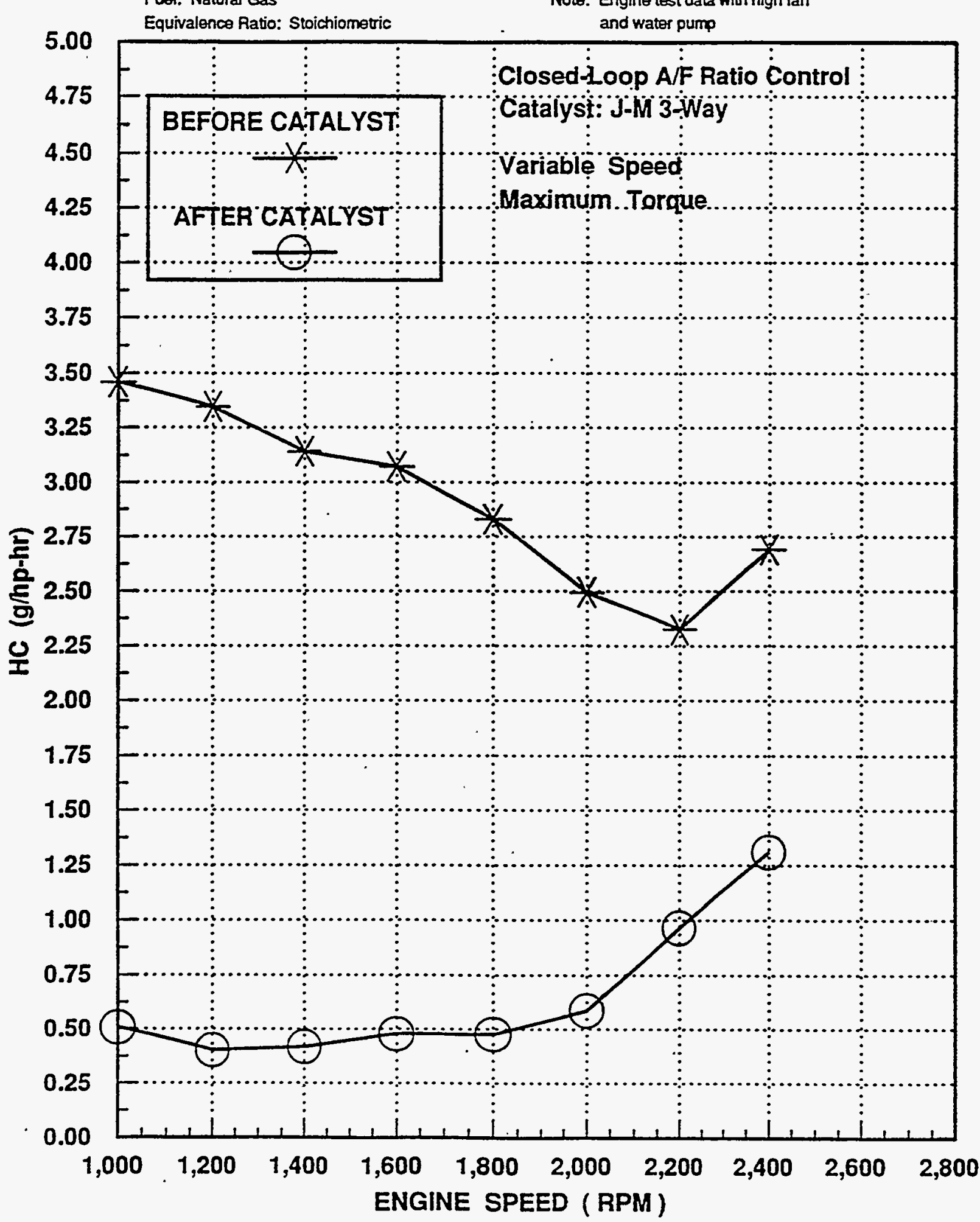

Camshaft: Tecogen 160 deg. Duration Intake

Turbocharger: Turbanetics

Compressor: TO4B 5.3

Dyno Run \#: 137. 138. 139.140, 141, 142.143.144

Note: Engine test data with high fan

and water pump
Turbine: O-Trim 0.69 AR On-Center 
the intake valve, a portion of the fuel, injected during the time when the valve was closed, leaked into the open intake manifold. The gas leaked into the manifold from each injector at different times, was redistributed unevenly among the various cylinders. The theory was further reinforced when the $\mathrm{NO}_{X}$ was plotted in Figure 5.38 as a function of the relative injection period, which is the ratio of the injection period to the cycle period. The cycle period is proportional to the inlet valve open period. Additional test data was obtained at a constant speed of $2400 \mathrm{rpm}$, but variable torque is also included in the plot. It is seen that the $\mathrm{NO}_{\mathrm{X}}$ emission increases linearly with the relative injection period. At relative injection periods below 0.22 , which is the relative period of the inlet valve open time, the $\mathrm{NO}_{X}$ emission reaches a constant minimum value of approximately $1.5 \mathrm{gm} / \mathrm{bhp}-\mathrm{hr}$.

Based on this result, we anticipated that the $\mathrm{NO}_{x}$ emission would be reduced if the overall fuel-air ratio were increased. In this case, the leanest cylinder would not produce a sufficient amount of free oxygen to cause the conversion of $\mathrm{NO}_{X}$ ineffective. However, the rich cylinder may produce excessive amounts of $\mathrm{CO}$. A test was run with increasing set voltage of the rich/lean threshold. Higher voltage shifted the overall fuel-air ratio to the rich side. Figure 5.39 is a plot of the A/F ratio vs. the rich/lean threshold voltage for the full load and $2400 \mathrm{rpm}$ condition. Figures $5.40,5.41$, and 5.42 are the corresponding emissions results. It is seen that the $\mathrm{NO}_{X}$ decreased and $\mathrm{CO}$ increased with a decreasing air-fuel ratio, as we had anticipated. Although this approach provided acceptable emissions results, we feel that it is necessary that the mixture distribution be improved in order to achieve the maximum potential in reducing the emissions.

Based on the above test results, it was decided that it was necessary to improve the mixture distribution in order to be able to minimize the emissions on $\mathrm{NO}_{X}, \mathrm{CO}$, and THC. The first step was to instrument the engine with an exhaust gas sampling probe in the exhaust passage of each cylinder so that the variation in air-fuel ratio can be quantified. The gas samples were analyzed with a Horiba air-fuel ratio analyzer. Emissions measurement for each individual cylinder was not feasible due to the fact that the sample would not represent the average composition of the exhaust gas. Figure 5.43 shows a plot of the air-fuel ratio for the 6 cylinders, when the engine was operated at $2400 \mathrm{rpm}$ and maximum torque condition. It is seen that the air-fuel ratio varied from 14.6 to 17.9 , or 1.13 to 0.92 in equivalence ratio. This wide mixture variation confirms the hypothesis for the poor emissions results.

The theory for the poor mixture distribution is that, at high speed and high torque conditions, a portion of the fuel injected during the period when the intake valve is closed could have been diverted into the intake manifold and redistributed into the other cylinders. Based on this, the intake manifold was modified to incorporate partitions, so that the diverted fuel would be contained within the passage for the intended cylinder. Figure 5.44 shows the partition design for the manifold.

Air-fuel ratio measurement for individual cylinders with the partitioned intake manifold is shown in Figure 5.45. A significant improvement in the mixture distribution was obtained with a variation in air-fuel ratio from 16.27 to 16.82 , or in equivalence ratio from 1.015 to 0.982 . Figures $5.46,5.47$, and 5.48 show the emissions data at variable speed and maximum torque conditions. The rich/lean 


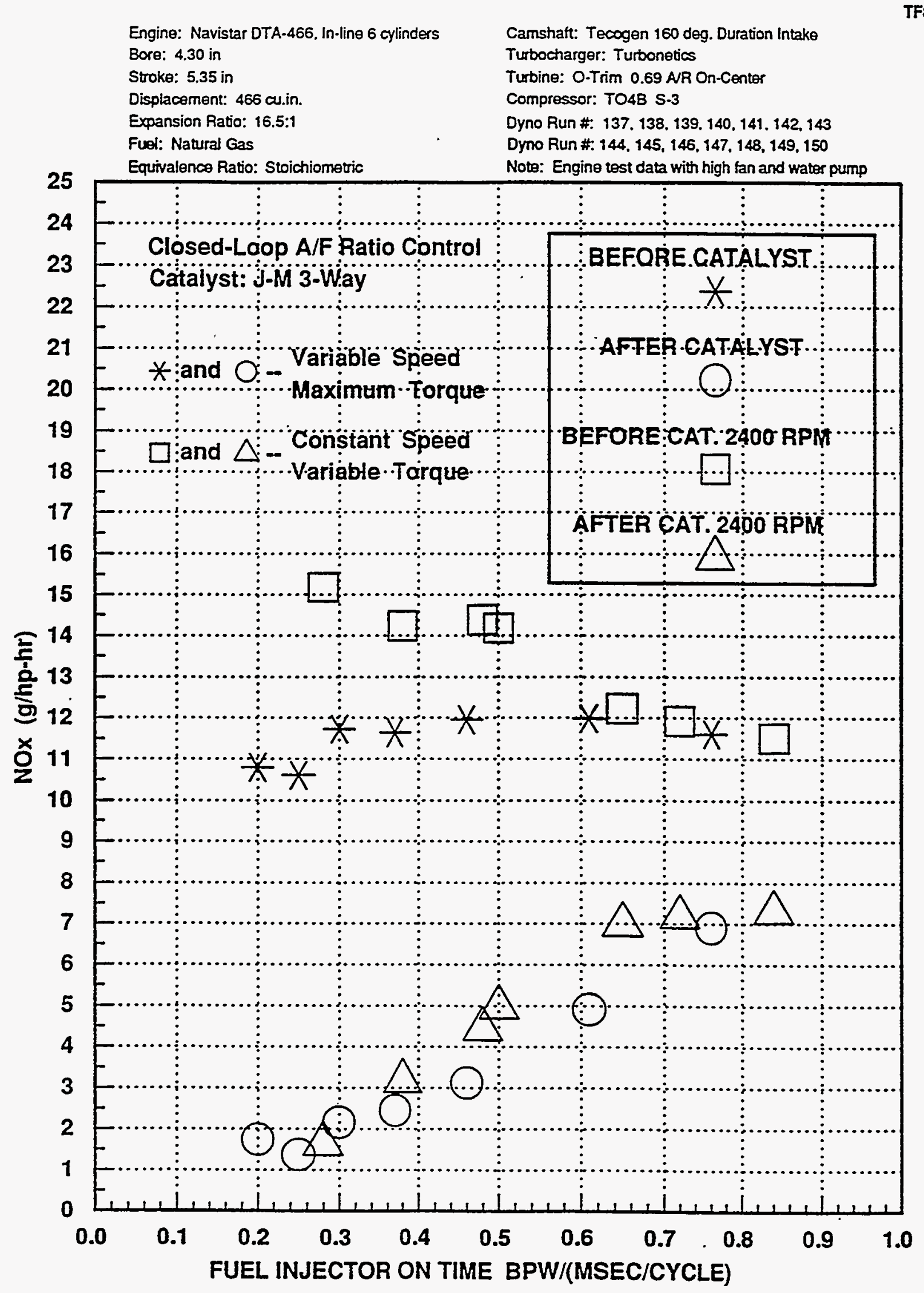

Figure 5.38 Engine Emissions vs. Relative Injection Period 
Engine: Navistar DTA-466. In-line 6 cylinders

Bore: 4.30 in

Stroke: 5.35 in

Displacement: 466 cu.in.

Expansion Ratio: 16.5:1

Fuel: Natural Gas

Equivalence Ratio: Stoichiometric
Camshaft: Tecogen 160 deg. Duration Intake

Turbocharger: Turbonetics

Turbine: O-Trim 0.69 AR On-Center

Compressor: TO4B S-3

Dyno Run \#: 151, 152, 153, 154, 155. 156, 157. 158

Note: Engine test data with high fan and water pump

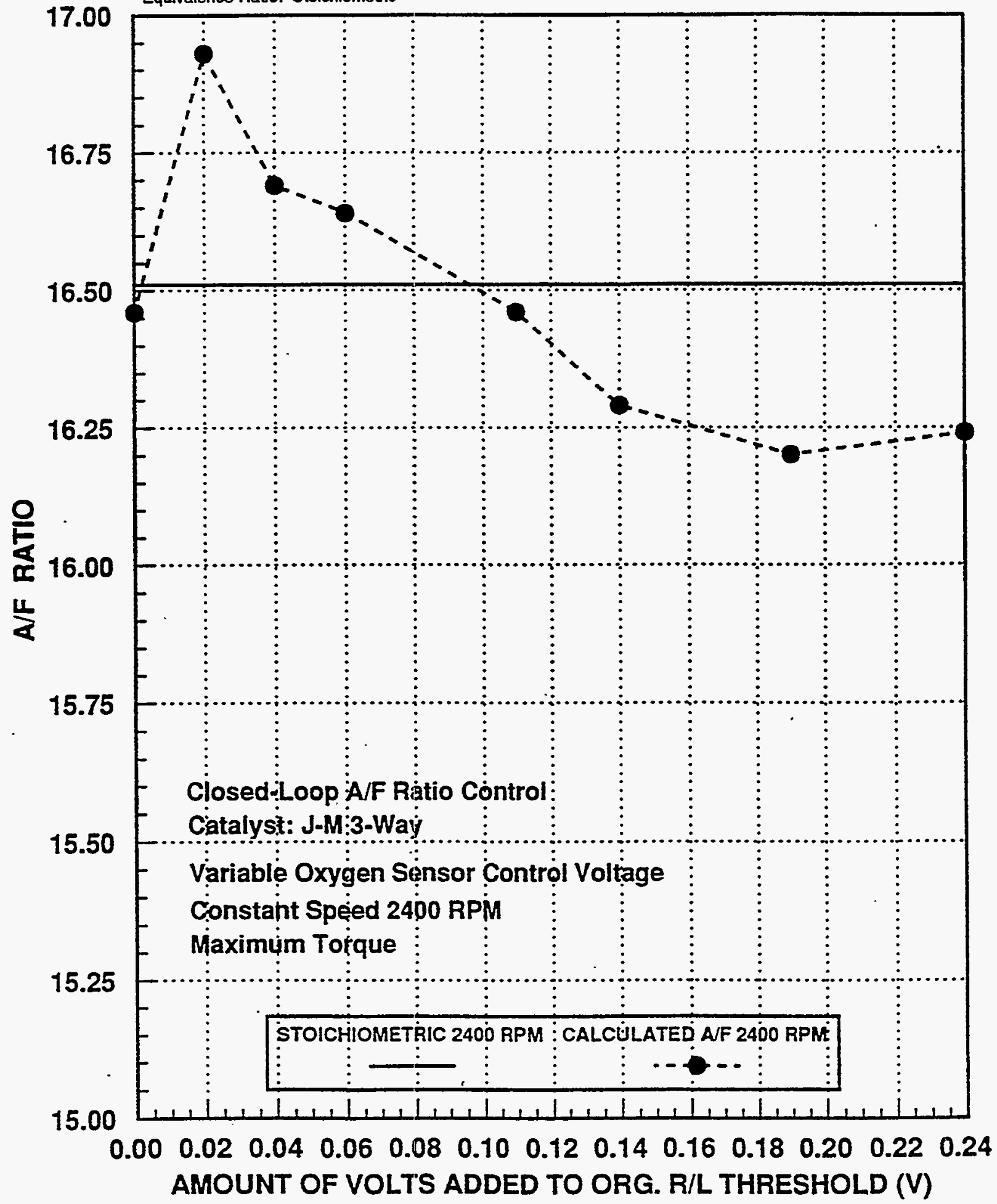

Figure 5.39 A/F Ratio vs. Threshold Voltage 
Engine: Navistar DTA-466, In-line 6 cylinders

Bore: 4.30 in

Stroke: 5.35 in

Displacement: 466 cu.in.

Expansion Ratio: 16.5:1

Fuel: Natural Gas

Equivalenco Ratio: Stoichiometric
Camshaft: Tecogen 160 deg. Duration Intake

Turbocharger: Turbonetics

Turbine: O-Trim 0.69 AR On-Center

Compressor: TO4B S-3

Dyno Run \#: 151, 152, 153, 154. 155, 156, 157. 158

Note: Engine test data with high tan and water pump

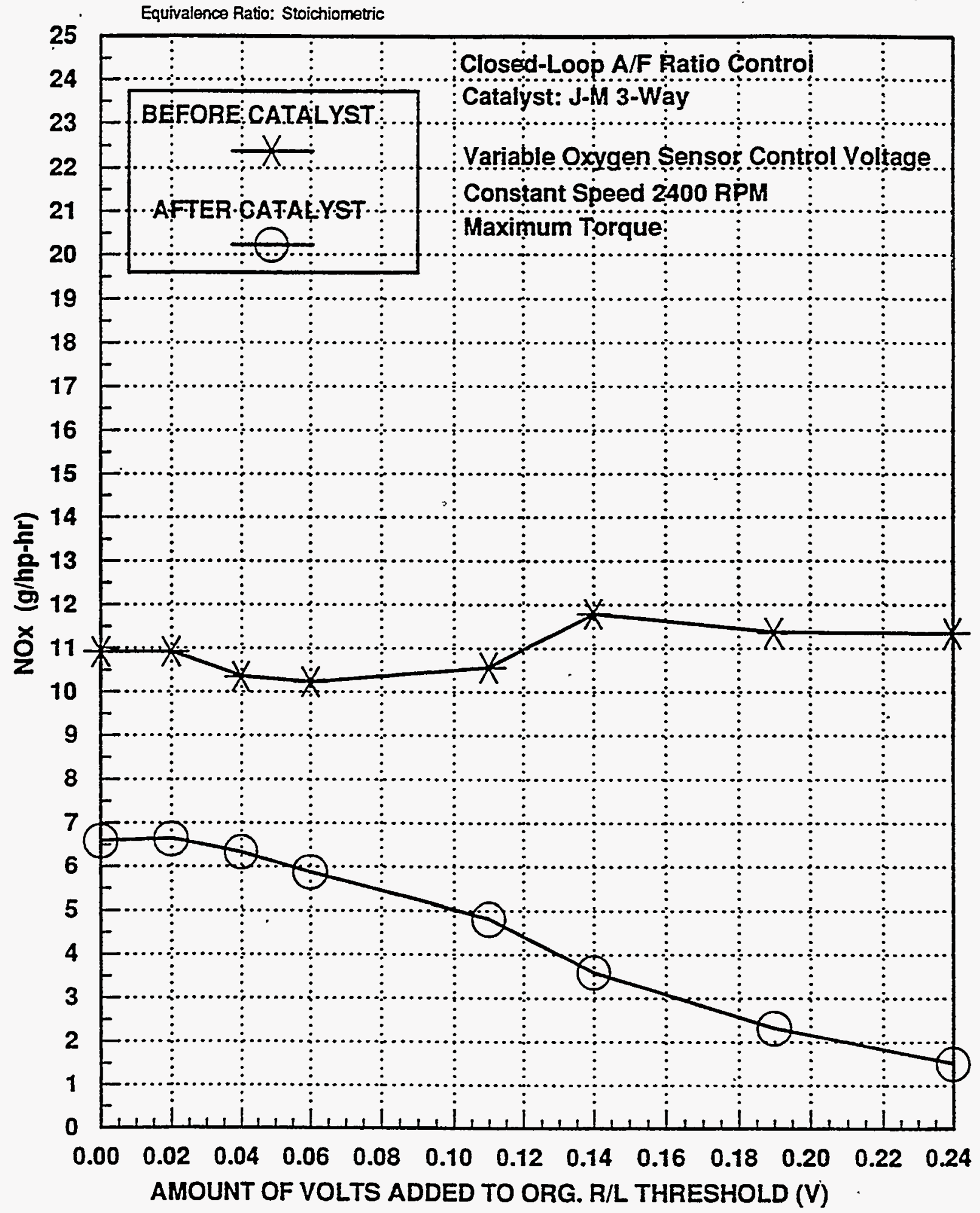

Figure 5.40 Engine Emission vs. Threshold Voltage 
Engine: Navistar DTA.466. In-line 6 cylinders

Bore: 4.30 in

Stroke: 5.35 in

Displacement: 466 cu.in

Expansion Ratio: 16.5:1

Fuol: Natural Gas

Equivalence Ratio: Stoichiometric
Camshaft: Tecogen 160 deg. Duration Intake

Turbocharger: Turbonetics

Turbine: O-Trim 0.69 AR On-Center

Compressor: TO4B S.3

Dyno Run \#: $151,152,153,154,155,156,157,158$

Note: Engine test data with high fan and water pump

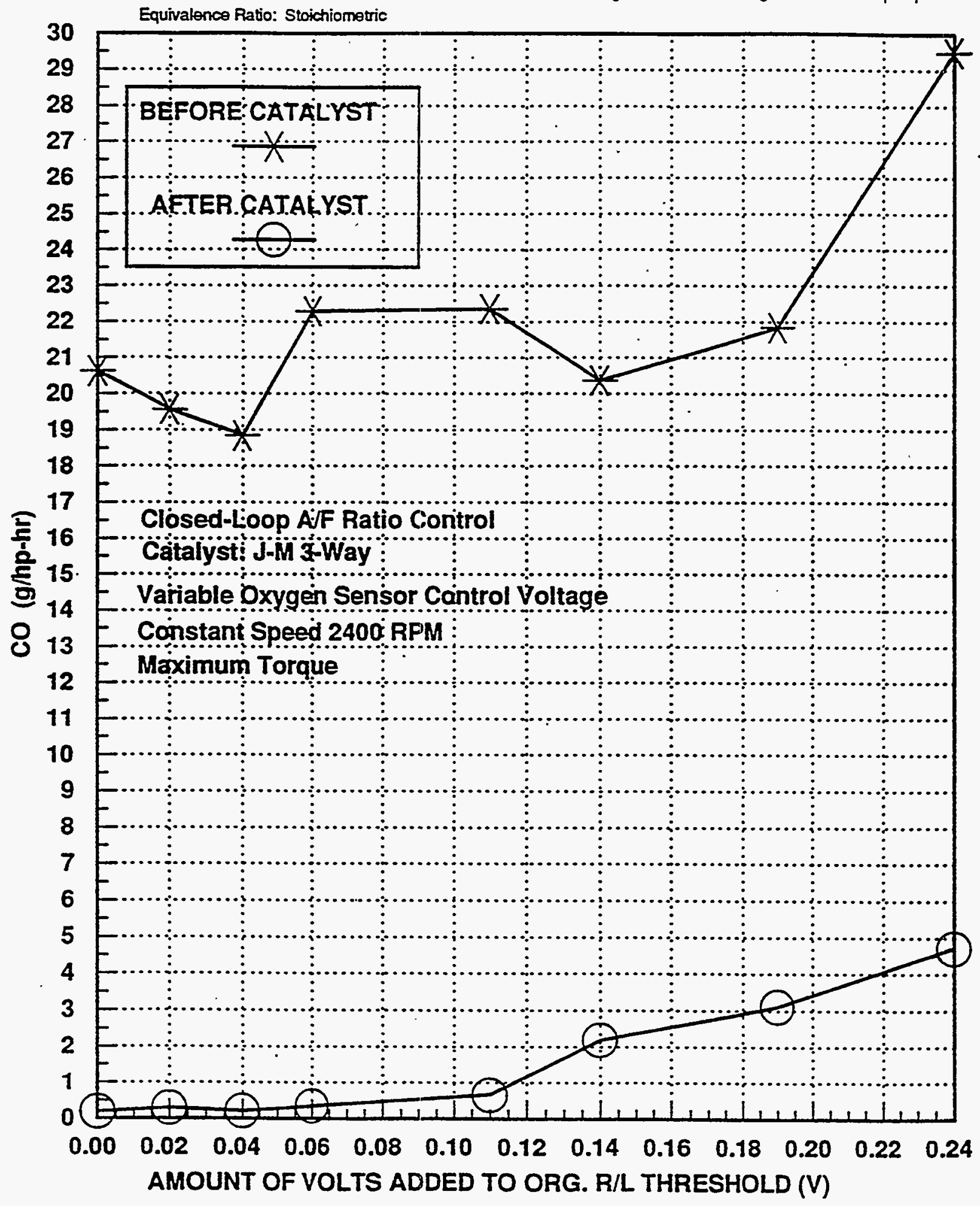

Figure 5.41 Engine Emission vs. Threshold Voltage 
Engine: Navistar DTA-466. In-line 6 cylinders Bore: 4.30 in

Stroke: 5.35 in

Displacement: 466 cu.in.

Expansion Ratio: 16.5:1

Fuel: Natural Gas

Equivalence Ratio: Stoichiometric
Camshatt: Tecogen 160 deg. Duration intake

Turbocharger: Turbonetios

Turbine: O-Trim 0.69 AR On-Center

Compressor: TO4B S.3

Dyno Run \#: 151, 152.153, 154.155, 156. 157. 158

Note: Engine test data with high fan and water pump

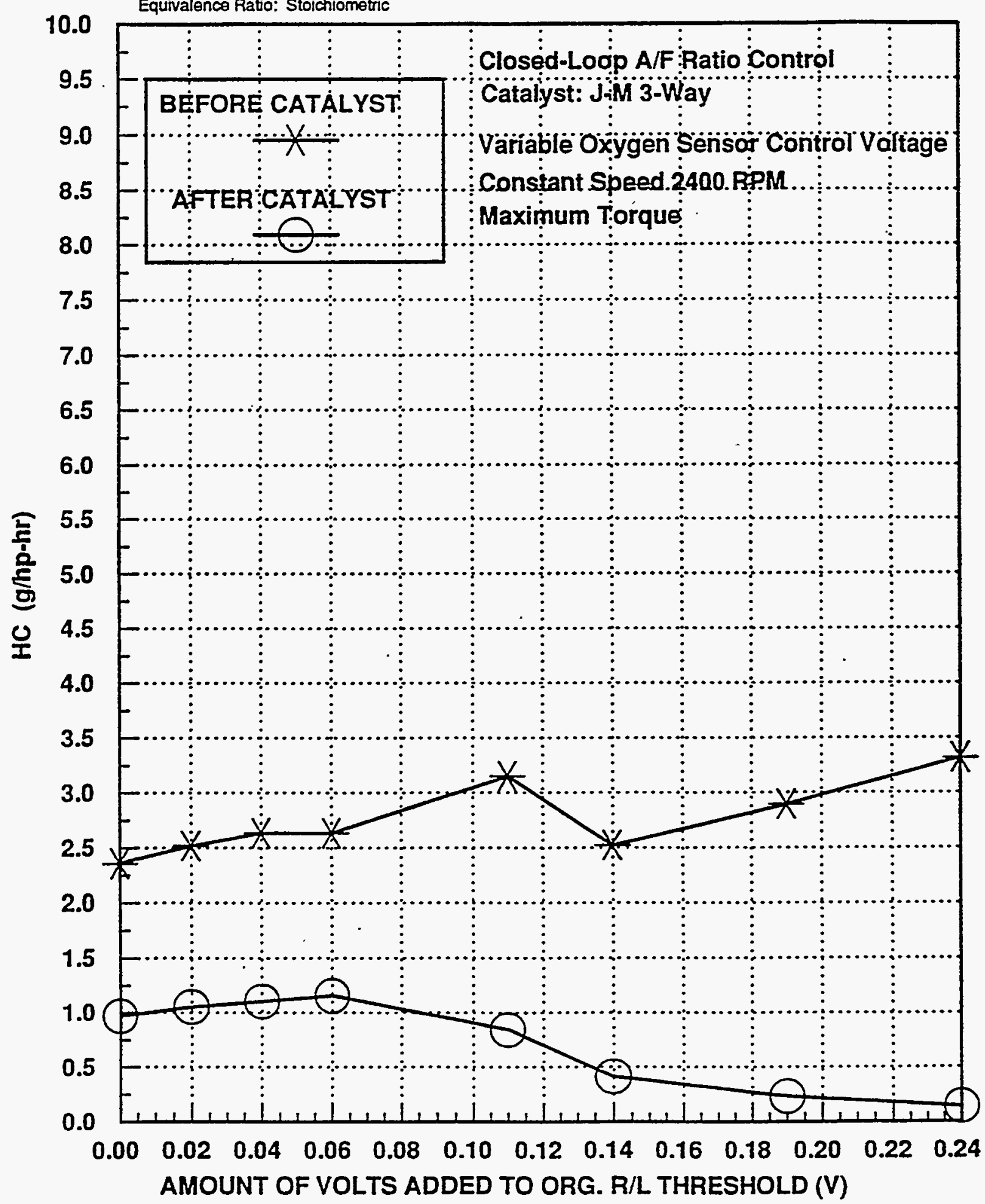

Figure 5.42 Engine Emission vs. Threshold Voltage 


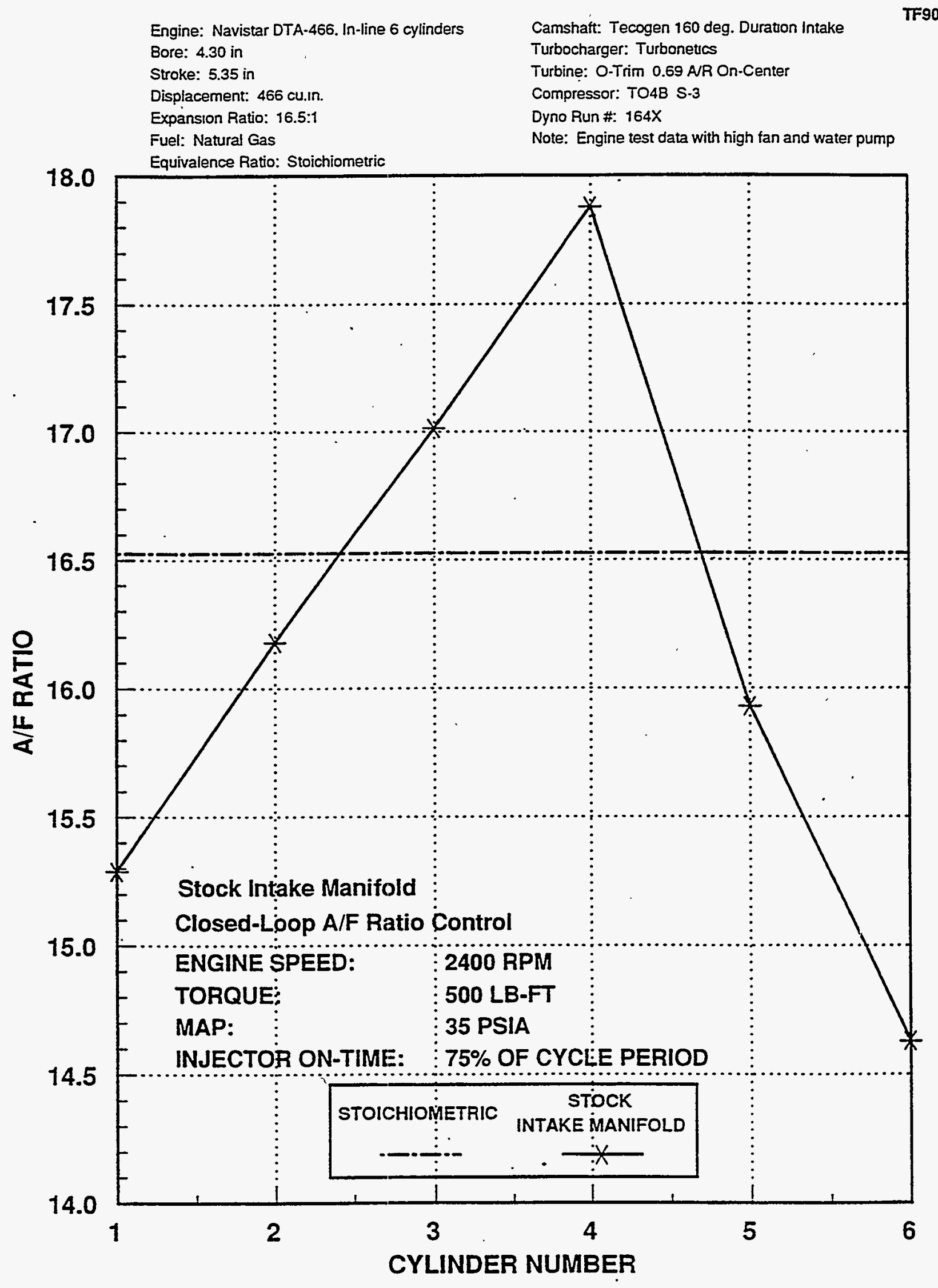

Figure 5.43 Cylinder to Cylinder A/F Ratio Distribution 


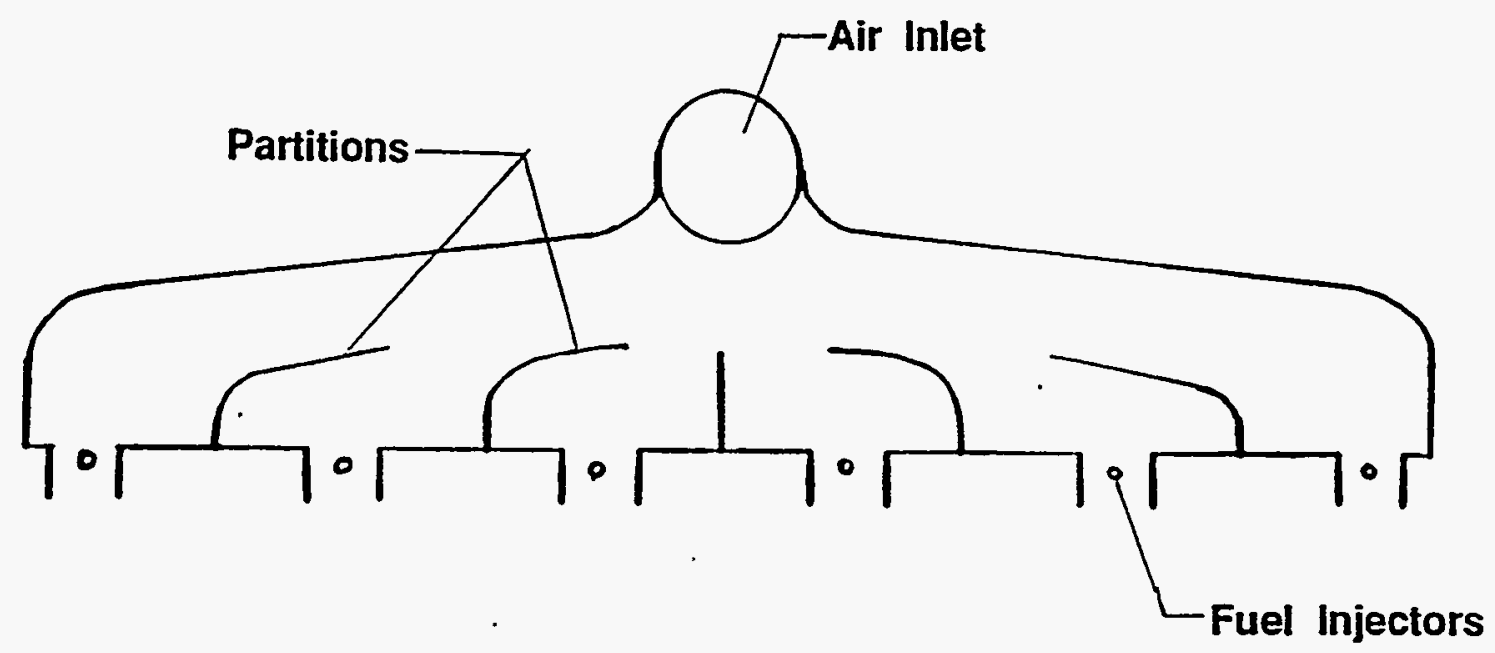

Figure 5.44 Partitioned Intake Manifold 


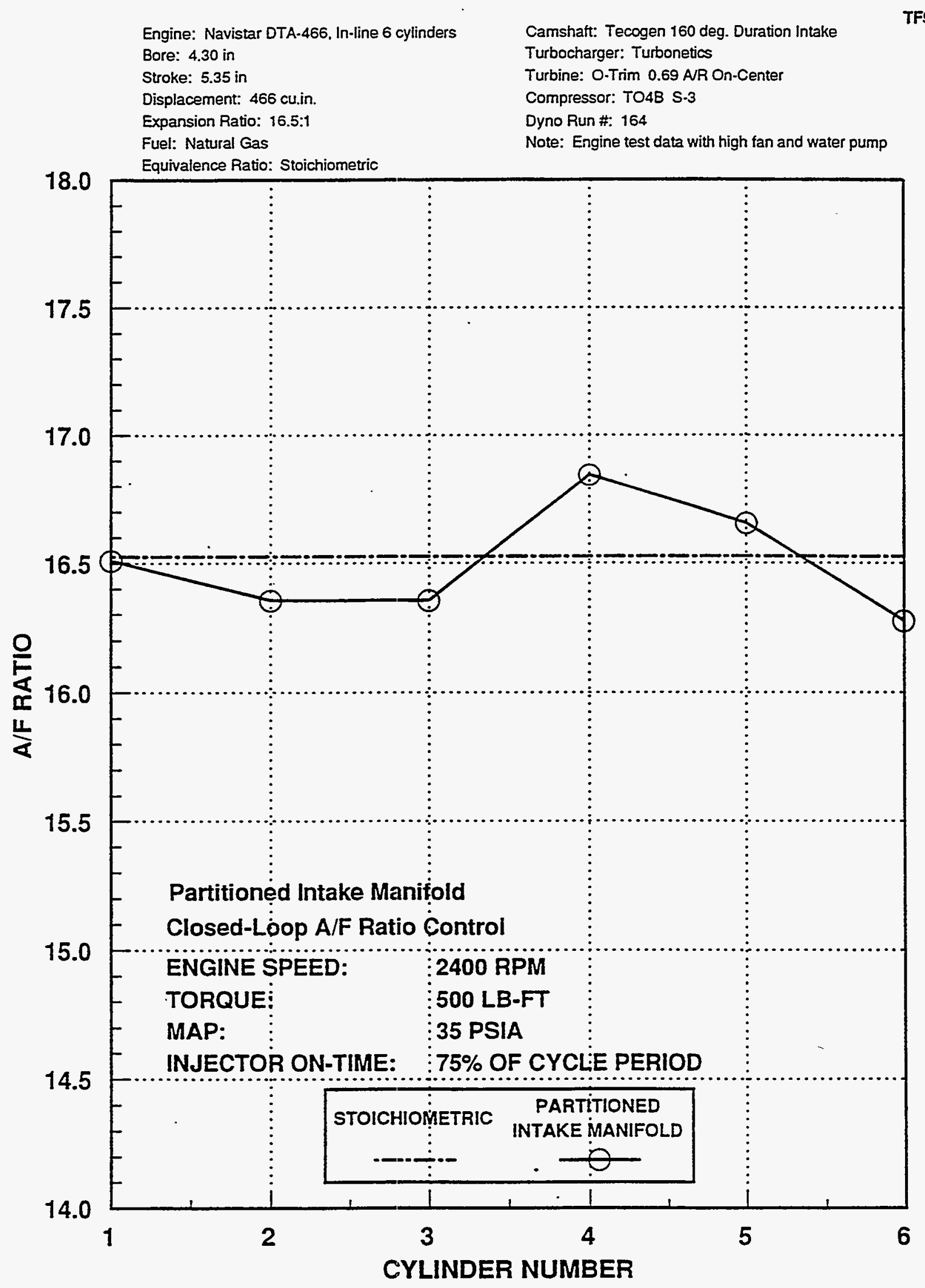

Figure 5.45 Cylinder to Cylinder A/F Ratio Distribution - Partitioned Manifold 
Engine: Navistar DTA-466, In-line 6 cylinders Bore: 4.30 in

Stroke: 5.35 in

Displacement: 466 cu.in.

Expansion Ratio: 16.5:1

Fuel: Natural Gas

Equivalence Ratio: Stoichiometric
Camshaft: Tecogen 160 deg. Duration Intake
Turbine: O-Trim 0.69 AR On-Center

Compressor: TO4B S-3

Dyno Run \#: 179, 178, 177, 176. 175, 174. 173, 172

Note: Engine test data with high fan and water pump

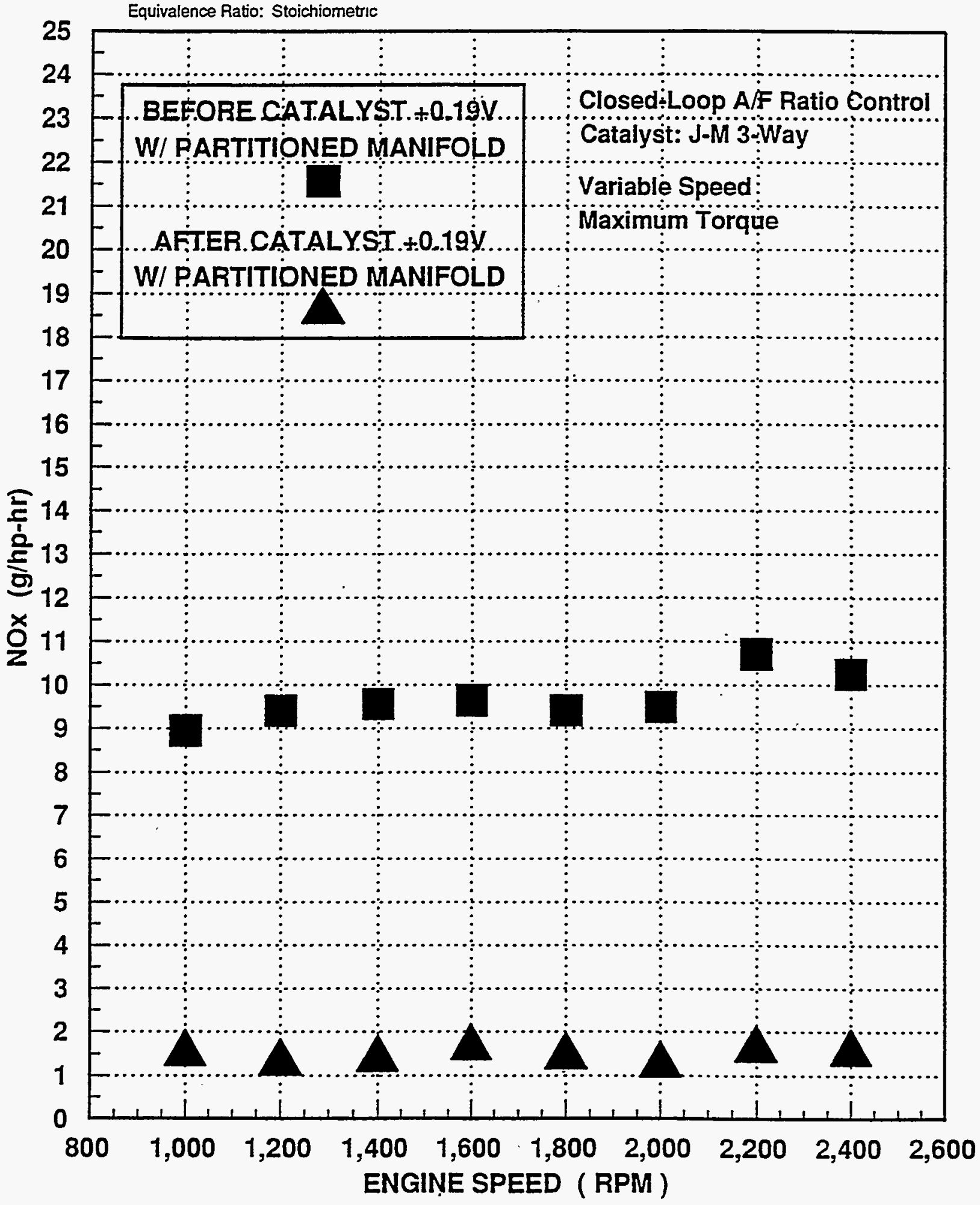

Figure 5.46 Engine Emissions With Partitioned Manifold 


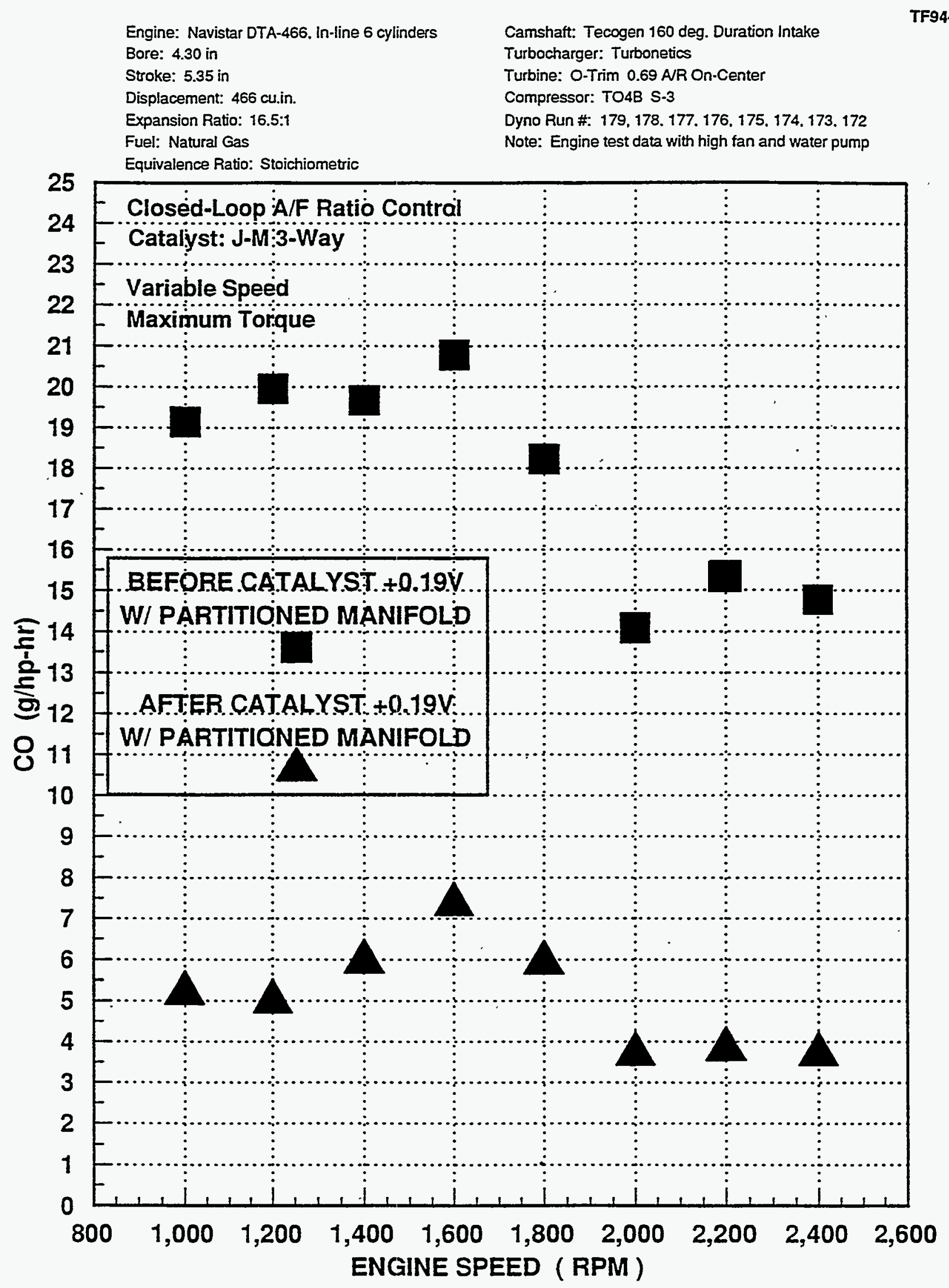

Figure 5.47 Engine Emissions With Partitioned Manifold 
Engine: Navistar DTA-466. In-line 6 cylinders Bore: 4.30 in

Stroke: 5.35 in

Displacement: 466 cu.in

Expansion Ratio: 16.5:1

Fuel: Natural Gas

Equivalence Ratio: Stoichiometric
Camshaft: Tecogen 160 deg. Duration intake

Turbocharger: Turbonetics

Turbine: O-Trim 0.69 AR On-Center

Compressor: TO4B S-3

Dyno Run \#: $179,178,177,176,175,174,173,172$

Note: Engine test data with high fan and water pump

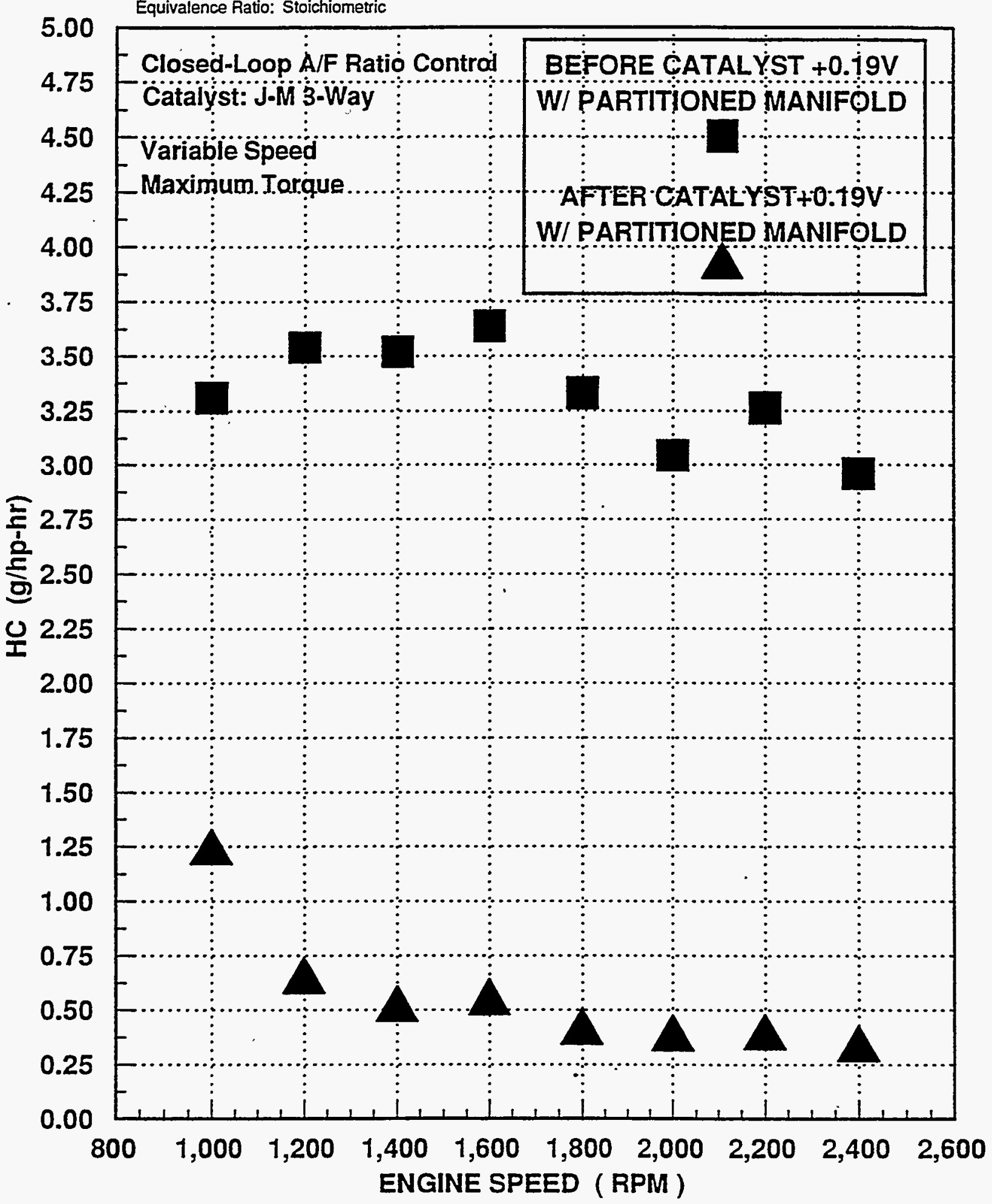

Figure 5.48 Engine Emissions With Partitioned Manifold 
threshold for the controller was set at a constant value. It is seen that the $\mathrm{NO}_{X}$ emission remained constant as the speed and load increased, which is significantly improved over the emissions results using the original intake manifold. Further improvement of the emissions may be possible by optimizing the rich/lean threshold set point at various operating conditions.

\subsection{DURABILITY TEST}

Durability of the converted Navistar DTA-466 engines depends on the components added to the engine and some of the original diesel engine components which are affected by the different characteristics of the natural gas fuel. Most of the add-on components, such as the throttle body, the ignition coil, and the fuel injectors, are commercially-available and are used on vehicles currently manufactured by OEMS. The durability of these components are not in question. The only one item that is in question is the spark plug, since it is modified from an off-the-shelf item: The question is whether or not the spark plug operates at a temperature level that is too high to be durable.

The original diesel components that might be affected by the natural gas operation are the intake and exhaust valves. The higher flame temperature and the lack of lubricating agent in the fuel may cause the valve to wear faster than that in the original diesel engine. Piston life is not likely to be reduced, since the peak firing pressure in the natural gas engine is lower than that in the diesel engine.

The durability of the engine has therefore been studied by examination of the spark plug operating temperatures and the recession rates of the valves.

\subsubsection{Spark Plug Life}

Six NGK D8HA spark plugs, which were modified for the Navistar DTA-466 natural gas engine, were submitted to NGK for inspection after they had accumulated 140 hours of operation on the dynamometer engine. The majority of the operating hours were at maximum torque conditions. The conclusion from NGK's visual inspection was that the porcelain insulation nose displayed normal coloration which indicated normal absorbing and transferring of heat from the combustion gas. The minimal wear of the electrodes indicated that it should offer a long life in this application. The NGK letter report is attached as Appendix 1.

The same 6 spark plugs were also sent to Champion for metallurgical analysis. A grain structure study indicated that the center electrode showed no sign of operating at elevated temperatures, while the ground electrode had reached high enough temperature that the grains had re-crystallized. This suggests that the ground electrode erosion rate could increase with time. The Champion letter report is attached as Appendix 2.

To determine the operating temperature of the spark plug, Champion conducted a test on the engine with 4 special $1 / 2$ " reach spark plugs (P7 TC) instrumented with thermocouples and read out 
instruments. These spark plugs were installed in cylinders $\# 1,4,5$ and 6 . The engine was operated at variable speed and BMEP. During the course of the test, a number of spark plugs failed due to arcing between the electrode and the thermocouple leads. However, sufficient data was obtained to establish the operating temperatures at the tip of the porcelain insulator. Figure 5.49 is a plot of the spark plug temperature as a function of BHP. It is seen that the temperature correlated quite well with BHP as expected. It is Champion's experience that the maximum tip temperature of $1120^{\circ} \mathrm{F}$ at peak load is well within the acceptable operating range of typical spark plugs. However, it was cautioned that the $3 / 4$ " reach spark plugs might operate at a higher temperature, which would cause higher erosion rate.

Based on this test, Tecogen selected the $1 / 2$ reach NGK D8HV, $12 \mathrm{~mm}$, thin wire center electrode spark plug for the engine.

\subsubsection{Valve Recession}

The valve height of the engine on the dynamometer test stand was used to establish the valve recession rate for the converted natural gas engine. The valve height was measured at the beginning of the test and after 372 hours of operation. During these time periods, the engine was operated at various speeds between 1000 and $2600 \mathrm{rpm}$. Except for approximately $10 \%$ of the time when the engine was operated at various partload conditions, $90 \%$ of the 372 hours were at maximum torque conditions.

The maximum, minimum, and average recessions are plotted in Figures $\mathbf{5 . 5 0}$ and $\mathbf{5 . 5 1}$ for the intake and exhaust valves. The recession rate for the intake. valves is very. low, about 0.3 mils/100 hours. This is very impressive compared to other turbocharged automotive-derivative gas engines where the recession rates are generally in excess of 2 mils/100 hours.

The average recession rate for the exhaust valves is 2.3 mils/100 hours. This recession rate is typical for a turbocharged gas engine. 


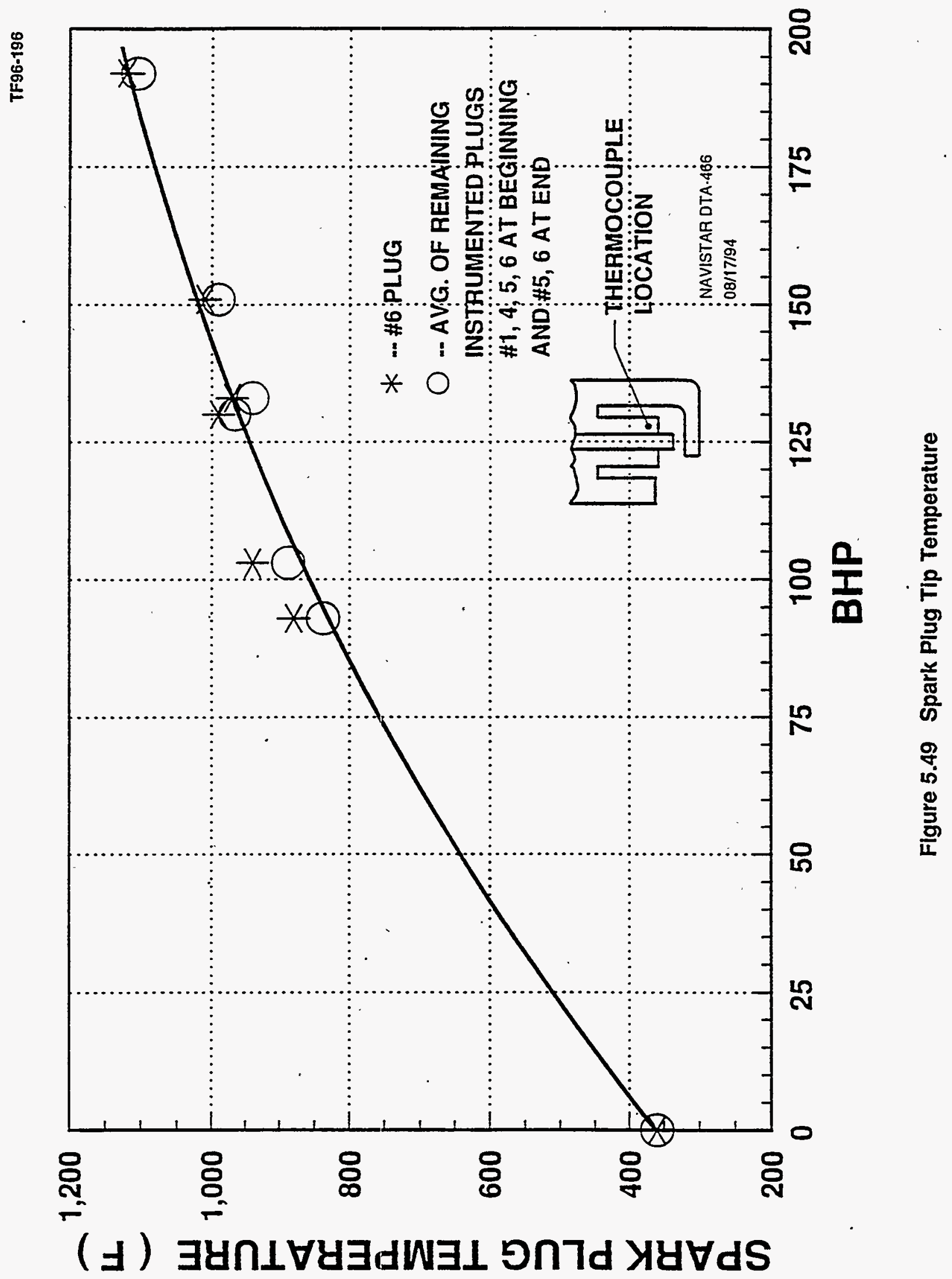


Engine: Navistar DTA-466, In-line 6 cylinders Bore: 4.30 in

Stroke: 5.35 in

Displacement: 466 cu.in

Expansion Ratio: .16.5:1

Fuel: Natural Gas

Equivalence Ratio: Stoichiometric
Camshaft: Tecogen 160 deg. Duration Intake Intake Valves: Stock

Intake Valve Seats: Stock

Intake Valve Springs: Stock

Exhaust Valves: Stock

Exhaust Valve Seats: Stock

Exhaust Valve Springss: Stock

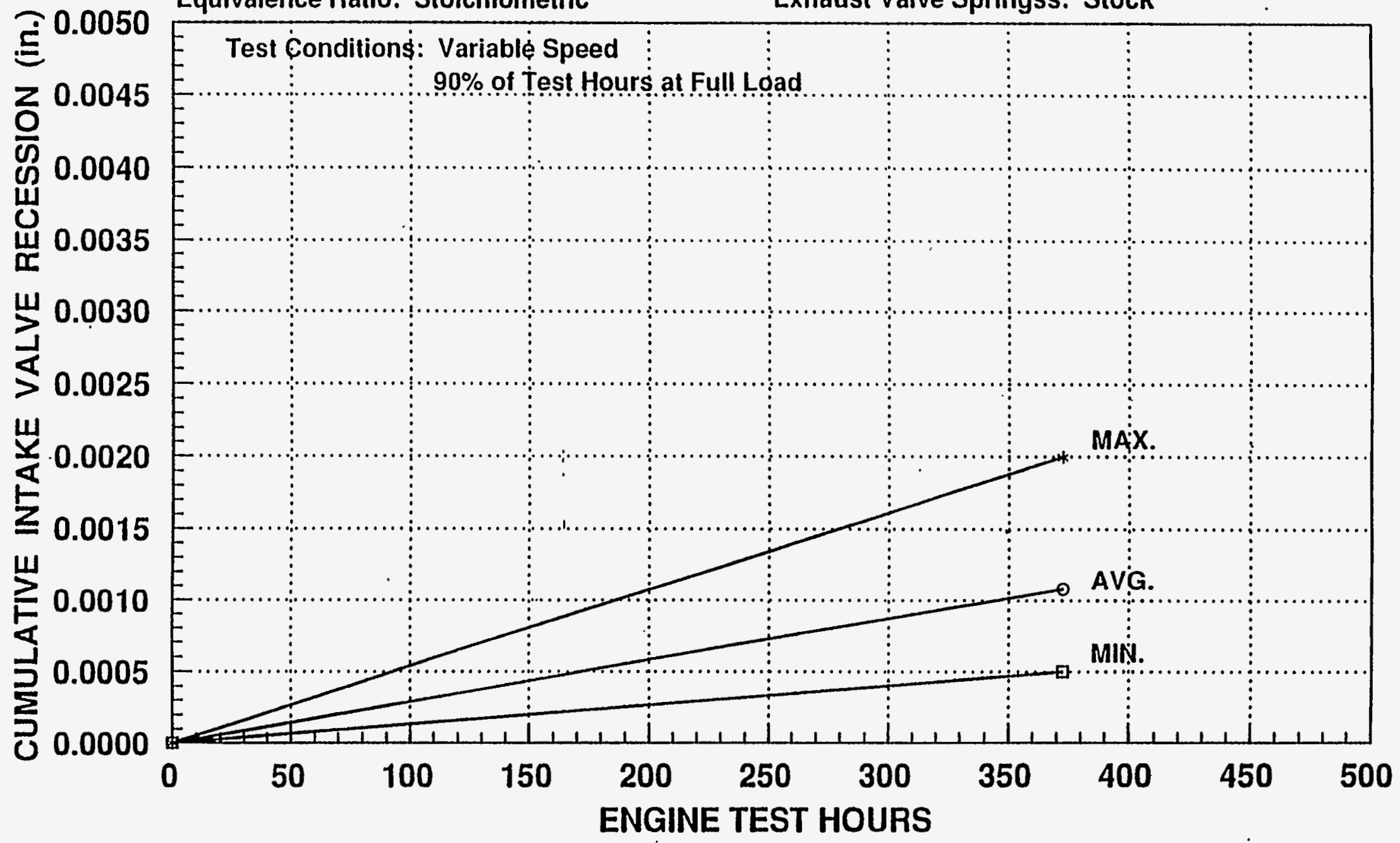

Figure 5.50 Intake Valve Recession 
Engine: Navistar DTA-466, In-line 6 cylinders

Bore: 4.30 in

Stroke: 5.35 in

Displacement: 466 cu.in.

Expansion Ratio: 16.5:1

Fuel: Natural Gas

E 0.012 Equivalence Ratio: Stoichiometric
Camshaft: Tecogen $160 \mathrm{deg}$. Duration Intake Intake Valves: Stock

Intake Valve Seats: Stock

Intake Valve Springs: Stock

Exhaust Valves: Stock

Exhaust Valve Seats: Stock

Exhaust Valve Springss: Stock

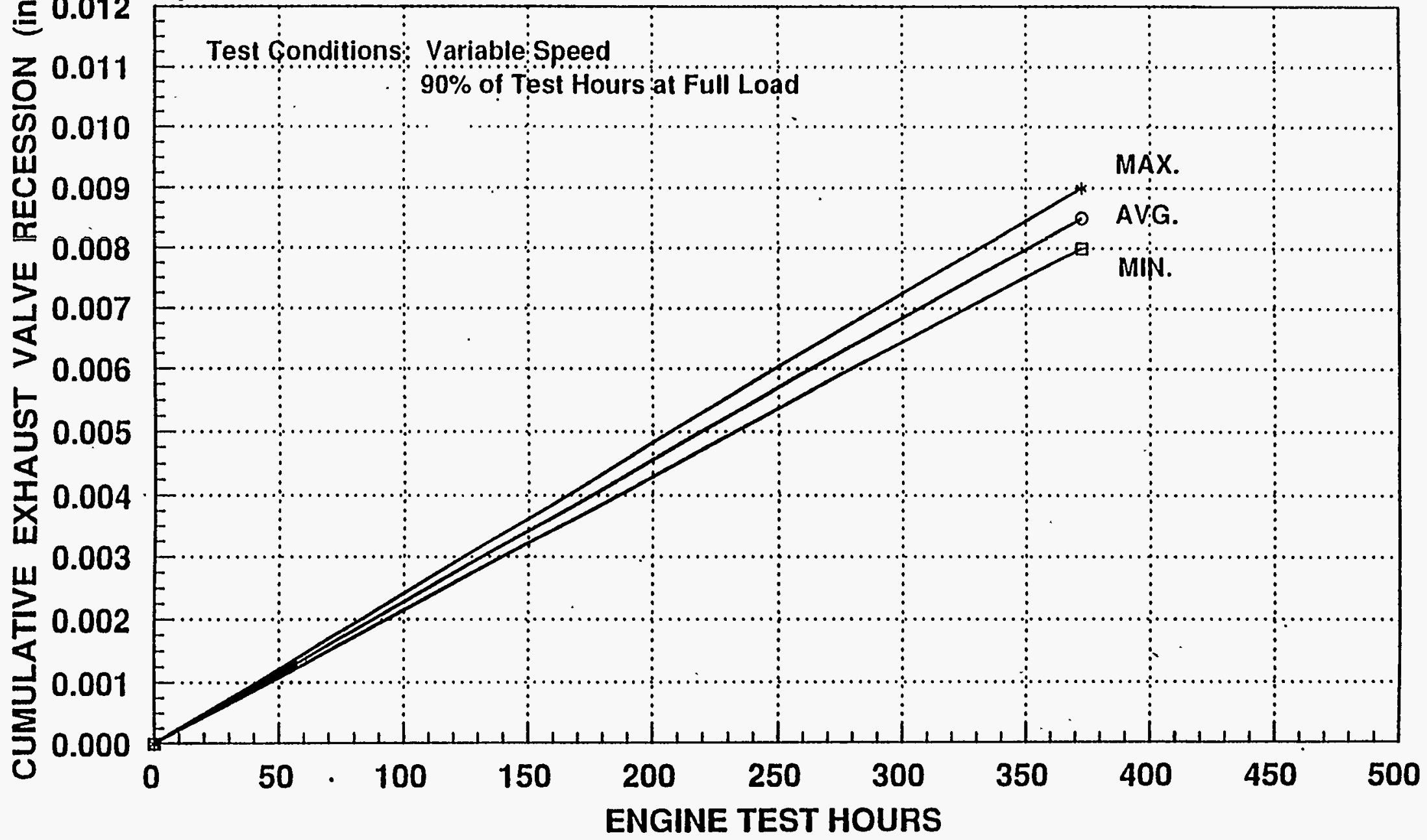

Figure 5.51 Exhaust Valve Recession 


\section{FIELD EVALUATION OF PROTOTYPE SYSTEM}

\subsection{ENGINE CONVERSION STUDY}

After having done the testing of the engine and a preliminary survey of Navistar chassis designs and vehicle body styles, it became apparent that Tecogen needed a typical vehicle at our facility so that we could determine all the spatial limitations in the engine compartment that may impact the design of the engine components. Navistar has made changes to the engine and auxiliary components over the years. Our conversion kit design must be somewhat universal to fit the different engine configurations.

In addition to making the components physically compatible, it was also necessary that certain calibration of the controller must be carried out on the vehicle with the development system on board. For example, the driveability and the stability testing of the boost control and speed governing system must all be done on a vehicle of certain weight and inertia. For these reasons, Tecogen purchased a diesel-powered school bus to be converted to natural gas operation.

This school bus' engine compartment was carefully surveyed to determine if there were interferences between the existing hardware and the add-on components. Three major problems were identified. The throttle body was located very close to the firewall (or the engine cowl), and it interfered with the cables extending through the firewall for speedometer and transmission. This indicated that the intake manifold must be modified to move the inlet port and the throttle body about 4" forward.

The second problem was the fitting of the aftercooler in front of the existing radiator. Since the inlet and outlet pipes of the aftercooler must pass over the radiator, it interfered with the engine hood. The existing radiator must therefore be replaced by a radiator designed specially to package with the aftercooler.

The third problem was that the existing exhaust pipe could not be used. Due to the addition of an integral wastegate to the turbine housing, the discharge flange was extended $2.5^{n}$. This caused interference of the exhaust pipe and the oil cooler. This was resolved by adopting a stock exhaust pipe for another Navistar engine.

\subsection{FUEL STORAGE SYSTEM DESIGN AND INSTALLATION}

A fuel storage system was designed and installed on the school bus. We decided to install 4 fuel tanks on the bus so that it would have an approximate range of 200 miles. The tanks are 15 " dia. $\times 54$ " long, and each has a capacity of 1,260 SCF of natural gas at 3000 psig. They are steel tanks with fiberglass wrap. The tank support system design was adopted from a previous design used by Tecogen on a Blue Bird school bus. The support was designed with a crash barrier, and it had been proven by a crash test. 
With the necessary modifications, the conversion process proved to be simple and straightforward. The engine was started and operated on the road without any obvious problem with the engine. Some problem with the controller was resolved by grounding the development unit with a heavy gauge wire. Starting of the engine was found to be difficult when the ambient air temperature was near freezing. An adjustment of the fueling table for cranking solved the problem. Since then, the engine started without any difficulty, even in sub-zero ambient conditions.

\subsection{FIELD TESTING OF THE VEHICLE}

The school bus with the converted Navistar DTA-466 natural gas engine was driven from Atlanta, GA to Austin TX, and then from Austin, TX to Boston, MA via Atlanta, GA, for a total distance of 3,792 miles. The purpose of this test was to determine the driveability of the vehicle under a variety of highway conditions and speeds, and to uncover any deficiencies of the system under realistic conditions. Ambient temperatures varied from the mid-50's to the mid-90's. The fuel storage tank pressure varied from 3500 psig down to as low as 150 psig.

In general, the engine performed very well. Only during extremely hot ambient conditions, $92^{\circ} \mathrm{F}$ and $97 \%$ humidity, a reduction of power was noticed. A range check made using one storage tank showed 60 miles/tank at 3000 psi fuel pressure, which is approximately 5.7 miles per equivalent gasoline gallon.

The GFI fuel regulator shut-off solenoid failed to reopen a few times when the engine was shut down below 400 psi fuel supply pressure. GFI is already aware of this problem from other uses of this. regulator.

Oil consumption was monitored. 2.5 quarts of oil were added during this trip.

One of the problems revealed during this field test was that, during heavy deceleration and idle conditions, visible smoke was observed at the discharge of the tail pipe. This was caused by the high vacuum developed in the intake manifold. Further adjustment on the idle control valve position and mixture ratio under these conditions solved this problem.

In general, we concluded that the cross-country test was successful. 


\section{CONCLUSIONS AND RECOMMENDATIONS}

The project has been successfully completed with all the objectives met. A conversion kit for converting the Navistar DTA-466 diesel engine to a dedicated natural gas engine has been developed which is cost effective and retrofitable to existing engines.

The work described in this report shows the feasibility of applying the MCEC to existing diesel engines. This work has shown that detonation does not limit BMEP to a level which is lower than that of the diesel cycle, and that the turbocharger performance required to get this level of BMEP is achievable with current configurations and in a single stage. Engine efficiency demonstrated here is significantly higher than that of conventional diesel-derivative industrial gas engines operating at the same fuel-air ratios.

The analytical technique presented is generally applicable and can be applied to any engine configuration in the same manner as described in this report. A method of converting the diesel engine without is disassembly has been demonstrated. The method of adapting spark plugs to the cylinder head without machining the heads has proven to give acceptable spark plug life.

With the demonstration of technical feasibility, aconversion kit which is economically attractive has been designed, tested, and demonstrated in a vehicle. The approach Tecogen took was to use higher volume production automotive equipment wherever possible. This included an electronic control module, sequential port injection, and a distributorless ignition system. The turbocharger boost level is controlled through an electronically-modulated wastegate. Emissions control is achieved through stoichiometric operation with closed-loop fuel control and a 3-way catalytic reactor. Initial cost estimates indicate that a kit based on this technology is economically attractive for converting existing diesel engines in trucks and buses. The high engine efficiency also suggests that this approach be considered for OEM natural gas engines.

We recommend that this conversion kit be extensively field tested to ensure the reliability and durability of the kit components, as well as the engine itself. The fuel economy improvement over the conventional Otto cycle gas engine should be demonstrated for different vehicle duty cycles.

Additional development of the conversion system is recommended for improving the full-load and part-load efficiency of the gas engine. This will be done through lean-burn operation, skip firing at low load, electronic variable wastegate, and stratified charge lean-burn to extend the lean limit. 


\section{REFERENCES}

1. Powell, C.K., et al., "A Thermodynamic Analysis for Detonation-Free Engine Performance," ASME Journal of Engineering for Power, July 1970.

2. Chen, T.N. and Alford, R.N., "Combustion Characteristics of Large Gas Engines," ASME Paper No. 71-DGP-6.

3. Chen, T.N. et al., "Detonation Characteristics of Industrial Natural Gas Rotary Engines," SAE Paper No. 860563, 1986, International Congress and Exposition. 
APPENDIX 1 


\section{NGK SPARK PLUGS (U.S.A.), INC.}

SALES HEADQUARTERS: 8 Whatney, Irvine, CA 92718

Phone: (714) 855-8278 Fax: (714) 855-8395

August 4, 1993

Mr. Jon Adams

TECOGEN INC.

45 First Ave.

P.O. BoX 8995

Waltham, MA 02254-8995

Re: NGK Spark Plug Analysis

Dear Jon,

Thanks for your patience! We have received and inspected six NGK \#D8HA spark plugs, which had been externally modified and run for 140 hours in a Navistar DTA 466 diesel engine converted for natural gas operation. Our analysis and additional related information is as follows:

SPARK PLUG PHYSICAI EVALUATION

1. All six spark plugs in question display a normal external appearance, with no indications of combustion gas leakage or overheating.

2. The metal housings on all six plugs have been modified by machining off the threads and removing the hex configuration, leaving the housing with a "slip-fit" appearance. In addition, the NGR-supplied gasket seat has been removed in favor of use of a copper washer as part of the engine retrofit.

3. Although the plug no longer utilizes a torqued compression gasket seat seal, the gas seal modifications seem to have worked very well. While the machined "threadless" lower housing displays some discoloration from exposure to combustion heat and gases, there is no discoloration of the upper metal housing or flat seat surface. This would indicate a good seal between the spark plug housing and the engine cylinder head.
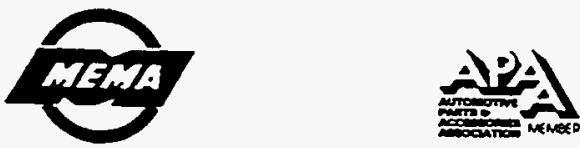
Spark Plug Analysis

Page 2

(continued)

4. The center and ground electrodes on all six plugs display minimal wear, given that they were combusting natural gas and run with very small gap settings between the electrodes. This would indicate that the electrodes operated normally, and were not affected by overheating or premature erosion.

5. All six plugs display light to medium tan coloration on the porcelain insulator noses, without any traces of combustion byproduct buildup. This indicates the insulator noses were absorbing and transferring combustion heat normally.

\section{ANAIYSIS}

While the spark plugs in question were externally modified to meet the engine conversion specifications, they appear to be structurally sound and defect-free. In addition, the physical appearance of each plug indicates they were operating normally, without any traces of combustion gas leakage or overheating. In our opinion, the NGR \#D8HA has performed very nicely, and should offer a long life in this particular application. It would be interesting to evaluate any of our plugs that have 500 or more hours on them and see if the wear is linear.

One of the concerns raised about modifying the metal housing of these plugs was. whether removal of the threads would impact the life span, gas tightness, or thermal transfer qualities in a negative manner. Based upon this preliminary evaluation with only 140 hours of use, we see no unusual signs that would indicate any operational problems.

I have been in contact with our spark plug Product Manager, and asked about the possibility of NGK producing this part number already modified for your application. I was informed that any part number production less than 100,000 pieces requires being run on our prototype production line, and the cost of this special run could cause the plugs to cost Tecogen upwards of $\$ 100.00$ PER PLUG. Suffice it to say that your in-house machining is probably much more cost-effective in this regard. 
Spark Plug Analysis

Page 3

(continued)

I am also waiting for price and delivery information on thermocouple plugs in the $\mathrm{BIOH}$ and $\mathrm{R} 5673-10$ configurations, as well as various instrumentation to use with these measurement devices. I will get this data to you as soon as it gets to me. Enclosed with this report you will find a copy of NGK's 1993 Master Catalog, along with our Engineering Manual. If you have any additional. questions or comments, please don't hesitate to contact me.

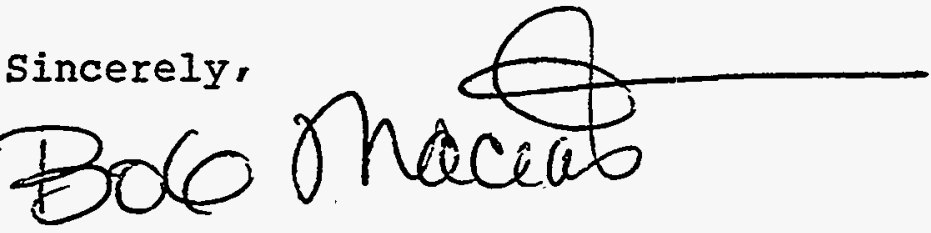

Bob Macias

Technical Service Manager

NGK Spark Plugs (U.S.A.), Inc.

cc: J. Hutchins, Northeast Region Sales Manager - NGK/NJ

R. Parker, OEM Sales Specialist - NGK/II 


\section{APPENDIX 2}




\section{GOOPER}

November 29, 1994

Mr. Bob Raymond

Tecogen, Inc.

45 First Avenue

P.O. Box 8995

Waltham, MA 02254-8995

Dear Bob:

Attached are the photomicrographs of the electrodes removed from the Champion P7G and NGK D8HA spark plugs that had been run in Tecogen's Navistar DTA-466 engine converted to run on natural gas. The metallographic mount that the photomicrographs were taken off of consisted of the center and ground electrodes from the one P7G and two of the six D8HA that were randomly selected. With both sets of D8HA electrodes showing similar grain structure, only one set was photomicrographed.

Attachment \#1 shows the firing ends of the electrodes from the P7G at $50 X$ magnification. You will notice that the center electrode (CE) has no noticeable grain structure. This is attributed to the lack of chemical activity on the gold/palladium CE material during the etching process, a process by which the grain structure is chemically enhanced. Why this occurred is not certain except that when $\mathrm{Au} / \mathrm{Pd}$ is mounted with nickel, the CE material to which the Au/Pd is attached, the etching is more focused on the nickel.

However, the Au/Pd CE has sharp, clean edges which is typical of an electrode that is running at relatively cool temperatures and/or has not been in operation very long. You had indicated that the P7G had only been run in the engine for a few hours.

The photomicrograph of the P7G GE shows a grain structure that is typical of the following: a new electrode, one that has little run time, or one that has not been subjected to high temperatures for any length of time. Since Champion's GE material is similar to that of the D8HA, which shows heavy grain growth due to high temperatures, I would have to say the P7G did not run long enough in the engine to produce any detectable grain growth. 
Mr. Bob Raymond

November 29, 1994

Page 2

Attachment \#2 shows the firing ends of the CE and GE from one of the D8HA spark plugs. The CE shows no sign of operating at elevated temperatures and its grain structure is typical of certain nickel alloys after extrusion. If the CE had experienced excessive temperatures, the grain structure would more closely resemble that plug's GE.

The grain structure of the GE of the D8HA indicates that this electrode had been operating at elevated temperatures. As with Champion's GE material, NGK's GE material normally has small, fairly uniform grains. However, as you can see, these grains are quite large and not very uniform in size, an indication that the grains have recrystallized due to the elevated temperature that the electrode was subjected to. These larger grains were evident the entire length of the electrode.

Continued operation of the D8HA would have most likely resulted in an accelerated gap growth due to erosion of the GE material. With the larger grains, any electrical or chemical attack would be removing larger grains, which would increase the rate of erosion. The photomicrograph of the GE shows the start of this granular attack on the perimeter grains.

You have indicated that you are trying longer reach plugs in order to improve idle stability and low speed operation. This will most likely improve ignitability, but I am concerned that the GE being further into the combustion chamber will most likely see higher temperatures. This could cause increased gap erosion, and worse, preignition if the GE temperature is high enough.

The A59GC spark plug that I suggested you try in the DTA-466 has a copper cored GE. The copper cored ground electrode will run cooler because the copper will help transfer the heat away from it-this may be ideal for your application. However, they are made in Europe, and I have yet to receive the test samples I promised; but as soon as I do, I will forward them to you.

Sincerely,

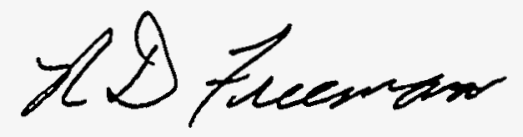

Robert D. Freeman

Product Engineer

Product Development

RDF/et

Enclosure

cc: T. R. Schuster

R. L. Keller

D. L. Tribble

W. D. Squier 
ATTACHMENT 1

PHOTOMICROGRAPH OF CHAMPION P7G ELECTRODES

Tip of Nickel Ground Electrode at 50X Magnification

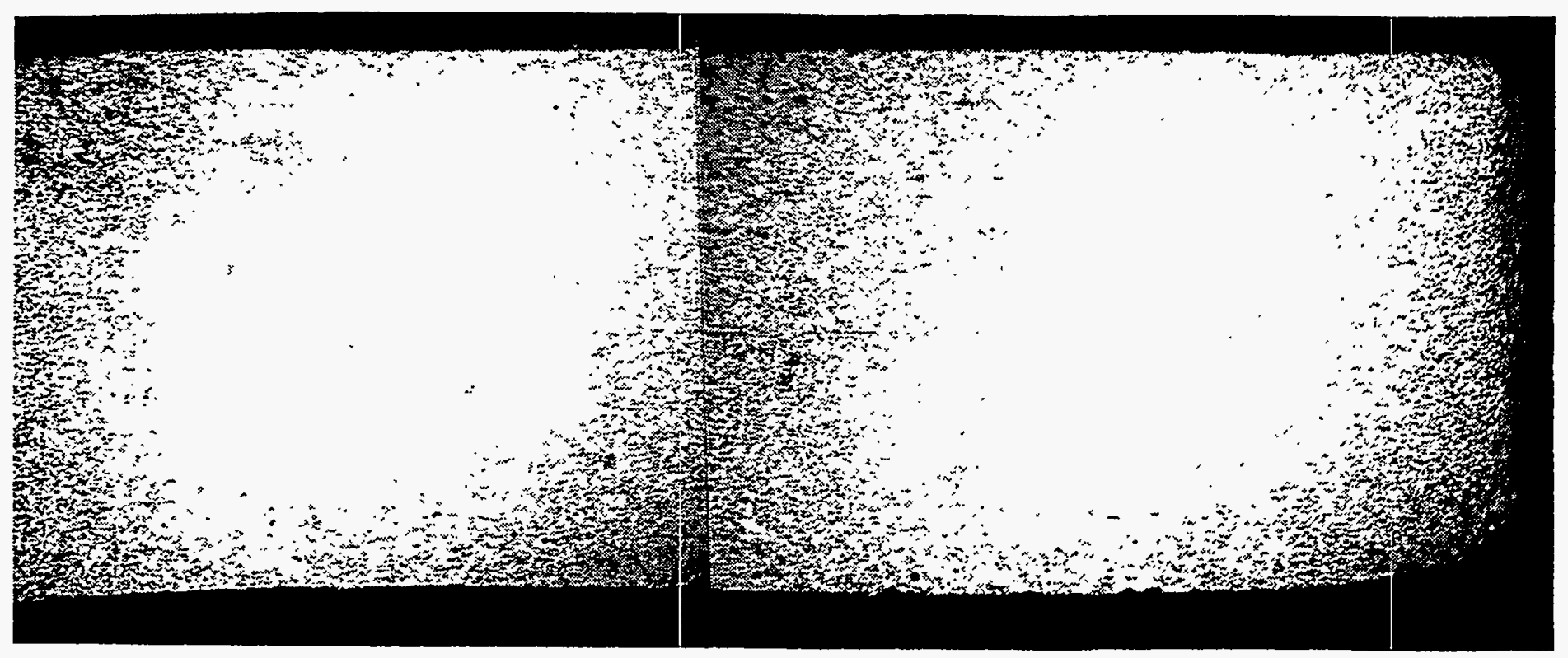

Tip of Gold/Palladium Center Electrode at 50X Magnification

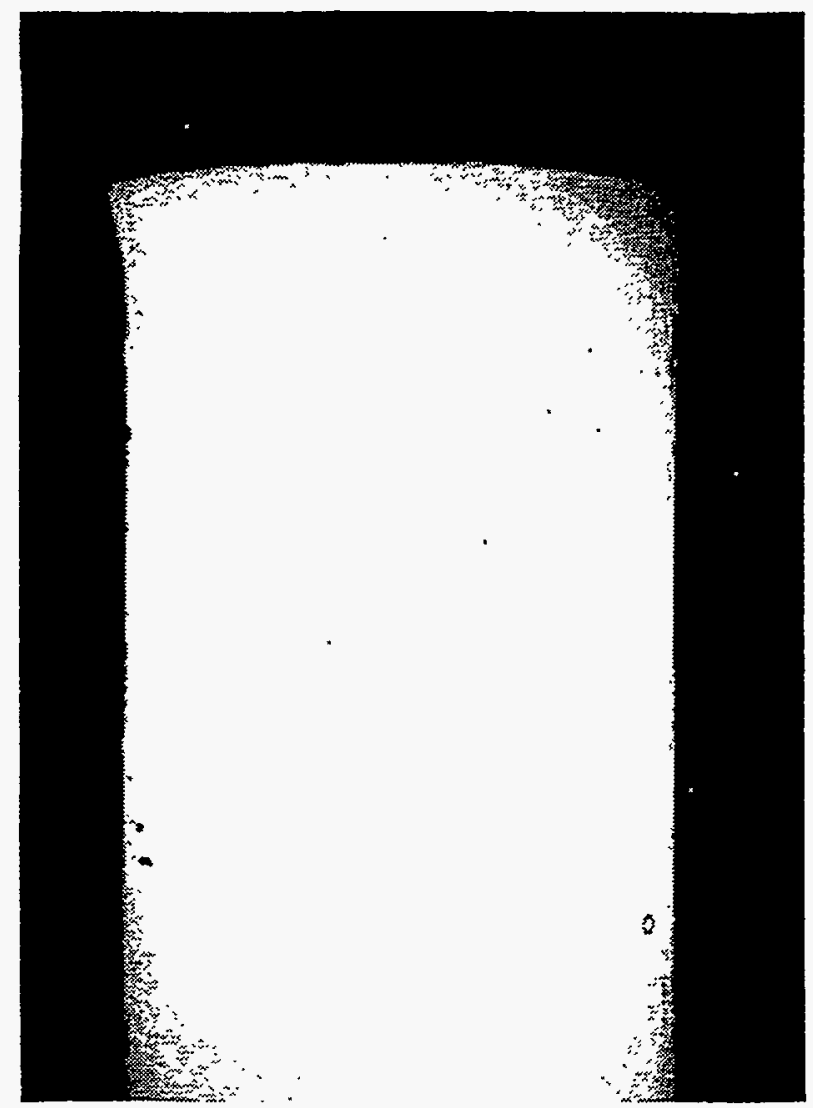


Tip of Ground Electrode at 50X Magnification
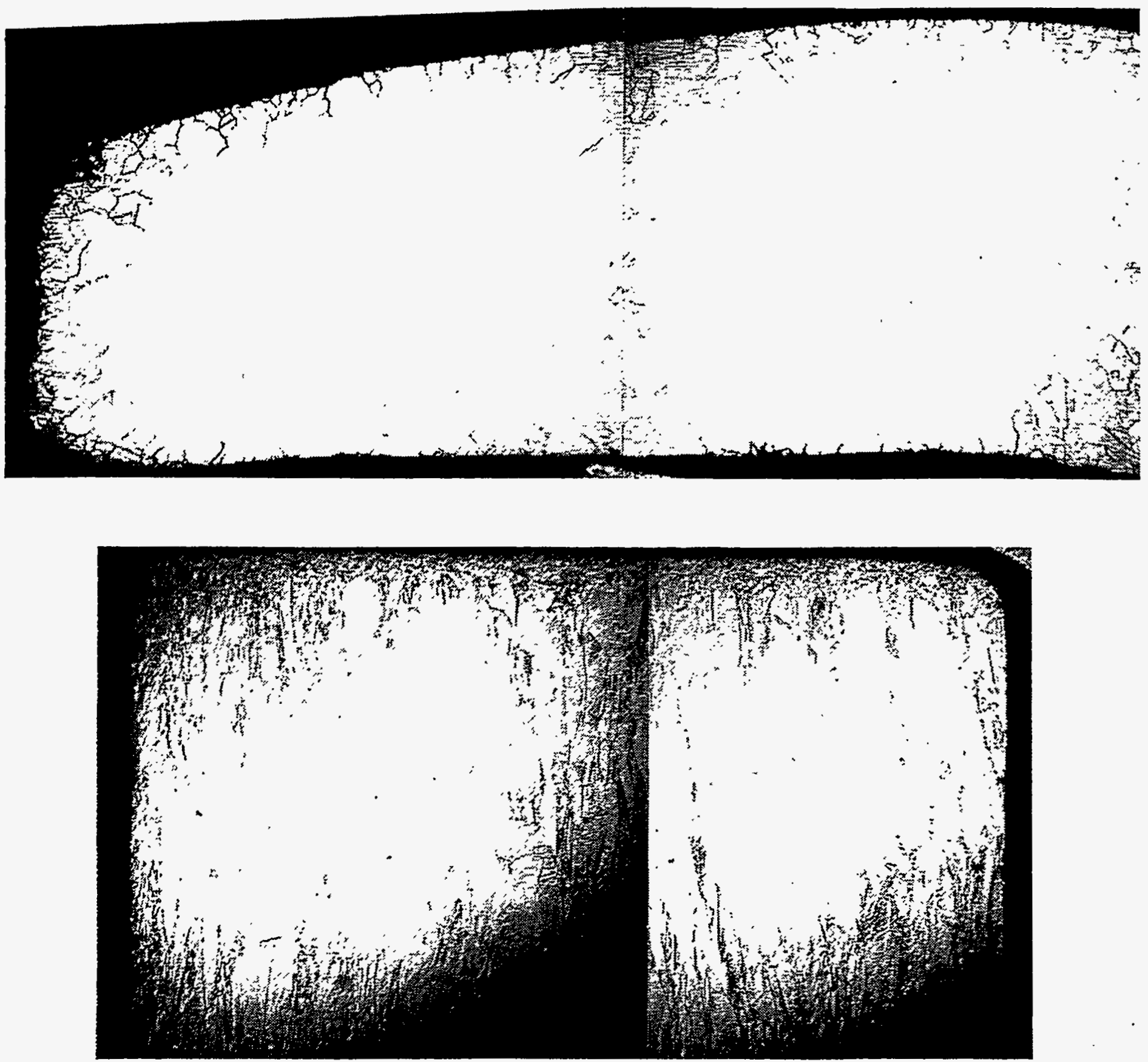

Tip of Center Electrode at 50X Magnification 
Tip of Nickel Ground Electrode at 50X Magnification

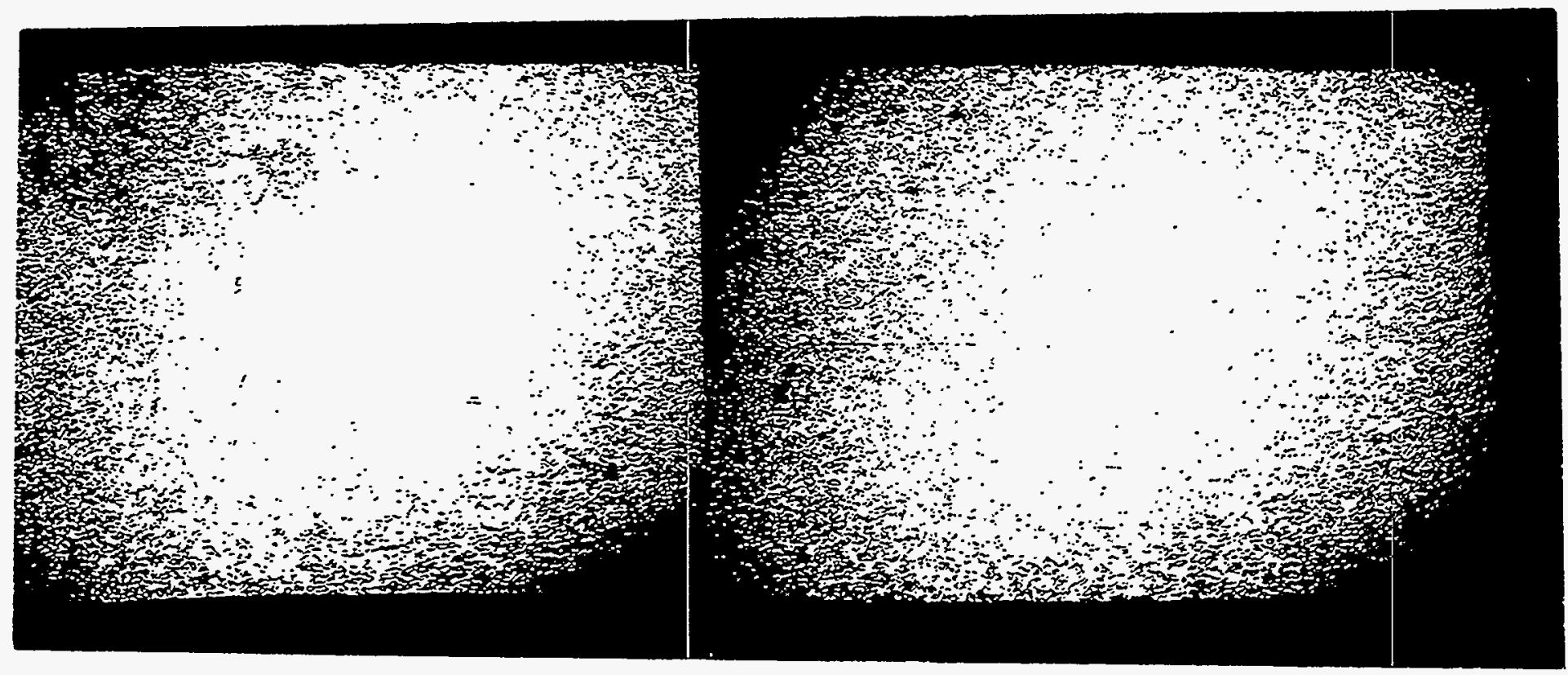

Tip of Gold/Palladium Center Electrode at 50X Magnification

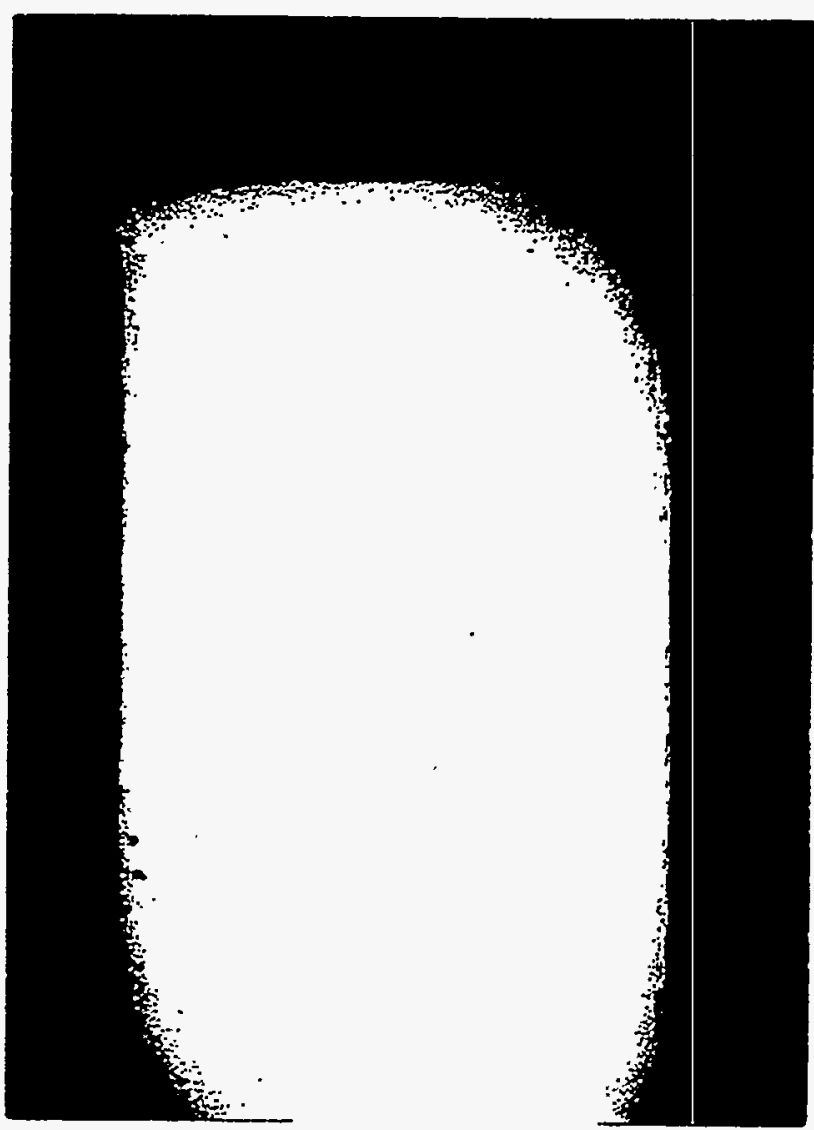


Tip of Ground Electrode aț $50 X$ Magnification
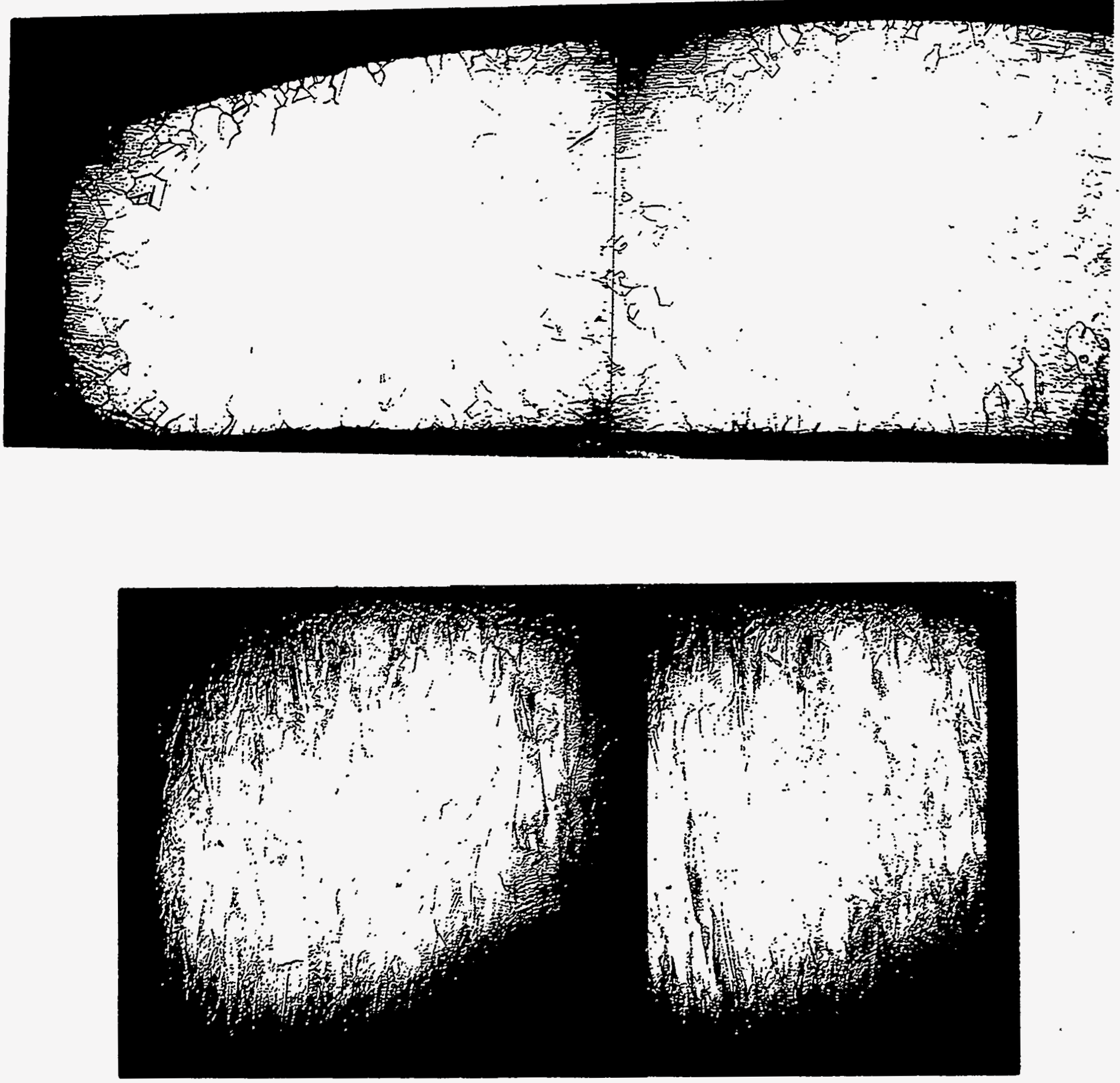

Tip of Center Electrode at 50X Magnification 


\section{REPORT DOCUMENTATION PAGE}

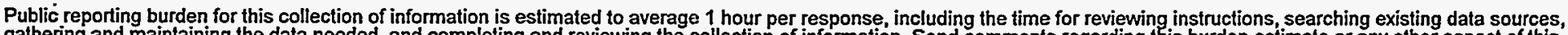

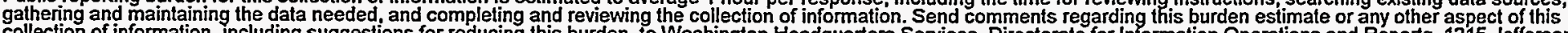

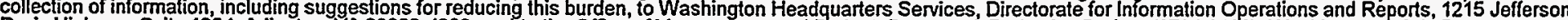
Davis Highway, Suite 1204, Arlington, VA 22202-4302. and to the Office of Management and Budget, Paperwork Reduction Project (0704-0188). Washington, DC 20503.

\begin{tabular}{|l|r|}
\hline 1. AGENCY USE ONLY (Leave blank) & $\begin{array}{r}2 . \text { REPORT DATE } \\
\text { September } 1996\end{array}$ \\
\hline
\end{tabular}

4. TITLE AND SUBTITLE

Conversion of a Diesel Engine to a Spark Ignition Natural Gas Engine

6. AUTHOR(S)

Tecogen

\section{PERFORMING ORGANIZATION NAME(S) AND ADDRESS(ES)}

Thermo Power Corporation, Tecogen Division

45 First Ave., P.O. Box 8895

Waltham, MA 02254-8995

\section{SPONSORING/MONITORING AGENCY NAME(S) AND ADDRESS(ES)}

National Renewable Energy Laboratory

1617 Cole Boulevard

Golden, CO $80401-3393$

\section{SUPPLEMENTARY NOTES}

\section{2a. DISTRIBUTION/AVAILABILITY STATEMENT}

National Technical Information Service

U.S. Department of Commerce

5285 Port Royal Road

Springfield, VA 22161

\section{REPORT TYPE AND DATES COVERED}

NREL Report

\section{FUNDING NUMBERS}

FU621010

ZCC-4-14290-01

8. PERFORMING ORGANIZATION REPORT NUMBER

DE96013107

10. SPONSORING/MONITORING AGENCY REPORT NUMBER

NRELTP-425-21682

13. ABSTRACT (Maximum 200 words) Tecogen has developed and applied a novel technique for converting turbocharged automotive diesel engines to operate as dedicated spark ignition engines with natural gas as fuel. The conversion process changes the engine cycle to a more-complete-expansion cycle in which the expansion ratio of the original diesel engine is unchanged while the effective compression ratio

\section{SUBJECT TERMS}

spark ignition engine, more-complete-expansion cycle, turbocharger
15. NUMBER OF PAGES 155

16. PRICE CODE
17. SECURITY CLASSIFICATION OF REPORT
18. SECURITY CLASSIFICATION OF THIS PAGE
19. SECURITY CLASSIFICATION OF ABSTRACT
20. LIMITATION OF ABSTRACT

Standard Form 298 (Rev. 2-89) Prescribed by ANSI Std. Z39-18 